Portland State University

PDXScholar

\title{
A Case Study of a Nationally Recognized Middle School's Decentralized Participatory Governance Structure
}

Donna Lynn Carman

Portland State University

Follow this and additional works at: https://pdxscholar.library.pdx.edu/open_access_etds Let us know how access to this document benefits you.

Recommended Citation

Carman, Donna Lynn, "A Case Study of a Nationally Recognized Middle School's Decentralized Participatory Governance Structure" (1987). Dissertations and Theses. Paper 841.

https://doi.org/10.15760/etd.841

This Dissertation is brought to you for free and open access. It has been accepted for inclusion in Dissertations and Theses by an authorized administrator of PDXScholar. Please contact us if we can make this document more accessible: pdxscholar@pdx.edu. 


\title{
A CASE STUDY OF A NATIONALLY RECOGNIZED \\ MIDDLE SCHOOL'S DECENTRAL IZED \\ PARTICIPATORY GOVERNANCE \\ STRUCTURE
}

by

DONNA CARMAN

\begin{abstract}
A dissertation proposal submitted in partial fulfillment of the requirements for the degree of

DOCTORATE OF EDUCATION
\end{abstract}

IN EDUCATIONAL LEADERSHIP

PORTLAND STATE UNIVERSITY

- 1987 Donna Carman 
TO THE OFFICE OF GRADUATE STUDIES AND RESEARCH:

The members of the Committee approve the dissertation of Donna Lynn Carman presented May 13, 1987.

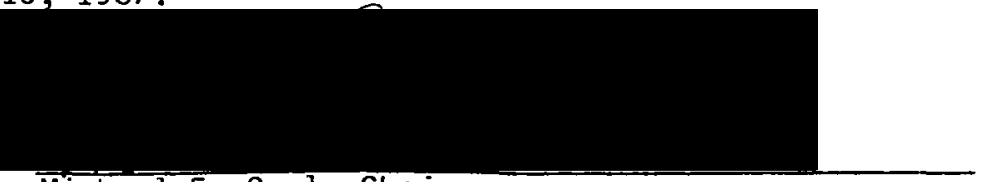

Michael E. Carl, Chairperson

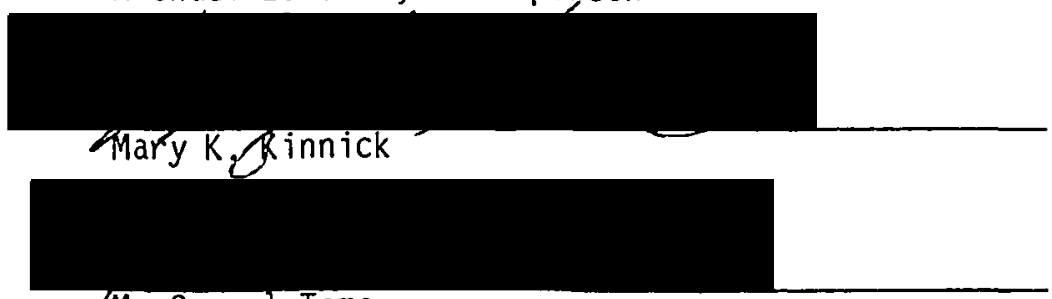

'M. Carrol Tama

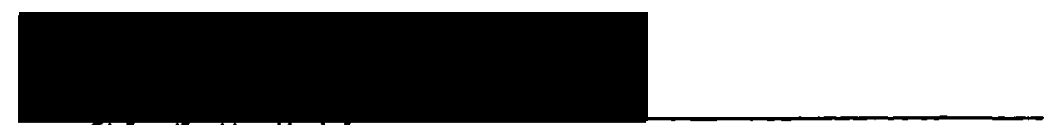

Ohoyge w. Hales

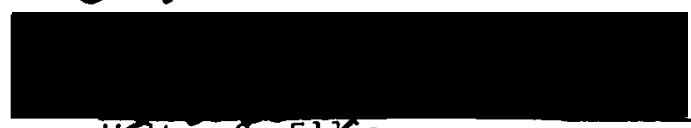

Walter G. ElXis

APPROVED:

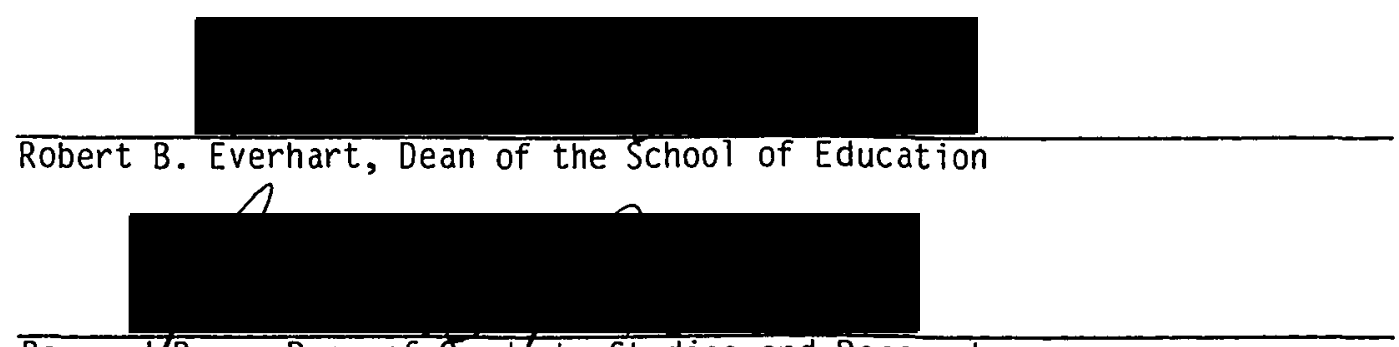

Bernard'Ross, Dean of Graduate Studies and Research 
AN ABSTRACT OF THE DISSERTATION OF Donna Lynn Carman for the Doctor of Education presented May 13, 1987.

Title: A Case Study of a Nationally Recognized Middle School's Decentralized Participatory Governance Structure.

APPROVED BY MEMBERS OF THE DISSERTATION COMMITTEE:

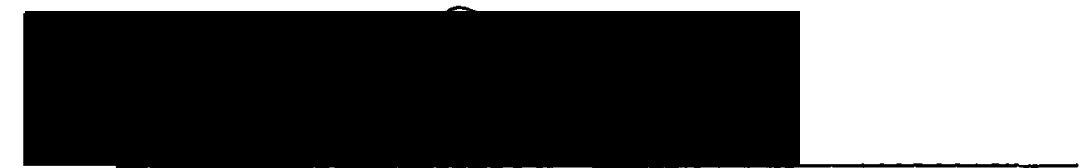

Michael E. Carl, Chairperson
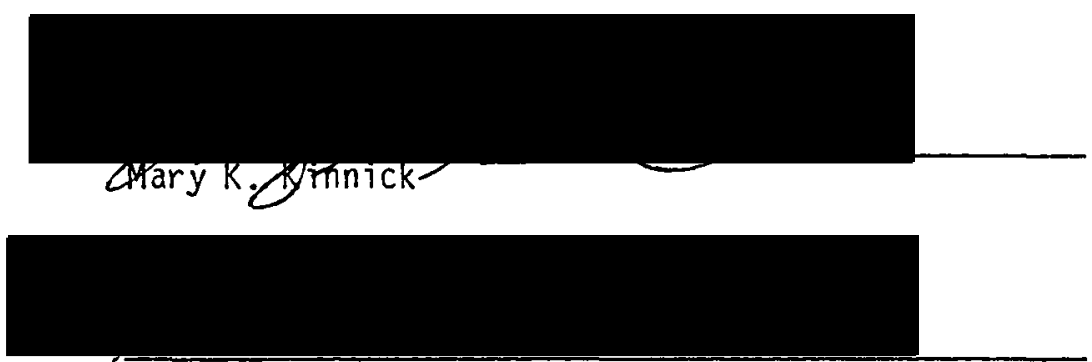

M. Carrol Tama

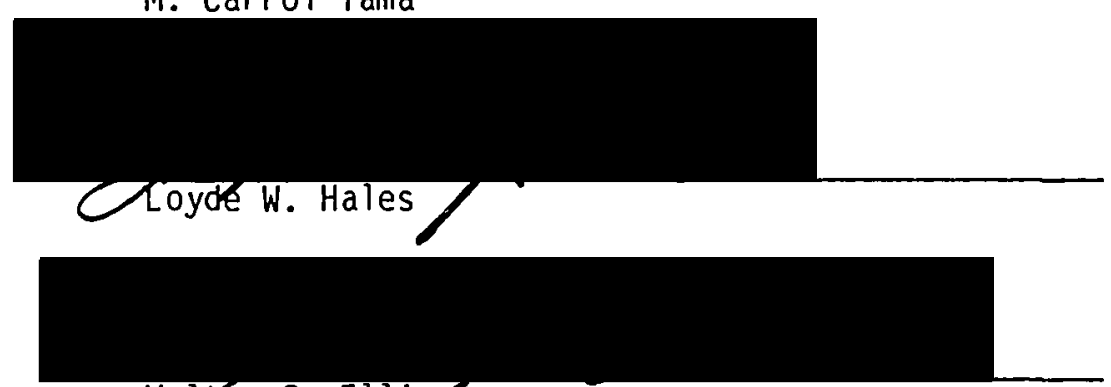

Walter G. Ellis

To effectively and substantively impact the realization of school improvement goals, there is a perceived need for the implementation of participatory processes that involve parents, patrons, students, and educators through decentralization of the planning, programming, and implementation phases. Related to this need is the pressing requirement of providing educational leaders with a greater understanding of what 
knowledge and skills they should possess to effectively guide and direct the implementation of decentralized participatory processes. An exploratory case study of a nationally recognized middle school's decentralized participatory structure was conducted. The purpose of this study was to provide the comprehensive context of an existing decentralized participatory structure from which needed knowledge and skills could be determined. The likelihood of successfully installing future partnership structures can be increased by providing educational leaders with a description, analysis, and interpretation of participatory involvements.

The conclusions for the case study were arrived at through a triangulation approach of key-informant interviewing, participant observation at meetings, and an investigation of essential documents. This researcher concluded that the following skills and knowledge base are important for participatory leaders to possess to successfully implement, direct, and guide a decentralized partnership program:

\section{$\underline{\text { Skills }}$}

1. Group dynamic skills

2. Human relationship skills

3. Communication skills

4. Decision-making skills 
Knowledge Base

A participatory leader must possess knowledge of 1) how to positively channel diversity, 2) motivation theory and ways to capitalize on motivation theory, 3) ways to develop participants' capacity to participate effectively, 4) how to effectively facilitate the communication and coordination between and among identifiable groups which interlace with the participatory process, 5) the school effectiveness leterature, 6) how to balance high task and high relationship, 7) how people learn most effectively, 8) goal theory and ways to set goals through other people, 9) effective planning procedures, 10) change strategy and how to effectively accomplish goals through other people, 11) the benefits of participatory decision-making, 12) the benefits of decentralization, 13) a range of leadership styles, 14) effective management practices, and 15) how to model a decentralized particpatory structure. 


\section{ACKNOWLEDGMENTS}

The interest, support, and help of so many people made the completion of this dissertation a reality.

My sincerest thanks and admiration go to Dr. Mike Carl, Chairperson of my Committee, for his guidance and insightfulness which directed me through my study. To the members of my Committee, I extend my deepest gratitude for their wisdom, guidance, and high expectations. Each phase of the dissertation process strengthened my study as a result of their constructuve comments and persistance. Dr. Mike Carl, Dr. Walt Ellis, Dr. Loyde Hales, Dr. Mary Kinnick, Dr. M. Carrol Tama, and Dr. Charles Tracy have nurtured me both professionally and personally. I will always remember them with warm regard.

Two individuals who willingly gave of their time and expertise were Mr. Paul Walden and Mrs. Teresa Baldwin. Their valuable input is greatly appreciated.

To my family, friends, and colleagues goes appreciation beyond words. Their psychological support was the catalyst for keeping my positive mental attitude intact.

Ila Westergard-Thorpe and Leigh Ann Callaway were my technical advisors and typists. Their countless hours of dedicated endurance will never be forgotten. Their friendship and support goes beyond explanation. Only they can understand how sincerely my thanks is given. 
Without the cooperation of administrators, parents, teachers, and students in the Battle Ground School District and the Pleasant Valley Intermediate School, this study would not have materialized.

Lastly and most dearly, I thank my wonderful husband and daughter. Tim and Jami have been the heart and soul of my existence throughout this past year. Their love, commitment, and encouragement have been the vehicle for making my dissertation a reality. It is to them that I lovingly dedicate this dissertation. 
TABLE OF CONTENTS

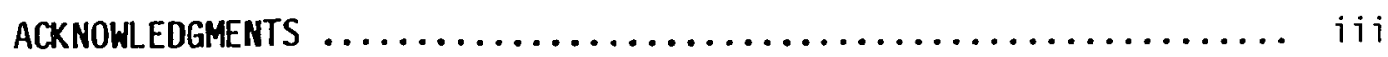

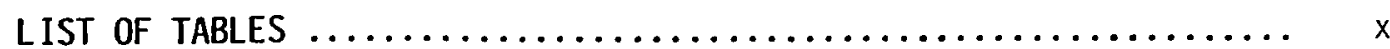

LIST OF FIGURES $\ldots \ldots \ldots \ldots \ldots \ldots \ldots \ldots \ldots \ldots \ldots \ldots \ldots \ldots \ldots \ldots \ldots \ldots \ldots \ldots \ldots \ldots \ldots \ldots$

\section{CHAPTER}

I THE SEARCH FOR INNOVATION: EFFECTIVE SCHOOLS PROCESS 1

Introduction $\ldots \ldots \ldots \ldots \ldots \ldots \ldots \ldots \ldots \ldots \ldots \ldots \ldots \ldots \ldots \ldots \ldots \ldots$

Background Information ...................... 3

Statement of the Problem $\ldots \ldots \ldots \ldots \ldots \ldots \ldots \ldots \ldots$

Justification of the Study $\ldots \ldots \ldots \ldots \ldots \ldots \ldots \ldots \ldots$

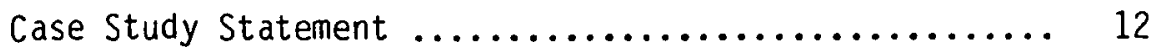

Significance of the Study $\ldots \ldots \ldots \ldots \ldots \ldots \ldots \ldots \ldots \ldots \ldots$

nperational Definitions $\ldots \ldots \ldots \ldots \ldots \ldots \ldots \ldots . \ldots . \ldots . \ldots$

II REVIEW OF LITERATURE $\ldots \ldots \ldots \ldots \ldots \ldots \ldots \ldots \ldots \ldots \ldots \ldots \ldots$

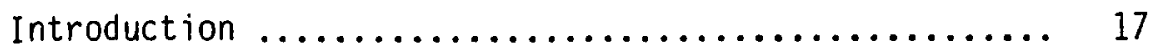

Participatory Decision Making ................. 18

Advantages

Disadvantages

Decentralization $\ldots \ldots \ldots \ldots \ldots \ldots \ldots \ldots \ldots \ldots \ldots . \ldots \ldots$

The Concept of Decentralization

The Need to Decentralize

The Benefits of Decentralizing

Precautions to Consider

Decentralization in Action - A Description 
Educational Planning, Goal-Setting, and

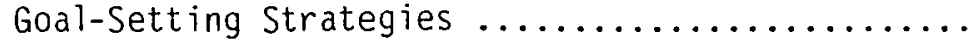

Educational Planning

Goal Setting

Goal Setting Strategies

School Effectiveness Literature - A Template for Educational Planning

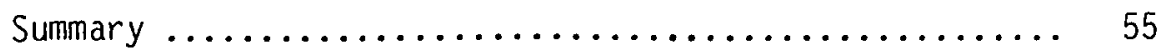

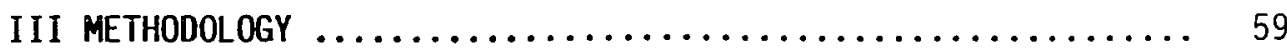

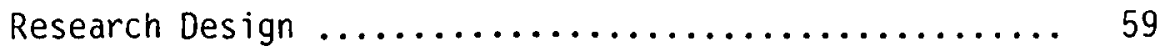

Population Description $\ldots \ldots \ldots \ldots \ldots \ldots \ldots \ldots \ldots \ldots, 62$

Categories of Investigation $\ldots \ldots \ldots \ldots \ldots \ldots \ldots \ldots \ldots$

Method of Collecting the Data .................. 65

Method of Organizing the Data ................ 71

Precautions Taken for Accuracy ............... 72

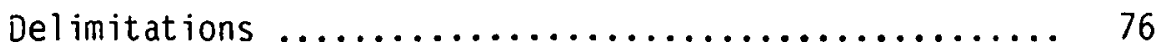

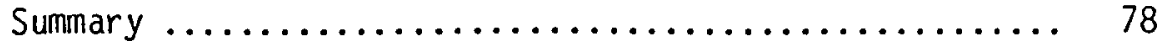

IV AN EXPLORATORY CASE STUDY $\ldots \ldots \ldots \ldots \ldots \ldots \ldots \ldots \ldots \ldots \ldots$

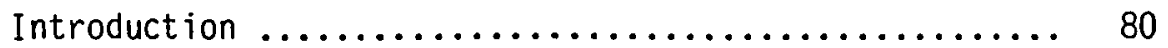

Case Study Context $\ldots \ldots \ldots \ldots \ldots \ldots \ldots \ldots \ldots \ldots . \ldots \ldots$

Original Training $\ldots \ldots \ldots \ldots \ldots \ldots \ldots \ldots \ldots \ldots \ldots \ldots \ldots$

Recruiting - Original Training

Planning - Original Training

Training - Original Training

Data Collection - Original Training

Design - Original Training

Implementation - Original Training

Surtmative Evaluation/Celebration - Original Training 
Evaluative Reflections Regarding Original Training .... 115

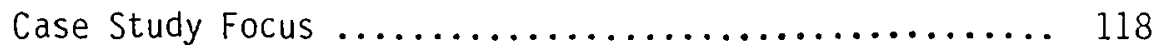

Pleasant Valley Intermediate School A Demographic Description

Formulation - Year one $\ldots \ldots \ldots \ldots \ldots \ldots \ldots \ldots \ldots \ldots \ldots \ldots \ldots$

Recruitment - Year one

Planning - Year One

Training - Year One

Data Collection - Year One

Design - Year One

Implementation - Year one

Evaluation - Year One

Celebration - Year One

Retrospect - Year One

Maintenance - Years Two Through Five

Recruiting - Years Two Through Five

Planning - Years Two Through Five

Training - Years Two Through Five

Data Collection - Years Two Through Five

Case Study Inclusion of Self-Study Needs

Assessment Instrument and Resulting Data

Design - Years Two Through Five

Implementation - Years Two Through Five

Evaluation - Years Two Through Five

Celebration - Years Two Through Five

Retrospect - Years Two Through Five ............. 183

Perception Check ........................ 186

What is the "Effective Schools Process"?

How has the "Effective Schools Process

benefitted you?

What is one frustration you have experienced

with the "Effective Schools Process"?

What could make MESP more effective at Pleasant

Valley Intermediate School?

Indicators of Success

The Principal

The Superintendent

The Students

The Teachers

The Parents/Community 
viij

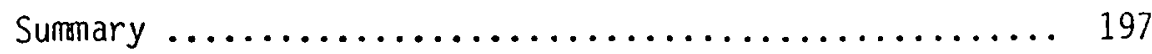

v CONCLUSIONS, ORSERVATIONS AND RECOMMENDATIONS $\ldots \ldots \ldots \ldots .199$

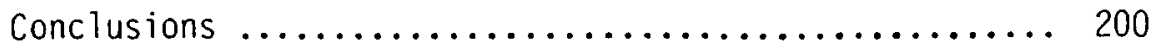

What Knowledge Base Should A Participatory Leader Possess To Effectively Implement

A Decentralized Participatory Structure?

What Skills Should A Participatory Leader

Possess To Effectively Implement $A$

Decentralized Participatory Structure?

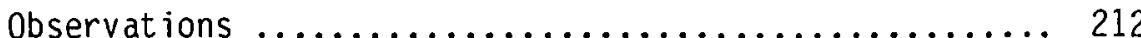

Why Do We Practice Decentralization?

What Do We Need To know About The

Characteristics And Dimensions of

Decentralized Program Operations?

What Has To Occur For Successful

Decentralization To Take Place?

How Do The Objectives of A Specific

Program Infiuence The Decision To

Decentralize?

How Can The Situation Be Modeled?

Recommendations and Implications for Further Research . 239

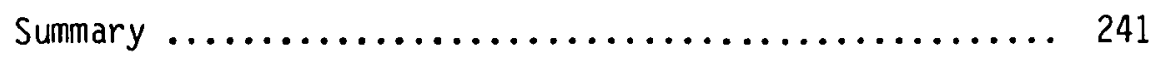

SUPPLEMENTAL REFERENCE NOTES $\ldots \ldots \ldots \ldots \ldots \ldots \ldots \ldots \ldots \ldots \ldots \ldots \ldots \ldots \ldots$

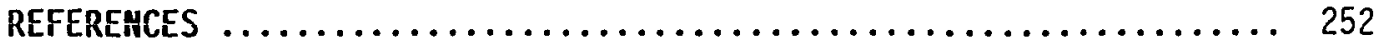

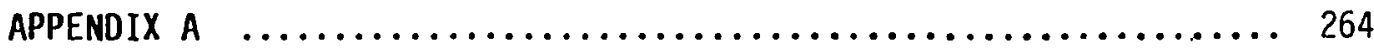

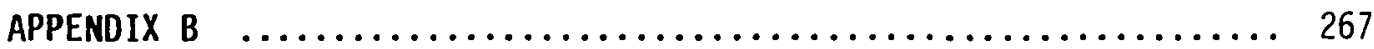

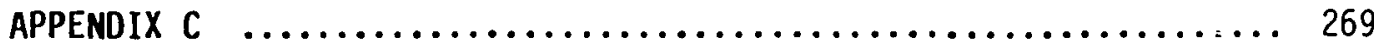

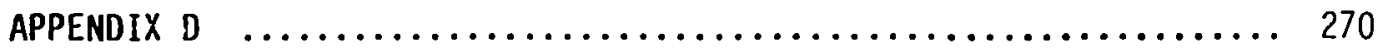

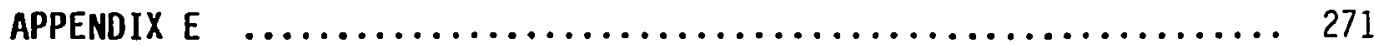

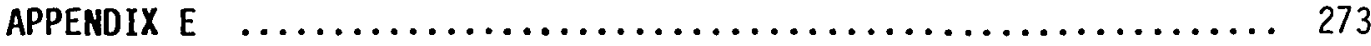

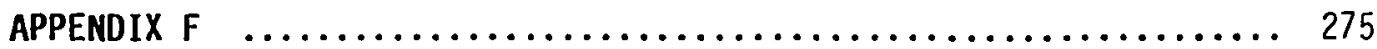

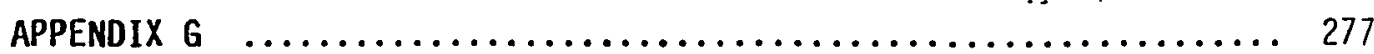

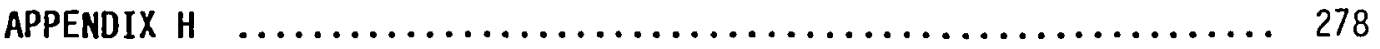




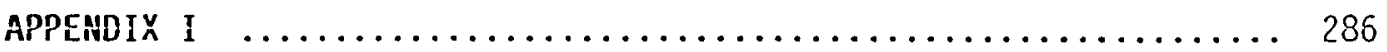

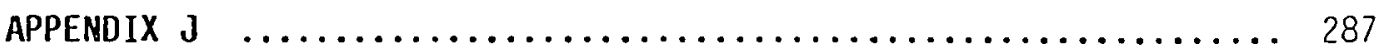

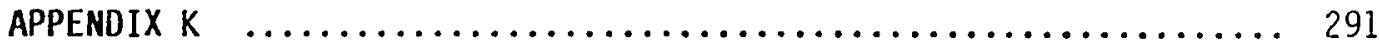

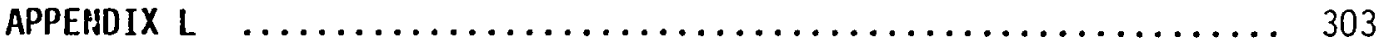




\section{LIST OF TABLES}

TABLE

PAGE

I Numerical Mix of Yearly Planning Teams $\ldots \ldots \ldots \ldots \ldots \ldots \ldots . \ldots . \ldots$

II Mean of Normal Curve Equivalent Scores for Pleasant

Valley Intermediate by Subtest with District Average ....... 190

III Rank Order of Knowledge Base ..................... 202

IV Rank Order of Leadership Skills $\ldots \ldots \ldots \ldots \ldots \ldots \ldots \ldots \ldots \ldots$ 


\section{LIST OF FIGURES}

1. Sequential flow chart of the case study narrative text $\ldots . .82$

2. The participatory concept of the $I / D / E / A$ model $\ldots \ldots \ldots \ldots 87$

3. Organizational chart of district and building level decision-making groups $\ldots \ldots \ldots \ldots \ldots \ldots \ldots \ldots \ldots \ldots \ldots \ldots$

4. Organizational chart of Pleasant Valley Intermediate's "More Effective Schools Process" ................ 122

5. Agenda for the first planning team meeting $\ldots \ldots \ldots \ldots \ldots 138$

6. Agenda for the second planning team meeting $\ldots \ldots \ldots \ldots \ldots 139$

7. Agenda for the third planning team meeting ............. 140

8. Agenda for the fourth planning team meeting $\ldots \ldots \ldots \ldots . \ldots 141$

9. Priority ranking of goals from the Phi Delta Kappa

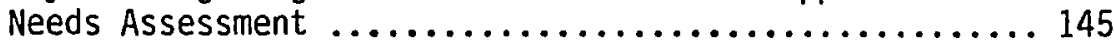

10. Mean scores from Phi Delta Kappa Needs Assessment displaying perceived goal attainment for each intermediate school

11. Pleasant Valley Intermediate's vision of excellence statement

12. Number of years a leadership position was held and then rotated to a different individual $\ldots \ldots \ldots \ldots \ldots 158$

13. Pleasant Valley Intermediate's revised vision of excellence statement

14. Frequency distribution chart displaying the number of interviews which surfaced each knowledge base and skills item 


\title{
CHAPTER I
}

\section{THE SEARCH FOR INNOVATION: EFFECTIVE SCHOOLS PROCESS}

\author{
INTRODUCTION
}

To answer the call for school reform, educational leaders have intensified the pursuit of educational excellence. To effectively and substantively impact the realization of school improvement goals, there is a perceived need for the implementation of participatory structures and processes that involve parents, patrons, students, and educators through decentralization of the planning, programming, and implementation phases. Related to this need is the pressing requirement of providing educational leaders with a greater understanding of what knowledge and skills they should possess to effectively guide and direct the implementation of decentralized participatory structures and processes. An exploratory case study was conducted to galvanize a greater understanding of what knowledge and skills a participatory leader should possess. Yin (1984) supports the justification of exploratory case studies - the goal being to develop pertinent hypotheses and propositions for further study. The purpose of this study was to provide the comprehensive context of an existing decentralized participatory structure from which needed knowledge and skills could be determined. In addition, the narrative text of this 
case study provides the rationale for why the knowledge and skills are deemed to be important.

Many school districts are restructuring to a decentralized model as a means to an end for achieving school improvement goals. These districts are formulating building-based planning teams to actively involve parents, patrons, students, and educators. The primary purpose of these planning teams is to crystalize and implement goals to meet the unique needs of the school, bringing it closer to a desired future state. The individual school is the primary unit to change. Giving automony to the individual buildings allows those people who are impacted by decisions to be a part of the decision-making process. Such planning teams capitalize on human motivation theory and goal theory the theory upon which this study is based. By broadening the base of ownership, subsequent commitment to change is strengthened. The literature reveals the many benefits attributed to the process of broadened participation. However, little is revealed regarding the process of how to effectively implement these building-based planning teams. Participatory leaders are finding the reality of achieving successful collaboration to be significantly more difficult in application than the simplified concept. Involving parents, students, and teachers in a partnership is a demanding, time consuming, and many times, frustrating task. In these partnerships, task forces are charged with developing goals that address difficult educational issues. Effective leadership is needed to coordinate and mobilize these planning teams' diverse partners. 
Comprehensive case study data can help practitioners successfully bridge the gap between idea and implementation, better enabling them to answer the following question: What must we do and what must we know to successfully implement, guide, and direct a decentralized partnership program? The likelihood of successfully installing future partnership structures and processes can be increased by providing educational leaders with a description, analysis, and interpretation of participatory involvements.

\section{BACKGROUND INFORMATION}

The shift from a national economy to a global economy has caused great concern regarding America's ability to compete in the international marketplace. Many foreign countries now have the advanced technology to compete, coupled with the willingness to work longer hours for less pay (Tucker, 1986). Several recent national reports, such as $A$ Nation at Risk (1983) and the Carnegie Study (1986), have spotlighted the need for school reform. The purpose of school reform is directly aimed at preparing our youth to be capable of competing in a global economy. The agenda for improving the schools grows out of the gap between what is expected of schools and what it is they are perceived to be doing. Educational leaders are responding to this gap by initiating school improvement programs.

The "what" for school improvement has been defined through the school effectiveness literature, and provides educators with goal defi- 
nitions. However, the implementation of these goals - the "how" and "why" for school improvement - presents the critical challenge. Many school districts are considering alternate methods as a means to an end. The issue of centralization versus decentralization as alternate methods has become a crucial consideration when addressing the "how" or implementation of goals. Centralization is typified by a bureaucratic, line and staff structure, with the district central office in control. There tends to be a uniformity of programs and prescriptions for all of the schools, disregarding the unique needs and characteristics of individual schools. According to Long (1977), decentralization is "decentralized decision-making" with greater involvement of parents and school building staff in certain decisions that affect the delivery of educational services to children. Many school districts are formulating building-based planning teams to actively involve parents, patrons, students, and educators. John Goodlad (1984) asserted that in each individual school involved in a decentralized model

it is essential that persons in addition to the principal be involved in decisions for the school's welfare. There should be, for example, some kind of planning group chaired by the principal and including teachers, students, parents, perhaps a nonparent, and, if possible, a representative from the district office. The group should be quite separate from the structure used to administer the school and from the usual processes of the faculty's deliberation over their immediate responsibilities.(p. 278).

Restructuring to allow for these decentralized planning groups makes it possible for the focus of school improvement to revolve around the individual school (Rutter, 1981). Centralization does not provide the vehicle for addressing those concerns which are unique to each school 
site. There is, therefore, a rebalancing of power occurring toward greater decentralization. The shift of power is from the more remote, less visible, more impersonal authorities heading the system to the more visible, more personally known, close-at-hand staff, students, and parents of the individual school (Goodlad, 1984). Establishing decentralized planning teams does not imply that the external directives and restraints of centralization should be abandoned. It is not an either/or dichotomy. A balance of power must be achieved, and a redefining of roles is necessary. Authority and responsibility must be differentiated and distributed across the system. An appropriate balance must be found by focusing on the means/ends relationship of centralization versus decentralization. The critical guiding questions must be: (1) What innovations must be put into place (ends)?, and (2) How best might this be achieved (means)?

School districts who restructure to allow for a decentralized governance must design a framework to assure school-to-school equity and a measure of accountability to state and local educational goals. Having a decentralized participatory structure is not having schools cut loose, but rather schools linked to a hub - the district office - and to each other in a network.

This case study will focus on a state and nationally recognized school that has a decentralized planning team comprised of the exact components as the planning team described by John Goodlad.

The primary purpose of the planning team is to crystalize and implement goals to achieve a desired future state for the individual 
school. This group holds formal monthly meetings, supplemented by task force meetings as needed. It is composed of the principal, volunteer teachers, students, parents, and a district office representative. Each member is responsible to contact designated people who are indirectly involved in the group's pyramid-grapevine communication network. The purpose of pyramiding is for broadened two-way communication and input to take place regarding the school's improvement effort.

Motivation theory, goal theory, and the school effectiveness research provide the theoretical framework for this study. The decentralized participatory structure reflects the organizational change that is occurring in education today. Participatory decision-making creates a feeling of ownership and influence and is directly linked to motivation theory. Goal theory supports the underlying belief that individuals are motivated to work toward a goal. The single most important activity that occurs through a partnership effort is the process of goal setting and the implementation of those goals for the purpose of impacting meaningful change. The school effectiveness literature provides for "goal definition", assuring a credible direction for school improvement.

This case study of an existing successful decentralized partnership structure is significant because the results can be joined with other qualitative and quantitative data. Educational practitioners can then coalesce the school effectiveness literature with processes and structures (i.e. decentralized planning teams), thus impacting substantive school improvement. 
The Carnegie report strongly emphasized the need for schools to push the organizational mission and goals downward to the lowest rung to involve parents, patrons, students and educators in the participatory decision-making model (Tucker, 1986). The difficult issues facing schools are not easy problems that can be solved by educators alone. Education is too important to be left only to educators, and too complicated for just the community. A home/school/community partnership can harness the diversity, creativity and expertise needed to repair American schools.

\section{STATEMENT OF THE PROBLEM}

There is a pressing requirement of providing educational leaders with a greater understanding of what knowledge and skills they should possess to effectively guide and direct the implementation of decentralized participatory structures and processes.

\section{JUSTIFICATION OF THE STUDY}

It is clear that effective leadership for tomorrow's schools will be very different from the leadership of the past. As a minimum, effective leadership will require the coordination and mobilization of the caring forces in education (i.e. parents, patrons, students, and educators). 
Lieberman (1986) contends that the climate for reform gives educators a rare opportunity to change the ways we work that may be both deep and lasting. However, the success of these changes are directly related to the knowledge and skills of the educational leaders who are responsible for guiding and directing the change.

Change requires very careful planning. Unfortunately, educational leaders at the helm of participatory planning groups are often expected to coalesce confrontational positions into a shared direction with very little qualitative information on which to rely. Forging an alliance among educational partners is a complicated process simply because of the multiple realities of the people involved (Sergiovanni, 1984). Diverse perspectives, culturally embedded meanings, and unstated agendas are brought to any collaborative effort. It is unrealistic to think that diverse groups can reflexively work in concert (Wynne, 1985).

An educational change agent, serving as catalyst, solution giver, process helper and resource linker, is dependent upon an adequate knowledge base and effective inter-personal skills. If leaders lack the necessary knowledge and skills, the results may be worse than a leader's autocratic decision.

The formulation and maintenance of a participatory process are fraught with potential problems and obstacles that can destroy, hamper or delay a collaborative effort. Educational leaders are grappling with understanding the dynamics and complexities of working together while balancing high task and high relationship activities (Jones and Maloy, 1986). 
In the $1986 \mathrm{fall} /$ winter edition of the Washington State ASCD Curriculum in Context, the editor stated that each of the authors, in the special issue dealing with partnerships, supports the concept that special nurturing is vital to an effective partner relationship (Wolfe, 1986). In-depth qualitative studies are needed to analyze and describe how to formulate, nurture and maintain a decentralized partnership structure.

In addition to possessing interpersonal skills to tap the potential of a diverse planning group, educational administrators need the technical knowledge of how to engage others in the process of goal-setting. The process of goal-setting often involves a series of complex decisions regarding the WHAT, HOW, WHO and WHEN of any prescription or program intended to positively effect school improvement. Leithwood and Montgoinery (1982) found that few educational change agents engage in goal-setting at al1, and when they do it is rare for them to even include staff, and rarer yet to engage the general public. Principals need to develop skills that would help them to establish clear priorities. More importantly, however, those goals need to be accomplished through the empowerment of other people. McInerney (1985) found that despite the growing body of literature dealing with educational planning, little information on the planning methods and activities employed by educational planners at the school district level is available. Qualitative studies are needed to highlight effective goalsetting processes for participatory planning groups. This qualitative study, is designed to address this growing need. 
The majority of the general research, to date, relates directly to "prescriptions" for achieving a more effective school while largely ignoring the "process" for implementation. The focus has been to concentrate on the "what" for school improvement, not on the "how", and the emphasis must now begin to shift from "prescription" to "process". Participatory processes and decentralized decision-making require leadership skills and a knowledge base that are currently less than well defined. While there is an abundance of statistical research relative to the positive effect of partnerships on student achievement, there is unfortunately very little qualitative analys is and interpretation of these partnership involvements. In most instances, the processes used to achieve successful partnerships are more illusive than the research itself.

Conway (1984) stated that the mastery of participatory decisionmaking is still as much theory based art as it is a structured science of behavior, and feels there is an equal need for naturalistic and exploratory inquiry. Muth and Bolland (1983) declared that careful research is needed in order to assess the perspectives of various participants, as well as the outcomes they desire and the effects these may have. Therefore, this case study will also investigate the implications for those people who have been affected by the partnership structure.

An additional justification for this study relates directiy to helping educational administrators in the state of Washington. In 1985, the state of Washington mandated the implementation of an educational quality self-study process by school districts that places emphasis 
upon: (1) achieving educational excellence and equity; (2) building stronger links with the community; and (3) reaching concensus upon educational expectations through community involvement and corresponding school management (WAC 180-53-005). Many educational change agents in the State of Washington are seeking out needed methods and processes to enable them to effectively come into compliance with the state law. In addition, the 1985 Washington State Legislature passed an initiative for $\$ 500,000$ which allowed 38 pilot schools to begin a decentralized schoolbased management process in the fall of 1986.

The saying "Words are fatter than numbers" succinctly describes the methodology of this study. Detailed, comprehensive field descriptions add a more personal dimension, providing the reader with an opportunity to apply the findings to his/her own unique cultural school setting. Sara Lightfoot (1978) refers to it as the "passionate ethnographic" element capable of creating symbols, images, people and ideas with whom practitioners can identify.

This case study will explore strategies and techniques that have been utilized to address such divergent and multiple dimensions as time, group cohesiveness, motivation, commitment, conflict resolution, decision-making, credibility, representation, communication, and planning, goal setting and evaluation. Dimensions of the structure itself will also be explored (i.e., coordination with district office). The study will look at ways the structure is valued by the people who have been affected by the programs and practices currently in place. In addition, those directly involved in the process will be given an opportunity to 
describe the relative strengths and weaknesses of the participatory model.

Bennis (1969) stated that any knowledge that is useful for planned and directed change is knowledge of an applied nature. If this study helps to make partnerships more successful, then important, calcified educational problems can continue to be addressed in an unending, cyclical process.

\section{CASE STUDY STATEMENT}

Jones and Maloy (1986) unfortunately reported that while some collaborative efforts have fulfilled their optimistic promises, most have generated frustration and conflict among partners. While it is true that most collaborative efforts have not been successful, several successful programs in existence could be studied to provide needed methods, tools and guidelines (Danzberger and Usdan, 1984).

The Battle Ground School District, in which the case study will be conducted, has a decentralized participatory structure that has been in place in eleven buildings for five years. The district has named their decentralized partnership program the "Effective Schools Process". Throughout the case study text, the acronym ESP will refer to this district program. The case study will be focused primarily on one of the district's middle schools, Pleasant Valley Intermediate. In 1985, this middle school received state and national recognition from the U.S. Department of Education. The school's decentralized participatory 
structure was highlighted in both of the summaries from the state and national level. The structure is perceived to be successful by those who are external and internal to the structure. It is believed to have positively contributed to the school's overall success. Pleasant Valley Intermediate has named their individual partnership program the "More Effective Schools Process". Throughout the case study text, the acronym MESP will refer to the middle school's partnership program.

Several overarching questions were formulated to guide the inquiry of the case study. They are as follows:

1. What knowledge base should a participatory leader possess to effectively implement a decentralized participatory structure?

2. What skills should a participatory leader possess to effectively implement a decentralized participatory structure?

3. Why do educators practice decentralization?

4. What do we need to know about the characteristics and dimensions of decentralized program operations?

5. What has to occur for successful decentralization to take place?

6. How do the objectives of a specific program influence the decision to decentralize?

7. How can the situation be modeled?

Through a review of literature, related research, and personal experience, the following important characteristics and dimensions have been surfaced that are associated with successful decentralized participatory processes:

1. Innovations will vary from school to school.

2. The rationale for adopting the process is research based. 
3. Special techniques and strategies have been used to negotiate diversity into a shared direction.

4. Recruitment, commitment, and evaluation have been an important focus.

5. Special nurturing has occurred to build trust, respect, and the willingness to take risks.

6. The broader base of ownership and commitment has produced indicators of success.

7. All participants possess decision-making skills and interpersonal skills.

8. Leaders have a working knowledge of how to crystalize and implement goals through the empowerment of others.

9. The credibility, reality, and appropriateness of decisions have been important considerations.

10. Those who are involved want to make a difference for kids, and are personally seeking self-actualization.

11. There is a coordination between district and building goals to include feedback to the district, some control by the district, and support by the district.

12. Complexities inherent to schools have impacted the partnership process.

13. Obstacles have been overcome that threatened to hinder or delay the effectiveness of the partnership.

14. Certain processes and practices have been used to positively impact the effectiveness of the partnership.

15. Several important learnings have resulted from the experience that would be important to share with others.

The preceding characteristics and dimensions of a successful decentralized participatory structure will be used as probes while conducting the in-depth, exploratory case study. 


\section{SIGNIFICANCE OF THE STUDY}

The narrative text of this study is a coherent, well-integrated description of a successful partnership structure that practitioners could choose to replicate or redesign. The conclusions of this case study highlight the skills and knowledge base deemed to be crucial for the effective implementation of a decentralized participatory structure. The study has generated fruitful hypotheses for further study suggesting important variables, processes, and environmental interactions that deserve more attention. Key findings can be generalizable to many areas of collaborative work that are grounded to motivation and goal theory.

This study is intended to strengthen the probability of success for future participatory structures. Once these structures are solidly in place, substantive school improvement can be continually pursued. If collaborative efforts fail, important problems go unresolved. If efforts are successful, then there will be further future commitment and involvement which can substantively impact meaningful school improvement.

As Winston Churchill once said, "First we shape our structures and afterwards, they shape us (Scarr, 1986, p. 10)". 
OPERATIONAL DEFINITIONS

Decentralized Participatory Structure - a representative group in the case study district comprised of the principal, volunteer teachers, parents, students, a district representative, and a group of people indirectly involved in a pyramid-grapevine communication network. The central purpose of the group is to crystalize and implement goals to achieve a desired future state for the individual school.

Effective Schools Process - the name given by the case study district to their decentralized participatory structure, with the acronym ESP.

I/D/E/A - the national institute that provided the training for the case study district's decentralized participatory structure in cooperation with the Kettering Foundation. I/D/E/A is an acronym for Institute for the Development of Educational Activities.

More Effective Schools Process - name given by case study middle school to their individual school's decentralized participatory structure, with the acronym MESP. This is in contrast to the district's acronym ESP.

Middle School - the middle school involved in the case study comprises grades 5-8.

PVI - acronym for the case study school, Pleasant Valley Intermediate. 


\section{CHAPTER II}

\section{REVIEW OF LITERATURE \\ INTRODUCTION}

This study revolves around the basic thesis that those people who are effected by decisions need to be a part of the decision-making process. Because a school system is such a complex organization, the structures and processes utilized for decision-making are varied, directly impact the quality of decisions made, and ultimately the extent to which decisions can be effectively implemented. This review of literature has been organized to investigate the who (participants), the how (structure), the why (motivation) and the what (planning processes and research base) of educational decision-making.

The first segment of the review of literature is focused on the participants in the decision-making process. A thorough investigation of participatory decision-making has been conducted to explore "who" needs to be involved and "why"?

The next segment of the review includes a description of participatory structures. Many school districts have restructured their organization to enhance participatory decision-making. In education, this restructuring is referred to as decentralization. A thorough 
investigation of decentralization has been conducted to explore the "how" regarding decision-making. Several examples of decentralization in action have also been included in this section.

The last segment focuses upon educational planning, goal setting and goal setting strategies. It is important to note that research has defined effective schools by separating out those characteristics attributed to schools that are deemed successful. In that regard, the school effectiveness literature is reviewed to explore the "what" for school improvement. This section concludes with a description of several participatory processes that are currently being operationalized in the state of Oregon.

The review of literature for this chapter, then, has been divided into three sections:

1. Participatory Decision Making

2. Decentralization

3. Educational Planning, Goal-Setting and Goal-Setting Strategies [ The school effectiveness literature is reviewed as a template for planning and thereby described in section three.]

\section{PARTICIPATORY DECISION-MAKING}

\section{Advantages}

Social scientists have described the participatory decision-making process as a democratic interchange in which many people are drawn into 
the shaping of important decisions as opposed to an autocratic or apathetic process (Powers, 1983).

The first study that distinguished between autocratic and democratic leadership was done by Lewin and Lippitt in 1938. This dichotomy has persisted in the literature since that time. Fiedler, in 1964, called the two types of leadership (1) task oriented and (2) relationship oriented. In the literature, task orientation or initiating structure are the elements of an authoritarian style of leadership, while considerations related directly to meeting workers' needs and indirectly to task accomplishment are elements of a democratic style (Powers, 1983).

Yuk1 (1981) points out that no leader is autocratic or participative all the time. There exists a continuum of administrative style between autocratic decision-making and true group decision-making that is often contingent upon the situation (Hersey, 1984). Yuk (1981) points out, though, that many leaders make the majority of their decisions in either an autocratic or participative manner. Yuk 1 said that leaders who choose participatory management can improve the motivation, performance and satisfaction of subordinates. He maintains that "Participatory management is consistent with American ideals of equality, democracy and individual dignity."

Vroom and Yetton's (i973) normative model of leadership includes five decision methods that involve subordinates in the decision process in varying ways and to varying degrees: 
1. The decision is made by the leader using information available at the time.

2. The leader obtains necessary information from subordinates and then makes the decision.

3. The leader shares the problem individually with subordinates, collecting their ideas and suggestions without bringing them together as a group. The leader then makes a decision.

4. The leader shares the problem with subordinates in a group, collecting their ideas and suggestions. The leader then makes the decision.

5. The leader shares the problem with subordinates in a group and together alternatives are generated and an attempt is made to reach consensus on a solution. The leader is willing to accept and implement any solution that has the support of the entire group.

Vroom and Yetton (1973) also state that because participation utilizes the expertise and analytical skills of subordinates as well as the leaders, better decisions can result. Argyris (1973), contended that participation is consistent with the needs of subordinates which include autonomy, achievement, self-identity and psychological growth. He said that autocratic leadership does not meet those needs, but is a cause for frustration, resentment and apathy.

Likert (1967) stated that commands are ineffective if issued without corsultation. His study contrasted "participative" leadership with "exploitive-authoritarian" leadership. According to Likert, 
"exploitive-authoritarian" leadership is the least effective style because it renders subordinates powerless. A spin-off effect of "participative" leadership is that the group applies social pressure to dissenters to accept or comply with decisions made by the group. Likert asserted that an interest in people approach is a necessity, not a luxury and can be effective for all kinds of tasks, in all kinds of organizations.

McGregor's (1960) Theory $X$ and Theory $Y$ is based on a set of fundamental assumptions relative to the makeup of people. He constructed two differing views of a human being in relation to his work. McGregor arbitrarily chose Theory $x$ to identify management's conventional conception of harnessing human energy to organizational requirements. Theory $X$ assumptions include:

1. The average human being has an inherent dislike of work and will avoid it if possible.

2. Because of the average human being's dislike of work, one must be coerced, controlled, directed or threatened with punishment to get one to put forth adequate effort toward the achievement of organizational objectives.

3. The average human being prefers to be directed, wishes to avoid responsibility, has relatively little ambition, and wants security above all.

Theory $Y$ is a set of assumptions about people that are quite different from those of traditional management philosophy. Theory $Y$ assumptions include:

1. The expenditure of physical and mental effort in work is as natural as play or rest.

2. External control and the threat of punishment are not the only means of getting people to work toward the organization's objectives. People will exercise self-direction and 
self-control toward achieving objectives to which they are committed.

3. Commitinent to objectives is a function of the rewards associated with their achievement (esteem and self-actualization, for example).

4. Average human beings learn, under proper conditions, not only to accept but to seek responsibility.

5. Most people are capable of a relatively high degree of imagination, ingenuity and creativity in solving organizational problems.

6. Under the conditions of contemporary industrial life, the average person's intellectual potentialities are being utilized only partially.

McGregor sees the "negative" behavior of Theory $X$ as being created by management through its excessive degree of control. McGregor believes that management must be ingenious enough to tap the hidden potential of its work force by capitalizing on the inherent need of people to be self-motivated and self-controlled.

McGregor's work was influential in the early stages of exploring the possibility of developing workers' potential to the fullest through management techniques (Powers, 1983).

Bennis (1969) also took a people-oriented stance as an advocate of organizational development. Bennis and Nanus (1985) project the same theme in their book Leaders. They believe a leader must work hard at understanding people, and that leadership relies more on relationship than it does on position. They contend that a one on one sharing has the potential for nurturing positive relationships which allows trust to accumulate. They maintain that trust is the emotional glue that cements an organization together; trust is the lubrication that powers positive change. They believe that effective leaders who utilize a participatory 
process will ultimately reap the human harvest of their efforts by the simple action of power's reciprocal-empowerment.

Blake and Mouton's (1964) Managerial Grid Analysis, based on a synthesis of the leadership style work conducted at Ohio State and elsewhere, documents clearly that the most effective, highly desirable and ideal managers have a high concern for people united with a high concern for production. The conceptual framework of the Grid grew out of Blake's belief that an unnecessary dichotomy existed in the minds of most managers between concern for people problems and concern for production problems. Blake holds that the two concerns are complementary, and that their integration in the management process would optimize both.

Smith (1976) asserts that in many complex hierarchically structured organizations, much of a worker's day is wasted coping with pent-up resentments against sources of low autonomy, job insecurity and frustration. Smith (1976) claimed that in an organizational democracy, these sources of resentment can be expected to decrease, allowing more useful time to be devoted to work itself. Coch and French (1948), in an industrial setting, show quite dramatically the effects of participation on efficiency, productivity, absenteeism, turnover, and incidence of grievances. Similar results favoring employee participation in decision-making have been reported by Guest (1960), Vroom (1960), Maier (1957) and Wickert (1951). 
Disadvantages

At a very general level, the literature indicates that the outcomes of participatory decision-making rely on such contingency factors as the nature of the problem or task, the organizational climate, and the cognitive abilities and psychological concerns of participants (Wood, 1984).

Empirical studies have shown that outcomes such as a high decision quality and satisfaction are mediated by other variables. The impact on decision quality depends upon how much information sharing takes place within the group (Sashkin, 1976). If the information flow increases as a result of participation, then decision quality increases. Similar factors influence satisfaction (Miles, 1965). There is a higher probability that group members will feel satisfied if they believe they have been listened to, and if they believe their influence has been incorporated into the decision or plan. If group members do not find satisfaction, they may become uncommitted to the decision and less productive than if they had not participated in the group decision (Miles, 1965).

Another factor that hinders the effectiveness of participatory groups is a phenomenon labeled "strain towards convergence" (Hall and Williams, 1970). In hierarchically differentiated groups, lower level participants tend to acquiesce to what they believe is the majority opinion because they believe their suggestions will be unacceptable to superordinates. These participants are self-censors and remain silent about their ideas. However, recent literature suggests that persons of 
different ranks can be effectively brought together with power equalization (Mansbridge, 1973). The Abilene Pardox (Harvey, 1975) or Group Think (Janis, 1972) are phenomenon in which group members do not experience a threat of reprisal but the members self-censor to avoid conflict. Rather than voicing their true opinion, participants will frequently end up doing what they do not want so as not to "rock the boat." Consequently, hostile rather than satisfied feelings are the result. Effective participation requires certain skills, understandings and knowledge. The effectiveness of participatory groups relies heavily on participants developing their capacity to participate effectively. Training should not be limited to expertise in the issues under consideration, but should include the acquisition of skills in areas such as group dynamics and self-expression (Wood, 1984).

Vinokur (1971) states that because group decision-making diffuses responsibility, the consequences for the decisions are difficult to assign. Groups, then, may tend to choose riskier alternatives that could have unfortunate consequences for their organization.

Powers and Powers (1983) believe that the disadvantages of participatory decision-making can be overcome through awareness, training and a careful, well-planned effort. They contend that the disadvantages of participation do not outweigh the advantages, and certainly would never turn to authoritarianism as a more effective approach. 


\section{DECENTRAL IZATION}

The Concept of Decentralization

According to Long (1977), decentralization is "decentralized

decision-making" with greater involvement of parents and school building staff in certain decisions that affect the delivery of educational services to children. Evans (1977) defines decentralization as the delegation of powers for decision-making to bodies other than those which remain mere agents of central authority. A number of studies indicate the need for a considerable amount of autonomy for each school building in determining school improvement alternatives, with an emphasis on school-specific culture (Rutter, 1981; Brookover and Lezotte, 1979).

Pierce (1980) designed a plan whereby the school replaced the central district office as the basic unit of educational management. School based management, as he called it, is an educational reform designed to improve public education through decentralization. Danzberger and Usdan (1984) believe that building such partnerships for decision-making is a theoretically sound approach to school improvement.

As Alexis and Wilson (1967) have asserted, "Flatter, less complex structures, with a maximum of administrative decentralization tend to create a potential for improved attitudes, more effective supervision, and greater individual responsibility and initiative". This approach to 
school management is consistent with an entirely separate body of theory and research on organizational effectiveness in private sector organizations (Goodman and Pennings, 1977; Mott, 1972). Bacharach and Conley (1986) believe that the time has come for educators to learn the lessons from effectively managed organizations, and refocus educational efforts on management philosophies and organizational processes. They assert that school districts should focus on the basic management structures and processes by which schools are administered, rather than focusing on such things as competitive pay schemes.

Decentralized, school-based management is one vehicle for providing a more appropriate structure and process.

\section{The Need to Decentralize}

There is sufficient cause for educational change agents to pay more attention to the need for increased involvement from parents/patrons, students and teachers. The recent Carnegie report (1986) strongly emphasizes the need for schools to push the organizational mission and goals downward to the lowest rung to involve parents/patrons, students and educators in a participatory decision-making model for the purpose of school improvement (Tucker, 1986).

The 1979 National Commission on Neighborhoods stated that participatory reform is crucial for the survival of urban America (Jennings, 1979). Fantini (1972) asserts that the participation in school governance by citizens is essential. Participation helps to 
maintain the control of public institutions by the people, also preventing the so-called "Tyranny of the Expert". The participation of citizens increases the consciousness of school personnel that they are accountable for the educational attainments of students. Seeley (1986) strongly believes that public education must be restructured to include a community perspective in forging a credible, appropriate and realistic direction for school improvement.

Productive, educational relationships must also take into account the importance of having students actively involved as a decision-making partner. Too often, students have been seen as "targets" of school services (Seeley, 1986). Rutter (1981) asserts, in his school effectiveness research, that students need to be given opportunities for ownership and responsibility in the learning act. It must be remembered that students are the prime producer of what we want from our schools (learning), and therefore they need to be a significant component of a participatory management model (Seeley, 1986).

The current and predicted future teacher shortage gives cause for creating opportunities for teachers to be a significant component of a participatory management model (Tucker, 1986). The U.S. Education Department has put out a prospectus stating that our best teachers are leaving the profession after seven or eight years of teaching. (Kappan, 1986). The projections show a need for 1.5 million new teachers by 1993, and if present trends continue, only $63 \%$ of that need will be met. "The fact is," the prospectus states, "that a drastically reduced 
number of young people are interested in becoming teachers ..." (Kappan, 1986).

The recent Carnegie report asserts that teachers need to participate in setting goals and creating a vision of excellence, and must be given the autonomy and responsibility to carry out that task, making the teaching profession more attractive while at the same time effecting substantive change (Tucker, 1986).

Parents have an enormous vested interest in the education of their children. Daresh (1986) has found that there is considerable research showing the importance of a school establishing positive interactions with the home and community. Wulff (1986) asserts that "All teachers would do well to remind themselves that they are a limited partner in a child's education. Parents are the first cause of the value of education within a culture. Learning and teaching are indeed complex issues, but they are not issues in isolation (p. 7)."

A large scale study conducted by Berman and McLaughl in (1978) highlights the importance of including community members, teachers and administrators in school improvement projects. The study reported that no real change is likely to occur if administrators initiated change but did not involve teachers. If teachers generated ideas to which the administration was uncommitted, the ideas remained ideas. The Berman and McLaughl in study (1978) also found that if the community does not understand or approve of a change, it is likely to be short lived.

A 1970 's Rand Corporation study arrived at similar conclusions. Organizations that successfully implemented changes that were mutually 
agreed upon developed horizontally as well as vertically (Joyce, Hersh and McKibb in, 1983).

\section{The Benefits of Decentralizing}

Joyce, et al. (1983) state that the solution to the phenomenon surfaced in the 1970's Rand study and the Berman and McLaughlin study (1978) is to build a continuous program-rethinking process which includes representatives of all three groups, parents/patrons, teachers and administrators.

A decision-making theory advanced by Vroom and Yetton (1973) advocates involving workers on matters which are relevant in order to promote understanding and acceptance. Decentralization would provide the structure for those impacted by educational decisions to be a part of the decision-making process. Likert (1967) asserts that a healthy organizational climate is built on trust. A decentralized structure would enhance organizational trust and positively affect human performance, with people appreciating other people's concerns. In order to change the climate of a school, Rutter (1981) and Brookover, et al. (1979) contend that it is necessary to view the school as a culture, formulated by people's attitudes and values. Therefore, Rutter (1981) believes that school improvement is more likely to be successful if attention is paid to people's attitudes within each school, and how people interface with each other and the environment. Caring, trust and cohesiveness can be natural by-products of decentralized, building based, participatory decision-making models. In A Place Called School, 
John Goodlad (1984) said that the individual school is the primary unit of change. Decentralization makes it possible for the focus of school improvement to revolve around the individual school (Watters and Talley, 1986). Decentralization also allows for an increase in the number of people who can be directly involved. Such direct involvement enhances individual opportunities for personal growth and development. A decentralized structure can capitalize on the theory of human motivation. Maslow (11975), in his "Hierarchy of Needs", surfaced those needs that people strive to satisfy in a search for self-actualization. As a result of this drive, the problem of motivation has drastically different overtones. People never lack motivation because they are involved in a continual search for enhancement. Management must create conditions where all participants in the educational setting are placed in a position where they can seek self-fulfillment. A decentralized decision-making structure can create those conditions.

Herzberg's (1968) research on job satisfaction reemphasizes the need for educators to restructure processes, thereby allowing for teacher involvement. Herzberg has clearly identified the hygienic factors by "pay and fringes", "working conditions", "supervision" and "policy" which are usually dissatisfiers for people. Herzberg contends that job content factors such as achievement, recognition, work itself, responsibility, advancement, and growth are satisfiers. Decentralized processes can enhance job content factors. Sharma (1955) found that teachers' satisfaction was directly related to the extent to which they participated in decision-making. Therefore, decentralization is a 
vehicle which helps to promote higher levels of job satisfaction for teachers.

Precautions to Consider

Decentralization involves empowering people and developing the capacity of people and institutions to change rather than trying to install innovations (Armenia, 1986). John Goodlad (Armenia, 1986) believes that this is a very difficult theory for people to grasp who have not been doing it all their lives. Goodlad stated that in these partnerships, task forces are charged with developing plans and strategies that address the most calcified, critical problems. Gorton (1977) concluded that involving parents and others is a demanding, time consuming, and, at times, frustrating undertaking. Muth and Bolland (1983) asserted that besides knowing who the participants are, change agents need to know their perspectives in order to anticipate what they value and how they will try to accomplish what they want.

In addition, there is always the danger that decentralized groups may propose unsatisfactory solutions which must be vetoed, leading to greater resistance and lack of satisfaction. It can also create unrest and misunderstanding when the discrepancy between promise and delivery is too large (McInerney, 1985). As parents, teachers and community members become involved, the initial period will be one of hesitation, possible distrust, and a lack of confidence. Administrators and school staff may be reluctant to work with parents and community because of 
previous negative interactions such as student discipline (Carney, 1984).

Although there is an abundance of research describing parent and community involvement, unfortunately there is very little analys is and interpretation of these involvements. Barriers to problems previously mentioned can be overcome if those people confronting them develop strategies to remove or circumvent the barriers, such as providing training in: conflict resolution, brainstorming, coming to consensus, or human development activities. Planners of decentralized models need to proceed slowly and deliberately, and learn valuable lessons from partnerships that already exist (Danzberger and Usdan; 1984).

\section{Decentralization in Action - A Description}

In 1985, the Washington State Legislature passed an initiative for $\$ 500,000$ to be given to 38 pilot schools to begin a school-based management process in the fall of 1986. The Washington State ASCD Conference in 1987 will feature community partnerships as one of their five themes. Washington Governor Booth Gardner encourages partnerships as a means of getting people involved in education (Wolfe, 1986). Watters and Talley (1986) have collated experiences from several school-based management sites and say that time considerations are essential when people work together. They recommend a two to three year plan, allowing a year to two for training its members and building trust. They contend that team members experienced frustration 
especially when they were invited to go through the necessary team building, training, and gathering data to support decisions. They maintain that the first year is indeed more process than product.

In 1976 the California School Improvement Program was initiated. The purpose of the School Improvement Program (SIP) was to insure that all students master basic skills while also acquiring broad knowledge that would enable them to be contributing citizens. SIP is based on the belief that each local school can best identify the needs of its students. Parents, teachers, principals, and students are best equipped to address those needs. A School Site Council must be established if the school is to receive state SIP funds. Carney (1984) contends that School Improvement Programs in California have been a successful vehicle for bringing the school and community together in a cooperative effort.

The Urban/Rural School Development Program (1970-1977) was a federally-funded effort designed to involve community members and school staff in joint decision-making. Twenty-five extremely poor neighborhoods were involved. School-community councils were at the core of the Urban/Rural Program. Lay persons and educators analyzed educational needs and found the means necessary to help teachers become a more vital force, (Joyce, et al, 1983). Several ways in which the Urban/ Rural program improved the process of educational decision-making are as follows: (1) by reducing alienation; (2) by increasing feelings of efficacy within the social system; (3) by increasing integration among teachers and community members in determining staff development activities; (4) by increasing the flow of community energy toward the 
improvement of education; and (5) by making local needs the focus of action. The Urban/Rural School Development was a grassroots democratic experiment. Thirteen sites were urban and twelve were rural. The student body of the smallest school was about 300 children and the largest was nearly 6,000 . The program schools were staffed by some 2,500 teachers. The program overall achieved a balance of community and professional input. It took from one to two years to get the councils organized, but once they were organized, they did an effective job of translating local needs. Participation increased feelings of efficacy among community members and professionals alike. The greater their involvement in the planning process, the greater their perceptions regarding the project's impact. It appears that teachers and community members can successfully assess and translate local needs. In many communities where members had sought participation but channels of participation were lacking, the Urban/Rural Program managed to utilize and focus the energies of those community members. Finally, the project found that due to the complexities of an urban society, the urban projects were more costly with less output for the dollar than rural projects (Joyce, et al., 1983, pgs. 152-160).

\section{EDUCATIONAL PLANNING, GOAL-SETTING AND GOAL SETTING STRATEGIES}

\section{Educational Planning}

Mottley (1972) defined planning as a major management function concerned with visualizing future situations. Carroll et al. (1980) 
supported this idea seeing the function of planning as developing a shared consensus of a vision for the future.

The process of planning involves deciding in advance what to do, and then subsequently how, when and who will be responsible for implementation. Planning provides a bridge to move individuals or organizations from where they are to where they want to be (Carney, 1984). Educational researchers have recognized that a school improvement planning process is essential in bridging the gap from "what is" to the "what is preferred" relative to school effectiveness.

\section{Goal Setting}

The school effectiveness literature indicates that the more successful educational change agents emphasize planning and goal setting. A goal is defined as any object of ambition or desire. Fairman and Renne (1983) have shown through studies utilizing a Organizational Health Instrument that goal focus is positively correlated with leadership effectiveness. Leithwood and Montgomery (1982) analyzed forty-one studies of "typical" principals. These studies indicated that the effective principals were clear on their own short and long term goals, influenced others in the school community by helping them to further the goals of program improvement, and disseminated information to significant others regarding school goals. Goals were found to help program development avoid the nebulous and global approaches to reform. If used early in the school year, it was 
found that goals clearly increased the effectiveness and efficiency of school programs.

Goal Theory provides the theoretical link between the process of goal-setting and motivation. Goal Theory is usually attributed to Edwin Locke's work in 1968. Locke set out to show that motivation can be consciously controlled. Locke (1968) defined a goal as "what the individual is consciously trying to do." Two major findings have been reported: 1) The harder the goal, the higher the level of performance, and 2) Subjects trying for specific hard goals performed at a significantly higher level than subjects trying to 'do their best.' Goal Theory, therefore, supports the underlying belief that individuals are motivated to work towards a goal, and the more difficult the goal, the more the individual increases the expenditure of energy.

Goal Theory supports the idea of goal-setting for the twofold purpose of guiding an individual's action and regulating motivation. Educational planning and goal-setting would seem to be worthy of an educational change agent's time and effort. Unfortunately, studies suggest that not all educational change agents place a great deal of emphasis on planning or goal-setting.

Bozeman and Schmelzer (1984) found that educators continue to lag behind business and industry in the area of planning, particularly strategic or long-range planning. This evidence resides in the midst of research showing that effective planning can significantly contribute to the climate, efficiency, and productivity of an organization. 
Leithwood and Montgomery (1982) have found that the typical principal does not engage even the school's own staff in goal or priority setting. The evidence indicates that few educational change agents engage in goal-setting at all, and when they do it is rare for them to include staff, and rarer yet to engage the general public. Lightfoot (1978), in her qualitative study of relationships between families and schools, went as far as to say that school members are "intent upon excluding families from school life." Coleman (1982) referred to Wolcott's study of a principalship in California and Duignan's study of the superintendency in Alberta. These studies state that it is common among educational change agents to be concerned with only maintaining the organization, while the type of leadership needed involves the establishment of goals to transform school systems. Goodlad (1983) believes that goals in education are seldom used let alone understood or well articulated. He recommended from his research entitled "Study of Schooling", that long-term plans of development should be expected from each school. Sergiovanni and Carver (1980) assert that one of the most important activities all educational change agents must orchestrate relates directly to the process of establishing goals for the school. They believe a leader renounces leadership responsibilities when no attempt is made to control school activities by developing and achieving goals.

If goal-setting is such a crucial component of a school improvement effort, then a logical question to ask is, "Who's values should influence goal and priority setting within a school?" Hall and Loucks 
(1975) stated that the most resistance to change comes at the value level; people have to value the change prior to responding positively to a new idea or practice.

If goal-setting, then, is the vehicle for change, the individuals or stake-holding audiences must value the goals that have been established. To ensure this, Guba and Lincoln (1982) believe that goal setting should be a process of mutual influence, involving all stake-holders. The research is clear concerning the many benefits that can be attributed to the process of broad participation in the planning process (Bean and Kuh, 1984; Bennis, Benne, and Chin, 1969; Boyd, 1983; and Mahoney, 1983). The most significant benefit is the sense of ownership people feel for the plan when the individuals are involved in the planning process. A sense of personal satisfaction is also attributed to participation in planning. Locke, in his $1970 \mathrm{~s}$ experiments relative to Goal Theory, found that satisfaction with performance is related to the degree to which a person's performance fulfills their desired goals or is divergent from the person's values. Schmuck and Runkel (1985) have found that opportunities for critical input and participation in the decision-making process provide individuals with a strengthened sense of competence. Hall and Alfred (1976) clarify that two crucial factors to a successful innovative process are that people have a say in the decision process and that there is a felt need for the change.

Van de Ven (1980) found that participation in planning was most effective if it was done in the early stages of the process. The 
research also emphasizes the importance of not only establishing a plan through goal-setting but also the importance of establishing long-range plans of two or more years.

They also perceive that intermediate and long-range planning has not reached a point of wide usage in the 1980 s.

Morgan and Scebra (1977) state that most educators do not have problems with short-range planning, but have occasional problems with intermediate planning. They contend that the real difficulty occurs when longer time frames occur. Goldman and Moynihan (1975) conducted a study to identify the difficulties that were encountered when attempts were made to introduce planning and orientation toward the future in a systematic way. Forty percent of the respondents encountered the most difficulty with creating a generalized desire and commitment on the part of participants for planning and change. Almost one-third of the 65 districts indicated they were unable to find adequate time for planning activities. One-fourth of the districts, however, reported difficulties in the following three areas:

1. Gaining commitment to the specific planning process and procedures used;

2. Resolving difficulties between and among identifiable groups which interlaced with the planning process; and

3. Facilitating communication and coordination among planning groups and between planning groups and their constituencies. Bozeman and Schmelzer (1981) found that conceptual or operational approaches to planning are not a part of the "core" framework in the 
majority of administrator preparation programs. Hager and Scarr (1983) found that principals generally lacked the skills necessary to establish goal priorities or to accomplish goals through other people. Bozeman and Schmelzer (1981) state that change agents need interpersonal and group process strategies to implement an effective planning strategy. Important areas in which to gain knowledge and skill include consensus building, communication, conflict management, and participating decision-making. They believe that many techniques such as Nominal Group Technique and others, can and should be utilized in a planning process.

The review of literature also incorporatea several strategies for goal-setting that have been utilized by school districts in the state of Oregon.

\section{Goal Setting Strategies}

Five strategies have been selected for this review of literature from a handbook funded by Weyerhaeuser Company Foundation under the guidance of the Oregon Department of Education (1976). The handbook, entitled Schools and Communities: Setting Goals, contains detailed descriptions of seven strategies for setting goals at the district level, two designed to set goals at the instruction level, and three procedures are included for conducting community surveys. The five strategies selected for this review of literature were chosen to present a balanced variety of strategies. The majority of the following descriptions have been replicated directly from the handbook. 
Community Expectations of Student Skills Program. The Beaverton district was funded by the Oregon Department of Education to test a number of strategies for involving the community in setting goals for schools. The program director, with the approval of the school superintendent and the board, selected Community Expectations as one of the strategies to be tested.

Participants were selected by name. It was recommended that 60 percent of those invited be representatives of the community-at-large, 20 percent be students, 10 percent be representatives of the business community and 10 percent be teachers/administrators representing the schools.

Community representatives expressed their expectations of what a student needs to know or do to "make it in life"once he or she leaves school. These expectations were expressed in brief statements followed by one or more phrases that clarify the meaning of the statements. In Beaverton, some 600 volunteers generated more than 3,000 statements. They also sorted these statements into 18 goal, or subject matter, areas. The district used these statements in assessing district goals and in making decisions relating to curriculum.

The district made a commitment to the community early in the program that it would actually make use of the data generated by the community. For example, the statements could be used to validate current goals, or to develop curriculum prior to textbook selection.

The Community Expectations Program has been thoroughly field tested in four school districts. They were satisfied with the results. 
With minimum training group leaders and trainers can follow a prescribed plan for organizing groups and generating statements.

Educational Goals and Objectives Model (EGOM). The Educational Goals and Objectives Model (EGOM), also called the Phi Delta Kappa model, is one of the better-known school/community goal-setting programs. EGOM is currently being distributeu through a network of 23 training centers. Some 300 school districts have implemented part or all of the program, and an estimated 10,000 educators and community members have been exposed to it.

Area or district task forces are formed. It is recommended that the district task force consist of a minimum of six people including at least one specialist each in elementary and secondary education. One condition for the success of the program is that administrators play an active role in securing the services of the community participants.

Eighteen goals provided by EGOM are ranked in order of priority by a committee representing the community. The community committee then scores each goal according to how well individual committee members feel current school programs are meeting the goal. The same assessment is made by representatives of the district's professional staff and by students. The main scores of the three groups show what the needs of the district are. The ranking of goals on a priority basis leads to the writing of performance objectives by the professional staff. A management design is developed to use resources which effectively meet the performance objectives of the district. Instructional programs are 
developed to meet perceived needs according to resource capabilities of the district.

The Phi Delta Kappa model is characterized by the fact that community, school and student groups rank, in order of priority, 18 goals provided by the program. EGOM participants do have the privilege, however, of suggesting additional goals but such suggestions have been rare.

Project Interaction. This State of Washington project was designed to help school personnel, working within the school system and with the community-at-large, to define educational objectives more systematically and to clarify roles and relationships.

Project participants develop "images of potentiality," each image being something desirable within the school system. Participants "take a trip" into the future, usually into the next year, and identify positive and satisfying features that they see. From these images are selected the priority goals for the year. Developers of this approach to goal-setting believe that creating positive and satisfying images of the future is more stimulating and productive than a negative or traditional problem identification approach.

Once goals are identified, the district may employ the process which brings out participants' perceptions of their role and their relationships with others in relation to key aspects of the educational job to be done. Differences in perceptions are resolved and plans are made to implement decisions and agreements. 
Community representatives participate by invitation. The principal criterion for selection is that participants should represent organizations or informal groups which are involved in children's education. Each group is invited to send a representative and an alternate who have authority to act on behalf of the organization. The project offers consultant skill training plus additional process training for district coordinators and superintendents. The school district can usually develop the skills necessary to continue implementation during the first year and to eliminate outside consulting help.

Reynolds - Delphi Program. Reynolds School District No. 7 serves a suburban-rural extension of the Portland, Oregon, metropolitan area. Most of the goal-setting activities reported here were conducted in 1973-1974.

After a decision was made to use the "Delphi" technique, an ad hoc planning committee was formed consisting of the two superintendents, four building principals and the director of special projects for the district. It was decided that the special projects director would coordinate the goals project because she was experienced in school-community relations and such projects were her official responsibility.

Once the planning committee had settled on a project design, a Goals Development Task Force was then appointed to help carry it out. The task force consisted of the assistant superintendent, principals, teachers, and parents. 
The Goals Development Task Force first established a set of 20 goal statements. These were adapted from the 18 goals used in the Educational Goals and Objectives Model.

The "Delphi" technique as it was used by Reynolds involved the mailing of a series of three questionnaires.

A mailing list of the 6,027 households in the original Reynolds district was used to represent the community. A questionnaire was mailed to every household. Every teacher and all students in grades seven to twelve were also given questionnaires.

The district first asked respondents to rank the twenty goals by priority. This was mailed to the households in the district. The same questionnaire was given to the teacher and student groups. The original questionnaire was then revised by listing the goals in the order suggested by the respondents and by adding six more goals. The second questionnaire was then mailed and returned.

The third questionnaire asked respondents to rate each goal statement according to how well the schools in the Reynolds district were achieving the goals. Again, percentages of the completed questionnaires were returned to the task force. This completed the survey.

Once the goals had been developed by the task force and ranked by respondents to the questionnaires, the district then began to formulate instructional objectives to implement the goals.

Although the district was primarily interested in the goal preferences of residential constituents, student and teacher populations 
were included in the surveys for comparison. In its report, the district states that its Goal Development Project was successful in accomplishing its stated purpose. The project also gave citizens, teachers and students a sense of participation in goal-setting.

Group Survey-Card Sort Technique. The Beaverton district devised and administered a technique for involving the members of selected community organizations in ranking of 17 goal statements. Members were asked to sort goal statement cards into three categories: most important, moderately important, least important. The sorting process was preceded by the showing of a set of slides which explained the purpose of the exercises. Participants were also asked to complete the brief questionnaire.

One thousand five hundred three members of 45 different community organizations and parent groups participated in the card sort. Selections among the groups were made to provide comparisons between parent-teacher clubs and nonschool-oriented community groups.

Once the organizations and parent groups were identified, the district sent letters to each organization asking if the members could be surveyed at a convenient time, usually during a regular meeting of the group. When permission was granted, a second letter explained in some detail the intent and methodology of the survey.

At the group meeting, a district representative began by showing a ten-minute slide-tape which explained the purpose of the survey and described other district activities relating to goal-setting. Each organization member was then given a sheet of paper and a stack of 
cards. On one side of the paper was a short questionnaire. It asked whether the respondent had children in school. The other side of the paper was marked off into three sections: most important, moderately important and least important.

Organization members then sorted the cards on the sheet of paper into three piles according to the printed labels: six goal statements considered most important, six moderately important and five least important. Participants then ranked all 17 cards in order of their importance with the top card being the most important and the seventeenth card being the least important. The cards and questionnaires were then collected.

An extensive analysis of all the rankings was made. Each participating organization received a summary of the way its members ranked the goals statements as compared to members of other participating organizations.

The five preceding strategies were selected for the review of literature to present a balanced variety of techniques that have previously been utilized by school districts. It is this writer's belief that school districts generally use a framework for planning that tends to generate outcomes that are less than consistent with the school effectiveness research. It is for that reason that this section will conclude with a description of how the school effectiveness research can be used as a template for educational planning and goal setting. 
School Effectiveness Literature - A Template for Educational Planning

Much has been learned about school effectiveness. Consequently, the task of school improvement can now be greatly enhanced if those involved become more aware of that knowledge (Purkey and Smith, 1982). Educational practitioners have been poorly informed by research in the past, largely because of inappropriate paradigms. The typical experimental and quasi-experimental studies reported in academic journals did not speak the same language as practitioners, and bore little relationship with the reality of schools (Hopkins and Wideen, 1984). However, the recent school effectiveness literature that is being related in practitioners' language through educational books, journals and magazines, intuitively makes sense. Much is now known about what works and what doesn't work. Hopkins (1984) believes that a useful starting point for schools engaging in a school improvement effort would be to step back and consider this accumulated wisdom. Over the past ten years, several educational researchers have demonstrated that schools do make a difference (Edmonds, 1979, Rutter, 1981, and Brookover and Lezotte, 1979). Schools have been identified in which children labeled as disadvantaged are achieving at a higher level academically than would be expected on the basis of socio-economic status. These schools have been described as "effective" and researchers are attempting to discover why the students are achieving so well; what the school is doing to help these students be successful; and 
what distinguishes "effective" schools from other schools where students from similar backgrounds are not mastering basic skills (Carney, 1984).

Not all of the answers are known. However, a list of characteristics and qualities of an effective school is emerging from the school effectiveness literature (Joyce, Hersh and McKibbin, 1983). Mann and Lawrence (1984) believe educators should be encouraged by the convergence of research on a limited set of process and product factors. They maintain that while the "effective" school does have implications for the individual classroom, the "effective" school is also an effective organization dealing with children over the course of their school experience. Purkey and Smith (1982) believe the list of effective school characteristics captures those factors which are likely to have a cumulative impact upon student achievement.

The school effectiveness iterature has provided a rationale for change, and "effective" schools has become one of the major concepts for improving education (Kirst, 1983). Purkey and Smith (1982) assert that the recent school effectiveness literature is far from useless or irrelevant, and should be read by school personnel if they want to improve their schools.

Bennis (1969) states that any knowledge that is useful for planned and directed change is knowledge of an applied nature. Purkey and Smith (1982) caution, however, that the adoption of effective schools characteristics is a complex process and should be individualized for each school. The list of school effectiveness characteristics are helpful because they give direction to schoor improvement efforts. 
Kirst (1983) finds it heartening to observe that very few of the school effectiveness critiques say that it is fundamentally incorrect and should be ignored. Rather, the critiques stress the uncertainties of implementation and lack of "blueprints" on how to make an ineffective school more effective. Kirst (1983) believes this leaves plenty of room for applied research and the development of training packages concerning components of effective schools.

Simply knowing the characteristics of an effective school will not make an effective school (Carney, 1984). Effectiveness requires sound planning, commitment and hard work. Sound planning requires a careful look at the alternatives that are available which will produce real results internally. An assessment must be conducted to determine what will be most effective in each individual school. Experiences from National Association of Secondary School Principals' Model Schools Project shows that such assessment demands total involvement of parents/patrons, students and educators (Carney, 1984). Children have several teachers during their stay in one school, and instruction is supported by the interaction of different roles. (Mann and Lawrence, 1984).

By no means does the array of available research-based knowledge add up to a complete, tested paradigm (Joyce, 1980). The school effectiveness characteristics can provide a set of common referents for participants as they explore alternative directions. Research allows for judgments based on objective assessments of reality rather than on the principles of advocacy or power which is often prevalent in 
collective decision-making. Participants can utilize the school effectiveness characteristics as a contextual map for school improvement (Muth and Bolland, 1983). It can be designed to structure content and maximize participants' focus of attention. A contextual map of school effectiveness characteristics could provide a practical guide to be used as an orientation, a benchmark, and a set of aspirations (Mann and Lawrence, 1984), and at the same time, prevent the development of policies that inadequately address educational problems (Muth and Bolland, 1983). Many times a school can become so attuned to the local community and its goals that it succeeds in disqualifying its pupils for education or work outside of the community. A balance must be made between local wishes and goals set by national education policies (Raaen, 1981). The use of a contextual map focused on school effectiveness characteristics could help maintain that balance. Change is a process, not an event (Fullan, 1982). The interactive phases of a process are affected by organizational choices of alternative solutions, and choices regarding who will participate and how they will participate in choosing, planning and carrying out a school improvement effort. Joyce, Hersh and Mckibbin (1983) offer five principles to follow in creating positive change. Number one on their list is the development of the "Responsible Parties" - building a collaborative local governance to include parents/patrons, students and educators. They strongly suggest that the "Responsible Parties" commence immediately by studying their school using the school effectiveness criteria. In the book The Structure of School Improvement (Joyce, et al., 1983), it is stated that 
a checklist of questions centered around the characteristics of an effective school could provide a convenient tool for commencing the study of a school.

They contend that any organization of Responsible Parties that asks these questions will find many opportunities to generate innovations or refine current practice. They recommend that as a list of priorities develops, an area of focus should be selected. They helieve that when a council is just beginning, it is wise to begin with the effectiveness criteria in Stage One. Stage Two and Stage Three can focus on curricuium areas and staff development. A beginning council, they repeat, should focus on the effectiveness criteria first and in so doing, find numerous ways to improve their school. They also firmly recommend that the focus should be one in which there is relatively high agreement and in which procedures can be easily developed. In their book, The Structure of School Improvement, they list two sets of attributes associated with effective schools. The two sets are listed under the headings, "Social Organization" and "Instruction and Curriculum". Under the heading "Social Organization" are items that pertain to the social system - the human community of the school. These attributes are: clear academic and social behavior goals, order and discipline, high expectations, teacher efficacy, pervasive caring, public rewards and incentives, administrative leadership, and community support. Hersh (1981) has found that these are the social conditions that help individual teachers and students to excel. The second heading, "Instruction and Curriculum", includes those items found in the 
most effective classrooms. These attributes are: high academic learning time, frequent and monitored homework, frequent monitoring of student progress, coherently organized curriculum, variety of teaching procedures can be easily developed. In their book, The Structure of School Improvement, they list two sets of attributes associated with effective schools. The two sets are listed under the headings, "Social Organization" and "Instruction and Curriculum". Under the heading "Social Organization" are items that pertain to the social system - the human community of the school. These attributes are: clear academic and social behavior goals, order and discipline, high expectations, teacher efficacy, pervasive caring, public rewards and incentives, administrative leadership, and community support. Hersh (1981) has found that these are the social conditions that help individual teachers and students to excel. The second heading, "Instruction and Curriculum", includes those items found in the most effective classrooms. These attributes are: high academic learning time, frequent and monitored homework, frequent monitoring of student progress, coherentiy crganized curriculum, variety of teaching strategies, and opportunities for student responsibility. These attributes in the context of the social climate of a school, help to promote the classroom conditions for maximum student engagement with purposeful learning. Both sets of conditions are overlapping, interactive, complementary and reciprocal. These fourteen attributes of an effective school were surfaced in a $\$ 2.5$ million NIE study conducted by Dr. Richard Hersh (1981). The U.S. Department of Education has and is currently utilizing 
the fourteen attributes as a framework for the National School

Recognition Program to identify and call attention to a national group of schools that are unusually successful in meeting the educational needs of all of their students.

The question most frequently asked regarding school effectiveness literature is as follows: "Can achievement be changed by manipulating (a) within school variables, (b) within existing resources? (Mann and Lawrence, 1984). Mann and Lawrence (1984) conducted a Delphi inquiry and the panel concluded that working on alterable variables within existing resources was a feasible and correct agenda for public schools.

\section{SUMARY}

Participatory decision-making was described as a process consistent with the American ideals of equality, democracy and individual dignity. Participatory decision-making positively effects the motivation, performance and satisfaction of subordinates. Other studies clearly show the positive effects of participation on efficiency, productivity, absenteeism, turnover and incidence of grievances. The disadvantages of participatory decision were noted because the outcomes tend to rely on such contingency factors as the nature of the problem, the organizational climate and the cognitive abilities and psychological concerns of participants. Effective participation requires participants and leaders to possess certain skills, understandings, and knowledge. This writer believes that the research clearly supports the position 
that the advantages of participatory decision-making far outweigh the disadvantages.

Many school districts are recognizing the positive benefits that can result from participatory management. Several school districts are restructuring their organization to a decentralized, school-based management mode1. Those structures allow persons who are impacted by decisions to be a part of the decision-making process, to include parents/patrons, educators and students. Giving individual schools more autonomy tends to create a potential for improved attitudes, more effective supervision, and greater responsibility and initiative. Precautions must also be made regarding decentralization. In a decentralized model, the individual school becomes the primary unit of change. Therefore, the individual school task force is charged to develop plans that address the most calcified, critical problems in education. Task forces can be demanding, time consuming and frustrating. To ensure that the effort is successful, careful and deliberate planning must be the vehicle used for participants to arrive at a desired future state. Many studies have shown that goals must be formulated to serve as a guideline, motivator and evaluation format. The school effectiveness literature indicates that the most successful educational change agents emphasized planning and goal-setting. Unfortunately, the research indicates that few educational change agents engage in goal-setting at all, and when they do it is rare for them to include staff, and rarer yet to engage the general public. For change 
to take place, however, it has been found that people must value the change. Goal-setting needs to be a process of mutual influence so that the surfaced goals reflect felt needs. A sense of ownership, satisfaction and competence result from participation in planning, coupled with an increased commitment for change. Many educational change agents experience difficulty with long-range planning, and lack the skill and knowledge of interpersonal and group process strategies. Many goal-setting strategies exist, some being more effective than others in formulating appropriate, credible and realistic goals. Many times, the procedures used directly impact the quality of decisions. The procedures and strategies vary from broad brainstorming sessions on the "best that can be imagined," to rank ordering of pre-determined goal statements, with a wide variety of techniques in between. A sufficient amount of research is saying that a good starting point for schools engaged in a school improvement effort would be to step back and consider the school effectiveness literature. Educators should be encouraged by the convergence of research on a limited set of process and product factors, and should seriously examine these prior to, and during any planning process.

It is this writer's view that the literature has clearly revealed a need for bringing diverse caring forces together for a long-ranged continued process of school renewal. This study will describe data that would be useful in avoiding or circumventing conditions or circumstances that could destroy, hinder or delay a collaborative effort. This study 
will also articulate strategies and techniques that can positively impact a participatory decision-making process. 


\section{CHAPTER III}

\section{METHODOLOGY}

Educational administrators are increasingly expected to involve diverse groups (i.e., parents, students and educators) in the formulation of a direction for school improvement. Administrators who are attempting to create a school improvement plan through diverse involvement need certain skills and a knowledge base regarding involvement and decision-making to successfully guide and direct educational partnership programs. The problem is that educational practitioners in charge of such partnerships are attempting to determine and fully understand what, exactly, is needed and why. This exploratory study defines the needed skills and knowledge base which are deemed to be important for effectively implementing a decentralized participatory structure. This chapter identifies the parameters which guided the research, and describes the methods utilized in solving the research problem.

\section{RESEARCH DESIGN}

Schatzman and Strauss (1970) suggest that a "method of inquiry is adequate when its operations are logically consistent with the questions 
being asked and when it adapts to the special characteristics of the thing or event being examined". According to Blumer (1966), the procedure suitable for studying a dynamic, social situation is "to approach the study of group activity through the eyes and experience of people who have developed the activity".

It was for these reasons that an exploratory case study method was chosen as a methodology appropriate to the problem under investigation. The expectations of utilizing such a method were that it would produce rich, descriptive data about the contexts, activities and beliefs of the participants in a successful decentralized participatory structure. This data provided the context from which the needed skills and knowledge base were determined. The narrative text provides a rationale for why the skills and knowledge base are determined to be crucial. In addition, this data can assist educational practitioners in responding more flexibly and appropriately when implementing decentralized planning teams by modeling or redesigning this case study paradigm.

The case study school district was selected for the following significant reason: Because decentralized participatory structures are such a new educational change strategy, very few districts have had them in place long enough for an ex post facto investigation. Battle Ground School District formulated their planning teams five years ago, with training provided by Kettering Foundation in cooperation with $I / D / E / A$. Each of the eleven buildings' steering committees (composed of one administrator, one parent, and one teacher) received the training. These people then replicated the training for their building teams under 
the guidance of Kettering and I/D/E/A. To assure the successful maintenance of the groups, intermittent training and assistance have been provided by the district to the eleven buildings in varying degrees.

The most effective and efficient way to produce the necessary data relative to decentralized participation was to delineate the focus of the case study upon one successful school site. Pleasant Valley Intermediate was selected as a focus for several reasons. The school recently (1985) received state and national recognition from the U.S. Department of Education. The school's decentralized participatory structure was highlighted in both of the summaries from the state and national level as having positively contributed to the school's overall success. The application of a knowledge base and skills that are surfaced from a successful program are more likely to positively impact implementation of the program in new settings. Another reason for the selection of the middle school for the case study relates directly to the adequate number and balance of parents, students and teachers who are on the school's decentralized planning team (i.e., the elementary schools do not have students directly involved). A final consideration in the selection dealt with the school's administration. Both principals who had provided the leadership for the school's partnership structure were still in the district. The principal who formulated and maintained the group for the first four of its five years in existence was the principal of the school with which this writer was associated. The feasibility and possibility was high of generating any relevant 
information deemed necessary from this valuable source regarding the formulation and maintenance of the middle school's partnership structure. The principal of the middle school for the past year provided valuable information unique to her situation of taking over an existing structure, because she was able to compare and contrast it to the structure she led in the previous two years. Likewise, the principal first described also compared and contrasted aspects of his present structure with that of the middle school being studied. By accessing these two principals, an extended in-depth insight into three separate partnership structures was gleaned. This helped illuminate additional dimensions to be investigated and those aspects that could be generalizable.

\section{POPULATION DESCRIPTION}

Appropriate permission was received from the superintendent of the Battle Ground School District, the principal of Pleasant Valley Intermediate, and the staff, parents and students actively involved in the middle school's decentralized partnership structure.

Four populations were utilized in this study: parents, students, teachers and administrators. All of the populations used in this study were associated directly with the case study school district. The district serves approximately 7,000 students with two secondary schools (9-12), four intermediate schools (5-8) and five elementary schools $(K-4)$. The district is located in a rural setting approximately thirty 
miles from a large metropolitan area. The school district covers a three hundred twenty-five square mile area, serving low, middle, and upper-middle class students.

All of those parents, students, teachers, and administrators who were involved in Pleasant Valley Intermediate's decentralized participatory structure were included in this study. In addition, a select group of parents from the middle school who were indirectly involved through the structure's pyramid-grapevine communication network were included to a lesser degree in the study. And finally, a random sample of parents, students, and teachers from the middle school who were not involved in the participatory program were involved briefly with the study.

\section{CATEGORIES OF INVESTIGATION}

A researcher involved in a qualitative investigation often enters the site with hunches and predictions of what dimensions may be important in solving the research problem. Such research allows the subjectivity of the researcher and participants to enter the study. However, bias is a threat to internal validity and the researcher must be cognizant of its potential presence (Tunnell, 1977). It is, therefore, especially important to avoid over-inferring in the chapters displaying the data.

To initially set a direction for the study, a researcher will many times formulate working hypotheses. The type of study being pursued and 
considerations regarding the appropriateness for solving a problem ultimately guide the existence or development of working hypotheses. Everhart (1975) refers to working hypotheses as antennae. As a study progresses, the investigation will begin to substantiate or contradict those working hypotheses. A qualitative study involves the constant process of refining the initial hypotheses. After an exhaustive review of literature on partnerships, it was believed that the guidelines established by Lieberman (1986) regarding collaborative work would best serve as an initial framework for the working hypotheses. These guidelines are as follows:

- Some type of organizational structure is needed to collaborate.

- A smali core of people actually work on the collaboration.

- Time for collaboration needs to be allotted.

- Skillful people working together enhance collaborative work.

- Initially, activities propel the collaboration, not goals.

- Large superordinate goals for collaboration become clearer after people have worked together.

- People often underestimate the amount of energy it takes to work with other people.

- Collaboration with schools demands an understanding of schools as complex social organizations shaped by the realities of specific contexts.

- Ambiguity and flexibility more aptly describe collaborations than certainty and rigidity.

- Conflict in collaborative work is inevitable; it has the potential for productive learning. 
- People can participate in collaborative work for different reasons, but they should include wanting to do things together.

- Products created by collaborating create an important sense of pride in collaborative work.

- Shared experiences over time build mutual trust, respect, risk-taking, and commitment (Lieberman, 1986, p. 7).

The dimensions underlying the above working hypotheses served as "antennae" for this study.

\section{METHOD OF COLLECTING THE DATA}

Everhart (1975) said that the process of data collection is as important as the data selected.

Flexibility was maintained in considering available alternatives, and initial decisions were continually reexamined and modified. The approach of triangulation was used for collecting data from different sources. A collection of ESP and MESP documents and products from the past 5 years was gathered. This researcher was a participant observer at four monthly meetings at Pleasant Valley Intermediate. In addition, key-informant interviewing was utilized to surface ex post facto data as well as current beliefs and perspectives of the main actors. Isaac (1971) stated that a multiplicity of data sources will strengthen the validity of results. The remainder of this section describes the content and procedures used in the case study interviews.

The essential instrument in an interview situation is the researcher himself. A flexible approach to interviewing must be 
balanced with a systematic structure of questioning to allow for unexpected responses not anticipated. Subsequent inquiry will enable a researcher to answer the whys and hows that surface. However, a pre-determined set of questions should be given each interviewee so the data can later be coded and arrayed in frequency distribution (Zeiditch, 1962). Frequency distributions gave this researcher a sense of weighting to assign to the various dimensions, and assisted in later organizing the data to be reported. See Figure 14 for the Frequency Distribution Chart.

Accurate and complete information is desired from an interview. Therefore, additional time must be taken to probe for underlying factors or relationships which are too complex or elusive to encompass in more straight-forward questions (Tuckman, 1972). A semi-structured interview format was developed around a core of structured questions (see Appendices $A$ and $B$ ). Additional exploratory questions were asked depending on the content of answers. All face-to-face interviews lasted approximately $11 / 2$ hours and were tape recorded to preserve the entire context of the qualitative process. Data from the tape recordings were later transcribed onto note cards. As the interviews progressed, more and more of the information gathered became redundant. This assures that the collected data was based on fact, thereby strengthening validity.

Content validity for the interview protocols was established by soliciting input from the following sources: Dr. Jon Paden, Research Director for $I / D / E / A$ in Ohio, assisted in formulating the interview 
questions for administrators, parents, students and teachers. I/D/E/A, to date, has provided training and follow-up guidance for over 400 school districts on formulating and maintaining decentralized participatory structures. The interview questions were then field tested. The questions selected were reviewed and revised by three administrators from the case study school district who have provided training in Indiana and Oregon for administrators interested in implementing decentralized participatory structures. The parent, student and teacher interview protocol was field tested with members of a decentralized participatory structure other than the case study middle school. Most of the changes that resulted from the field tests were in the form of suggestions for additional questions, or suggestions to avoid ambiguous language.

A total of 23 face-to-face interviews were conducted for this study. Face-to-face interviews were conducted with the two principals who had been involved with the middle school, one assistant superintendent who coordinated the district Effective Schools Process, one school board member and the superintendent. Face-to-face interviews were conducted with all of the current members of the middle school's decentralized planning team.

A total of 31 telephone interviews of varying length were conducted for this study. Telephone interviews were conducted with parents, students and teachers involved in the pyramid-grapevine communication network at the middle school. Lengthy telephone 
interviews were conducted with several parents, teachers, and students who had been past members of the iniddle school's planning team. A random sample of parents, students, and teachers from the middle school who were not involved in the process were also contacted.

Following are the core questions used with administrators:

- What is the Effective Schools Process?

- What were the reasons for putting this structure in place?

- To what extent has the original plan worked? What aspects have worked; what aspects have not worked? Why?

- Do you perceive it as successful?

- What training has been received that you feel to be essential? Why? In what areas might further training be needed? Why? In what ways do you feel this training should/could have been adjusted?

- What are some indicators of success that justify maintaining the structure?

- What decisions should the planning teams make?

- What are some important factors when considering the formulation of such a structure? How do you go about it?

- What are some important factors that affect the maintenance of such a structure? How do you renew commitment?

- How important is good communication to the success of this structure?

- What do you believe are the most significant obstacles that may hinder, delay or destroy the effective formulation and maintenance of a partnership program?

- What strategies have you used to overcome or circumvent these obstacles?

- What techniques have you used to positively influence the successful implementation and institutionalization of the partnership program? 
- What skills and knowledge base do you believe an educational change agent must possess to successfully guide a partnership program? Why do you feel these are important?

- What are the consequences for those people who are and are not involved?

- What do you feel are the advantages and disadvantages/ strengths and weaknesses to a partnership program?

- To what extent has it helped or hindered your role as an educational leader?

- Describe the process for goal-setting; include both short and long-range planning.

- What sets the direction for goal-setting on your planning team? How do you determine or assure that the plan is credible? Appropriate? Realistic?

- In what ways will your partnership planning team utilize the data generated from the self-study instrument?

- How will you prioritize those areas of need where discrepancies exist in the self-study data?

- How do you intend to implement the goals that result from the self-study process?

- How are building and district goals coordinated?

- What advice or guidelines would you feel compelled to offer to someone interested in developing or building a partnership program?

Following are the core questions used with parents, students and teachers at the middle school:

* NOTE: MESP is an acronym for More Effective Schools Process. Pleasant Valley Intermediate uses this acronym to identify their decentralized structure.

- What is MESP?

- Why do you think MESP was put into place?

- What are your expectations of MESP? 
- Do you perceive it as successful?

- Why did you choose to be involved?

- What concerns did you have when you first joined MESP? Have these concerns changed? What are the reasons for the change?

- How is MESP different from other parent organizations (i.e., PTSA)?

- What have you gained personally from participating?

- What would make MESP better or more effective?

- What decisions should MESP make?

- Have you experienced any frustrations working on MESP? Explain.

- What has MESP accomplished? What are some indicators of success that justify MESP's existence?

- What processes are used for goal setting? How does this insure a plan that is credible? Realistic? Appropriate?

- How would parents, teachers and students effect change if MESP did not exist?

- What are the consequences for those people who are not involved with MESP?

- What skills and knowledge base do you believe a principal must possess to successfully direct MESP? Why?

- What keeps you involved?

- How has MESP enhanced your role as a parent, teacher or student?

- What are the strengths and weaknesses of the process?

- What contributions to MESP do you feel you can make in your role as parent, teacher or student?

- What are some key elements that make MESP work?

- What skills do you feel are essential for participants to possess? What training should be given to develop those skills? 
- In what ways is MESP utilizing the data generated from the self study?

- What process is being used to prioritize the needs that surfaced as a result of the self study?

- How do you feel MESP contributed to the state and national recognition awards?

- What advice would you feel compelled to give to a parent, student or teacher who was considering joining MESP?

\section{METHOD OF ORGANIZING THE DATA}

As the study progressed, specific dimensions of decentralized participatory partnerships were amplified. Relationships between clusters of categories emerged that allowed for a coherent, well-integrated reconstruction of the structure under investigation. The refined working hypothesis is also served as an advanced organizer when categorizing, organizing, and summarizing the data collected. All of those characteristics determined to be essential for developing a successful partnership have been addressed. It was deemed essential to first document what the innovation was that was put into place, discuss why and how it was implemented, what theory the decision was based upon, and what expectations were held for the plan. Because the Effective Schools Process was a district-wide adoption, the study focuses first at the district level.

Human behavior cannot be understood "without understanding the framework within which the subjects interpret their thoughts, feelings and actions" (Wilson, 1977). The study focused on the middle school 
because it is description of how the plan was put into play at one successful site - highlighting the processes, activities, products, and consequences for those involved. Indicators of success are shared to document or justify how the plan is working at the site. The perceptions of the key players in the Effective School's Process are described and reported by role (i.e., parents' perspective, etc.).

\section{PRECAUTIONS TAKEN FOR ACCURACY}

The following discussion regarding the precautions taken in the study is included for the purpose of ensuring that an acceptable degree of internal and external validity was met. The extent to which research is believable relates directly to the quality of the research. Because quality varies, it is important to measure a study by its validity both internal and external.

External validity is judged by the extent to which certain findings or results can be generalized to other areas, other schools, or other states. The data generated in this study can be generalized to those districts having similar demographic charisteristics. The working hypotheses structured around Lieberman's (1986) guidelines for collaborative work allowed this study to include (but not be limited to) those dimensions generalizable to many forms of collaboration that are grounded on motivation and goal theory.

Several aspects relating to internal validity have been mentioned in preceding sections. The triangulation of sources (document 
collection, participant observation, and key-informant interviewing) strengthened the reliability of data by cross-verification. Tape recording the interviews preserved the context and discouraged the subjective inclusion or exclusion of information through interview notetaking. Interview tapes were later utilized to explore important dimensions. A system of coding was developed to reflect a frequency of distribution for the purpose of weighting and amplification. See figure 14 for the Frequency Distribution Chart. Clusters of categories were then developed and included in the narrative text. The reliability of the interview questions was strengthened by seeking qualified input from: 1) practitioners who have provided training in Indiana and Oregon for administrators in the process of formulating decentralized participatory structures, 2) a research director from I/O/E/A who assists in the training of administrators in formulating and maintaining decentralized partnerships, and 3 ) by field testing the interview questions on administrators and participants of a planning team other than the case study middle school. Construct validity of the case study was strengthened by seeking guidance from qualified sources knowledgeable in case study research. Direct input was received from the following persons: Or. Robert Everhart (Portland State University); Dr. Jon Paden (Research Director, I/D/E/A); Dr. Ann Lieberman (University of Washington); and $\mathrm{Dr}$. Dan Duke (Lewis and Clark College). Construct validity of the case study report was increased by having the draft reviewed by the coordinator of the Battle Ground Effective Schools 
Process and by the principal of Pleasant Valley Intermediate. This review enhanced the accuracy of the final case study report.

This writer has personally been a member of a decentralized planning team in the case study school district for five years. Our primary school planning team closely paralleled the team at the middle school upon which this study has focused.

Depending upon the purpose of the study, Eisner (1978) asserts that researchers who are connoisseurs of an educational practice by virtue of their background are more able to understand those characteristics and qualities that may be relevant to a particular study. He maintains that a connoisseurship model opens a new window through which educational practice can be studied and described. He believes it provides a bridge needed by others to experience the qualities and relationships within some area of activity.

Cusick (1973) states that:

As one lives close to a situation, his description and explanation of it have a first-person quality which other methodologies lack. As he continues to live close to and moves deeper into that situation his perceptions have a validity that is simply unapproachable by any so-called standardized method. Likewise, as his validity becomes better, so his reliability, which is an extension of his validity, becomes better. As the researcher is the actual instrument, as he becomes more aware, more valid, so he must of necessity become more reliable (p. 232).

Cusick also believes, however, that the real proof of validity comes from the presentation of the data. He contends it is . . .

For that reason, one reporting such a study must present his findings in extensive narrative form. It is especially important to avoid over-inferring in the data chapter. The writer must allow the reader to draw his own conclusions from 
the data as he presents that data in as realistic and complete a manner as possible. in iact, tinis is a major test of validity. If as others who are engaged in similar situations upon reading the data agree that "that is the way it is", so the researcher's findings demonstrate a higher degree of validity (p. 232).

The next important issue to address is the existence of bias. Since the observer is the most significant instrument, the observations and findings can be distorted by the pre-conceptions and prejudices brought to the study by the observer. Although an ethnographic approach admits the subjective experiences of both investigator and participants into the research frame, the researcher must honestly deal with the issue of bias. In qualitative studies, it is possible to limit observer bias, but probably impossible to eliminate (Stufflebeam, 1971). Observers and interviewers cannot report everything they experience so arbitrary choices must be made.

The purpose of this study was not to argue for the success of decentralized partnership structures, therefore, the issue of bias has been significantly reduced. This study illuminates the complexities (both negative and positive) inherent to partnerships. An accurate reconstruction of these realities has tended to minimized the bias question. The presentation of data reflects the guidelines given earlier by Cusick (1973). Over-inferring in the data chapter was avoided, thereby allowing the reader to draw his/her own conclusions.

The following three questions helped this writer be cognizant of internal validity: 1) What is my observational bias?, 2) Were certain points of view or categories of information dismissed?, and 3) Is the data elicited or volunteered information? 
The precautions taken in this study have strengthened internal and external validity and minimized possible bias.

\section{DEL IMITATIONS}

The following are limitations of this study:

1. The study was limited to the 1986-1987 academic school year.

2. The study was limited geographically to parents, students and educators in the case study school district. The data generated in this study can be generalized to those districts having similar demographic characteristics.

3. Perceptions held by parents, students, and teachers were limited to the case study middle school.

4. Interviews were limited by time and the content of questions.

5. The number of variables in a qualitative study make any replication difficult.

6. Qualitative researchers cannot record everything they experience, so arbitrary choices were made which may have introduced bias.

7. Data that was recorded needed to be subjectively reduced.

8. A qualitative study is a human task with human limitations.

9. This study is an exploratory case study and is not intended to be an evaluation study of the Effective Schools Process.

10. The final draft of this case study was reviewed by administrators to strengthen validity. It was not reviewed by students, parents, or teachers. 
11. The review of literature for this study was limited to the Portland State University Library, other libraries through inter-library loan, a computerized E.R.I.C. search, and a computerized Education Research Service search.

12. The descriptors utilized to conduct the two computerized searches for the review of literature were limited to the following: school-community-relationship, cooperative planning, participant satisfaction, group dynamics, needs assessment, educational planning, parent participation, school involvement, delphi-technique, formative evaluation, communication skills, leadership, organizational theories, organizational guidance, goal-setting, group unity, conflict resolution, change strategies, school effectiveness and decentralized decision-making. 


\section{SUMMARY}

An exploratory case study method was chosen as a methodology appropriate to the problem under investigation. The rich, descriptive data about the contexts, activities and beliefs of the participants in a decentralized participatory structure helped answer the following question for practitioners: What must we know and do to successfully imolement, guide, and direct a decentralized partnership program?

The Battle Ground School District was selected because it has formulated and maintained eleven building partnership programs for the past five years. The most effective and efficient way to produce the necessary data was to delineate the focus for the majority of the case study upon one of those eleven building partnership structures that was perceived as successful. A middle school was selected for the delineated focus. Those people affected by the decentralized planning structure at the middle school (i.e., staff, parents, students) were involved in the study.

To initially set a direction for the study, this writer decided to utilize Lieberman's work (1986) regarding collaboration as a framework for the working hypotheses. As the study progressed, the investigation began to amplify or diminish these working hypotheses. They initially served as antennae for determining which dimensions of collaborative work should not be overlooked.

The approach of triangulation, involving a multiplicity of data sources, was applied and utilized. A collection of documents and 
products was gathered, planning team meetings were attended, and key-informant interviews were conducted. The data has been organized in a coherent, well-integrated manner. Numerous precautions have been taken to protect the external and internal validity of this study. This chapter concluded with a list of delimitations unique to this study. 


\section{CHAPTER IV}

\section{AN EXPLORATORY CASE STUDY \\ INTRODUCTION}

There is a pressing requirement of providing educational leaders with a greater understanding of what knowledge and skills are required for effective implementation and institutionalization of decentralized participatory structures and processes. This case study generated data which highlighted the knowledge base and skills that educational leaders should possess to effectively implement decentralized participatory structures. It presents the real life context of an existing successful decentralized participatory school improvement model. This context provides a rationale for why the knowledge base and skills are considered crucial. The resulting analysis of the descriptive data collected can better enable practitioners to bridge the gap between the simplified concept of decentralized partnerships and its successful implementation. Bennis (1969) states that any knowledge that is useful for planned and directed change is knowledge of an applied nature. This study is intended to strengthen the probability of success for future building-based school improvement efforts.

A case study data base has been established to verify a chain of evidence. Documents and interview tapes from the case study have been 
numbered and are included in the data base, available through the case study researcher. The sequential, elevated numbers utilized in Chapter IV correspond to numbers in the Supplemental Reference Notes section.

Pleasant Valley Intermediate School in Battle Ground, Washington was selected for the case study focus. In 1985, the school received state and national recognition from the U.S. Department of Education. The recognition application submitted by the school reflects an internal perception of the success of their decentralized participatory structure. 1 Likewise, the summary of the national recognition visitation team reflects an external perception of the model's success. 2 The knowledge base and skilis that are surfaced from this case study of a perceived successful partnership would be more likely to positively impact implementation than the knowledge base and skills surfaced from a structure not perceived as successful. By focusing on a perceived successful partnership, educational practioners can more fully understand the characteristics of effective implementation.

The move to a decentralized participatory governance model was a district-wide innovation in the Battle Ground School District. Therefore, this case study will first describe the innovation from the district view, and then correspondingly focus on the individual site. A clearer picture can be gleaned of the middle school's structure by presenting it in total context. See Figure 1 for a sequential overview of the case study narrative text. 

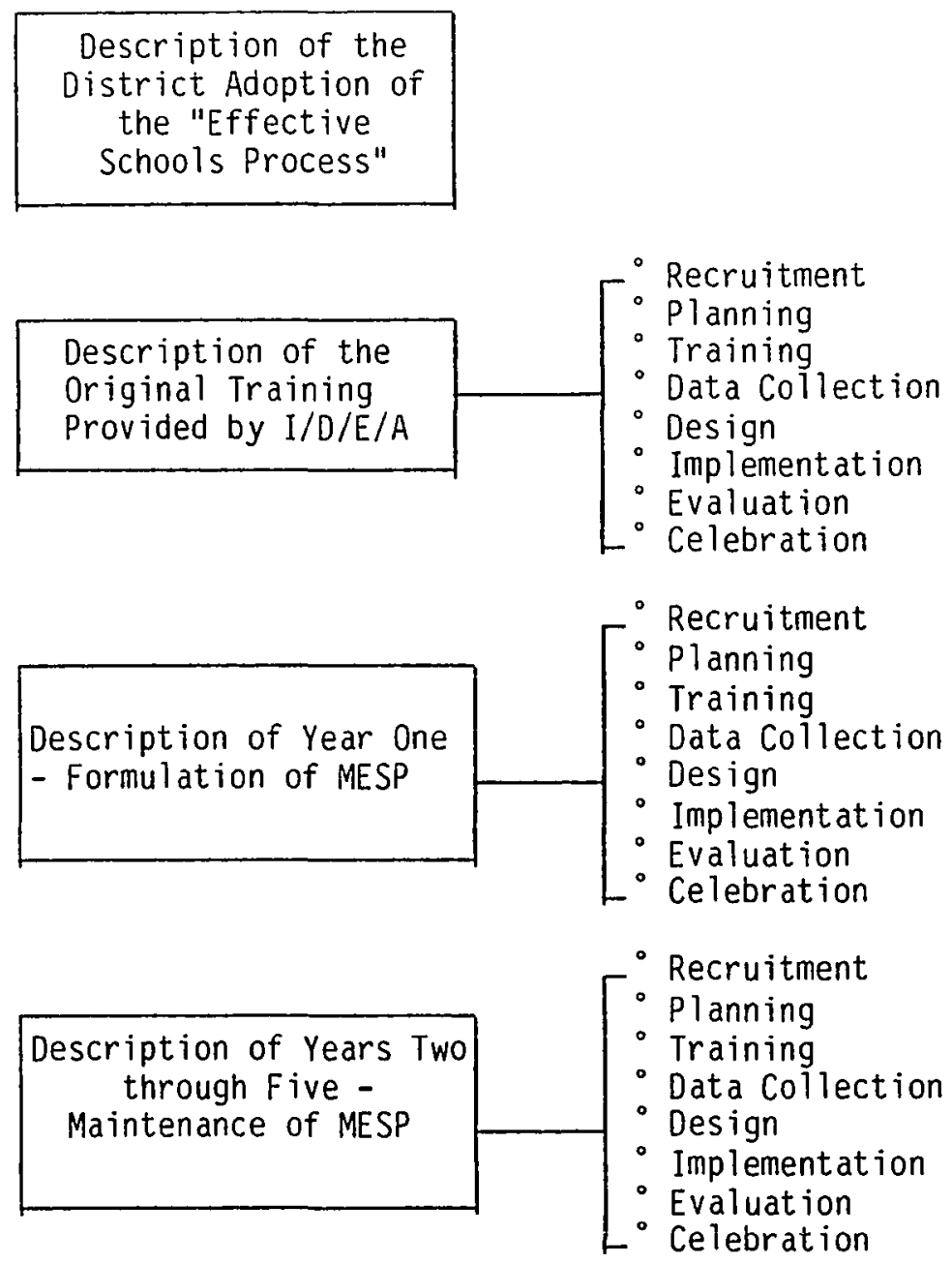

Perception Check of MESP Participants

Indicators of MESP's Success

Conclusions and Recommendations

Figure 1. Sequential flow chart of the case study narrative text. 


\section{CASE STUDY CONTEXT}

In the fall of 1981, the Battle Ground School District initiated an intensive school improvement effort. Like many districts, the Battle Ground School District was responding to the pressures for school reform. Reports such as A Nation At Risk provided the district with a window of opportunity to pursue educational excellence. In addition, the school effectiveness literature was emphasizing that schools do indeed make a difference. Research had determined that student achievement did not necessarily depend upon family background or socio-economic status. A sense of hope was rekindled in the Battle Ground School District through the knowledge that certain variables could be manipulated to impact school effectiveness. Or. Richard Hersh, then with the Department of Education at the University of Oregon, was invited to Battle Ground in the fall of 1981. He presented a district in-service session on "The Fourteen Attributes of an Effective Schoor".3

The fourteen attributes are the result of a $\$ 2.5 \mathrm{million}$ research project funded by NIE. (Refer to page 57 in the review of literature for a complete description of these fourteen attributes.) The U.S. Department of Education is currently utilizing these fourteen attributes as a framework for the National School Recognition Program. The U.S. Department of Education has attempted to identify and call attention to a national group of schools that are unusually successful in meeting the educational needs of all of their students. [See Appendix D for recognition application format]. 
Dr. Richard Hersh's discussion of the fourteen attributes of a more effective school intuitively made good sense to the Battle Ground staff. They became enthusiastic about the opportunity to improve the quality of the educational program. A year of awareness ensued relative to the characteristics of effective schools. A barrage of communication including such things as newsletters, bulletins, discussions, and in-service training, successfully raised the level of staff and community awareness. 4 The Assistant Superintendent for Curriculum and Instruction described the district progress as follows:

By the end of that awareness year, we had a good $f i x$ on the prescriptions for school improvement but we didn't have a solid understanding of the process for implementing the prescriptions. We'd fumbled around with the fourteen attributes for about a year without a lot of noticeable success. We were experiencing some quiet frustrations. 5

It was at this point that the district established a Research and Development Committee composed of several administrators. Their charge was to explore the possibilities for substantively implementing school improvement goals. The driving and penetrating question had been clearly articulated: "How do you go about improving the schools?" The district already had an established District Lay Advisory Council. During an interview with the superintendent, several points were made regarding the Lay Advisory Council. Citizen participation was clearly a needed component for change. However, it was believed that the advisory model could not provide the vehicle for meaningful change. Unfortunately for the Lay Advisory Council, the buildings had control of many of the variables already in place. The Lay Advisory Council had 
eighteen representatives who theoretically represented the buildings to discuss concerns and surface methods of addressing those concerns. In reality, the Lay Advisory Council had no functionary role except to ask extraneous questions and point fingers. The members seldom represented their schools and tended to express their own opinions. Because the council did not have an established process for data collection or goal-setting, the meetings generally turned into complaint sessions. The superintendent recalled that

a number of discussions ended up being blood baths. A number of the administrators who attended left bloody, feeling attacked for a whole number of things that weren't always within our means to solve at that point. Some of the advisory people thought all you had to do was snap your fingers and solve their problems for them. Wel1, it just doesn't work that way. 6

The Research and Development Committee felt that the Lay Advisory Council could not provide the vehicle nor the environment to impact building-based change. The committee intuitively realized they needed community involvement, but those people needed to be working and involved at the building level.

- It is important to note that participatory decision-making was already deeply engrained in the district curriculum process. Every teacher had experienced direct, substantive input into the curriculum adoptions for the 1980-81 and 1981-82 school years. The district curriculum director stated that the powerful impact of ownership was 
during the implementation phase. Because these and other components of the curriculum process had also proven effective, the committee kept those variables in mind while searching for a solution to their problem. The curriculum model comprised a capacity approach rather than a deficiency approach. In other words, curriculum development emphasized the use of activities like team builders, needs assessments, and envisioning to bridge the gap between the actual ("what is") and the ideal ("what is preferred").7 The capacity approach that had been so effective in curriculum development helped to guide the district in their search for an effective decentralized school improvement model. All in all, they researched and reviewed 33 participatory models. The committee felt extremely lucky that they "stumbled onto the I/D/E/A model." I/D/E/A is an acronym for the Institute for the Development of Educational Ideas. The I/D/E/A model is a cyclical building-based school improvement plan. It is a grassroots participatory process that involves parents, patrons, staff, and students in both the decision-making and implementation phases of school improvement. I/D/E/A (1982) stated the following:

We are not advocating a single packaged program nor set of prescriptions for each school district. Our experience leads us to believe that almost any practice or any program can be successful if there is a process that develops ownership from the participants. It is that powerful process that we have been sharing with local school communities which have enabled them to select and design prescriptions and programs appropriate to their own local situation. We are not a prescription, not a program, but a process (p. 3$) .9^{9}$ 
The I/D/E/A model consists of a voluntary planning team, formulated with a recommended balance of 5 parents, 5 patrons, 5 students and 5 staff. This committee of 20 is deemed small enough to efficiently accomplish goals, yet large enough to create a diversity of input. The leadership for the planning team comes from the steering committee, comprised of the principal, one parent, and one teacher. Each member of the planning team is formally assigned to communicate with 5 additional people who are directly associated with or interested in the school. Parents contact parents, patrons contact patrons, students contact students, and teachers contact teachers. This pyramid-grapevine communication network is likened to the Amway approach.

Ideally, an additional 100 people can be indirectly involved in two-way communication, thus broadening the input for decision-making and subsequent support. The planning team meets once monthly during the school year. They formulate and carry out goals in a cyclical, unending process that would bring their school to a desired future state. Figure 2 visually illustrates the participatory concept of the I/D/E/A model.

Planning Team with the Steering Committee as the nucleus

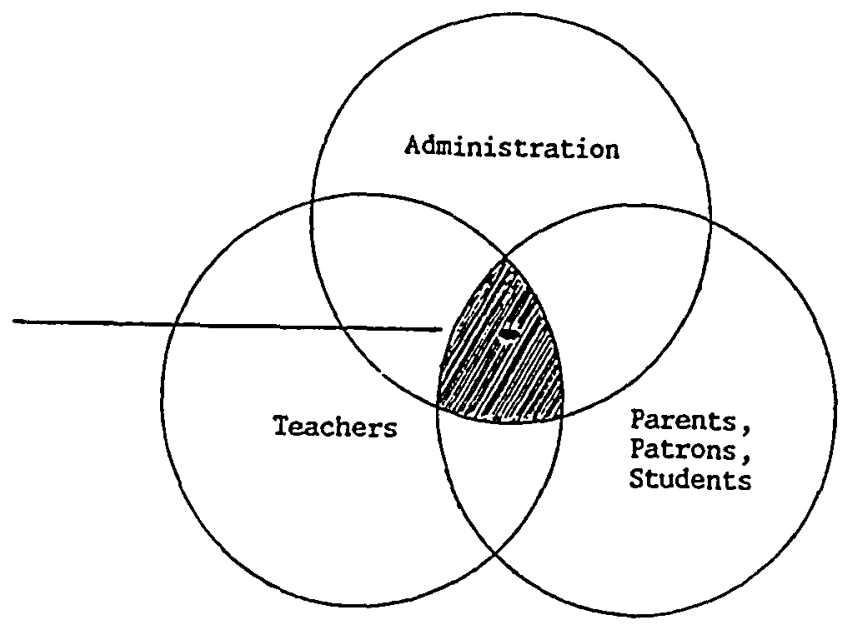

Figure 2. The participatory concept of the I/D/E/A model. 
The Research and Development Committee became extremely excited about the concept because they believed the prescription for school improvement was the process. School administrators felt very strongly that had the district not experienced the potential of the participatory curriculum process in the preceding years, the power of the $I / D / E / A$ model would not have been recognized.10 There were, however, two important differences. The area being targeted for improvement differed significantly. School administrators simply decided to extend the effective curriculum processes to the area of building-based improvement. Secondly, the number and type of people involved in the project differed significantly. In the curriculum model, the cuinmunity and students were not as actively involved as is required by the $I / 0 / E / A$ process.

The committee fully understood that new leadership behaviors would have to be addressed. They felt it was crucial to gain commitment from all levels of the administration before such a comprehensive undertaking was initiated. An I/D/E/A director, Dr. Gary Philiips, was invited to speak to the district's principals, superintendent, assistant superintendent, one board member, and key communicators from ESD \#112. Dr. Phillips shared a description of the process and provided the team with vital information, to include the conception of the idea and indicators of success. The I/D/E/A model grew out of the research iniatiated by the Secondary School Improvement Project co-funded by the Kettering 
Foundation and Lilly Endowment. Dr. Phillips was the director of that project.

The project's goal was to surface a school improvement plan that would have substantive impact at the high school level. Dr. Phillips initially contacted the superintendent of the Indianapolis, Indiana School District. Of the thirty-three high schools in the system, they targeted the one school that by everyone's perception was in tremendous disrepair. George Washington High School was perceived to be out of control. There were barriers between teachers and kids, vandalism, and crime just to name a few of the problems. Or. Phillips intervened by setting up a planning team as previously described. The project was acclaimed as a success. 11 Indicators of quality were measured in terms of school climate, test scores, student attendance, course enroliment, reduction of academic underachievement, dropout rate, suspensions, fights, and discipline referrals.

Dr. Phillips also shared with the Battle Ground Committee the school effectiveness literature relating to participatory decision-making. The underlying principle of the I/D/E/A model is that the grassroots participants are empowered to improve the schools themselves.

The decision to have the Battle Ground School District proceed with the $I / D / E / A$ model was a shared decision. Two principals were "soft on the idea. They were close to retirement and felt intimidated. The model obviously necessitated a new leadership style. Ultimately, those two principals did retire after the first year of the program."12 The committee derived a total consensus commitment. 
A strong "felt need" existed for using the model as a means to an end for the following reasons:

1. A vehicle was needed to effectively incorporate, at the building level, the fourteen attributes of an effective school; 2. The existing Lay Advisory Council structure was perceived as ineffective in actively accomplishing unique building goals;

3. The district had conducted a comprehensive district wide needs assessment in the spring of 1982 utilizing the Phi Delta Kappa Model (refer to pages 45 and 46 in the review of literature for a description of this EGOM mode1). Further frustration surfaced when the prescriptive results of. the Phi Delta Kappan assessment were determined. The Management Team could clearly see the convergence of a limited number of prescriptions for school improvement. However, a process was not in place for making those prescriptions a reality.

4. The district's participatory curriculum process had provided the necessary groundwork for an understanding of the power of participatory decision-making.

5. The district needed a school improvement plan that would not cost additional dollars. The district is a fiscally poor district, ranking 81 st out of 81 districts of its size in cost per pupil expenditures. Beyond the necessary initial training sessions and refresher training, the cost of the program is allocated out of existing basic education funds. 13 
The Battle Ground School District finally moved to a decentralized participatory governance system in the fall of 1982 . They coined their new direction the "Effective Schools Process" (ESP). The goal of ESP was to bridge the gap between where they were and where they thought they needed to be based initially on the fourteen characteristics as described by $0 r$. Hersh, as well as the building priorities surfaced in the Phi Delta Kappa Needs Assessment. 14 The district requested Dr. Phillips to provide the training but he was reluctant. He was not interested in having a west coast affiliate at that time. However, the proposal made to him by the district was mutually beneficial. Fortunately for the Battle Ground School District, the I/D/E/A school improvement process had been used only at the high school level. The district proposed to use the program K-12 in all eleven buildings simultaneous1y. They promised total support and "guaranteed success". Dr. Phillips "bought the challenge" and agreed to work directly with the district. It did indeed become a mutually beneficial marriage. The district perceives their five year program to be a success, and I/D/E/A has since put the program into place at all levels in over 400 districts nationwide. 15

Because the decentralized program was operationalized in all eleven buildings, it became important to redefine central office and building roles. It was essential to establish a coordinated effort to ensure success. Having a decentralized participatory governance process did not mean that each school was totally free to make decisions independent of the district. Buildings needed to follow school board policy and the 
direction set by state educational guidelines. Other district directives were established as follows: 16

1. The Management Team comprised of eleven principals and central office administrators would stay in place as the district communication and networking group.

2. The curriculum process would remain a district-wide endeavor. 3. The district Research and Development Committee would stay intact to provide quality information and set a general direction for school improvement.

4. Building Research and Development ( $R$ \& D) Committees would be established in each school in addition to the ESP planning teams. The building $R$ \& $D$ team would be comprised of the principal and voluntary teachers. Their responsibility would be to determine staff development needs and provide inservice at the building level for five contracted days. Two to three of those five days needed to fall within the realm of the general direction set by the district $R$ \& D Committee.

5. A district "link" person was assigned to each school ESP planning team. This communication network was designed to increase coordination and support from the district for building-based decisions. It was felt that there needed to be a commonality with regard to program design in certain areas. The district "link" needed to work in a positive way to affirm or redirect the schools' focus on an "as needed" basis. 
6. A basic rule of thumb regarding ESP building decisions was established: If the decision affects just your school, then the plan is affirmed. If it is a decision that has implications for other schools or for the district, however, then the decision needs to be discussed with the district "link". An example might be an issue dealing with report cards.

In August of 1982, an intensive week long training session initiated Battle Ground's school improvement effort. The following mission statement and vision statement reflects the district's commitment to their "Effective Schools Process":

\section{Mission Statement}

As a result of our school effectiveness effort, we anticipate that all members of the school community will be able to clearly articulate the purpose of the school. We anticipate a clarity regarding the school's mission. We feel that it is crucial that each school community identify and articulate well-defined educational direction. Each school must come to see itself in unique ways and associate any improvement effort with the perceived mission of the school. In addition, we believe the crucial change agent in creating more effective schools is the school principal. The principal must be an educational leader with the ability and will to articulate his/her school's "vision of excellence". In addition to the principal, other members of the planning committee must also actively articulate the ideology of the 
school improvement effort. Once a school's mission has been clearly identified, the many school improvement efforts can be readily prioritized. The principal's role, then, is to insure that the mission of the school is apparent to all members of the school community. 17

\section{$\underline{\text { Vision Statement }}$}

The Battle Ground School District will make the pursuit of educational excellence of paramount importance to students, parents, patrons, and staff. 18

\section{ORIGINAL TRAINING}

The following section describing the original training is intended to solidily present the framework, background and experiential base of the case study school, Pleasant Valley Intermediate. On numerous occasions, during the interview phase of this case study, there were comments referring to the crucial role that the original training had played. It was perceived by all members of the leadership team at Pleasant Valley Intermediate School that the initial success of the "Effective Schools Process" was directly related to the intensive training that was originally provided. It is for this reason that the original training will be described. The method of triangulation was utilized to accurately present the content of the five day session. Documents were reviewed, original participants and the district ESP director were interviewed. 
Reflecting back on the training session, the principal of Pleasant Valley Intermediate said,

It was an intense experience emotionally. It would be tough on a principal to have to repeat it but would be extremely valuable even a second time through. The cohesiveness that developed between the three of us on the steering committee was vital. We came out feeling as one--a tight team. An unusual relationship came out as a result of the training. We all had a clear understandiig of the process. We were real close in knowing what to do and what to expect. We could have anticipated one another's scripts! In looking around the district, I have found that those buildings who followed the original training have been the buildings who have had success. One crucial variable, however, was the mentality of the building principal. If the principal is authoritative with a divine rights of kings and queens mentality, then the training is going to be superficial. Philosophically, the principal must have the belief that parent involvement is important and meaningful.

In the summer of 1982 , each of the eleven principals self-selected one teacher and one parent to serve with the principal on the building steering committee. Each steering committee would provide the leadership for the building planning team. Careful consideration was made in the selection of the steering committee. It was recommended that the parent (1) be an active supporter of the school; (2) be a key communicator in the school community; (3) have credibility with the school community; (4) be relatively articulate; and (5) be a team player. It was recommended that the steering committee teacher have the same qualifications and be perceived by the staff as possessing effective leadership skills. Five days of intensive training was provided for the steering committee, led by Or. Phillips. The training encompassed the following areas:19 participatory decision-making, school improvement and school effectiveness research, decision-making skills, group dynamics, human relationship skills, visioning, needs assessment, 
planning, goal setting, implementation, evaluation, celebration, commitment, and recruiting. During the interview phase of this case study, two aspects of the original training repeatedly surfaced. This researcher felt those aspects were appropriate to highlight.

1. The technique of modeling was continually used throughout the training by Dr. Phillips. While teaching the brainstorming skill, he would use the brainstorming strategies. When he was teaching the human development skills, the group was always involved in a human development activity themselves. The repeated use of modeling was viewed by participants as an effective training strategy.

2. Role playing during the training was perceived by several participants as being extremely valuable. They believed that the simulated experiences better prepared them to fulfill their leadership roles. There was an atmosphere of risk taking that encouraged participants to learn from their respective mistakes. Redundant role playing helped build confidence and provided the opportunity to capitalize on group critique. New information and knowledge was more readily learned when integrated with applied practice. In addition, the technique of modeling a role playing situation using both the "right way" and "wrong way" resulted in a clearer picture for those observing. I/D/E/A's rationale for role playing was later discovered. Their training philosophy is grounded on the belief that "transfer" is increased significantly for workshop participants when theory, 
demonstration, practice, and feedback are planned components of the training session.20 It became obvious that the practice/feedback phase had been an important component for several participants. One steering committee parent said, "I was so nervous about having to recruit people to be on the planning team. The role playing really helped calm my jitters." 21

Key elements of the original training will be highlighted to include recruiting, planning, training to replicate for planning teams, data collection, design, implementation, evaluation, and celebration. An understanding of these components will facilitate a clearer view of the middle school's participatory process.

Recruiting - Original Training

The steering committee members were given the crucial task of mobilizing the educational partners at each building site. Maintaining a balance of the representative groups became an important consideration.

A planning team of five parents, five teachers, five students, and five patrons in addition to the steering committee is recommended. Such a balance ensures a broadened power base and a diversity of input. If one group membership is lacking, however, the steering committee is forced to spend a disproportionate amount of time communicating with that particular group outside of the planning team meetings. When the numbers are adequate for each group, communication is eased and the quality of decisions enhanced. Getting the group too large can also 
present problems of efficiency and expediency. The concept of pyramiding allows a wide base of involvement while at the same time does not make the planning team cumbersome. While the steering committee is hand picked, the planning team selection process is more fluid. The team should be viewed as an open vehicle for diverse perspectives. Diversity is an essential component of the model. A diverse mix of feelings, attitudes and ideas helps to shed different light on the same problem. It is important to note that the steering committee was encouraged to have a core of people on the team who were key communicators and who have a degree of credibility in the school community. It was advised that an attempt be made to detect any hidden agendas that accompanied team players. The steering committee later reported that a working knowledge of such agendas helped to anticipate and diffuse potential adversarial situations. It was recommended that personal contacts be made by the steering committee to ensure commitment. Being honest about the amount of time and energy required was important from the start. I/D/E/A believes that people who are reluctant to participate because of the time commitment should still be encouraged to participate as part of the pyramid network.

Pyramid groups have proven to be an excellent source for future planning team membership. Recruiting key communicators in the community into the pyramid network was strongly suggested. Those people might include the barber, beautician, or bartender, referred to as the " 3 B's". Their conversations frequently involve schools. Establishing two-way communication with these people could harness the potential for 
positively sharing about school improvement. For convenience, it was recommended that planning team participants select some people with whom they have regular contact. Obviously, including those who are strong advocates of school programs is also extremely helpful.22 However, a diversity of opinion is also considered important at the pyramid level. For that reason, including people that were known to be in opposition to school programs or critical of school personnel was desirable. I/D/E/A believes that any force that is powerful enough to be a constraint has the potential for being a source of assistance for program improvement. They feel most will become willing if the organization makes positive contribution more rewarding than negative leadership. Principals are, therefore, encouraged to seek out negative as well as positive staff members to serve on the planning team.23

Recruitment of the majority of participants by the end of summer is preferable.

\section{Planning - Original Training}

"First you plan your work, and then you work your plan," said a steering committee parent. 24 Comprehensive planning by the steering committee is critical to ensure the successful flow of the process. Before the steering committees completed the five day training session, timelines and masterplans for the first year had been constructed. Detailed agendas for the first four meetings were prepared.25

During the first year, the steering comittees were invited to focus more heavily on process than on product. It is important to note 
that a significant amount of time was needed to be scheduled into the agendas to adequately cover the training needed by the planning team. In that regard, each steering committee was encouraged to block out a yearly calendar. Impatient planning team members would then be able to see that the goal-setting and implementation phases were a part of the yearly plan. Steering committees were forewarned to anticipate pressures from the planning team to "fix the schools right now".26 Previous experience had made it clear that successful implementation would occur only if more time were spent initially on process than product. That emphasis was judged to be critical in providing the planning tean with the skills necessary to become more effective decisionmakers.

A yearly masterplan was developed to address the components of recruiting, planning, training, data collection, design, implementation, evaluation, and celebration. Meeting agendas were also planned in great detail during the five day session. It was determined that each meeting should begin with "high relationship" and end with "high relationship", with "high task" sandwiched in-between. The yearly cycle was also designed to begin" high relationship", move to "high task", and end on "high relationship". Meetings were designated to start and stop on time and be approximately two hours in length. Refreshments should be served. Time was structured into the agenda for pyramid reporting and determining needed pyramid input. Each meeting was planned so that the participants would leave with a good feeling regarding what had been accomplished. 
The steering committee was encouraged to communicate essential information where and when appropriate between meetings. Also, a critical role of the leadership team was to monitor and ensure that the planning team stayed on track, adjusting timelines, responsibilities, and resources when necessary. 27

Training - Original Training

The steering committee needed to replicate certain segments of the training for the planning team. 28 Steering committees were charged with the dual responsibility of first learning several new skills during the five day training and then later teaching those skills to others. The steering committee was invited to use the modeling and role playing techniques when replicating the training. The specific skills needed were decision-making skills and human relationship skills. It is also important to note that the leadership teams were also informed of the research relative to school improvement, described here as content.

Decision-Making Skills. Brainstorming and consensus decision-making were emphasized in the original training program.

Brainstorming has proven to be an effective technique for generating creative ideas, exhausting possibilities, encouraging participation, and appreciating a diversity of opinion. Brainstorming has been utilized effectively in the process for data collection, program design, and implementation. All members of the steering committee became familiar with the technique and its rules. During training, a facilitator announced that the group would have a specific time limit to generate as 
many potential solutions for a stated problem as possible. The ideas were posted in plain sight of all group members. The rules of brainstorming are as follows: (1) no criticism allowed, no explanations needed; (2) be free wheeling, anything goes; (3) seek combinations and improvements; and (4) seek quantity over quality.

The practice sessions began by brainstorming something simple and fun. The initial training provided steering committees with a number of possible ideas including uses for a broom handle, uses for an old ice box, or uses for a box of ping pong balls. The second brainstorming session was designed to more closely resemble a real situation. Ideas for the second practice session included brainstorming the characteristics of an effective workshop leader, how to publicize an upcoming school event, and how to reward and recognize outstanding staff members. It should be emphasized that the rules became harder to follow when the topic was a real problem. The steering committees learned that brainstorming is not a game, it can work in real situations. 29

Consensus decision-making re-emphasizes the importance of shared commitment. An I/D/E/A training packet describes consensus in the following way:

Consensus, first of all, means a general agreement "the judgment arrived at by most of those concerned"--"Group solidarity in sentiment and belief."

It is clearly emphasized that consensus is built on trusting relationships. It is informally achieved. The original Latin stem sentiere means "feel" and its prefix con means "together." Consensus, then, is 
an affirmation of community and cannot be forced anymore than can fellowship. It was important, then, that the group became a team or a community before they attempted to arrive at consensus. I/D/E/A maintains that the following points are necessary for a group to arrive at consensus:

1. The group must work together in positive ways to achieve a workable level of mutual trust and understanding.

2. The group must be presented with a problem and asked to arrive at a solution to which each group member can agree; right from the start the group members assume that they will have differences of opinion. Disagreement is taken for granted but not emphasized. 3. Brainstorming is one of the most productive and least personally threatening first steps the group takes. In a brainstorming session many ideas, appropriate or not, are generated and no value judgments are made.

4. The ideas are then considered, one by one, and those that are clearly unworkable are discarded.

5. The remaining ideas are considered, and arguments pro and con are given. During this process some group members tend to change their minds, bringing the group closer to consensus.

6. The group works within itself to agree on the two or three best (most workable, under the circumstances) solutions. Consensus decision-making has proven to be an effective technique during the data collection, program design, and implementation phases of the participatory model. 30 
Human Relationship Skills. The original training emphasized that mutual trust and understanding was a prequisite to effective consensus decision-making. It is believed that a group must work together in positive ways to achieve a necessary level of trust. Relationship building must be a planned component of every meeting. It is the general feeling that if time is not set aside to nurture and to care, then positive relationships will not develop. The diverse make up of the planning team itself calls for a need to build relationships. The training emphasized that parents, patrons, and students must be made to feel welcome and comfortable. Establishing a close bond between the partners is considered essential. I/D/E/A believes that if the partnership fails then school reform will ultimately become a series of plastic prescriptions. One steering committee teacher commented, "Task is the track, relationship is the vehicle." 31

It took this researcher several interviews to realize that "Getting to Know You," "High Points," "Team Builders," "New Games," "Whip," and "Human Development Activities" were all coined words for various human relationship skills. 32

Examples of human relationship activities that were used during training were: sharing special events in your life, sharing a high point during elementary school, sharing about smells associated with childhood, and sharing about an ideal vacation.

Relationship building is an essential component of the participatory process. It appears that the trust that is developed and nurtured 
encourages planning team members to be open and honest and see differences as strengths.

Content. It is clear that the school improvement plan described herein is based on a solid research base. It is believed that if credible, quality decisions are to emerge from the process, then the planning team must understand and utilize research. The training facilitators maintained that putting good information in a timely manner into the hands of decision-makers positively impacts future decisions. The following examples were a portion of the content given to the steering committees during training. They are not intended as suggestions for what content should be used. The examples are included to emphasize the focus placed on providing quality content.

1. School Effectiveness Literature (generous doses) 33

2. Brain Research34

3. Indicators of a Quality School 35

4. Forecasting Our World-1990's

5. Raise Student Achievement 37

6. Planned Change Films

7. Nine Principles of Challenge Education (see Appendix E) ${ }^{38}$

8. Participants were encouraged to seek out pertinent information relating specifically to their student population. For example, Pleasant valley Intermediate focused heavily on the unique needs of the middle school child. It was impressed upon the leadership teams the importance of their role in providing pertinent information to the planning teams. If the 
purpose of planning was to reach a desired future state, the planners must know what is desirable.

Data Collection - Original Training

Data collection was viewed as an extremely vital piece of the school improvement effort. The original training session highlighted the following important aspects of data collection: The school improvement plans that are generated should grow directly out of the data that is collected about the school. The data collection phase should be a very intensive, all-inclusive look at all areas impacting school achievement. The school's readiness to change should be assessed by gathering information about such conditions as the climate of trust, the use of effective communication procedures, the willingness to take appropriate risks, and the commitment to support the planned effort. Other important aspects that could be investigated by the leadership team include test scores, attendance, honor roll, underachievement, remedial program results, discipline referrals, school climate, available resources, district comparisons, etc. Vital, pertinent information should be communicated to the planning team, and where feasible, to the pyramid network.

Trainers recommended that a discrepancy needs assessment be conducted prior to the goal-setting stage. The process should center around an instrument that utilizes the school effectiveness research as a framework. In so doing, the ultimate goals that are surfaced are viewed as credible.39 The gap between "what is" and "what is preferred" provides data for articulating goals. It was emphasized that positive 
data surfaced during this phase will also highlight the strengths of the school. The steering committees were reminded that such data was a source of pride and celebration and should be used later to create a maintenance of effort plan. The instruments that were immediately available to the steering committees for data collection revolved around: 1) A simplified discrepancy instrument centered around the fourteen attributes of an effective school, 2) Phi Delta Kappa Needs Assessment , 3) Nine Principles of Challenge Education, and 4) Rate Your Community School. 41 The following point was well made: Before and simultaneous to the needs assessment, generous amounts of quality research should be made available to the planning team. Information relevant to current school effectiveness literature helps to provide a track for decision-making.

Design - Original Training

Dr. Phillips stressed that the design phase would become the road map for the school improvement journey.

Vision. The original training focused heavily on "vision", including these key elements: In order to provide a direction for change, planning teams must make a commitment to some key elements of effective school improvement that finds a definition in a "vision of excellence" related to the future. In order to achieve excellence, planning teams should be instructed to collectively elaborate on what an ideal end product would resemble. Creating a "vision" of the best that can be imagined for the school in five or so years tends to provide a 
catalyst for change. 42 Identifying such a "dream with a deadline" was described by $I / D / E / A$ trainers as a difficult task. Therefore, planning teams were encouraged to hold a day retreat to produce a vision statement.

Additional key elements regarding "vision" were explained to the steering committees during the five-day session: A vision statement is considered important because it stresses the capacity approach to school improvement. It helps to answer the question "Why should our school get better?" The capacity emphasis stimulates talks about the best that could be imagined rather than the deficiencies of the school. A vision statement is described as a yet undiscovered capacity.

The following five guidelines were given to be used in the creation of the vision statement: 1) it needs to be short, 2) it needs to be clear, 3) it needs to be attainable, 4) it has to be a statement about what is good for kids, and 5) it has to be communicated. One of the main responsibilities of the principal is to communicate the vision of the school. Workshop participants were taught that a vision needs to be a clear and concise statement about the personality and purpose of the school. It should be a constant reminder which relates to what the school is all about. It was understood that the initial vision statements would be rough but eventually they would be a refined statement of the school's actual purpose. That vision was to become a rich tradition communicated in symbols, slogans, bulletins, etc. The following analogy was shared in explaining a vision: "Everyone knows the 'vision' of the Boston Celtics and it shouldn't be changed. It's a 
vision of a group of people who have a blue collar mentality about playing basketball. They play a power game. They come to play; they come to work!" 44

Every person in the school should be able to succinctly state the purpose of the school to a visitor. The vision statement was to remain unchanged as long as it was alive, understood, and an accurate description of the school.

Goal-Setting. The original training provided the leadership team with the following background relative to goal setting: The first stage of design can be likened to random/abstract thinking. Brainstorming and consensus activities comprise this stage. The second stage of design is more linear/sequential. Priorities are surfaced and goal statements, objectives, and activities are specified and written down. 45

Random/Abstract. Once the data is collected and the vision statement created, it becomes time to identify areas of focus for improvement. Brainstorming was determined to be an especially effective tool during this phase of design. It allows broadened input without judgment. Everyone can get their favorite agenda into the arena. One leader likened it to a legislative session "where everyone is writing their bills and getting them into the hopper, hoping their bill will make them famous. It's a wild, chaotic time until there are no more bi11s!"46

I/D/E/A supports the idea of inviting the entire school community to participate in the initial brainstorming session. The community 
quickly comes to understand that a vehicle exists which actually invites diverse community input. It is believed that by broadening the initial input base, future support for goals is strengthened. Workshop participants were taught to allow time after the brainstorming session for explanations or clarifications. Bringing in pertinent information from the data collection phase (i.e., attendance figures) is considered appropriate at this point. During clarification of ideas, the leadership team was reminded to provide guidance regarding some issues. Easy, attainable goals should be encouraged during the first year of the process. As skills are refined and trust accumulates, more difficult goals can be suggested. One trainer emphasized the importance of initially setting a goal that ensured success. He said,

The first thing you start on needs to be successful. It's like a football season. The coach really wants to win that first game out to build confidence. If the team loses, then it's tougher to feel confidence. If the team loses, then it's tougher to feel up for the second game. If you lose the second game, you become even more doubtful! 47

Ultimately, the results of the discrepancy needs assessment were to be used in conjunction with brainstorming data to set goals. The clarification stage was viewed as an appropriate time to also review assessment data. It was suggested that when planning team members were asked to clarify, the leadership team should remind the group that it is not a "sales pitch" stage. It was emphasized that enough time should be made available during the clarification stage to assure individuals that they were listened to. Each idea must be given equal consideration. 
Eventually, the leadership teams were taught a number of strategies for narrowing the focus and beginning the process of consensus. One strategy was to invite each person to assign two points to their number one priority, and one point to their second priority. The points could then be totaled and the ideas rank ordered according to point totals. The list could then be typed and sent out to all staff, students, parents, and interested patrons. Pyramiding networks would then become an important resource if this strategy is used.

However, the group may feel they want to formulate goals at the meeting without further input. The rank ordered priorities could then be reduced to an arbitrary number. Each member could be given a sticker to spend on their priorities. All of the stickers might be spent on one idea or they could be distributed between several ideas. Preferred goals would be visually apparent by using this techniques. Once preferred goals are selected, total consensus could be sought. It was stressed that consensus does not mean that everyone agrees with the selected goals. Consensus means that those members who continue to disagree indicate that they are willing to experiment for a prescribed period of time. It was emphasized that no one should leave the meeting with the objective of undermining team goals. Negotiations were judged to be an integral part of consensus decision-making. The process of consensus can be used to work out predictable trouble spots. It is recognized that not every goal is credible, but there remains a firm belief that the process of consensus is the most effective way to establish felt needs. 
Linear/Sequential. The leadership team was taught that goal-setting moves from a less structured stage to a more linear/sequential stage. They were informed that once consensus has been reached, goals need to be written down in the form of a statement. Steering committee members were given an opportunity to practice this skill during training. Each devised a personal improvement plan. A goal statement was formulated, supported by objectives and activities. Anticipated outcomes were described that could be measured. The measurable outcomes eventually became the evaluation tool.

Once the leadership teams became proficient at setting personal improvement goals, then the same procedure was used for writing school improvement plans. An eight step process is followed to insure success (see Appendix E).

They were then taught how to formulate one and five year plans. The five year plan was to be quite flexible. However, the one year plan is considered more concrete. It is believed that constructing a detailed masterplan and timeline helps to facilitate motivation and monitoring. The leadership team also became aware of the need to determine the coordinating and governing structures that would be needed to support the implementation. It is considered essential that a plan be developed to secure the necessary training and resources. The steering committees were shown that the "What", "Who", and "When" should be issues that are decided formally.

In addition to the plan for improvement, a maintenance plan is also considered vital. If it is determined that certain aspects of the 
program are effective, the team was taught strategic steps to insure that the effort would be maintained. In doing so, new implementation would not edge out effective existing programs.

Implementation - Original Training

"First you talk your walk and then you walk your talk!"48

Previous experience with the Secondary School Improvement Project had led the trainers to believe that implementation is a fragile phase in the road to institutionalization. Because the improvement plan is the result of a participatory process, successful implementation is generally strengthened. However, the steering team members were warned that the investments of planning are lost if implementation is taken for granted. Because the planning team meets only monthly, task forces must be established to conduct the committee's work between full meetings. When formulating task forces, it was suggested that a balance be maintained regarding partner representation. It was found that having a blend of parents, students and staff on a task force facilitates communication. The ad hoc nature of task groups contributes greatiy to a committee's progress. 49 During implementation, it is crucial to communicate with those who are effected by the change. It became clear that the role of the leadership team is to monitor the implementation, providing guidance, support, resources, and motivation when needed. Formative evaluation should be an on-going component of implementation. 
Summative Evaluation/Celebration - Original Training

It was emphasized that evaluation should be built into both the plan for improvement and the maintenance of effort package. Anticipated outcomes should be stated in measurable terms so they can be used as the evaluation criteria. The evaluation phase is seen as an appropriate time to critique what went well during implementation, what did not go so well, and why. Such analysis is believed to yield usefur guidelines for future implementation.

When goals have been reached, I/D/E/A believes it is critical to celebrate their attainment. For that reason, celebration is a planned part of the Effective Schools Process. Brainstorming sessions are focused on accomplishments and quickly become a real source of pride. Celebrating successes had apparently cemented the bond and trust relationship between partners during the Secondary School Improvement Project and thereby served as the glue for subsequent decision-making. Seeing the fruits of their labors was a reward in itself, and had rekindled renewed effort and commitment.

It was shared that by giving plaques or certificates as an extrinsic show of appreciation, an internal pride could be nurtured. Publishing results and accomplishments, with indicators of success, is also believed to be good public relations. It was reported that "tooting your horn" through booklets, brochures or newspapers yields satisfaction for the planning team. Such publicity also advertises to the entire school community that a process is in place as a vehicle for input and action. 
A concept that continued to emerge during training relates to the notion that excellence is not a state of being, it is a process of becoming. The evaluation/celebration phase is viewed as only one stage of an ongoing, cyclical process of perfecting. The DDAE cycle of Dialogue, Decision, Action and Evaluation has become a central feature of the I/D/E/A model, allowing for persistent improvement efforts. 50 Training is available through I/D/E/A. Refer to the Supplemental Reference Notes for the Institute's address.

\section{EVALUATIVE REFLECTIONS REGARDING ORIGINAL TRAINING}

All members of the original steering committee had strongly stated during the interviews that the initial success of Pleasant Valley's "Effective Schools Process" was perceived to be directly related to the intensive training originally provided. This evaluative section is intended to share insight into what areas of the training were perceived to have worked well.

In addition, a description is given regarding those aspects of training that did not work well. This information could strengthen the positive adjustments for future training sessions.

The guidance given to principals prior to the workshop sessions regarding the careful selection of the parent and teacher steering committee members proved to have a perceived positive impact. The following criteria for selection of the steering committee parent and teacher was considered: 1) be a key communicator in the school community;.2) have credibility with the school community; 3) be an 
active supporter of the school; 4) be relatively articulate; and 5) be a team player.

Role.playing opportunities helped the steering committee feel more at ease and confident with newly learned behaviors. A strong example that was given related to role playing the recruitment of new planning team members.

Applying the skills needed to be learned to an easier, more personal task was an effective training technique. When learning how to set goals, each steering committee member was asked to create a self-improvement plan. When learning how to envision, the steering committee wrote a vision for the best they could imagine regarding their own role on the leadership team.

The trainers' use of modeling was perceived to be a successful strategy for teaching new concepts. When teaching brainstorming skills, the trainers used brainstorming as part of the lessons. When teaching consensus decision-making, the trainers had steering committee members come to consensus during the lessons.

Opening and closing each day of training with a human development activity strengthened the relationship and bond between the steering committee members. Pleasant Valley's principal stated that the cohesiveness which developed between the three steering committee members was vital to the success of those first few months.

Preparing four monthly agendas and a yearly timeline and masterplan during the training session was perceived as extremely valuable. 
Training emphasized the need to place a priority on process over product during the first year. All three of Pleasant Valley's original steering committee members felt that building trust and respect and building the capacity of people to make good decisions paid dividends in later years.

Steering committee members were encouraged to begin the first year with small, easily attainable projects to allow for an emphasis on process, yet calm the impatience of planning team members who were anxious to see substantive improvement. This advice proved helpful, but the impatience was still evident. Several students and teachers had difficulty realizing the benefits, initially, of focusing on process.

The training sessions recommended the use of a process observer for each planning team meeting to evaluate how well the meeting proceeded. The Pleasant Valley steering committee felt that using a process observer was less than effective. The steering committee decided to meet soon after each meeting to evaluate the meeting among themselves rather than take up planning team time.

The I/D/E/A participatory model stresses the importance of including patrons on the planning team. However, Pleasant Valley's steering committee has found this idea difficult to realize. Within the first year of existance, over half of the patrons quit the planning team. The steering committee has found it difficult to keep patrons motivated and committed when they do not have an emotional tie to the school. 
Agendas prepared during training sessions allotted time for pyramid sharing relative to input received and input desired. The pyramid concept worked extremely well during the first year. Subsequent years' agendas show the sporatic structuring of pyramid sharing into the meetings. Correspondingly, the success of the pyramid-grapevine communication concept is perceived to have been sporatically successful.

\section{CASE STUDY FOCUS}

The preceding explanation of Battle Ground's "Effective Schools Process" and the original training received will provide a substantial understanding of the underlying context from which Pleasant valley's success has emerged. Repeated throughout the interviews with Pleasant Valley participants was a reference to the original training, following established guidelines, staying with the plan, and getting that good foundation. Perceptions were very strong regarding the link between the training and their perceived success. The principal asserted,

"If you have a good foundation, the process will run itself. Run itself is a misnomer, of course. If you want participation and you involve people with their ideas, if they're doing things and they're being successful, they'il continue to be involved. And that is what has happened. We have a lot of participants and they have been successful. It perpetuates itself." 51

\section{Pleasant Valley Intermediate School - A Demographic Description}

The case study now shifts to the on site structure at pleasant Valley Intermediate School (PVI). Pleasant Valley Intermediate School is one of four middle schools, grades 5-8, in the Battle Ground School District, Battle Ground, Washington. The school sits in a pristine, 
rural setting, approximately thirty miles north of Portland. Pleasant Valley Intermediate's student population is 405 . The school has one administrator, 12 full time and 3 part-time classroom teachers. The racial/ethnic composition of the student population is as follows: $92 \%$ white, $4 \%$ Asian, $2 \%$ Hispanic, and $2 \%$ Black. Of the student population, $11.75 \%$ come from low income families.

When the building opened in 1976, staff and patrons in the service area spent a week charting the directions that the new school would take. Three principals have provided the leadership over the past ten years, with a rotation after four years, five years, and the present principal of one year. The building is on the same campus as Pleasant Valley Primary, which has allowed much interchange between the two schools, to include student activities, staff development, and parent participation.

The economical base for the school community is diverse, including logging, dairy farming, and light industry. The Battle Ground School District has a history of levy failure. However, the Pleasant valley Intermediate service area has a record reflecting a high percentage of positive vote. Of the 25 voting precincts in the Battle Ground School District during the 1984 levy election, the four precincts with the highest percentage of positive votes were from the Pleasant Valley service area. One of those four precincts voted 100 percent positive. Organizational Structure. Figure 3 visually represents the decision-making groups at the district and building levels. Although Pleasant Valley's "Effective Schools Process" Committee is only one of 
many decision-making groups in the school, it is perceived to be an influential decision-making governance structure because of the combined inclusion of parents, students, teachers, and administration. Figure 4 shows the organizational chart of the "Effective Schools Process" Committee itself. This committee is the focus of this case study. Student Opportunities. Many opportunities are provided for the students at Pleasant Valley Intermediate School to enhance their development both academically and socially. Positive attempts are made to preserve the intimacy of the elementary school, while providing the diversity of a high school with low risk, supportive, exploratory opportunities. 


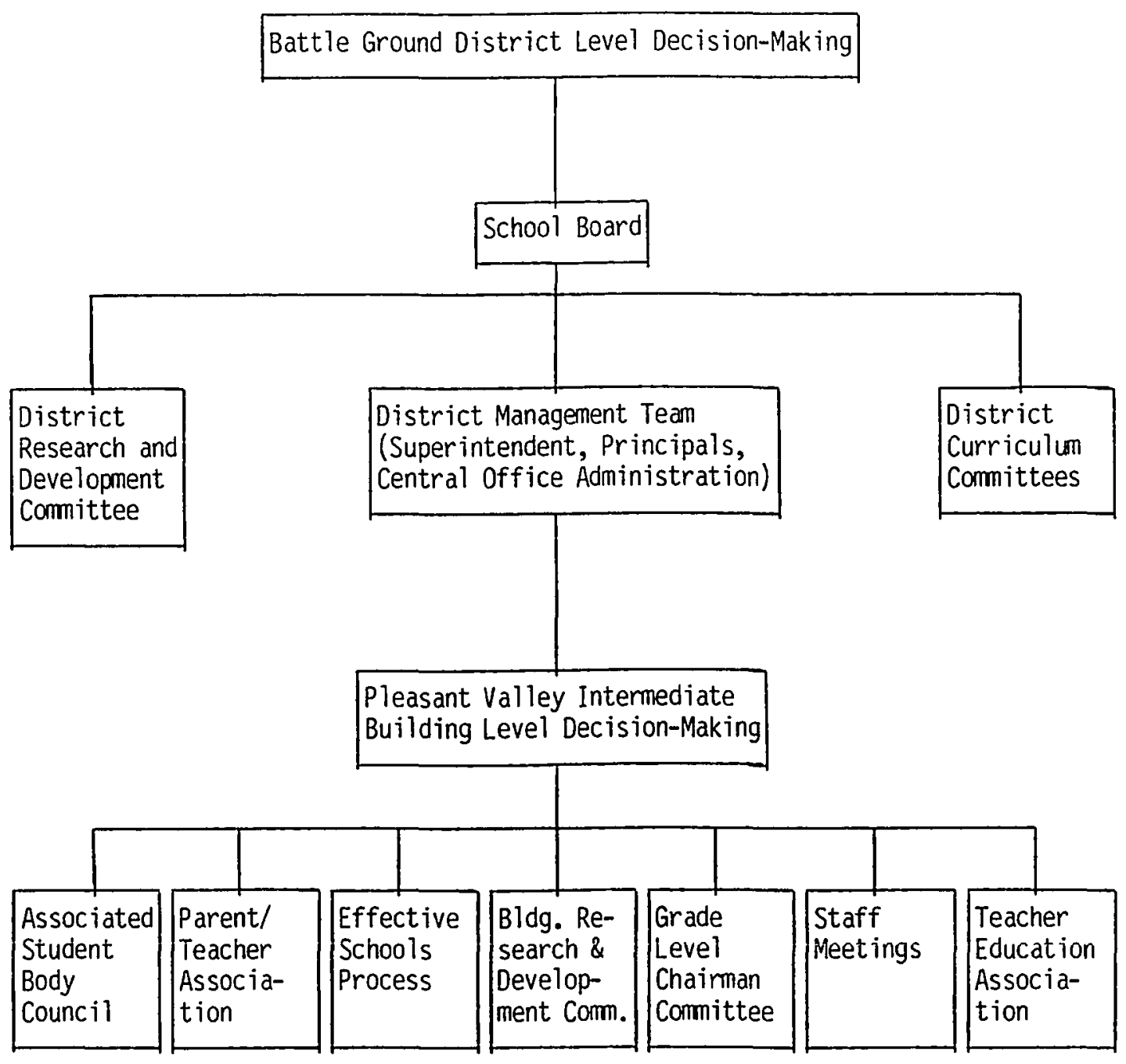

Figure 3. Organizational chart of district and building leve1 decision-making groups 


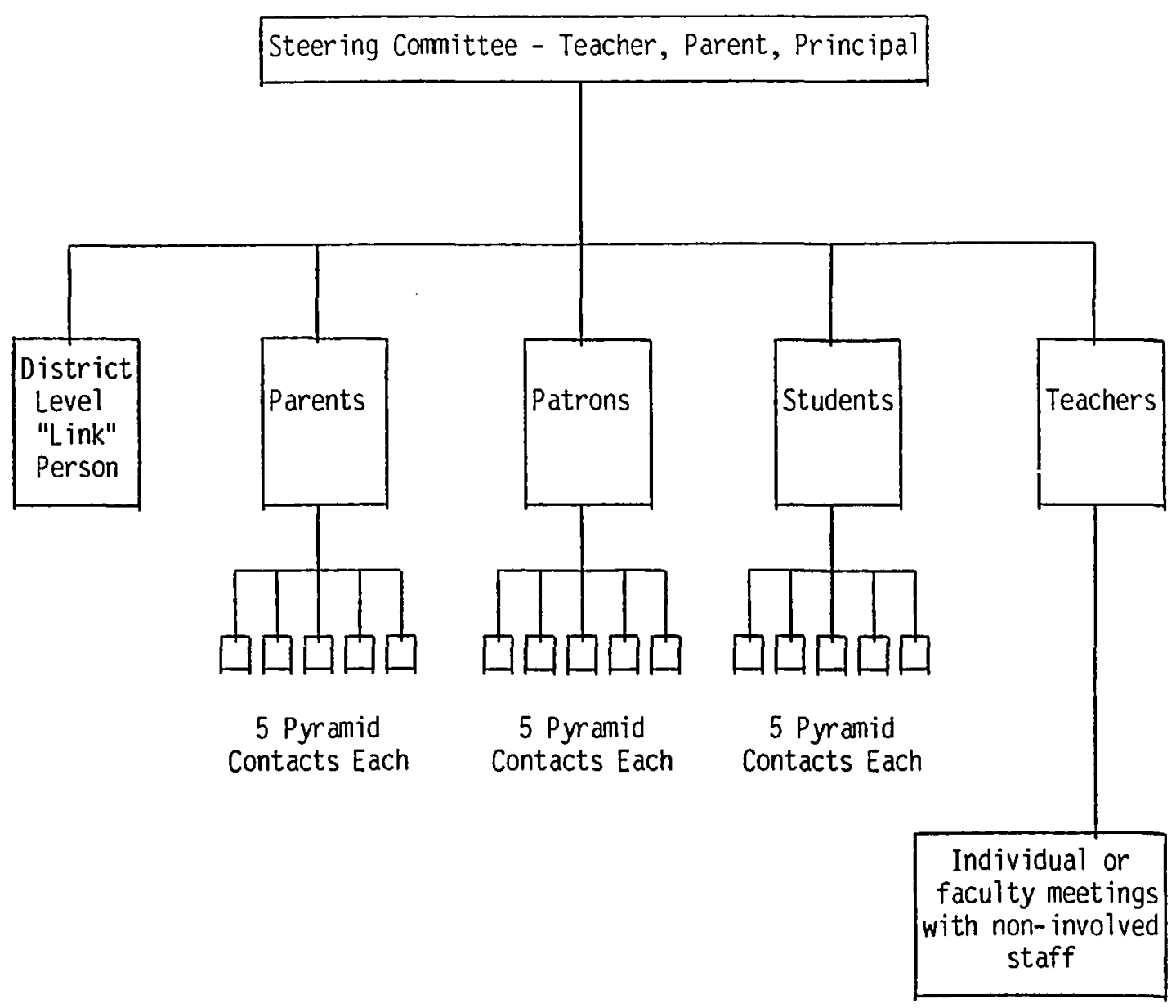

Figure 4. Organizational Chart of Pleasant Valley Intermediate's "More Effective Schools Process". 
The Associated Student Body Council deliberates on issues of importance to the school at regular monthly meetings. The student body has adopted as their mascot the symbol of an eagle wearing patriotic, Uncle Sam clothing. They have named themselves the "Patriots".

Elective courses serve seventh and eighth grade students beyond the regular program in nine to eleven different areas per quarter. Outdoor School enriches the curricuium of sixth graders. Computers are accessible to students for classroom extension work during lunch and after school, and regularly serve about 20 students.

One quarter of computer literacy and word processing is offered to each student in a 16 unit computer lab. PVI piloted and utilizes the nationally recognized and state disseminated four year Project Write, a mastery written language program. Each fifth and sixth grader receives media center instruction from a written curriculum. Each year, all sixth, seventh, and eighth graders write at least one formal research paper.

In the Advisor/Advisee program, cross-grade level groups learn listening, interpersonal communication, and study skills in formal lessons. All staff and students read silently for 20 minutes on Friday.

Math 01 ympics and the Computer Club provides approximately 50 students with enrichment activities. Community Education offers a wide variety of classes for students. Eleven extra-curricular sports programs sponsored by community groups are well attended by PVI students. 
Physical education and music courses, to include band, are an integral part of the diverse program offerings. A student newspaper provides for the development of student responsibility. Student art is regularly displayed in the district Discovery Gallery.

Many other student activities, too numerous for inclusion, help make PVI a busy, productive environment for learning.

Learning Environment. PVI staff emphasizes student responsibility. Staff authored a consistent discipline program based upon three principles: (1) students will behave in an appropriate manner which will help the teacher teach; (2) students will behave in ways which will enable themselves to learn to the best of their ability; and (3) students will behave in ways which will help others learn. Prominently displayed rules and consequences provide a consistent process for dealing with infractions, using in-class procedures and a time management room (TMR). TMR provides a closely monitored, socially isolated, study area when disruptive behavior warrants removal from the classroom. These procedures have decreased the need for principal intervention by 80 percent.

Incentives for good behavior constitute an integral part of PVI's plan and create a positive approach to discipline. Teachers generated a list of forty-nine ways to regularly reinforce students' appropriate behavior.

Teacher attitude and example provide a tremendous push for student excellence. PVI focuses on student achievement and publicizes it by 
means of an honor roll display, certificates of achievement, Principal's Award, and "Give This Kid A Hug" cards.

Academic Learning Time (ALT) has been an important focus. The length of the school day has been increased from 6 hours, 10 minutes to 6 hours, 30 minutes. The use of the intercom has been rigidly controlled. A short passing time of two minutes is allotted for class period changes. An academic learning time survey study was conducted this past school year. Dr. Gary Phillips conducted a school climate audit with very positive results. The hallways are large, bright, and carpeted to cut down on noise interference. Healthy, mid-morning snacks are eaten to stimulate brain functioning and provide a pause from academics.

Student Services. Many student services are provided to meet the individual, unique needs of PVI students.

Special education serves students in the Skills Center. Direct instruction, computer-assisted instruction, and tutorial instruction assist students. A Communication Disorders Specialist and Psychologist are housed on campus to work with the student population. A multidisciplinary team, consisting of special education and classroom teachers, an administrator, and psychologist, screen referrals and develop Individual Educational Programs involving parental input. A Remediation Assistance Program (RAP) of computer instructed assistance in math and reading serves students referred by classroom teachers. These students are not low enough to qualify for special education. Peer tutors assist students on a regular basis. 
The Psychologist, Communication Disorders Specialist, bi-lingual aide, RAP, and the Skill Center assist and monitor approximately 18 percent of PVI's students.

Occupational versatility tests, related career inventory, the 7 th/8th grade career day, field trips, classroom community speakers, student interviews of community workers, career units in the science and social studies textbooks, and eighth grade counseling from high school counselors all help students focus on career and post-secondary education opportunities.

An Extended Studies Program for academically gifted students has been developed for fifth and sixth grade students.

Student Evaluation. The State of Washington required implementation of a Specific Student Learning Objectives Law for reading, mathematics, and 1 anguage arts in 1981. Physical education and social studies objectives were required by 1983 and objectives were extended to all subject areas by 1986. Student Learning Objectives (SLO's), assessed annually, measure student achievement. PVI students' profile cards in reading and math record percentages of mastery and must be completed each year. Based on random samples, student mastery levels range between 85 and 90 percent, depending on the subject area. Informal student learning objectives exist in the areas of art, library science, and music. In these subjects, individual classroom teachers monitor mastery levels.

PVI's curriculum process model calls for systematic evaluation and regeneration of instructional programs and their delivery system. Each 
curriculum committee remains intact to evaluate the effectiveness of the curriculum after implementation. When a gap exists between "what is" and "what is preferred", the committee initiates appropriate modifications. Evaluation strategies vary from area to area, but include paper and pencil tests, teacher judgment, student surveys, parent surveys, teacher surveys, standardized tests, and current research data. In addition, the California Achievement Test and the California Academic Aptitude Test are given to students to determine program effectiveness.

Quarterly report cards are sent to parents in addition to a midquarter progress report. Phoning parents of students with repeated absences has reduced the absentee rate. The most recent attendance statistics show daily student attendance at $95 \%$, in-school suspensions at $4 \%$, and out of school suspensions at $1 \%$. Homework provides another evaluation tool. Homework is enforced by grading it, coordinating the amount given through the grade level coordinators, and having students call home if the assignment is incomplete.

The remedial programs provide classroom teachers and parents with periodic evaluation reports. The success of PVI students is also assessed by collecting data from the high school regarding former students. Information is gathered relative to percent on the honor roll, awards, and offices held, and percent of college enrollment.

Staff Development. Pleasant Valley Intermediate has twenty-five certified staff members. Sixteen staff members have their Masters degree and nine staff members have their Bachelors degree. Ages range 
between 25 years and 58 years. The breakdown is as follows: Nine members are between the ages of 25 and 35 years old; thirteen members are between the ages of 36 and 45 years old; and, three members are between the ages of 46 and 58 years old. Five curriculum development days are available each year for staff development inservice training. The Building Research and Development Committee provides the direction for staff development. The Research and Development ( $R$ and $D$ ) team is an ongoing group that reads and works with current research. That team focuses on school improvement through research and the application of that research to everyday instruction.

A major focus of the school improvement effort has been centered around the characteristics of an effective school, with specific attention paid to the unique needs of the middle school child. Nationally recognized resource personnel have been invited to the school and district to enable the staff to be on the "cutting edge" of research. Two experts on the middle school child, Dr. J. Howard Johnston and Dr. Alfred Arth, held workshops for PVI teachers and perents. Other recent staff development programs include (1) utilizing a variety of teaching strategies (i.e., Concept Attainment and Taba Inductive); (2) providing equitable opportunities for response and feedback to perceived high and low achievers; and (3) teaching students thinking skills which increase their ability to learn content and to apply ideas to problems.

Collegial teams facilitate staff communication and stay current with challenges faced by the building. Those teams either meet those challenges at their own level or take them to the building level. 
Staff development has also been enhanced through the district curriculum process. A written curriculum has been developed for almost every instructional area. The use of the curriculum model has resulted in the complete revision and adoption of new $\mathrm{K}-12$ curriculum materials in social studies, science, physical education, instructional media, math, art education, music education, health education, drug and alcohol education, and computer education grades 6-8. In addition, PVI piloted the development and implementation of Project Write. The project is in the process of being disseminated regionally and will be selected as a component for the National Dissemination Network.

Building Leadership. Two principals have been at the helm of PVI during the past five years - the span of this case study. The principal of the first four of the past five years was described as a participatory leader who maintains an open door policy for input. He was perceived by students, teachers, and parents as an effective educational leader. The year the case study was conducted, PVI had new leadership. The new principal had been the previous elementary principal at Pleasant Valley Primary. She was already acquainted with many of the parents, students, and staff as a result of this transition. She also was perceived by students, parents, and teachers as an effective participatory leader.

Parent Involvement. PVI enjoys a supportive and positive relationship with parents. This has not always been true. PVI's recognition application stated the following: 
Five years ago, parents expressed that they did not feel they were partners with the school in providing for the education of their children. An adversarial relationship existed between parents, students, and staff in which none felt they had an opportunity for input for change. PVI's "More Effective Schools Process" gave parents, community, students, and staff a shared responsibility in effective school operation and outcomes. Consequentiy, the educational community nurtured an ongoing, positive partnership.

This case study will describe the "More Effective Schools Process" group. Parents have, however, been involved at PVI in other capacities. The PTA has actively supported PVI by donating significant amounts of money for the following: library materials, computers, computer software, Young Audience concerts, a copier, VCR, video camera, and the eighth grade brunch. The PTA has 219 members who work with staff to put on an annual faculty/parent basketball game, and sponsors an annual talent show. In addition, a recent year, 123 volunteers contributed to 30 different areas of involvement, from magazine sales to supervision of field trips. Parents also show support by participating in school sponsored meetings and programs. For example, during one recent year:

- 274 parents attended the teacher conferences

- 220 parents attended the Fall Parent Orientation

- 450 parents attended the Winter Music Concert

- 470 parents attended the Spring Open House and Concert

Much of the information in the preceding description was gleaned from interviews, on-site visitations, and documents, to include PVI's National Recognition Application Document. 52 
FORMULATION - YEAR ONE

The first year of implementing the "Effective Schools Process" was significantly unlike the following four years. When bringing diverse groups of people together in new ways, it was unrealistic to think that the diverse partners could reflexively work in concert. In addition, the principal of PVI had no experience with directing a group of diverse participants. He had previously worked through the participatory model with teachers as part of the districts' curriculum process. He had worked cooperatively with parents through the PTA, which had a strong emphasis on fund raising. He had worked closely with PVI's students through the student council. However, he had never attempted to combine these groups into a single governance structure with everyone being as equals. The following excerpts from interviews are intended to describe the diverse perspectives regarding the formulation phase of the planning team.

Parent: I had some experience with solving problems with teachers before, but it always involved just my child. If I tried to voice my opinion, I always sensed them getting defensive. It was uncomfortable at first to be in a meeting with teachers as equals. I had started to think of them as the enemy. 53

Teacher: Teachers had to realize that parents were, in a sense, equals with real input into the school. We had to re-adjust and ask, 'Whose school is it?' Several of my colleagues didn't feel comfortable with that! 54

Student: (This student is now in high school and had served four years on the committee, grades 5-8.)

A lot of the students were a little nervous. It was like the saying 'Kids should be seen and not heard'. When we were at the meetings, it really helped when the principal would say, 'Let's get a student's perspective'. Many times when we weren't specifically 
asked, we wouldn't speak up. A few of the adults sometimes would dominate the conversation. 55

The principal not only was bringing together diverse groups for the first time, but he was also involving a teacher and a parent as equals on the leadership team. His reaction to the steering committee structure was as follows:

Neat concept!!! The parent should be someone who is a recognized leader in the school community and the teacher should be a leader in the building. The parent selection is critical. From the beginning, that person is going to have to go out and speak to parents and speak to groups. That person needs to have a positive image towards the school and be articulate, too. The teacher leader must be someone who compliments your personality but yet has the ability to sit down with teachers and discuss controversial situations. That person needs to have good communication skills and also be respected. Academic skills are not nearly as important as the relationship skills.

When asked if he had considered all of this before he selected the steering committee, there was a resounding answer of "You bet!" followed by four intermittent replies of "You bet".

The principal needs to make the final decision about who is selected for the steering committee. The staff can offer several recommendations, but the principal needs to make the final decision based on personality and leadership. It's one of the few and last decisions a principal makes by himself in this process. I'd just as soon tie my own noose rather than have someone hang me. 56

The principal, teacher and parent on the original leadership team all felt strongly that the team was a "beautiful complement". The principal stated that his strength was organizational skills over relationship skills, and the teacher's strength was relationship skills over organizational skills. He felt that their personalities matched very well as a team, and the parent's personality seemed to sandwich right in the middle. 
With a common experience through training, the well-meshed leadership team began their first year of the "Effective Schools Process". To create a uniqueness to the process for their building, the name was changed to the "More Effective Schools Process" (MESP).

During the interview phase of this case study, one issue was repeatedly amplified: Year one was a year dominated by process and not by product. It was set apart from the other four years by that very reality.

The success of MESP was perceived to be a partial result of year one's focus on process. For this reason, the case study analys is has described year one separately from years two through four. Expecting participants to remember back five years can introduce bias into a study simply because of the unreliability of memory. Therefore, the information that reflects year one is a product of triangulation. Available documents and multiple verifications through interviews solidified "this is the way it was".

To present a well organized, coherent report, the case study format has adhered to the same structure used in the training section: recruitment, planning, training, data collection, design, implementation and evaluation/celebration. Many pieces of information generated during the case study investigation do not all neatly fall into these categories, however. To include these vital pieces, a section entitled "Retrospect" will immediately follow the year one and years two through five sections. This section allows for the inclusion of advice, precautions and amplified learnings worthy of sharing with others. 
Recruitment - Year One

The steering committee was selected by the principal. Intensive training had been provided for the leadership team. Their first charge was to assemble a planning team of five parents, five students, five teachers and five patrons. They immediately brainstormed a long list of names, narrowiing it by considering diversity and availability. The steering committee parent said, "We made a real effort to get a diverse blend. We did not try to eliminate people of opposing opinions".58

Trying to recruit patrons in the community was more difficult than recruiting the other groups. It became apparent that the patrons did not have an emotional investment in the school. To stimulate enthusiasm about their commitment was difficult. "I'm so thankful we concentrated on role-playing of recruitment during training! It really helped me to become more confident and enthusiastic," said a leadership team member. 59 The patron membership was finally completed with the inclusion of a senior citizen, a Community Education Coordinator, a minister and his wife, a secretary from an electronics firm and a dentist. Within the first year, however, the mortality rate of patron membership was 50\%. The minister was building a new school and was extremely busy. The senior citizen, who is no longer living, came to only two meetings. His reasons for quitting were not known. It is interesting to note that the electronics firm supported their secretary's involvement by providing her with time off of work to attend the several meetings held in the morning before school. They even helped design and print the MESP logo letterhead. 
The completed planning team included twenty individuals.60 Several participants felt that the steering committee's initial enthusiasm provided the necessary momentum to get the planning team established. It was also mentioned several times that the principal had a strong, positive attitude towards participation. Personal contacts, letters, and phone calls helped to solidify commitment and reinforced participation.

Some of the parents and teachers who were recruited were also members of the school Parent Teacher Association (PTA). One parent had been the president of PTA the previous year and gave up her active participation in PTA to devote time to MESP. This parent stated that feelings of jealousy and territoriality were natural and expected. A redefinition of purpose was necessary, yet both groups are still very much intact with clarified roles and responsibilities. PTA is involved in such things as fund raisers, health screening, drug awareness, and the Picture Lady. MESP is involved in more substantive programs. Regarding MESP's role, one parent stated, "When you have an opportunity to sit down at a table with the administrator and teachers regarding school improvement, substantive programs result."61

To expand the base for input and decision-making, pyramid groups were formed. Each member recruited five people with which to communicate on a regular basis. Names, phone numbers, and addresses of the pyramid members were collected by the leadership team. They were placed on $5 \times 7$ cards for each planning team member, and also posted so people on the planning team would be more accountable in contacting 
their pyramid network. It was a very structured procedure specifically designed to increase effectiveness. That particular strategy is perceived as a critical component of the pyramid network's effectiveness. Had they merely said to be sure and contact five people between each of the meetings, it is perceived that this tactic would not have been effective.

At the end of the first year it was evident that recruitment continued to be an important concern. A reminder letter which was sent to members regarding the last yearly meeting encouraged members to invite an interested person to attend. "New Memberships" was indeed a listed item on the last agenda for the year. An attempt was made to solidify new recruitments for the following year by the end of summer.

\section{Planning - Year One}

The steering committee rigidly followed the procedures described during training for the first year. The four agendas for the first four meetings had been constructed as a guided team effort during training. Only minor adjustments to the agendas were necessary. The leadership team tried for several meetings to have a process observer, as was recommended during training. However, the process observer did not prove effective for MESP. The leadership team found it was more valuable for the steering committee to come together after the meeting and evaluate what went on rather than waste meeting time.

The various components of the training session are reflected in the four agendas in Figures $5,6,7$, and 8 . The charge of the leadership 
group was to replicate their training for members of the planning team. The first six months were primarily devoted to building relationships, learning effective group decision-making skills and becoming aware of the school effectiveness 1iterature. Easily attainable goals that ensured success were initiated as soon as possible to quiet the impatience of planning team members to improve the school. These goals did not overshadow the primary focus, and correspondingly did not sacrifice process for product. A timeline was prepared for the last three months that included: 1) a retreat to formulate a vision statement and intended outcomes, 2) a design team to construct goals, objectives and activities, and 3) a task force responsible for initiating implementation. 
I. Introduction/Questions

* Why are we here?

* What are we going to do?

* Why was I selected?

* What is our final product?

* How long will this process take?

* Why is this so important?

II. Organization of small groups

III. Group Skill Development

* Activity \#1

* Activity \#2

IV. Understanding Mission/Commitment

* Adolescence

* Effective Schools

* Film

* Handout

V. Developing pyramid groups

VI. Future meetings/questions

Figure 5. Agenda for the first planning team meeting. 
I. Introduction of New Member

Review Profile of a Middle School

Common Characteristics of a Middle School

Adolescent Student

II. Whip Activity - An ideal vacation would be...

III. Introduction of Process Observer

1. Review Brainstorming - Consensus Building

2. Activity E.C.S. Priorities in order of importance to your group (Education Commission of the States Report)

IV. New Game Activity

V. Pyramid Group

Report and Interview

Assignment

1. Rose play assignment

VI. Final Business

Next Meeting

1. Time

2. Place

Final Questions

Figure 6. Agenda for the second planning team meeting. 
I. Whip Activity

- Human Relationship Skills

II. "Goals We Value"

- Individual

- Group

III. Pyramid Group

- Names

- Feedback

IV. Whip Activity

V. Forecasting Our World

- Handout

- Discussion

VI. Brain Research

- Tape

VII. "Goals We Value"

- Share with group

VIII. Timeline

- Assignment to pyramid

- Future agenda

- Workshop day

- Next meet ing

Figure 7. Agenda for the third planning team meeting. 
I. Review Skill Development

II. Personal Goals/Self Improvement Plan

III. Middle Schools (Film Strip)

IV. Share Personal Goals/Self Improvement Plan

V. Planning Session Details

- Where?

- When?

VI. Process Observer

VII. Tour of Building (Optional)

Figure 8. Agenda for the fourth planning team meeting. 
Another important component of the planning phase involved structuring the meetings to maximize the effectiveness of the pyramid concept. The pyramid network was intentionally targeted as a formalized procedure. Time was allotted during the meetings for reporting and collecting needed input from the pyramid group.

The following considerations were also made by the steering committee during the planning stage of year one:

- Communication was a key element for consideration. All those who were impacted by decisions needed to be informed and have input. The leadership team facilitated the coordination between and among identifiable groups that were interlaced with the planning process.

- Repeated communication with the planning team through letters and phone calls was important for revitalizing commitment and motivation.

- During the first six months, all members of the steering committee needed to encourage planning team patience, and not let the principal alone respond to the group's impatience with process.

- Openness was encouraged between the steering committee members regarding people with hidden agendas. They needed to discuss the situation and decide together what approach to take.

- A clarification of the leadership team's role during planning meetings was important. Steering committee members realized that they simply could not have hidden agendas of their own. Their role was to 1) listen, 2) involve people, and 3) help the group come to consensus on ideas.

\section{Training - Year One}

The training that was replicated for the planning team fell under two categories, decision-making skills and human relationship skills. The human relationship skills training focused discussion on such things as openness, honesty, trust, conflict resolution, ways to encourage involvement, strength in diversity, and equality of input. Each meeting 
opened and closed with a high relationship activity such as sharing about a favorite hobby. Human development activities were critical components of each meeting and designed to nurture relationships between partners. Justifications were made and understood regarding the time commitment to "relationship building". One person explained,

Relationship in a school is important. Think about the common 'problem' we've all gathered around to solve. The 'problem' is the child. Education is in fact a partnership between home and school because of the 'problem' -- the child. Therefore, any school reform effort needs to develop positive relationships between those major organizations that ultimately affect the life of the child. 62

Decision-making skills were a major focus of the training. Brainstorming was taught by first brainstorming something fun. Later, brainstorming sessions included typical problem solving situations. The parents perceived the brainstorming sessions as useful and patiently adhered to the planned practice sessions. Teachers on the other hand were less patient because they had been exposed to brainstorming previously. Several had been using it as a teaching technique in their classrooms. One teacher shared that a colleague became impatient during a brainstorming training session and commented conspicuously, '0h, gag me!! I've done this before!' "63

The skill of consensus decision-making was perceived as extremely valuable by all participants. One parent said, "During consensus everyone was heard. No one ever came out as a winner or a loser. It wasn't a vote but a coming to agreement that sometimes involved negotiating. "64 A student said, "I was so used to voting and having the majority rule. I think consensus is great because even if you have a different opinion, 
you knew you'd get to express where you were coming from. If you just vote, you don't feel like your opinion was heard."65 This student was in high school and had served on MESP during its first year. Of all the interviews conducted by this investigator, his explanation was the most meaningful interpretation of consensus.

During the third meeting of year one, a situation developed on the planning team that required the real-life application of the consensus process. The situation developed early-on in the training while people were still learning the skill. The incident was explained by a steering committee leader in the following way:

I was facilitating a meeting and one of the teachers complained that they didn't like giving up evenings to meet. The teacher requested that the next meeting be held during the day and have substitutes provided for the teachers. I opened the idea up for discussion. No one disagreed with the option. The decision was made to get substitutes to release teachers for meetings. But a few days later there was a quiet upheaval from the parents. They didn't think it was right to pay for substitutes when they were volunteering their time. They also did not like the teachers being away from the students. Well, we went ahead and got substitutes for the meeting as we had planned. The first thing on the agenda was to be open and upfront about the issue. We had a long conversation about the importance of all members being open and expressing their real feelings. Discussion was pursued regarding the negative potential of not coming to consensus. This issue could have really flared up and hindered or destroyed our whole partnership. Before that meeting ended, people could tangibly see the importance of consensus decision-making.

The leader commented that the incident was really a blessing in disguise. It solidified the group and developed unanimity. It clearly demonstrated that power needed to be balanced and not controlled by teachers or by parents. The incident brought out future openness and honesty. "We couldn't have planned it better!"66 
Data Collection - Year One

A majority of the data that was collected came from informally comparing Pleasant Valley Intermediate to the school effectiveness research.

Providing the planning team with school improvement and school effectiveness research was a major accomplishment for the leadership team. 67 The reaction by parents and students to the school effectiveness research was varied.

Parent: I thought it was extremely useful. It was flattering that they thought we were smart enough to look at the current literature.68

Student: I didn't really see the need for the education part. I guess it was important to parents, especially the things about middle schools. 69

Principal: Everything that the leadership team was exposed to during training was replicated for the planning team in a quality manner. We also provided extensive literature regarding the unique needs of the middle school student. Information was collected about advisor/advisee programs because self-esteem was such a focus. Once the team had enough quality content, there was really a felt need for change. 70

Each time the research was discussed, an informal needs assessment was occurring. The team also utilized test scores and honor roll statistics as indicators of areas that could be targeted for improvement. The results of the Phi Delta Kappa Needs Assessment also proved to be a helpful database. (See Figures 9 and 10). 
Priorley Ranking of Goale

Batele Crovad School Dletrice

Session I Resulte

Intermedlate Cotmunity

COAIS

Learn how to be a good citizen

Learn how to respect and get along

wich peosle who think, dress $c$...

Learn about $\&$ try to unoerstand the

changes that take place in the vold

Develop skills in reading, witing.

speaking. and listening

Understand and practice democratic

ideas and ideals

Learn to examine and use informstion

Understand and practice the skill of

fanily livino

Learm to respect and get along with

people with whom we vork and live

Deveiop skills to enter a specific

field of work.

Learn how to be a good manager of

money, property and resources

Develop a desire for learning now $c$

in the future

Learn hor to use leisure tim

Practice and understand the ideas of

healeh and sefety

Appreciate culcure and beauty in the

vorjd

Gain inforastion needed to make jos

Gelections

Develop pride in wo:k and a feeling

of self-worth

Develop good character c self-respect

Gain a general educacion

\section{Figure 9. Priority ranking of goals from the Phi Delta Kappa Needs Assessment.}




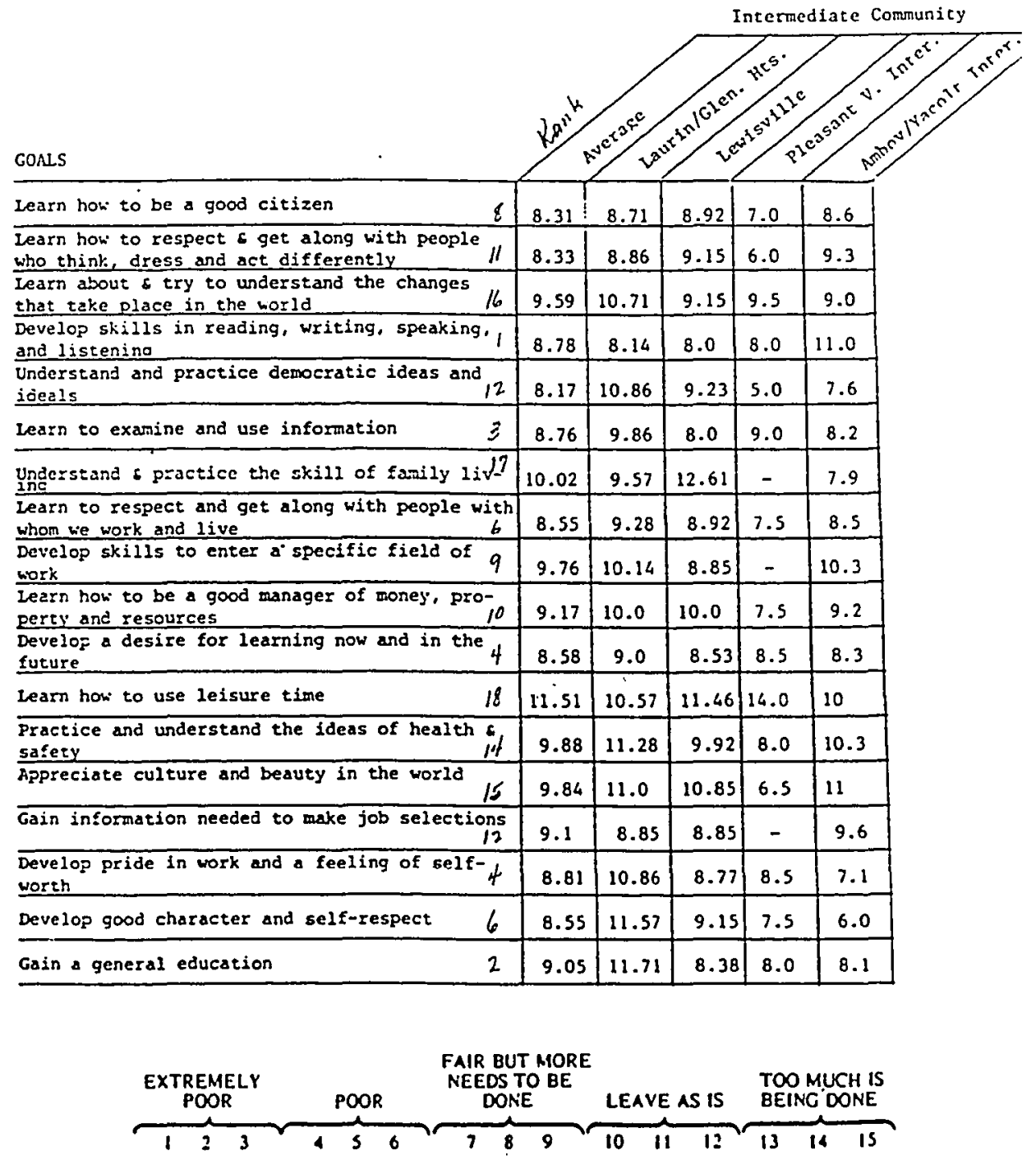

Figure 10. Mean scores from Phi Delta Kappa Needs Assessment displaying perceived goal attainment for each intermediate school. 
Data collection during year one was also pursued in the following ways: The committee conducted a school wide survey of the assertive discipline program. Additional data was generated through the active pyramid network. The planning team also used a brainstorming session during a meeting to surface a whole host of focus areas. A participant vividly remembers appreciating the contributions from parents and students during that brainstorming session.

Some of the ideas that were generated really had the whole child in mind. Too often teachers are primarily concerned with academic issues. Students open up more at home, and parents are sensitive and aware of the need for balance. That's how the whole advisor/ advisee program was initiated. Parents and students really wanted to emphasize self-esteem. 71

Design - Year One

The data collection phase was complete after six months of study and discussion. The design phase then began with a retreat in late February of 1983. The purpose of the retreat was to create a "vision statement" which was a description of the best that could be imagined for the school in five years. The planning team then created a series of intended outcomes that would be used by students, parents, staff and community to ultimately achieve the vision. The outcomes could also be used to verify that the committee was on target by serving as a template for monitoring and evaluation. Before the retreat, planning team members were asked to contact their pyramid groups. Each person in the pyramid network was asked to answer each of the following two questions: 1) What is one of the best things happening at Pleasant Valley Intermediate? 2) Name one thing that could happen or be added at Pleasant 
Valley Intermediate that would benefit the school?

Each planning team member was to bring the answers with them to the retreat. A dentist on the committee invited the group to hold the retreat in his office suite. The retreat was held from 9:00 - 4:00 with a pot luck lunch served. The first part of the morning was spent in relationship building and celebrating past accomplishments. The remainder of the morning was planned to give team members a broadened perspective of education for the 21 st century. Nine Principles of Challenge Education were discussed in depth (see Appendix E). From these the group selected three by consensus. These three later guided the creation of the vision statement. In addition to discussing the Nine Principles, the committee invited an international consultant to come and speak to the group. The consultant worked for a research and development company that specialized in export marketing. His work required that he travel to all parts of the world, which helped him develop a broadened perspective well worth sharing. He focused his presentation around the book Megatrends by J. Naisbett, discussing the global economy, and stressing the important skills children would require for employment in the future.

Following lunch, the planning team used the brainstorming technique to describe what they wanted their school to look like in five years. After the ideas were generated, a few individuals were sent off to put the ideas into sentences. 72

"It was a very challenging task," remembers one participant. 
We would come back with sentences and ask if they were clear. 'No, change this -- change that'. It was difficult forcing people to articulate a vision they agreed upon. It was in reality forcing them to develop an ideal plan to implement. It seemed impossible to place so many ideas into a conceptualized format. We wanted it concise yet meaningful. 73

Another participant asserted, "A vision statement is important. It is a general consensus of purpose - a shared unfragmented direction - a guideline."74 Pleasant Valley Intermediate's vision statement is stated in Figure 11.

$$
\begin{aligned}
& \text { "Unless our reach exceeds our } \\
& \text { grasp, what's a heaven for?" }
\end{aligned}
$$

"Hold fast to dreams, for if dreams die, life is a broken winged bird that cannot fiy."

PLEASANT VALLEY INTERMEDIATE WILL INVOLVE SCHOOL, HOME AND COMMUNITY SO THAT :

EACH STUDENT MAXIMIZES HIS/HER POTENTIAL AS A POSITIVE PRODUCTIVE CONTRIBUTOR TO SOCIETY:

THE LEARNER WILL HAVE IDENTIFIED AND PURSUED EXCELLENCE IN HIS/HER AREA OF STRENGTH:

THE STUDENT WILL HAVE BECOME SELF DIRECTED AND HAVE LEARNED THE BASIC SKILLS NEEDED TO CONTINUE LEARNING, ANTICIPATE CHANGE, AND MAKE TRANSITIONS THE REST OF THEIR LIVES.

Figure 11. Pleasant Valley Intermediate's Vision of Excellence Statement. 
Once the vision statement was finalized, intended outcomes of the vision were developed for students, parents, staff and community (see Appendix F). When the retreat drew to a close, the planning team had a sizable reason for celebration. "The whole day was one big human development activity!" exclaimed a teacher. 75

The intended outcomes were then sent to the pyramid network. The pyramid members were asked to prioritize the outcomes for each group parents, staff, students and community. The prioritized outcomes and vision statement were refined and polished for publication at the March meeting and a five year plan was constructed (see Appendix G).

The next step was to formulate a design team to develop specific activities to accomplish the outcomes. The activities were developed around a threefold purpose: (1) To construct a maintenance of effort activities package to insure the extension of effective practices; (2) To develop activities that would cause program refinement; and (3) To develop plans for program improvement.76 Seven people were selected for the design team. The design team met four times during the month of April. The proposed activities were presented to the planning team and were finalized by consensus at the May meeting (see Appendix $\mathrm{H}$ ). A task force was assembled to initiate implementation plans for the 83-84 School Year target goals (see Appendix I).

\section{Implementation - Year One}

Implementation was not a significant component of MESP's first year effort. Time had been allocated so as to tip the scales toward 
process, leaving product purposefully lean. The groundwork provided a solid foundation. The subsequent success of MESP is perceived to have stemmed from the cohesiveness and skill building which was developed during year one.

Small projects were easily implemented sporatically throughout the year. Tangible accomplishments were important to temper the ever growing elements of impatience. Some example areas that were successfully addressed were 1) rewards and incentives, 2) self-esteem, 3) fifth grade orientation,4) home/school communication, 5) utilizing spring test scores for fall conferencing, and 6) assertive discipline evaluation.

Evaluation - Year one

Because year one was process, the summative evaluation centered around a process focus. The following six statements were printed on an MESP handout, evaluating that process:

ESSENTIAL KEYS FOR M.E.S.P. SUCCESS

1. District administration must delegate authority to individual buildings.

2. Caring atmosphere through human skill development.

3. Diverse ideas through brainstorming techniques.

4. Acceptable decisions through consensus.

5. The best you can dream/imagine through a written vision statement.

6. Dreams become reality through an action plan. 
To provide an overview of how many meetings were held during year one, the following schedule has been collated:

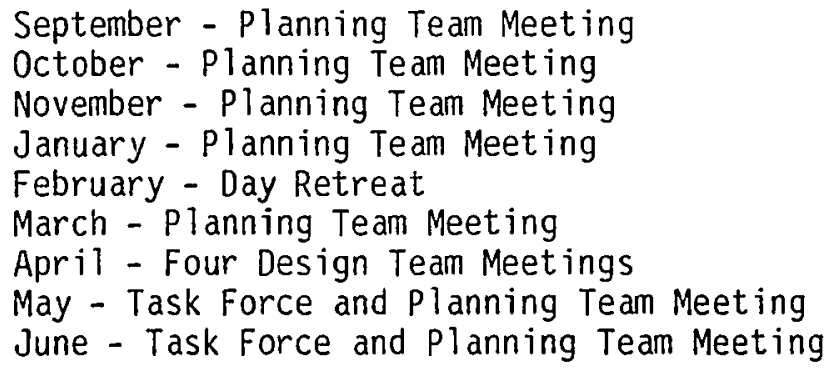

Celebration is a basic ingredient in the MESP recipe. Celebration has surfaced intrinsic pride and satisfaction, and has been used as a tool for rekindling commitment and motivation. Certificates of appreciation were awarded to all planning team members publically during a district patron tour. A planning team parent recalled, "It's just a piece of paper, but I welled up with tears!"77

\section{RETROSPECT - YEAR ONE}

This section of the case study is intended to provide information that could not cohesively be included into the preceding categories. The format includes the use of direct quotations from the interviews. Information made available in this section represents pieces of advice, precautions, and additional amplified learnings from year one.

Participants shared the following:

Looking back on the plan for year one, I'd recommend following the same schedule of six months of group dynamics and skill building and three solid months of planning for the next few years. 78 
place. Community involvement is one of the attributes, so staff understood the need when we set up the MESP process.83

The parents' perspectives were really important to our planning team. Students go home and share things with parents that they don't share with teachers. 84

It should be carefully communicated to the PTA in the beginning that MESP is different and doesn't conflict with PTA's role in the school.85

I learned the techniques of brainstorming and consensus decisionmaking through MESP. Now I use them frequently in my work with Christian Women's Ministry. You wouldn't think you'd see much conflict in a group like that but it's there! I've used those skills to resolve serious conflicts. 86

If you don't take the time to build relationships and move too quickly to task, it's possible for adversarial relationships to deve1op. The planning team generally understood that at the end of the first year. They felt efficacious about what could then be done in the school.87

The steering committee and administration were learning the process right along with us that first year. We all felt like we were taking it step by step together. 88

It was important to recruit student leaders. They really talked the process up and the other kids thought it must be an okay thing. 89

The principal kept encouraging us students to talk. If he hadn't done that, I don't think we would have given much input. 90

Focusing so much on process the first few months was boring for the students. I could see the promise in it but my son didn't see much nitty-gritty! 91

The students learned how to actually write out goals. That was valuable in itself. 92

My son was on the high school planning team the same time I was on the middle school team. They started on task right away and didn't spend much time practicing consensus. It seemed like all year long the meetings were spent battling out views.93 


\section{MAINTENANCE}

\section{YEARS TWO THROUGH FIVE}

To insure clarity and consistency, the format used in the preceding section wili be replicated here. The length of the various descriptions will vary, however, to more accurately reflect the attention and emphasis given those components.

Recruiting - Years Two Through Five

Effective recruiting is a key activity in developing a successful participatory process. In that regard, the following information is the collated rank order perception regarding ease of recruitment for the various groups:

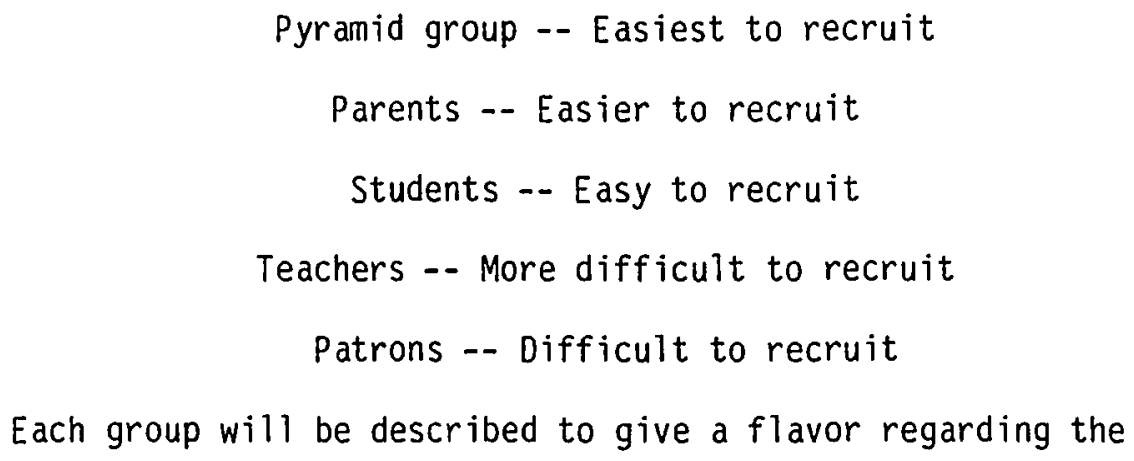


Pyramid Group. Recruiting people to participate on pyramid groups is a relatively easy task. Their only real commitment is to be available by phone and to remain informed of MESP's progress, giving input when requested. The difficult challenge surrounding the pyramid concept is a problem relative to the follow-through by planning team members.

The success of broadened input is directly connected to the reality of actual contact. Some months and years have been better than others. It is a majority perception, however, that the pyramid network has not been totally successful. It is also a majority perception that the success or failure of the pyramiding process is directly linked to the emphasis placed upon it. The extent to which it has been formally addressed at meetings by the steering committee is directly linked to the success of the pyramid process. Year one of MESP was a success relative to pyramiding. There is a direct link through documentation that the pyramid concept was a formalized priority. Documentation during years two through four shows sporatic formalization of the concept. It was suggested that the parent on the leadership team be assigned to assure the pyramid network is consistentiy addressed. Several members suggested that time be made available at each meeting to share the input they had collected from the pyramid. One parent shared her frustration by saying, "I was really conscientious one month and called all my pyramid people for input. They had some great things to 
share. We were never asked to report, though, at the next meeting. The following month I didn't bother calling".94

Parents. As the participatory process continued to develop, the parents became more and more aware of the importance of involvement. One person attributed it to the global economy saying, "parents understand that education is important to their child's ability to successfully compete for a future job."95 Parent involvement has been consistently high over MESP's five year history. That is not to say that parents have been overly available. On the contrary, the two principals who have been responsible for recruiting testify that many, many hours were spent on phone calls, personal contacts and letters. It is important to note, however, that several parents who previously served on MESP during the early years are now vital members of high school ESP groups.

Students. PVI's student council has typically served as a source for student recruitment of MESP. In fact, a number of the substantive programs were developed primarily by student leaders. More recently, student participation has declined to only four students. When asked for a reason, the students who were interviewed explained, "Well, our principal is new this year. She asked all of the student council officers to join. They didn't know her very well and they're pretty busy. One of the officers asked me to join instead and I said sure. I brought along a couple of friends, too".96 Another student said, "I really wish we could get some more kids to come. We're really 
outnumbered. Besides, I'm the only boy".97 A third student said, "She's really good about getting input from the kids about MESP. She meets every Friday with eighteen homeroom leaders and we talk about MESP a $10 t " .98$

Teachers. Recruiting teachers tends to be a little more difficult. It is directly connected to the limited number of teachers available as a source. There are only a few teachers at PVI who do not want to be involved, and those few who are perceived by colleagues as preferring status quo. One teacher also explained, "There are always a few teachers on a staff who are more authoritarian by style and don't want to be involved in a participatory process".99 Consistently over the five years, teacher participation has been good, fluctuating between four - six members each year out of a staff of about twelve full time teachers. One steering committee parent remembers the year that teacher membership was low. She felt that communication with the uninvolved staff suffered somewhat that year. It also happened to be a year when there were many parents on MESP from one housing subdivision. She said,

I think a few of the teachers who weren't on the committee thought the parents had a little too much control. One referred to us as the Mt. Vista Maffia. Overall though, that wasn't the feeling we got from the rest of the staff. I think the problem was having such an obvious over-representation of one group. During our original training, they really emphasized the 5-5-5 balance. I think balance is an important consideration. 100

New parents keep coming and going as their children go through the grades while the same core of teachers remain intact. "There's really a potential for burnout," said one teacher.101 This most recent year, the principal has included MESP as a committee sign up option with five 
slots available. It is understood that these five teachers will have less responsibility on other school committees. The teachers can then rotate every year if they wish. This plan was perceived as a potential solution to address possible burnout.

Patrons. Patrons are the most difficult group to recruit and retain. It is perceived that patrons would rather serve on district level committees than at the building level. It is also believed that because they have no children going to PVI, the emotional connection is missing. MESP has dealt with this issue in four important ways. 1) They have included parents who are key communicators in the community primarily because of their employment situation, 2) They have held two fall community goal setting sessions sending out invitations to surrounding businesses, 3) They have an MESP member also serving on the Community Education Advisory Council, and 4) They have developed a computer based community resource bank of guest speakers and then used them as a potential patron source. 
Steering Committee. Figure 12 presents a visual chart showing the rotation and length of involvement by years for each leadership position.

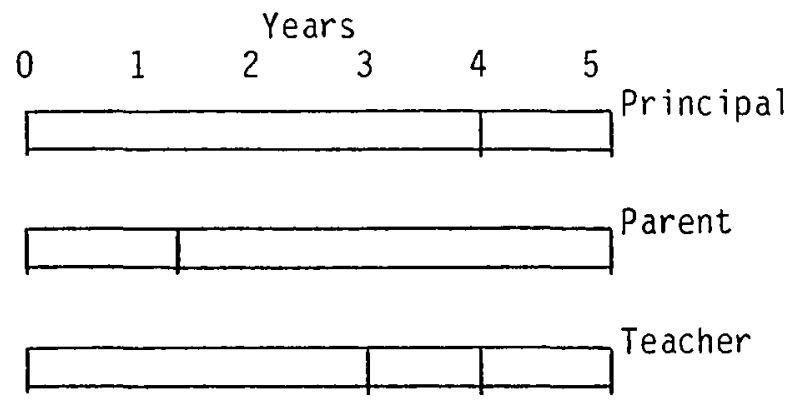

Figure 12. Number of years a leadership position was held and then rotated to a different individual.

Table I highlights how the numerical mix of the planning team has changed in recent years.

TABLE I

NUMER ICAL MIX OF YEARLY PLANNING TEAMS

Years

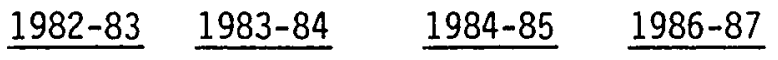

Steering Committee

Teachers

Students

Parents/Patrons

Total

\begin{tabular}{rrrr}
3 & 3 & Exact & 3 \\
4 & 6 & \#'s & 5 \\
7 & 10 & not & 4 \\
6 & 16 & available & 14 \\
\hline 20 & 35 & \\
\hline
\end{tabular}

Please note that MESP did not hold a formal meeting in the fall of 1985, but did resume training in February of 1986 . The 1985-86 academic year followed an exhausting, all encompassing implementation of the 
advisor/advisee program. In addition, the school had recently won national recognition in the spring of 1985 . Everyone involved recognized the need to officially rest and recuperate. The principal recalls the previous year of implementation. "You couldn't have asked for more commitment from a staff!"102 Once the MESP program resumed in February, nineteen people attended that meeting, seven wanted to attend and were unable, and thirty-nine asked to be on a pyramid list.

\section{Planning - Years Two Through Five}

The "Effective Schools Process" was a district wide adoption. Because of this commitment, the district has provided building steering committees. with the necessary support. A timeline and masterplan was constructed, with district guidance and is used as a guideline for all schools. The timeline and masterplan for this past year is included to show the unending cyclical process (see Appendix J).

\section{Training - Years Two Through Five}

The Battle Ground School District provides each building steering committee with a 2-3 day refresher training generally scheduled near the end of each summer. Or. Phillips provided training for the first three summer sessions. Battle Ground utilized district personnel for the most recent session. One principal said she always benefitted from the reruns, adding, "It really pumps me up; inspires me!"103

For five years, the leadership team had recognized how important it is to teach, maintain and fine tune the planning teams decision making skills and human relationship skills. Providing the most current educa- 
tional material for the planning team is another component built into the annual training program. These areas will be elaborated upon to provide a greater understanding of the real life context into which they fit.

Decision-Making Skills. Brainstorming and consensus decision-making are the two key decision-making skills utilized in the MESP process.

In the past five years, MESP has held two fall community goal setting evenings called "A Piece of the Pie" night. Everyone who comes gets a "piece" of the action and a real "piece" of pie. One community meeting brought out nearly 100 people. Small tables were set up with parent facilitators at each table. At a previous session, all parent facilitators were trained to use brainstorming and clarification skills. One parent had been on Pleasant Valley Primary's ESP team the year before and explained the facilitator training.

The steering committee and three others role played a small group brainstorming session. One person was the facilitator and the others had scripts for different personalities. There was a grump, a whiner, a silent type, a pushy person and an interrupter. It was excellent because it gave me some ideas of how to handle different situations. I was terrified of the idea of being a facilitator. once I saw how it was done, though, it took the edge off. 104 Community night encourages everyone to participate, getting their ideas into the open. Brainstorming is an excellent process for describing and analyzing hidden agendas. It helps people who are champions for an idea to realize that either people agree that their idea is workable or they see that it's down on the priority list. 
Consensus decision-making has been critical in the success of many of MESP's programs. It has proven especially useful before the implementation phase. Talking an idea out and looking at it from all angles has paid big dividends when programs have finally been implemented. "Once you've gnawed and haggled over something long enough it usually surfaces as workable," said one principal.105 "Everyone has a chance to see how it will impact them. Before you implement a program, it's wise to banter it about. In that way, you're not walking down the path with blinders on".106 The principal asserted, "You're going to have disagreements in a group like this. The art of working with controversy is essential, being able to come to consensus out of disagreement. It takes time but the leaders cannot give up no matter how far apart we are. You have to keep it open and let people voice their opinions".107

The district ESP coordinator summarized the decision-making process by saying, "The glue that holds the fabric together is the decision-making process because of the effect it has on a decision". 108

Human Relationship Skills. If there is one thing that has been absolutely consistent at every meeting of every year in MESP, it has been the inclusion of a human development activity. Many times, more than one has been shared. Examples have been 1) What memories do fall leaves bring to mind,2) Tell us something you're especially proud about, 3) Or tell us the craziest thing you ever did as a kid. The list goes on and on. I/D/E/A provides a list of 200 ideas.109 Why waste so much meeting time on human development activities? That seems a logical question. Here are several of the answers: 
It makes us all more human, more tolerant and understanding of each other's feelings. 110

I'm a 'let's get down to business' person and I come across as too assertive. The human development activities help loosen me up. I still think they spend too much time on them, but then that's just me.111

Real friendships grow out of partnerships like MESP. There were many nights when I went to lock up and people would be laughing and talking a half hour after the meeting ended.112

I was on Pleasant Valley Primary's ESP team last year and the teachers are more smiley there. It took me a while to get used to the change from elementary to middle school. The human development activities helped me get acquainted and comfortable with the teachers at PVI. of course, I realize it takes a different kind of personality to work with a seventh grader compared to a kindergartener.113

Sometimes the nature of a discussion can become extremely adversarial because the issue is so sensitive. If you don't take the time to develop high relationships, then often times a meeting can fall into a series of allegations and controversy will arise. So clearly and simply, I see relationship training as an investment -- an investment in good decision making. Good decision-making is an investment in the ultimate quality of the climate that will be exuded.114

Other points brought out during the interviews which are deemed to be relevant are:

1) The Nominal Group Technique is effective for involving shy group members,

2) Make an extra attempt to intermix representative groups when sitting at small tables, therefore, teachers aren't always sitting with teachers, etc. An extremely effective technique to accomplish this also doubles as a human relationship activity. The technique works as follows: Scenario: You have 5 tables, 20 people and it is St. Patrick's Day. Take 5 shamrocks (any shape will suffice) and cut them into four pieces each. Give each person one piece and tell them to find the matching pieces. Each team of four people are table mates for the evening.

3) Some occasions require a teacher to professionally dialogue with parents who have surfaced an unfeasible idea. Parents are many times unaware of the complexities inherent to schools. The principal felt strongly about the need for 
teachers to honestly, yet tactfully, provide that type of guidance.

4) Parents must be discouraged from conceding to ideas of staff simply because they feel their ideas are not of equal merit. All ideas have value.

5) A motto heard at MESP meetings is: What we say, we mean and what we mean, we say. 116

Content. A vital concern of MESP has been to ensure credible decisions and an effective direction for school improvement. Presenting current school effectiveness research to the decision-makers has strengthened the probability that quality decisions have been made. A principal shared this explanation,

As an educational leader, you could go in and tell them that this is what I know so this is what we should do. But that's like dangling puppets on a string and you' 11 meet resistance. Doing so isn't participatory decision-making. The visible benefits of participatory decision-making are really seen during implementation. That attitude of ownership gives an idea momentum. When things go wrong, everyone's willing to solve the problems because it was their idea.117

A concern regarding participatory decision-making is centered around the capacity of parents, patrons, students, and staff to make credible decisions. The ultimate responsibility for the school's success rests with the principal. Many educational leaders lack the confidence that partnerships are capable of establishing an effective direction. The principal who had been involved in MESP for four years asserted,

I have a fundamental belief that they can make good choices. Parents and teachers have a gut feeling about what's right and wrong. A leader can play the research in to verify or clarify direction if they need to get back on track. If you do plant a seed with content, you have to be very careful that they don't see it as your hidden agenda. But if you're directing the action and following the process, it will work.118 
The majority of the school effectiveness research that has been shared with MESP members was in the following areas: attributes of an effective school, 119 brain research, 120 middle school child, early adolescent development, self-esteem literature, 121 and the miscellaneous research that planning team members gathered. During an interview, a parent produced from her MESP file an article she had taken from U.S. News \& World Report regarding decision-making skills students will need for the future.122 A steering committee teacher stated,

In reality, many of the parents were more informed about the current literature because of MESP than some teachers who weren't involved. Those teachers had been focusing on the day-to-day needs of the classroom. It became obvious when MESP was designing the advisor/advisee program. MESP members had a real felt need because we had been studying the literature. Some of the parents were quietly frustrated because they thought all of the staff would jump on board sooner than they did. The parents were put back on their heels a little bit. The leadership team just had to wear the buffer at times. You can't go as fast as you always want. It did work, though, because we spent time going through the process and not leaving out the steps of consensus. We pounded it out until everyone got on board. You've heard the story of the train that keeps going around and around the track past the station until everyone gets on board. That's consensus.123

It was feit that Hersh's fourteen attributes were only indirectly related to the salient issues of a middle school. By having the MESP members study the literature specifically relating to the needs of a transescent child, the planning team finally approached the fundamental question, "Why does Pleasant Valley Intermediate School need to get better?" It is perceived by all participants that the MESP noon hour intramurals program and the advisor/advisee program where a direct result of the awareness regarding the needs of the middle school child. 
The following pieces of research were highlighted in the literature used by MESP.

- Provide opportunities for students to achieve and demonstrate excellence in a number of domains (i.e., the arts, athletics, crafts). Make certain that every student in the school has a reasonable opportunity to excel at something (Intramurals addressed this).

- Provide opportunities for students and teachers to socialize informally, outside the classroom (Intramurals addressed this).

- Create a caring, supportive atmosphere that tolerates and welcomes wide ranges of student diversity. (Advisor/advisee addressed this - each homeroom class is a balanced mix of 5 th- 8 th grade students).

- Institute student advisement programs that assure each student regular, compassionate, and supportive counsel from a concerned adult about his or her academic progress, adjustment to school, and personal adjustments. (Each student at PVI has the same advisor for all four years, twenty minutes a day).124 One administrator summarized it by saying, "The transescent child needs not only the intimacy of the elementary school, but also the diversity of a high school, but for different reasons altogether. It is 
so every kid in school can find a way to be a champion in an environment that is forgiving, supportive, and nurturing."125

The following guest speakers conducted in-service sessions in the Battle Ground School District to which staff and MESP members were invited:

Dr. Roberty Slywester, University of Oregon (Brain Growth)

Or. Joyce Garrett (Classroom Management)

Dr. J. Howard Johnston, University of Cincinnati (Middle School Education)

Dr. Alfred Arth, University of Wyoming (Middle School Education)

Providing quality content to MESP members is perceived to be directly linked to the credible direction the group has pursued.

\section{Data Collection - Years Two Through Five}

Formulating school improvement goals necessitates the collection of pertinent data. Goals should be credible, appropriate, realistic, and attainable. Data collection strengthens the effectiveness of decisionmaking. MESP and the leadership team have collected or analyzed the following information:

- $\quad$ Student performance test scores (California Achievement Test, Metropolitan Achievement Test)

- $\quad$ Student ability test scores (California Academic Aptitude Test)

- Student surveys (Intramural Interest Survey, Career Fair Interest Survey, After School Activities Survey, Assertive Discipline Survey)

- Parent Surveys (Resource Bank Survey, Communications Survey, Assertive Discipline Survey) 
- Teacher Surveys (Vertical File Subject Survey, Resource Bank Survey, Assertive Discipline Survey, Academic Learning Time Survey)

- School Climate Audit - conducted for PVI by Dr. Gary Phillips

- Community "Piece of Pie" input127

- Pyramid Network input

- $\quad$ Student council input

- $\%$ of student participation in extracurricular activities

- Assessment of present practices

- Effectiveness of the communication network

- Willingness of participants to take risks

- Commitment to support

- Remedial program results

- Results of yearly Student Learning Objectives (SLO's)

- \% of mastery on student curriculum profile cards

- Planning team input (meetings, retreats)

- $\quad$ Guest speakers

- Current research literature

- High school follow-up of PVI students (\% on honor roll, \% receiving awards, \% holding offices, \% going on to college)

- District curriculum evaluations

- Discrepancy analys is instruments showing PVI needs assessment, intermediate level comparisons, district comparisons (Phi Delta Kappa Needs Assessment, 1982 (see Figures 9 and 10), and the Self-Study Needs Assessment built around the fourteen attributes of an effective school, 1986 (see Appendices K and L)

- Predicting readiness of PVI to change 
- Forecasting availability of resources

- Staff development needs

- Attendance at parent/teacher conferences

- Workload and energy level of staff, to include teacher attendance

- Informally comparing PVI's programs with the needs of a middle school

- Faculty meeting input

- Pertinent district data

Case Study Inclusion of Self-Study Needs Assessment Instrument and Resulting Data

Rationale: The review of literature for this case study repeatedly surfaced the need to explore long-range planning at the school district level (see Educational Planning in Chapter Two). Bozeman and Schmelzer (1981) have found that educators continue to lag behind business and industry in the area of long-range planning. Goodlad (1983) believes that goals in education are seldom used. He recommended from his research entitled "Study of Schooling" that long-term plans should be expected from each school. Guba and Lincoln (1982) also believe the stake-holding audiences must value the goals, and goal-setting should be a process of mutual influence. However, evidence indicates that few principals engage in goal-setting at all, and when they do it is rare for them to include staff, and rarer yet to engage the general public. The Self-Study Needs Assessment Instrument (see Appendix K) and resulting data analysis (see Appendix $L$ ) are included in this case study report for the following reasons: 
1) It is being used by MESP for the purpose of long-range planning.

2) The process used to collect the data was one of mutual influence involving parents, students and staff.

3) The generated data will be the basis for preparing MESP's five year plan for the school years 1987-1992.

4) The instrument was developed by the Battle Ground School

District around the fourteen attributes of an effective school. This frame work will further ensure credible goalsetting. Administrators reading this case study could utilize the same framework to rein force confidence in the credibility of participatory decision- making.

5) The inclusions offer administrators an example of discrepancy analysis needs assessment.

6) The construction of the self-study instrument included a synthes is of seven discrepancy instruments from around the nation. It was an extremeiy time consuming task. Therefore, administrators could capitalize on this effort and choose to replicate or redesign the instrument for their own use.

7) This case study report describes the process MESP has used and intends to use in analyzing and utilizing the generated data. The "prescriptions" that are generated for PVI as a result of the self-study instrument are not described in this case study report. The precise and relevant focus here is upon the "process" utilized by MESP to produce a new five year plan. The instrument, visual graphs, and 
statistical outcomes are included as part of this case study. It is recommended that this information be reviewed before reading the following description of MESP's process for using the data (see Appendices $K$ and $L$ ).

Design - Years Two Through Five

The design phase of years two through five was basically the same as year one. For this reason, the procedures for goal-setting during those four years will not be described. However, the Battle Ground School District was involved in a mandated self-study during year five. MESP has played a significant part in this self-study. The data that has been generated will be utilized to design MESP's new five year plan. For this reason, the process for utilizing the data is discussed here.

A 115 item self-study instrument was given to every staff and MESP member at Pleasant Valley Intermediate (see Appendix K). A random selection of parents and students were given a reduced self-study instrument. The instrument is centered around the fourteen attributes of an effective school. The Battle Ground School District began, in 1981, to focus its school improvement effort upon implementing the fourteen attributes in all eleven buildings. Utilizing the fourteen attributes as a framework for the needs assessment instrument was deemed appropriate. The instrument was given to MESP members at their October meeting. Results were returned from the district office to each building by mid-january (see Appendix L). Two of the four MESP meetings 
attended during the case study focused on the analysis of the data. At the first meeting, the principal gave an explanation regarding the statistical format used. Planning team members then turned to page three and focused on "Sort by Difference" - ALL. The nine attributes that had the least discrepancy between ideal and actual were analyzed during that meeting. The principal had one primary reason for selecting this focus. She wanted to use a capacity approach to first analyze those areas in which Pleasant Valley was perceived to be doing well. She assigned each of the nine attributes to teams of 2-3 people each. She selected an attribute and modeled for the group. The modeling was to demonstrate how she wanted the visual graphs for each attribute to be interpreted. A number comparison between ideal and actual was to be given for each of the five bar graphs relating to only PVI. Comparisons to other middle schools and the entire school district was given using only the "All" bar graphs. The team was encouraged to brainstorm and share reasons why they thought the attribute was rated the way it was. Self-study instruments were available to help the planning team review the general context under each attribute. Time was given for team analysis. The remainder of the meeting was spent sharing and discussing analysis with the entire group. A design team will use these nine attributes to assist in formulating a two year maintenance of effort plan. The MESP team was asked to review the remaining nine attributes for the next MESP meeting. The same analysis procedure was used with PVI's staff during an in-service day. The second MESP meeting focused on those nine attributes that were perceived by all as having the 
biggest discrepancy between ideal and actual. The same process which was used during the preceding meeting was followed. Specific item analysis information was requested from the district in those nine areas for creating a five year plan. This plan will also have staff input. The principal intends to share the five year plan next fall during the "Community Piece of Pie" meeting. Two goals will be selected from the five year plan and designated as MESP goals for the year. An additional one or two goals will be surfaced through the usual brainstorming procedure at the "Piece of Pie" meeting. In addition to the MESP goals, the staff of PVI will select goals from the five year plan that deal with curriculum or staff development.

The feelings of MESP members towards the self-study have varied from generally negative (i.e., because of the length of the instrument) to generally positive. All of the MESP members were impressed by the graphic and statistical display of the results. One parent commented, "Filling the instrument out was so tedious but now that I've seen the results, I'm realiy intrigued. It's fascinating to compare the different perspectives. I hope we get to fill out another instrument next year - I won't complain!"128

A Revised Vision Statement. MESP was inactive from the fall of 1985 until February of 1986 . The principal recalled that those five months were needed to recuperate from the previous hectic and productive year. Pleasant Valley had successfully implemented the ir substantive advisor/advisee program. The school had also won national recognition the spring of 1985. By February of 1986, twenty-six MESP members were 
eager to resume the process of school improvement. The leadership team felt it was an opportune time to revise the vision statement, created three years earlier. Vivid, happy memories of the retreat convinced them that establishing a group consensus towards a vision would bond the group together and solidify a renewed direction. Two prior preparation meetings were held to provide adequate background information. One meeting was planned to sensitize MESP members to the unique needs of the middle school child. The other meeting was planned to make MESP members aware of students' needs for the future.

Prior to meeting one, MESP members were each given the booklet entitled "An Agenda for Excellence at the Middle Level."129 Each member was invited to read the booklet before the meeting because of a very "special" meeting agenda. The "special" agenda was a perceived success. A teacher presented a model of teaching synectics lesson and correspondingly generated compressed conflicts (i.e., concepts that do not fit well together). Examples could be brightly/lonely or miserably/excited. The group came up with powerfully/helpless. They each wrote a paragraph about the transescent child using the compressed conflict of powerfully/helpless. The following paragraph was one member's interpretation:

The transescent child is powerfully/helpless. His great power of perfect helplessness brings many a strong parent to tears, anger, resignation and retaliation. The child cannot learn the simplest things: how to turn socks right side out, make a bed, take out the garbage or hear the first dozen times a request is made. A child's helplessness can cause parents and teachers to throw up their hands in despair, yet he can learn a tremendous array of songs, baseball stats, and girls'/boys' phone numbers by heart. 
The activity stimulated a productive discussion of the middle school child's needs.

To provide the planning team with adequate background information, a guest speaker from ESD \#112 was invited to speak to the MESP group at their second meeting. The guest speaker had recently been named Time Magazine Teacher of the Year. The speaker's talk focused on the five C's of future education-those skills that students would need to be successful in life. They are: Communication, Critical Thinking, Cultural Awareness, Creativity, and Coping Life Skills.

The two preparation meetings had provided the newly regrouped MESP with a common body of information from which they created their new motto and vision statement, shown in Figure 13.

Motto: In a spirit of cooperation, Pleasant Valley Intermediate will involve the parents, educators, and patrons in developing the highest possible educationa) standards.

Vision: Through this spirit:

The student will become well-balanced through the pursuit of excellence in the areas of intellectual stimulation, interpersonal communication and acceptance, creative expression, and wellness.

The student will be helped to explore his potential as a positive, productive contributor in our worldwide, technologically inter-dependent society.

The student will have become self-directed, organized and responsible; he will have applied those traits to practicing the basic skills needed to continue to learn, anticipate change, think critically and generate solutions.

Figure 13. Pleasant Valley Intermediate's revised vision of excellence statement. 
The vision statement has been calligraphied, framed and posted as a reminder of Pleasant Valley's "Quest for the Best."130

Implementation - Years Two Through Five

Several quality programs have been implemented over the past five years directly as a result of MESP. This section will highlight MESP's accomplishments. In that regard, this portion of the case study will provide a clearer understanding of:

1) What kind of projects have been feasible,

2) how many projects have been possible, and

3) what school arenas have been impacted.

$1982-83$.

Small, easily attainable projects were implemented during this year. (See Implementation, Year One.) Stressing process over product enabled the team to build relationships, develop decision-making skills, and generate a common background of school effectiveness information. 1983-84.

- Assertive Discipline Program. An assertive discipline program was already in place at Pleasant Valley Intermediate. An MESP task force conducted a formal evaluation of the program in the spring of 1983. Survey results indicated a desire by respondents to continue the program but with some refinement necessary. The task force assembled a comprehensive list of forty nine suggestions of positive consequences to be used for the assertive discipline program. Examples are: 
1) bumping privileges (sit where you want),

2) raise one grade (daily assignment),

3) rent slips to buy free time, media center time, or recess time.

Input was generated from pyramid groups, parents, students, staff, a guest speaker, an assertive discipline workshop, and assertive discipline literature,. The list was published in the teachers' handbook. 131

- Rewards and Incentives. This task force established a three level award system for academic achievement. These levels are: Honors 3.0-3.49; High Honors 3.5-3.99; Highest Honors 4.0. Citizens of the Month Awards for each grade level was a recommendation by the task force.132 A colorful brochure was also published to recognize eight staff members who had received "Apple" awards for professional service.

- Self-Esteem. There was a perceived need for more counselors at Pleasant Valley Intermediate. Because of fiscal realities, those counselors could not be added. In an effort to solve the problem, the MESP task force pursued the possibility of implementing an advisor/advisee program. The year was spent in data collection.

- Improved Communication. This task force published a monthly calendar that included dates of school activities and dates that major assignments were due.134 In addition, the task force revised the fifth grade orientation program. They also published a twenty-four page booklet with pictures and biographical sketches of the staff. "Patriot 
Profiles" was developed to acquaint the school community with PVI's

professional staff. 135

- Noon-hour Intramural Program. This noon-hour program featured classroom competition in group and individual sports and mental games, (i.e., three days a week). Traveling trophies were awarded for sportsmanship, participation, and tournament success. Student leadership was developed into the program. Students served on the advisory board, served as scorekeepers and referees, and managed equipment. The successful program has been adopted district-wide with some format changes.

$\underline{1984-85}$.

The advisor/advisee program was MESP's most substantive project. One entire year was spent in comprehensive data collection and design. The program was implemented during the 1984-85 school year. The program has undergone three years of formative evaluation. A three year summative evaluation will take place in the spring of 1987 . The program was highlighted in the national recognition summary as being a significant contributor to the overall success of PVI. The advisor/advisee homerooms meet twenty minutes daily. There is a balanced mix of students grades 5-8 in each homeroom. Each student stays with his/her advisor for four years. The advisor/advisee program objectives are as follows:

1. To assist students in understanding and utilizing personality traits: identifying and solving their problems which hinder self-development. 
2. To help the student to recognize his/her aspirations in relation to his/her abilities, aptitudes, interests, and career planning.

3. To assist the student who needs help in developing a more positive self-concept, resolving conflicts, developing values, problem solving, decision-making, and setting short term goals in relation to school work.

4. To assist the student in identifying hobbies, social abilities, and occupational interests.

5. To help students become self-directed individuals.

6. To review the academic and social progress of each student.

7. To assist in the development of social skills for understanding and relating to others.

8. To help students realize their community responsibility.

As has been previously suggested, the advisor/advisee program was

one of MESP's most successful, substantive projects. Correspondingly, it was the most difficult to implement primarily for the following reasons:

1) Few advisee/advisor programs were in place to model;

2) The felt need was stronger by MESP members than uninvolved staff;

3) The program impacted academic learning time;

4) New teacher behaviors were required (i.e. assuming an advisory role, being responsible to student needs grades 5-8, guiding career awareness, increased work load, etc.);

5) District support and fiscal resources were needed, resulting in a revised district proposal;

6) Parental awareness and support was a pre-requisite. Resistance to the program by fundamentalist Christians in the school community became a reality.

7) Student awareness was necessary;

8) Formulating a comprehensive plan was extremely time consuming; 
9) An Advisory Coordinator was needed to attend to logistical concerns;

10) An Advisory Board was established to oversee the program;

11) Staff in-service training was required;

12) Evaluation criteria needed to be established.

MESP members collectively felt the implementation phase was

successful for the following reasons:

1) Self-esteem literature was provided to all staff to impact felt need;

2) A Practitioner's Grant was written and received which allowed five MESP members to design the program during a three day retreat. The workshop director was a coordinator of an established advisory program;

3) Approximately $90 \%$ of the staff spent a day visiting model advisory programs in four different districts;

4) A philosophy statement was cooperatively created;

5) A survey was developed to solicit teacher reaction to the advisory concept;

6) Appropriate time was allotted to gain total consensus and support from all staff;

7) Staff was encouraged to risk and learn from mistakes;

8) Formative evaluation was enhanced by establishing an eighteen $\underline{1985-86}$. member student advisory board and a staff advisory board.

No new MESP programs were implemented during the 1985-86 school

year. MESP was inactive for five months because of reasons previously explained in this case study report. 
$\underline{1986-87}$.

Three MESP projects are currently being implemented. They are at different stages of development and, therefore, will only be briefly described:

- Career Fair. The Career Fair has previously been a PTA project. MESP and PTA are jointly expanding the project. The Career Fair is an exploratory program for 7 th and 8 th grade students. The program is intended to increase student awareness and understanding of a variety of career clusters. 138

- Community Resource Bank. The computerized bank stores information on people in the community who would be willing to share their areas of expertise with students in various ways. The bank can be drawn upon by teachers who would like help from people outside the classroom to enrich their students' learning experience in specific areas. 139

- Vertical file Folders. Vertical files will provide an additional source of information for students doing research on various topics studied in the classroom. Task force members will collect information from a variety of media such as newspapers, magazines, and video taped programs. The files will be housed in the media center. 140

\section{Evaluation - Years Two Through Five}

Evaluation has been an important, on-going component in MESP's school improvement process. Upon completion of their vision statement five years ago, intended outcomes of the vision were written for students, staff, parents, and community (see Design - Year One). These intended outcomes have successfully served as both a monitoring and 
evaluation tool over the past five years. Specific activities initiated to accomplish the outcomes have been analyzed by MESP to determine what is different and why. Outcomes were written for students, staff, parents, and community because MESP members believe that any change should enhance and contribute to the life of everyone in the school community. Evaluation results have not always been black and white. Most MESP programs have yielded more qualitative than quantitative indicators of success. Staff morale has improved, the climate for learning has been enhanced, and students feel generally more positive about PVI. Subjective measures have been a more valid evaluation method for MESP than relying on quantifiable and empirical data. Correlational links between program effectiveness and measurable results can be attributed to MESP programs but cannot be proven as causal. For instance, MESP members believe that their rewards and incentives program has had a positive impact upon honor roll percentages, and that the noon hour intramurals have increased student attendance. It is believed that the staff recognition program has contributed to teacher job satisfaction, and so forth. These claims are less than scientific. However, MESP members believe their programs have an accumulative, positive impact on student achievement.

The most important evaluation for MESP members, however, has been their own evaluation of the MESP process. If the process remains in place, it is believed that the school improvement effort will be unending. All participants interviewed evaluated the process as being extremely successful. One principal commented, "If there is enough 
enthusiasm for continuing the process without spending a disproportionate amount of time maintaining it, if participants are seeing things accomplished, and good things are happening for kids, then the process is a success."141

\section{Celebration - Years Two Through Five}

A principal spoke about celebration in this way: Children need praise and so do adults. As a leader, you find successful things and you key in on them. When you recognize people's sacrifices, you foster future motivation and commitment."142

The MESP leadership team has included celebration not only on a regular, routine basis but also annually in a formal way. Certificates of Appreciation have been given annually. Yearly accomplishments have also been shared with the public through newspaper articles. MESP published and distributed a fifteen page spiral booklet entitle "Success Stories." Within the booklet were printed the vision statement, intended outcomes, the five year plan, the yearly targets, the target actions, and indicators of success. 143

MESP members were also directly involved in writing the national recognition application document. Naturally, winning state and national recognition was an opportune time to celebrate. It isn't every year that the principal is presented with a plaque from the President of the United States on the White House lawn, followed by a handshake from the Secretary of Education! 
Celebration has been effective?y used as a tool in MESP to strengthen the success of the participatory process.

\section{RETROSPECT - YEARS TWO THROUGH FIVE}

The following section is a collation of reflections from participants who were interviewed for this case study. This potpourri of retrospective information is intended to provide the reader with advice and precautions judged to be important to share. These synthesized perspectives are meant to add to the knowledge base regarding participatory processes.

- $\quad$ Adopting the decentralized process district wide generated a collegial base of support and encouragement. The shared experience facilitated the willingness to take risks.

- The superintendent advised that those districts who are contemplating the adoption of a participatory process should seek out guidance from districts currently utilizing the model. "I wish we would have had that opportunity five years ago but the information just wasn't there."144

- The superintendent further advised such districts to use the Japanese model - plan, plan, plan, and then implement.

- The two principals involved at PVI have needed to determine when to make decisions in an autocratic way and when to involve others in the participatory process. They have found the choice to be situational. Efficiency, effectiveness, and organizational 
health are all considerations that impact the way decisions have been made.

- Middle school students have been more effective partners than it was originally thought. It is felt that including students in original training sessions would be beneficial.

- The district coordinator of ESP also perceived PVI's pyramid network to be functioning less well than intended. The pyramid network has been difficult to establish at all eleven sites. The more formalized the pyramiding procedures, the more effective the network has operated.

- Experience has determined that it is wiser to begin with projects of a narrower scope and gradually progress to more substantive goals. It is believed that issues dealing with the organizational structure are more appropriate early in the process. Issues dealing with curriculum or instruction could be attempted in subsequent years. MESP's first goal was revising the assertive discipline program. It was an issue that dealt with the organization as a whole. Two years into the process, the more substantive advisor/advisee program impacted curricular arenas. - Decreasing the number of goals to be implemented each year has increased the managability and success of the process. "Otherwise, you see a lot of little sparkles without hearing the big bang!"145 - $\quad$ Steering committee members found that some MESP groups had relied on the leadership team to facilitate task forces. This overburdened the effectiveness of the leaders. When group members 
were tactfully invited to take on leadership roles, the process improved. The steering committee has seen several group members begin to self-actualize and gain personal satisfaction from their new leadership roles.

- A student felt strongly about the following piece of advice: Give students who are on MESP substantial responsibility. Have the students take the leadership for some tasks but have adults guide them.

- Parents have tended to be more ambitious than staff, especially new parents joining MESP. They see the projects as directly affecting their own children. Both principals who have been asSociated with MESP have had to balance those good intentions with the reality of schools. If teachers are overburdened, it has been feared that the process may not be successfully in place in five years. Dedicated teachers cannot be expected to overload their resources. Keeping a core group of parents on the MESP committee to share the realities of school to new parents has addressed this concern.

- The leadership team believes that the open access of MESP has served as a major vehicle for redirecting negative energies into more positive channels. The following MESP parent comment and steering committee member comment explain this more vividly. Parent: I'm a very outspoken person and I had been in the principal's office several times, pounding on his desk. He recruited me for MESP. He probably thought "this lady has so much to say, let's put her to work!'146 
Steering Committee Member: MESP is very time consuming for a principal. But it all boils down to this: What would you rather do? Meet once a month with MESP, improving the school with a strong base of support, or meet in your office with an angry parent because things aren't getting done?147

- One district administrator's perspective dealt with the issue of burnout.

Because the ESP process is an ongoing, long, and arduous process, ESP groups and individuals within those groups need to be given real freedom to back off and rest. Encouraging individuals to continue their input through the pyramid network as an alternative becomes mutually beneficial.

\section{PERCEPTION CHECK}

Responses to four questions have been displayed to share perspectives from five (5) different actors (superintendent, principal, parent, teacher, and student). A flavor of commonalities and differences can hopefully be realized by comparing these snapshop points of view. The four questions are:

1. What is the "Effective Schools Process"?

2. How has the "Effective Schools Process" benefitted you?

3. What is one frustration you've experienced with the "Effective Schools Process"?

4. What could make the "Effective Schools Process" at Pleasant Valley Intermediate more effective?

\section{What is the "Effective Schools Process"?}

Superintendent. ESP is a copulation of a whole number of programs that have been pursued to make the school district a more liveable place for students and employees, and to create a more positive climate for learning. 148

Principal. MESP is a process where parents, community, students, building staff, and principal work together to make the educational process in a school more effective for kids.149 
Teacher. MESP is a process to get the people in a school community involved in improving schools, making their school the best it can be. 151

Student. MESP is a program to make our school better. It's giving input to a question, everyone gets to say something, and no one puts down your idea. 152

How has the "Effective Schools Process" benefitted you?

Superintendent. Although it is easier to maintain a mediocre schoot district, being on the cutting edge of education is more rewarding. It's like the lead dog theory on a husky sled team. The view from the front is much better than the view from the back of the pack!153

Principal. Before using the "Effective Schools Process", there never seemed to be a common agenda. There were pressures coming from different directions -- parents, teachers and central office. The structure has helped to create some common agendas. 154

Parent. Being a part of MESP has allowed me to give something back to the community. When you live somewhere, you should give and the most likely place for me to give was through the school.155

Teacher. I've gained so much by being on the steering committee. I've experienced a tremendous amount of personal growth by leading groups, presenting at conferences, stretching myself to take risks -that doesn't happen in the classroom.156

Student. I'm glad I have a chance to tell what the other kids want. I'm helping to make the school as good as it can be so my friends can get a good education.157

What is one frustration you have experienced with the "Effective Schools Process"?

Superintendent. In our decentralized district, there is a lot of change going on -- sometimes too much. The principals get involved with all of it. They become extremely tired at times.158

Principal. When you involve people to get the job done, you spend many sleepless nights fretting if it's going to happen. There are a lot of things you do behind the scenes to keep the ball rolling, but that's the price you pay. 159

Parent. When new parents come on the planning team, they don't always know what's gone on before they joined. It really slows the process down. It reminds me of a neighborhood homeowner's association I 
belonged to. New people kept moving in and we'd rehash the same things. I finally just quit! 160

Teacher. Some parents on MESP, who had been involved on the primary school planning team, wanted to set up hands on learning centers in the hallways. That idea works well at the elementary level but we didn't see how it was feasible for us. We finally settled on creating Vertical files that the teachers would really use.161

Student. It's really touchy when I have to bring up a complaint about a teacher. Once the teacher was a good friend so I just tried to make it funny. I told him the kids thought he gave too hard of tests. 162

What could make MESP more effective at Pleasant Valley Intermediate School?

Superintendent. We need to provide another intensive training session for all of the buildings. That would really help to institutionalize the process. Many of the people who are involved now were not here for the training five years ago.163

Principal. We've had problems keeping patrons involved. The Senior Citizen's Center is a resource we haven't really pursued as much as we could. That would help us pass levies.164

Parent. Setting aside time during the meetings to share about the pyramid groups is important, I think. We could be more consistent about that. We're also not having refreshments at the meetings this year. That should be done. 165

Teacher. I'm new on MESP this year and I didn't help create the vision statement last spring. It's pretty fuzzy, foggy to me. Maybe clarifying the sentences by giving examples would help. 166

Student. I think we should have more than one meeting a month, and we should get someone to help the principal with all the paperwork. She's really got a lot to do!167

\section{INDICATORS OF SUCCESS}

1. Statistics were available for 1985 in the areas of attendance and suspensions with comparisons made to 1982 statistics:

Daily student attendance $95 \%$ (up from $94 \%$ )

Daily teacher attendance $96.5 \%$ (same)

Suspensions (in-school) $4 \%$ (down from 10\%) 
Suspensions (out-of-school) $1 \%$ (down from $5 \%$ )

2. Test Scores (see Table II): Statistics were available for comparison purposes from the years $1982,1983,1984$. In 1985, the district discontinued administering the Cal ifornia Achievement Test (CAT) and began administering the Metropolitan Achievement Test (MAT). A change was also made regarding the grade levels selected for testing. For these reasons, comparisons could not be made between 1982 and 1986 test scores. The following statistics compare the fifth grade scores of 1982 with the seventh grade scores of 1984. In this way, essentially the same student population is represented. Average growth in mean percentile was 26 percentile points. In the strongest area, language mechanics, a growth of 41 percentile points was shown on the nationally normed test. Even in the weakest area, language expression, an increase of 13 percentile points are shown. 
TABLE II

\section{MEAN OF NORMAL CURVE EQUIVALENT SCORES FOR PLEASANT VALLEY INTERMEDIATE BY SUBTEST WITH OISTRICT AVERAGE}

\begin{tabular}{|c|c|c|c|c|c|c|c|c|c|c|c|}
\hline $\begin{array}{l}\text { PVI } \\
7 \text { th } \\
\end{array}$ & $\begin{array}{l}\text { READ } \\
\text { VOC. }\end{array}$ & $\begin{array}{l}\text { READ } \\
\text { COMP }\end{array}$ & $\begin{array}{l}\text { READ } \\
\text { TOTAL }\end{array}$ & $\begin{array}{l}\text { SPELL- } \\
\text { ING }\end{array}$ & $\begin{array}{l}\text { LANG } \\
\text { MECH }\end{array}$ & $\begin{array}{l}\text { LANG } \\
\text { EXPR }\end{array}$ & $\begin{array}{l}\text { LANG } \\
\text { TOTAL }\end{array}$ & $\begin{array}{l}\text { MATH } \\
\text { COMP }\end{array}$ & $\begin{array}{l}\text { MATH } \\
\text { C.AP }\end{array}$ & $\begin{array}{l}\text { MATH } \\
\text { TOTAL }\end{array}$ & $\begin{array}{l}\text { BATTER } \\
\text { TOTAL }\end{array}$ \\
\hline $\begin{array}{l}1982 \\
1983 \\
1984\end{array}$ & $\begin{array}{l}62 \\
59 \\
74\end{array}$ & $\begin{array}{l}63 \\
59 \\
72\end{array}$ & $\begin{array}{l}64 \\
60 \\
76\end{array}$ & $\begin{array}{l}62 \\
64 \\
75\end{array}$ & $\begin{array}{l}69 \\
68 \\
93\end{array}$ & $\begin{array}{l}62 \\
61 \\
69\end{array}$ & $\begin{array}{l}66 \\
65 \\
79\end{array}$ & $\begin{array}{r}57 \\
53 \\
77\end{array}$ & $\begin{array}{l}61 \\
59 \\
76\end{array}$ & $\begin{array}{l}60 \\
56 \\
77\end{array}$ & $\begin{array}{l}63 \\
60 \\
79\end{array}$ \\
\hline
\end{tabular}

$\underline{5 t h}$

$\begin{array}{llllllllllll}1982 & 56 & 57 & 57 & 57 & 52 & 56 & 56 & 48 & 49 & 48 & 53\end{array}$

$\begin{array}{llllllllllll}1983 & 58 & 59 & 59 & 57 & 59 & 63 & 62 & 57 & 53 & 55 & 58\end{array}$

1984 Not available - tests were not given to 5 th graders in 1984 .

3. Dr. Gary Phillips conducted a climate audit in 1984. The student survey results found $85 \%$ made positive statements regarding their feelings of acceptance at PVI.

4. The MESP intramural program was perceived as a success and was adopted district wide with some format changes.

5. Of the 25 voting precincts in the Battle Ground School District during the 1984 levy election, the four precincts with the highest percentage of positive votes were in the Pleasant Valley Service area. The highest precinct gave 100 percent positive vote. The district average is 61 percent.

6. Students randomly selected perceived the advisor/advisee program as a success. Comments made by a sixth grader and an eighth grader clarify their evaluation: 
Sixth Grader: When we have discussions during advisory time, the eighth graders really understand because they've been through the same things. 168

Eighth Grader: We have study hall once a week in advisory. The older kids help out the younger kids. Their math is fun. 169

7. The Washington State Legislature is providing funding to encourage schools to implement self-esteen programs. Pleasant Valley Intermediate's advisory program was listed in a recent newspaper article as being an exemplary program in the state to be used as a model.

8. The remainder of this section will describe indicators of success relative to the MESP process, rather than its products.

a. The superintendent believes that the emergence of teachers as leaders has been the most successful spin-off of the ESP process. No other avenues were available for professional leadership except through union activity.

b. Several members who are currently active on high school ESP groups were formerly members of MESP.

c. Parents had tried to initiate a self-esteem program through PTA, with little success. MESP has implemented the advisor/advisee program which is a direct result of MESP parent persuasion to increase student self-esteem.

d. The Lay Advisory Council was dismantled because ESP was perceived as being a more effective vehicle for school improvement. 
e. Staff, steering committee members, and both principals have been invited to speak at several conferences on the MESP process. They include:

- Coalition of Oregon School Administrators (COSA)

- Washington State Association of Supervision and Curriculum Directors (WASCD)

- Edmonds School District - Middle School Principal's Meeting

- Summer I/D/E/A Conference

- St. Helen's Middle/Junior High Principal Region (Advisory program presentation)

- Department of Education, State of Indiana (Training - ESP mode 1)

- School Improvement Project, State of Indiana (Training - ESP model)

\section{INDICATORS OF SUCCESS - NATIONAL RECOGNITION DOCUAENTATION}

Harriet Adair, principal of Martin Luther King, Jr. E.C.E.C. in Portland, Oregon served as a site visitor for the national recognition selection committee in 1985. She spent two days on site at Pleasant Valley Intermediate to interview the school community and gather documentation. Her final summary report, submitted to the selection committee, contained the following 5 pages of excerpts directly relating to MESP: 


\section{The Principal}

The principal stated they were beginning to meet to rejuvenate their Effective School's plan. This was in his words, 'a massive effort.'

Mr. Walden believes the process the school implemented when they initiated the Effective Schools thrust would sustain their current level of progress and would suffice as a method for problem solving. 'The process is good and we will rejuvenate and re-evaluate our three to five year blueprint to reaffirm the outcomes for students, staff and parents. This will enable us to reaffirm our vision statements. Within the next two years, we will start redeveloping relationships, recycle the process we have used thus far and develop a new three to five year blueprint.'

The principal plans to realize his vision through the staff development program currently in place and undergoing revision, as well as through the revitalized MESP process and through 'seed planting in the MESP committees.'

\section{The Superintendent}

The thing I am proudest of is the input and the support of the parents and the community. There were approximately 200 people present at the meeting to set goals for the school. If I had to identify one school that had more parental involvement than any other, it would be Pleasant Valley Intermediate.

The comment the Superintendent made which impressed me most as a powerful testimony for the success of Pleasant Valley's program was:

I haven't had a parent call with a complaint from this school in almost two years. 
The Students

Pleasant Valley Intermediate School students are proud of their school. They enjoy coming to their school. They feel their school is one of the best in the district. When asked to describe their school, their words were:

$$
\begin{array}{ll}
\text { - } & \text { Improving } \\
\text { - } & \text { Great } \\
\text { - } & \text { Nice } \\
\text { - } & \text { Awesome } \\
\text { - } & \text { Preasant } \\
& \text { Friendly }
\end{array}
$$

When asked what was their school's strongest quality, they responded "The Advisory Program". They felt the Advisory Program was a good way to get to meet other students in the school from all grade levels and it gave them an opportunity to discuss issues that were of concern to them.

Other qualities they emphasized were the MESP Committee which allowed them to have input into the school's policies, the intramural program and the diversity of the things available for them to do.

The students expressed feelings of acceptance, recognition and respect. They said they felt teachers admired and respected them as people. One student said, "People would listen now. Two years ago, someone would say, they're kids, don't listen, but now people will listen to us when we talk. They're interested in our opinions." 


\section{The Teachers}

The teachers' perceptions of the current state of the school is that the efforts of the last three years were beginning to pay off. The teachers commented that the Central office support over the years had been beneficial. They felt the Effective Schools thrust started by the Central office in 1981 had helped them focus their goals and had resulted in a program of which they were proud and in which they felt a sense of ownership.

When the teachers were asked why they felt Pleasant Valley was a good school, they responded by saying they felt the different prograns they had initiated, the teamwork exhibited throughout the staff, and their willingness and ability to accept change were the keys to their success. They stated that there was a tremendous amount of teamwork with parents and teachers that hadn't been present when the school first opened. Since the inception of the Effective Schools Program three years ago, however, there had been high levels of achievement for students, larger numbers of parents involyed in the program and all teachers were generally committed to working together to make things work. One of the teachers stated the key to their achieving success was that "We've had a plan for the last three years and we have had the ability to keep that plan going".

Teachers said several times they played meaningful roles in planning and decision-making. The More Effective School Program Committee they had established allowed them access to decisions. They 
humorously stated that sometimes they had too many opportunities to give input.

Examples of collaborative decision-making included the building's MESP Team, the Collegial Teams and the Curriculum Level Teams. These committees, they stated, were their formal avenues for input, feedback and peer support.

\section{The Parents/Community}

The parents were proud of their school. They felt it was a great place to be. They noted that three years ago there was a problem in communication with the school. They didn't feel quite as welcome as they currently do. In the past, if they had questions, the explanations received didn't always ring quite true. They now felt the school was far more open, honest and receptive to their questions, and the staff didn't feel quite as threatened by their presence. This change was due, they felt, to the Effective Schools Program.

"It gave us an avenue to express our views. It channeled all of the energy that was out there into positive avenues."

The parents were enthusiastic about the Effective Schools Program and noted that they had

"seen a real change in the principal in four (4) years. [He] has grown a lot."

The group also felt the Advisory class and the discipline philosophy of the school were teaching their children how to adapt and react to people, how to accept criticism, that there are rules and what happens if he/she follows or doesn't follow the rules. 
"It gave us an avenue to express our views. It channeled all of the energy that was out there into positive avenues."

The parents were enthusiastic about the Effective Schools Program and noted that they had

"seen a real change in the principal in four (4) years. [He] has grown a lot."

The group also felt the Advisory class and the discipline philosophy of the school were teaching their children how to adapt and react to people, how to accept criticism, that there are rules and what happens if he/she follows or doesn't follow the rules.

"With the Effective Schools Program, students now have access to the decision-making process. This access before was only available through the student government. The students are learning consensus building." "I'm getting good feedback from my student at home about being involved in making decisions that affect the school. She expresses a real pride in the program at home."170

\section{SUMMARY}

This descriptive case study provided a real-life context from which was surfaced a knowledge base and skills deemed essential for effectively implementing and institutionalizing a decentralized participatory process. The narrative text gives practitioners a fuller understanding of why the knowledge base and skills are considered to be important. The "Effective Schools Process" was a district wide innovation. To present a clearer description of Pleasant Valley Intermediate School's MESP, the case study began with a district focus. 
The original training was perceived to have positively impacted MESP's success. Therefore, important components of the training have been included. The case study format distinguishes between year one and years two through five for one significant reason. Year one focused primarily on process over product, while years two through five balanced product and process more proportionately. A retrospect section shared information which could not be placed within the established framework of recruitment, planning, training, data collection, design, implementation, evaluation, and celebration. Perspectives were displayed to differentiate the views of the main participants. Indicators of success verified MESP's perceived success. Excerpts from the national recognition summary verified an external perception of MESP's success. This case study presents a participatory paradigm that practitioners could choose to replicate or redesign. Chapter $V$ highlights the conclusion and recommendations from this study. 


\section{CHAPTER $V$}

\section{CONCLUSIONS, OBSERVATIONS, AND RECOMMENDATIONS}

To effectively and substantively impact the realization of school improvement goals, there is a perceived need for the implementation of participatory structures and processes that involve parents, patrons, students, and educators through decentralization of the planning, programming, and implementation phases.

Related to this need is the pressing requirement of providing educational leaders with a greater understanding of what knowledge and skills they should possess to effectively guide and direct the implementation of decentralized participatory structures and processes. This exploratory case study has described an existing successful decentralized participatory structure. The data base which has been generated from this study has galvanized the knowledge base and skills which are deemed important for patricipatory leaders to possess to successfully implement a decentralized partnership. The case study context has shown why certain skills and knowledge are considered essential, and has presented a situation which could be modeled.

Seven overarching questions were formulated to guide the inquiry of the case study. They are as follows:

1. What skills must a participatory leader possess to effectively implement a decentralized participatory structure?

2. What knowledge base must a participatory leader possess to effectively implement a decentralized participatory structure?

3. What do we need to know about the characteristics of decentralized program operations? 
4. What has to occur for successful decentralization to take place?

5. Why do educators practice decentralization?

6. How do the objectives of a specific program influence the decision to decentralize and what is actually done?

7. How can the situation be modeled?

The first two questions address the research problem and will therefore be discussed in the conclusions section. The last five questions relate to additional aspects, characteristics, and dimensions of decentralized participatory structures and processes. Throughout the case study, specific components were amplified which were perceived or observed to have had an impact on the success of Pleasant Valley Intermediate's decentralized planning team. These important learnings are shared in the observations section.

The final section of Chapter $V$ suggests recommendations and implications for further research.

\section{CONCLUSIONS}

What Knowledge Base Should A Participatory Leader Possess To Effectively Implement A Decentralized Participatory Structure?

The Frequency Distribution Chart in Figure 14 was used to determine the rank order of the knowledge base displayed in Table III. The X's on the Frequency Distribution Chart represent the number of interviews which surfaced each knowledge base and skills item. The total number of face-to-face interviews which surfaced each item was compared to the total number of face-to-face interviews conducted. Percentages and rank ordering were then determined. 
몸

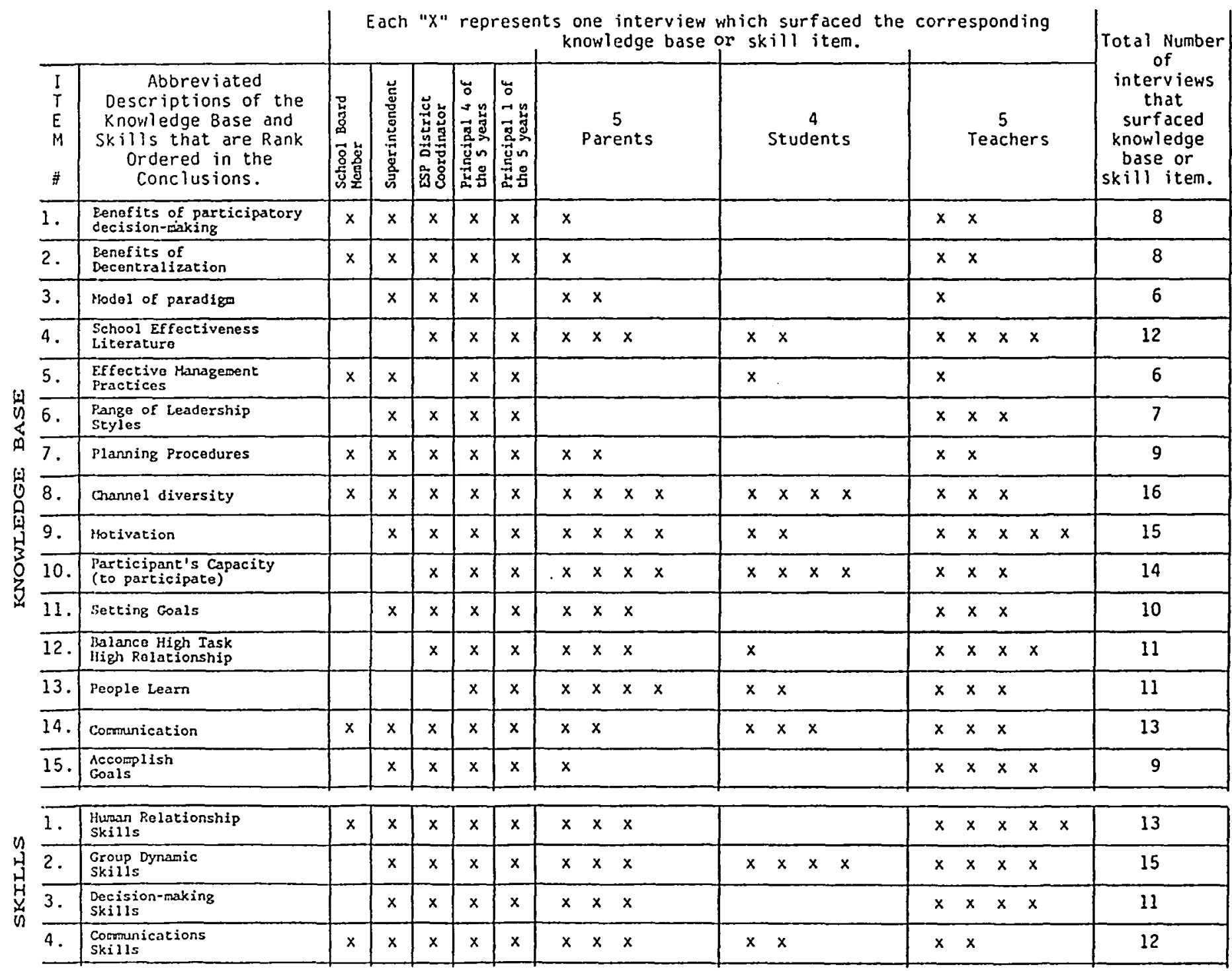


TÁbLE III İ

RANK ORDER OF KNOWLEDGE BASE

\begin{tabular}{|c|c|c|}
\hline Percentages & & Knowledge Base \\
\hline $84 \%$ & 1. & $\begin{array}{l}\text { A participatory leader must possess knowledge of how } \\
\text { to positively channel diversity. }\end{array}$ \\
\hline $79 \%$ & 2. & $\begin{array}{l}\text { A participatory leader must possess knowledge of } \\
\text { motivation theory and ways to capitalize upon } \\
\text { motivation theory. }\end{array}$ \\
\hline $74 \%$ & 3. & $\begin{array}{l}\text { A participatory leader must possess knowledge of } \\
\text { ways to develop participants' capacity to } \\
\text { participate effectively. }\end{array}$ \\
\hline $68 \%$ & 4. & $\begin{array}{l}\text { A participatory leader must possess knowledge of how } \\
\text { to effectively facilitate the communication and } \\
\text { coordination between and among identifiable groups } \\
\text { which interlace with the participatory process. }\end{array}$ \\
\hline $63 \%$ & & $\begin{array}{l}\text { A participatory leader must possess a knowledge of } \\
\text { the school effectiveness literature. }\end{array}$ \\
\hline $58 \%$ & 6. & $\begin{array}{l}\text { A participatory leader must possess knowledge of how } \\
\text { to balance high task and high relationship. }\end{array}$ \\
\hline $58 \%$ & 7. & $\begin{array}{l}\text { A participatory leader must possess knowledge of how } \\
\text { people learn most effectively. }\end{array}$ \\
\hline $53 \%$ & 8. & $\begin{array}{l}\text { A participatory leader must possess knowledge of } \\
\text { goal theory and ways to set goals through other } \\
\text { people. }\end{array}$ \\
\hline $47 \%$ & 9. & $\begin{array}{l}\text { A participatory leader must possess knowledge of } \\
\text { effective planning procedures. }\end{array}$ \\
\hline $47 \%$ & 10 & $\begin{array}{l}\text { A participatory leader must possess knowledge of } \\
\text { change strategy and how to effectively accomplish } \\
\text { goals through other people. }\end{array}$ \\
\hline $42 \%$ & 11. & $\begin{array}{l}\text { A participatory leader must possess knowledge of the } \\
\text { benefits of participatory decision-making. }\end{array}$ \\
\hline $42 \%$ & 12 & $\begin{array}{l}\text { A participatory leader must possess knowledge of the } \\
\text { benefits of decentralization. }\end{array}$ \\
\hline $37 \%$ & 13. & $\begin{array}{l}\text { A participatory leader must possess knowledge of a } \\
\text { range of leadership styles. }\end{array}$ \\
\hline $32 \%$ & 14. & $\begin{array}{l}\text { A participatory leader must possess knowledge of } \\
\text { effective management practices. }\end{array}$ \\
\hline $32 \%$ & 15. & $\begin{array}{l}\text { A participatory leader must possess knowledge of how } \\
\text { to model a decentralized participatory structure. }\end{array}$ \\
\hline
\end{tabular}


The following section expands upon the conclusions that relate to the knowledge base. An explanation is provided to explain why such knowledge is considered essential.

A participatory leader must possess knowledge of how to positively channel diversity. Of the face-to-face interviews, $84 \%$ surfaced the importance of this knowledge base. A participatory leader must understand that diversity is inherent in a decentralized participatory structure. A blending of different perspectives produces the creative solutions needed to revise and revitalize the schools. Although diversity of opinion can be a source for powerful innovation, it has the potential to create an adversarial climate. An effective leader must know how to negotiate diverse perspectives into a shared common direction.

A participatory leader must possess knowledge of motivation theory and ways to capitalize on motivation theory. Of the face-to-face interviews, $79 \%$ surfaced the importance of this knowledge base. A participatory leader must understand the makeup of people - their needs, their drives, their values, and their perceptions of satisfiers and dissatisfiers. The concept of decentralized participatory decision-making is dependent upon empowering people to change the school. An effective leader must know ways to initiate involvement and ensure commitment by capitalizing on the inherent need of people to be self-motivated and self-controlled.

A participatory leader must possess knowledge of ways to develop participants' capacity to participate effectively. Of the face-to-face 
interviews, $74 \%$ surfaced the importance of this knowledge base. A participatory leader must ensure that each diverse partner in a decentralized participatory process has appropriate input. The strength of the partnership stems from combining diverse perspectives to solve educational problems. A leader must find ways to balance partner input, and create power equalization among parents, students, teachers, and patrons. An effective leader must be capable of utilizing human relationship skills, decision-making skills (i.e., brainstorming and consensus), and group dynamic techniques to develop the partners' capacity to effectively participate.

A participatory leader must possess knowledge of how to effectively facilitate the communication and coordination between and among identifiable groups which interlace with the participatory process. Of the face-to-face interviews, $68 \%$ surfaced the importance of this knowledge base. A participatory leader must realize that $\mathrm{plans}$ and programs initiated from a decentralized participatory process have implications for people who are not directly involved with the planning team. A leader must effectively communicate among and between those people who are impacted by decisions. In addition, the leader must coordinate with central office to ensure district support and an appropriate balance between building and district goals. An effective leader must be cognizant of the many complexities inherent to schools, and effectively communicate and coordinate when necessary. A participatory leader must possess a knowledge of the school effectiveness literature. Of the face-to-face interviews, $63 \%$ surfaced 
the importance of this knowledge base. A participatory leader must be able to articulate a school's purpose, a "vision of excellence", and a well-defined educational direction. A leader must know that the school effectiveness literature provides for goal-definition. An effective leader must realize that the accumulated wisdom of the school effectiveness literature can be utilized as a contextual map for school improvement. A desired future state must first be crystallized before a credible, appropriate, and realistic direction for school improvement can be pursued.

A participatory leader must possess knowledge of how to balance high task and high relationship. Of the face-to-face interviews, 58\% surfaced the importance of this knowledge base. A participatory leader must understand the sensitive balance between the concern for people and the concern for production. Decentralized planning teams are charged with solving difficult educational problems, and are expected to do so by coalescing diverse opinions. Therefore, decentralized participatory processes must link motivation theory with goal theory. Educational leaders must know how to keep the diverse partners positively working in concert, accomplishing goals, and realizing rewards from those accomplishments. An effective leader must believe that both concerns are complementary and that their integration into the decentralized participatory process will optimize both.

A participatory leader must possess knowledge of how people learn most effectively. Of the face-to-face interviews, $58 \%$ surfaced the importance of this knowledge base. A participatory leader must know how 
to teach the planning team to be effective decision-makers. A leader must train participants to use human relationship skills so that a positive climate develops. Planning team members must learn decision-making skills such as brainstorming and coming to consensus. Leaders must provide team members with school effectiveness literature to positively impact the quality of decisions. A knowledge of strategies such as role playing and modeling or balancing process and product enhances the learning of parents, students, teachers, and patrons.

A participatory leader must possess knowledge of goal theory and ways to set goals through other people. Of the face-to-face interviews, $53 \%$ surfaced the importance of this knowledge base. A participatory leader must realize that goal focus is positively correlated with leadership effectiveness. A leader must believe that goals clearly increase the effectiveness and efficiency of school programs, thus avoiding a nebulous and global approach to reform. The primary purpose of a decentralized planning team is to determine and achieve goals that will bring their school to a desired future state. An effective leader must know ways to actively involve the partners in the process of setting short and long term goals.

A participatory leader must possess knowledge of effective planning procedures. Of the face-to-face interviews, $47 \%$ surfaced the importance of this knowledge base. A participatory leader must understand that planning is an essential function when utilizing a decentralized participatory process. An effective leader must realize that planning 
involyes deciding in advance what to do, and then subsequently how, when, and who will be responsible. Planning by utilizing agendas, timelines, and masterplans provides a bridge to move decentralized planning teams from where they are to where they want to be. Planning maximizes the effectiveness of a recommended solution, maximizes the likelihood of the inplementation of a solution, and maximizes the effectiveness of resources used.

A participatory leader must possess knowledge of change strategy and know how to effectively accomplish goals through other people. Of the face-to-face interviews, $47 \%$ surfaced the importance of this knowledge base. A participatory leader must be able to recognize factors within and outside of the organization that can influence change. Ownership and commitment are natural spin-offs of a decentralized participatory process, thus the implementation of goals is positively impacted. However, a leader must understand the fragile nature of change and provide the necessary support and resources that are required for success. The following components must be consciously addressed: Adequate training and allotted time, a climate that tolerates failure and encourages risk, technical feedback, personal reinforcement, necessary monitoring, formative evaluation, maintaining effective present practices, and not overloading existing resources (i.e., teacher burnout). An effective leader of a decentralized participatory structure must be a change agent, but must also wisely ensure that the structure remains successfully in place. School 
improvement can then be continued through the unending, cyclical process of decentralized participatory decision-making.

A participatory leader must possess knowledge of the benefits of participatory decision-making. Of the face-to-face interviews, $42 \%$ surfaced the importance of this knowledge base. A participatory leader must believe that participatory decision-making is an effective way to substantively address the problems facing schools. An understanding must exist of the simple action of power's reciprocal - - empowerment. An effective leader must realize the potential of broadening influence and ownership, and know that such input positively impacts commitment and accountability.

A participatory leader must possess knowledge of the benefits of decentralization. Of the face-to-face interviews, $42 \%$ surfaced the importance of this knowledge base. A participatory leader must believe that decentralization is an effective means for addressing the unique needs of each school site. A leader must realize that autonomy provides for a greater involvement of the diverse partners in the decision-making process. An effective leader must know that decentralization can capitalize on the theory of human motivation, and insure that those people who are impacted by educational decisions are a part of the decision-making process.

A participatory leader must possess knowledge of a range of leadership styles. Of the face-to-face interviews, $37 \%$ surfaced the importance of this knowledge base. A participatory leader must understand that there exists a continuum of administrative style between 
autocratic decision-making and true group decision-making that is often times contingent upon the situation. Decision-making should be discretionary. An effective leader must assess the organizational health, and also the effectiveness and efficiency of the decision-making alternatives before deciding to delegate, participate, sell, or tell.

A participatory leader must possess knowledge of effective management practices. Of the face-to-face interviews, $32 \%$ surfaced the importance of this knowledge base. A participatory leader must be capable of effectively and efficiently managing the school organization. Issues related to facilities, personnel, policy, supplies, and resource allocation must first be under control before successful change can be initiated. Succinctly put, BBB must precede DDAE. Buses, buildings, and budgets must be soundly managed before the dialogue, decision, action, and evaluation of participatory decisionmaking can be effectively implemented.

A participatory leader must possess knowledge of how to model a decentralized participatory structure. Of the face-to-face interviews, $32 \%$ surfaced the importance of this knowledge base. A participatory leader must have a general understanding and realistic overview of the innovation which is being implemented. An educational leader must have a holistic idea of what pieces comprise a decentralized participatory puzzle and how the puzzle should look upon completion. A leader must know that training is available, current research has been conducted, and that existing successful partnerships can be modeled. A leader must 
realize that learning lessons from others who possess the necessary knowledge will strengthen the likelihood of successful implementation.

What Skills Should A Participatory Leader Possess To Effectively Implement A Decentralized Participatory Structure?

The Frequency Distribution Chart in Figure 14 was used to determine the rank order of the skills base displayed in Table IV. The X's on the Frequency Distribution Chart represent the number of interviews which surfaced each skills item. The total number of face-to-face interviews which surfaced each item was compared to the total number of face-to-face interviews conducted. Percentages and rank ordering were then determined. 
TABLE IV

RANK ORDER OF LEADERSHIP SKILLS

\begin{tabular}{|c|c|c|}
\hline Percentages & & Skills \\
\hline $79 \%$ & 1. & $\begin{array}{l}\text { Group Dynamic Skills } \\
\text { - } \quad \text { Encouraging honesty and openness } \\
\text { - } \quad \text { Appreciating diversity } \\
\text { - Power equalization } \\
\text { - Conflict resolution }\end{array}$ \\
\hline $68 \%$ & 2. & $\begin{array}{l}\text { Human Relationship Skills } \\
\text { - } \quad \text { Fostering trust and respect } \\
\text { - } \quad \text { Bolstering self-esteem } \\
\text { - } \quad \text { Creating a positive climate }\end{array}$ \\
\hline $63 \%$ & 3. & $\begin{array}{l}\text { Communication Skills } \\
\text { - Being a good listener } \\
\text { - Articulating purpose and direction }\end{array}$ \\
\hline $58 \%$ & 4 & $\begin{array}{l}\text { Decision-Making Skills } \\
\text { - Brainstorming and clarification } \\
\text { - Consensus decision-making }\end{array}$ \\
\hline
\end{tabular}




\section{OBSERVATIONS}

Why Do We Practice Decentralization?

Motivation theory, goal theory, and the school effectiveness research provided the theoretical framework for this study. The conclusions of this study focused on a need for educational leaders to have an understanding of motivation theory, goal theory, and the school effectiveness literature. This section of the conclusion chapter will highlight those aspects of theory that this researcher feels has been significantly verified through this case study.

Motivation Theory. The following portions of Douglas McGregor's Theory $Y$ were verified in this case study of Pleasant Valley's "More Effective Schools Process".

- People will exercise self-direction and self-control toward achieving objectives to which they are committed. Decentralization has given MESP the autonomy necessary for self-direction and self-control. The process of participatory goal-setting has resulted in achieving a multitude of objectives. Commitment has been a direct result of establishing feit need.

- Commitment to objectives is a function of the rewards associated with their achievement. A commitment to MESP objectives has resulted from the intrinsic rewards received from their accomplishments. Feelings of self-actualization, improved self-esteem, pride in the results, or being able to give of oneself are examples of the intrinsic rewards which were realized. 
- Average human beings learn, under proper conditions, not only to accept but to seek responsibility. MESP has provided the proper condition for parents, teachers, and students to seek responsibilities. The many task forces created over the five years have made it possible for a broad number of participants to be in positions of responsibility. - Most people are capable of a relatively high degree of imagination, ingenuity and creativity in solving organizational problems. The process of brainstorming and consensus decision-making has produced a high degree of imagination, ingenuity, and creativity when setting MESP goals. The diversity of input as a result of MESP's home/school/community partnership has enhanced creative problem solving.

- Under the conditions of contemporary industrial life, the average person's intellectual potentialities are being utilized only partially. The "More Effective Schools Process" has shown how to capitalize on the intellectual potential of parents, students, and teachers. Parents on MESP have utilized the school effectiveness literature to help assure credible goals. The leadership team of MESP believes that they did not fully realize five years ago how effective students can be as partners. The superintendent believes the most rewarding spin-off of ESP has been the tremendous professional growth that has occurred with teacher leaders. MESP has allowed for the intellectual potentiality of the school community to be utilized more fully.

McGregor believed that management must be ingenious enough to tap the hidden potential of its work force by capitalizing on the inherent 
need of people to be self-motivated and self-controlled. The description of Pleasant Valley's MESP has shown educational leaders one way to tap the hidden potential of a school community.

Herzberg's (1968) research on job satisfaction emphasizes that job content factors such as achievement, recognition, work itself, responsibility, advancement, and growth are satisfiers.

MESP has addressed these job content factors. Increased job satisfaction resulting from involvement in MESP was obvious during teacher interviews for this case study. Also, the national recognition summary highlighted the increase in several aspects of teacher job satisfaction resulting from MESP participation.

Maslow (1975), in his "Hierarchy of Needs", believes that people never lack motivation because they are involved in a continual search for enhancement.

MESP provides an avenue for students, parents, and teachers to seek self-fulfillment in a positive way. The Lay Advisory Council did not provide a positive vehicle for parent involvement as MESP does. Student council did not allow students to be included in setting school-wide goals as MESP does. Teachers had only one avenue for leadership available before MESP was initiated. That avenue was the teachers' union which generally had negative overtones. MESP provides the opportunity for all school community members to search for enhancement.

Likert (1967) believes that one spin-off of "participative" leadership that impacts motivation is the social pressure applied by the group to dissenters to accept or comply with decisions made by the 
group. Many times during the MESP case study interviews, the crucial role of consensus decision-making was revealed. It was the process of establishing total support through consensus which many times prevented the subversion of an idea.

Goal Theory. Goal theory provides the theoretical link between the process of goal-setting and motivation. Locke (1968) set out to show that motivation can be consciously controlled. He defined a goal as "what the individual is consciously trying to do". Goal-setting has the twofold purpose of guiding action and regulating motivation.

Two major findings have been reported from goal theory research:

1) The harder the goal, the higher the level of performance; and 2) Subjects trying for specific hard goals performed at a significantly higher level than subjects trying to 'do their best'.

The "More Effective Schools Process" has utilized goal-setting for the two purposes previously stated: guiding action and regulating motivation. Developing a vision statement of a desired future state increased motivation. MESP members crystallized a common direction and purpose for Pleasant Valley Intermediate. By subsequently developing specific activities to make the vision a reality, MESP utilized goals to guide their action.

MESP found that the harder the goal, the higher the level of performance. The intramural program and advisor/advisee program were the most difficult goals to be accomplished by MESP. However, by all indications of the MESP goals, the intramural and advisor/advisee 
programs have had the greatest perceived impact on Pleasant valley Intermediate School.

School Effectiveness Literature. A serious problem inherent to educational participatory decision-making is this: Many times, a school can become so attuned to the local community and its goals that the school succeeds in disqualifying its pupils for further education or work outside of the community. By utilizing the school effectiveness literature as a contextual map for school improvement, a participatory leader can maintain a balance between local wishes and requirements needed to keep students externally competitive. Mann and Lawrence (1984) believe that educators should be encouraged by the convergence of research on a limited set of process and product factors. They believe educational leaders should seriously consider the accumulated research when making improvement plans. Sashkin (1976) has conducted a study showing that the impact on decision quality depends upon how much information sharing takes place within the group.

MESP has conscientiously focused on the school effectiveness literature. The majority of the programs that MESP has implemented have been directly in response to current educational literature. The leadership team provided the planning team with recent research, to include specific needs of the middle school child. Goals that have been set are perceived to be more credible because of the concentrated focus on content. In addition, Pleasant Valley's MESP members believe that by combining the results of the recent self-study instrument with results from the Community Piece of Pie night, a necessary balance can be 
maintained. The self-study instrument is centered around the school effectiveness research. By using those results for goal-setting, MESP can better assure that Pleasant Valley students will be capable of competing for future jobs. By blending in the results from the Community Piece of Pie night, local needs can also be addressed. Among other things, educational leaders must possess knowledge about motivation theory, goal theory, and the school effectiveness literature to successfully implement a decentralized participatory structure.

What Do We Need To know About The Characteristics And Dimensions of Decentralized Program Operations?

A list of fifteen characteristics and dimensions associated with successful decentralized participatory processes were developed to initially guide the inquiry of this study. Those fifteen items are included here with an explanation of the extent to which they were or were not a part of Pleasant Valley Intermediate's "More Effective Schools Program". Two examples from the case study text will be used for each explanation. In addition, ten more characteristics and dimensions were surfaced as a result of the case study which were not on the original list. These additional ten items follow these original fifteen:

1. Innovations will vary from school to school.

- The advisor/advisee program was put into place only at Pleasant Valley School.

- Pleasant Valley's MESP group is the only one in the 
district to hold an annual community goal-setting "Piece of the Pie" night.

2. The rationale for adopting the process is research based.

- The district utilized the research of Sergiovanni, Goodlad, Bennis, and Joyce, to name a few, when considering the adoption of the "Effective Schools Process".

- Dr. Gary Phillips of I/D/E/A shared the research base from the National High School Improvement Project with district officials before the innovation was adopted.

3. Special techniques and strategies have been used to negotiate diversity into a shared direction.

- Before a final proposal was submitted by the MESP group to the staff regarding the implementation of an advisor/advisee program, approximately all of the staff were sent to visit existing programs in four different school districts.

- The process of consensus decision-making is taught and used to assure that all opinions are voiced and clarified. Once a decision has been reached, the consensus process strengthens the probability of shared commitment.

4. Recruitment, commitment, and evaluation have been an important focus.

- A conscientious attempt has been made to keep the numbers of each involved group (parents, students, and teachers) balanced and also adequate for legitimate representation. 
- Intended outcomes have been written for MESP goals which are later utilized during the evaluation phase. Informal and formal celebration has been built into the evaluation process to stimulate pride, motivation, and subsequent commitment.

5. Special nurturing has occurred to build trust, respect, and the willingness to take risks.

- A retreat was held during the first year of MESP to develop a vision statement for the school. The agenda reflects many human development activities intended to nurture trust and respect.

- When the leadership team wanted parent facilitators to lead the community goal-setting evening, special training was provided so that the parents felt willing and comfortable to take the risk of leadership.

6. The broader base of ownership and commitment has produced indicators of success.

- The MESP noon-hour intramural program broadened the base of leadership for students. Students served on the advisory board, served as scorekeepers and referees, and managed equipment. The successful program was later adopted district wide.

- The National Recognition Summary from the U.S. Department of Education states that the parents, students, and teachers all perceive MESP to be an open vehicle. They 
feel the broadened input has significantly impacted the success of Pleasant Valley Intermediate School.

7. All participants possess decision-making skills and interpersonal skills.

- Training has been consistently provided for all MESP

members in the use of brainstorming and consensus

decision-making skills.

- An oper philosophy exists which encourages power

equalization between all groups. No one group's opinions necessarily carry more weight than another representative group. Members have been taught that the health of MESP is enhanced when everyone feels as equals.

8. Leaders have a working knowledge of how to crystalize and implement goals through the empowerment of others.

- Crystalizing goals has been accomplished by developing a vision statement and setting goals intended to make the vision a reality. Each leader possesses the decision-making skills of brainstorming and consensus decision-making. The self-study instrument and analysis data have also been utilized by the leadership to help crystalize goals.

- The leaders have successfully guided the coordination and implementation of the annual Career Fair which actively involves MESP, PTA, students, parents, teachers, and community resource persons. 
9. The credibility, reality, and appropriateness of decisions have been important considerations.

- A significant effort has been made to insure that decisions are credible. The school effectiveness literature has been consistently shared with MESP members, to include specific research on the middle school child. Outside speakers have been brought in to present material to the MESP members regarding the future and its implications for Pleasant Valley's students. The self-study instrument is built around fourteen characteristics of an effective school.

- The reality and appropriateness of decisions have been important. When several MESP parents wanted hands on learning centers for the hallways like the primary building, teachers had to tactfully negotiate the idea. It was neither realistic nor appropriate for the middle school. Together, they developed a Vertical File Folder Program to provide supplemental media sources for student research projects.

10. Those who are involved want to make a difference for kids, and are personally seeking self-actualization.

- All MESP members who were interviewed stated in so many words that they were involved to make Pleasant Valley a better place for kids to be.

- Only three people interviewed stated that they were personally involved because they wanted to grow as an 
individual. Two of the people were teachers and the other person was a parent on MESP's steering committee. This information was unsolicited.

11. There is a coordination between district and building goals to include feedback to the district, some control by the district, and support by the district.

- MESP has a district representative who acts as a link between MESP and central office. MESP's "linker" happens to be the superintendent. A rule of thumb regarding building and district decisions is this: If the decision affects just your school, then the plan is affirmed. If it is a decision that has implications for other schools or for the district, then the decision needs to be discussed with the district "link". An example might be an issue dealing with report cards.

- The district has provided the MESP steering committee with annual training sessions in the summer for two or three days. The district has also fiscally supported several of MESP's programs to include the advisor/advisee program and the intramural program.

12. Complexities inherent to schools have impacted the partnership process.

- The aspect of teacher burnout has been a real consideration for the MESP group. Teachers have so many different roles and responsibilities, with limited time and energy. New 
parents and students have been drawn upon to keep their representative groups motivated and committed. However, the same pool of teachers must be used, and burnout has occurred. A new strategy of rotating teacher membership yearly, if requested, has been started. Other school committee responsibilities are correspondingly minimized for those teachers involved in MESP.

- Battle Ground School District is a fiscally poor district and is incapable of providing transportation home for students following after-school programs. MESP is attempting to develop a program to challenge high achievers and also provide alternatives for latchkey children. However, the complexities of the transportation issue have hindered consistent progress of the MESP goal.

13. Obstacles have been overcome that threatened to hinder or delay the effectiveness of the partnership.

- During the first year of MESP, approximately the third meeting, an incident occurred that could have caused an adversarial feeling between parents and staff. The incident was handled skillfully by emphasizing the importance of power balance, openness and honesty. The incident is reflectively viewed as having solidified the group and helped develop unanimity.

- Following an exhaustive year of implementing the advisor/ advisee program, the MESP group found itself to be reaching 
a stage of near burnout, particularly by the staff. The school received national recognition, which heightened expectations in all areas of the school program. During the fall of 1985, MESP was not active. In February of the same school year, MESP resumed by revising its vision statement. This revision helped motivate and set the MESP process in motion once again.

14. Certain processes and practices have been used to positively impact the effectiveness of the partnership.

- Every meeting of MESP over all five years has included a human development activity for the purpose of positively impacting the partnership. Examples have been: 1) What memories do fall leaves bring to mind?, or 2) What is the craziest thing you ever did as a kid?

- The leadership team has purposely sent letters and made phone calls to parents and patrons on the MESP team for the purpose of motivation and renewing commitment. Celebrating accomplishments and publicizing indicators of success have compounded the feelings of pride and ownership. A booklet entitled "Success Stories" was published one year by MESP.

15. Several important learnings have resulted from the experience that would be important to share with others.

- The majority of those members who were a part of MESP during its formulation year strongly feel that the emphasis placed on process over product was very important. Getting 
the group working well together in a harmonious and skilled way was perceived as a significant aspect of MESP's future success. Having easy, realistic goals to begin with helped to temper the impatience of those members who did not want to spend time building the team's cohesiveness and effectiveness.

- The concept of the pyramid-grapevine communication network was much more effective when it was included in a formal way into the agenda of each meeting. Time must be set aside to structure desired pyramid input and to share solicited comments. Without this formalized structure, the pyramid concept was not a viable part of the Effective Schools Process.

Ten characteristics and dimensions were surfaced as a result of the case study which were not on the original list. They are as follows:

1. MESP's leaders philosophically believed in the benefits of participatory decision-making.

2. MESP's leaders philosophically believed in the benefits of decentralization.

3. The original training received from $I / D / E / A$ is perceived to have played a significant part in MESP's success.

4. Sharing the school effectiveness literature with MESP members has contributed to the quality of the decisions made. 
5. MESP's leaders felt it was essential to have effective management practices in place. The organizational efficiency of Pleasant Valley was solidified before change was initiated by MESP.

6. MESP's leaders felt that utilizing a range of leadership styles on a continuum from autocratic to participative was important to ensure organizational health.

7. Careful planning has increased the implementation of goals through utilization of agendas, timelines, and masterplans specifying what, who, when, and intended outcomes.

8. An emphasis on developing MESP members to participate effectively has positively impacted the success of the process.

9. The leadership team has needed to be cognizant of how MESP members learn most effectively. Training in decision-making skills and human relationship skills must be provided. Important aspects of the school effectiveness literature must also be shared. Training has also been provided to encourage students and parents to take on leadership roles on task forces.

10. Achieving a balance between "high task" and "high relationship" has been an important aspect for MESP because of the diversity of group inembership and because of the vision to bring the school closer to a desired future state. 
What Has To Occur For Successful Decentralization To Take Place?

Lieberman (1986) has published thirteen guidelines for

collaborative work. It was decided to utilize Lieberman's work regarding collaboration as a framework for the working hypotheses of this case study. The guidelines initially served as antennae for determining which dimensions of collaborative work should not be overlooked. As the narrative text of this case study is read, a verification of Lieberman's work is evident.

The purpose of this case study was not to prove or disprove the validity of Lieberman's guidelines. However, this researcher found that the guidelines held true throughout the study of Pleasant Valley Intermediate's decentralized participatory structure. Therefore, this study strengthens the validity of Lieberman's work. Cusick (1973) states that "If as others who are engaged in similar situations... agree that 'that is the way it is', so the researcher's findings demonstrate a higher degree of validity".

This study supports Lieberman's thirteen guidelines. They are as follows:

- Some type of organizational structure is needed to collaborate.

- A small core of people actually work on the collaboration.

- Time for collaboration needs to be allotted.

- Skillful people working together enhance collaborative work.

- Initially, activities propel the collaboration, not goals.

- Large superordinate goals for collaboration become clearer after people have worked together. 
- People often underestimate the amount of energy it takes to work with other people.

- Collaboration with schools demands an understanding of schools as complex social organizations shaped by the realities of specific contexts.

- Ambiguity and flexibility more aptly describe collaborations than certainty and rigidity.

- Conflict in collaborative work is inevitable; it has the potential for productive learning.

- People can participate in collaborative work for different reasons, but they should include wanting to do things together.

- Products created by collaborating create an important sense of pride in collaborative work.

- Shared experiences over time build mutual trust, respect, risk-taking, and commitment (Lieberman, 1986).

Several important learnings were gleaned from this case study which would be useful to share with others who are implementing decentralized partnership programs. By applying advice and precautions galvanized from an existing decentralized structure, future implementations of participatory processes can be strengthened. The format of this case study was organized around the areas of recruitment, planning, training, data collection, design, implementation, evaluation, and celebration. Therefore, for the purposes of clarity and consistency, this section will be organized around the same format.

Recruitment.

- Maintain a balance in numbers for each of the representative groups for power equalization.

- Welcome, don't discourage, diversity of opinion. 
- Try to detect hidden agendas of new members quickly to prevent adversarial incidents from occurring.

-Be honest and upfront about the time and amount of energy it takes to be on the planning team.

- Having the steering committee role play recruitment beforehand builds confidence.

- Steering committee enthusiasm is perceived to have provided the necessary initial momentum.

-Phone calls, letters, and personal contacts by the steering comittee strengthens commitment.

- Attempt to have recruiting completed by the end of the summer.

- Patrons are difficult to recruit because they have no real emotional ties to the building.

- Parents and students are easier, to recruit than teachers because they have a fresh pool of people each year from which to draw.

- Teacher burnout is a real factor. Rotating planning team slots yearly can help, and reducing other school committee responsibilities will encourage continued participation.

- Explain the planning team concept to PTA members to relieve any feelings of territoriality or jealousy.

- Structure the input received and desired from pyramid members into each meeting agenda. This strengthens the follow through of contacting pyramid members, who can provide a valuable source for future planning team membership. 
- Students have proven to be much more effective partners than earlier anticipated.

-A diversity of student leadership is desirable.

Planning.

-Utilize timelines and masterplans to maximize effectiveness (see Appendix J).

-The steering committee should meet within a few days after the planning team meetings to evaluate and plan for the next meeting. -A meeting cycle and yearly cycle should begin with "high relationship", end with "high relationship", and sandwich "high task" in between.

- Meetings should start and stop on time, last approximately two hours, and refreshments should be served.

- Phone calls or letters should be sent to planning team members to summarize each meeting and remind them of the next meeting.

-The steering committee should communicate essential information to the appropriate people when and where it becomes needed.

-The steering committee should monitor the progress of the planning team. Timelines should be flexible enough to be adjusted.

- Support and resources must be provided by the planning team to insure successful implementation of ideas.

-When formulating a planning team, emphasize process over product for the first year. 
${ }^{\circ}$ The first year when process is the focus, create a visual calendar so impatient members can see the design and implementation phases to come.

Training of Planning Team Members.

Decision-making skills, human relationship skills, and school effectiveness content should be taught to planning team members so they can work well together and be effective decision-makers. 'The two most useful decision-making skills are brainstorming and consensus decision-making.

'When teaching brainstorming, begin with something fun like "What are some uses for an old broomhandle?" Then progress to a more serious educational issue.

'When teaching consensus decision-making, emphasize such things as openness, honesty, trust, conflict resolution, ways to encourage involvement, strength in diversity, and equality of input.

'Human development activities should be a part of every meeting to build trust and respect among the diverse partners. An example might be, "What was the craziest thing you did as a kid?"

'Provide recent school effectiveness literature to all planning team members.

-Encourage parents, teachers, and students to provide the team with relevant content (i.e., articles from Newsweek).

- Bring in guest speakers to provide school improvement content for the planning team. 
When teaching the planning team new skills such as goal-setting, have them first apply it to a personal task. An example is to have each person develop a self-improvement program by setting short and long term goals.

-The use of modeling and role playing techniques are effective when teaching planning teams a new skill.

Data Collection.

- Brainstorming, followed by a clarification session, is a useful skill for generating ideas before goals are established.

- A community brainstorming night in the fall broadens ownership and future support.

'Pyramid members' input is a valuable source for data collection.

- Student, teacher, and parent surveys are effective gathering tools.

-Informally assessing the school as the school effectiveness content is shared provides a useful data base.

-Forecasting available resources (capital and human) is wise during this phase.

-Evaluating the school's readiness for change is essential (i.e., climate of trust, or effective communication procedures).

-Utilizing discrepancy analysis instruments help determine gaps between "what is" and "what is preferred".

- Discrepancy analysis instruments framed around the school effectiveness literature ensure a credible direction. 
- Hard data such as test scores, attendance, or mastery of learning objectives are valuable data to collect.

Design.

- A vision statement should be constructed to reflect a desired future state for the school - a yet undiscovered capacity. -A day long retreat to create the vision statement is an effective strategy.

-Guidelines to help create a vision statement are to make it short, clear, and attainable, make it be a statement about what is good for kids, and make sure it can be communicated.

- Consensus decision-making is an effective tool for goal-setting.

- Consensus should be reached on goals so no one leaves the meeting with the intention of undermining planning team efforts. - Credible, realistic, and appropriate goals should be selected. -Data from the data collection stage should be shared at this time (i.e., teacher workload, test scores, etc).

-Attempt to balance goals to merge both local wishes from the community goal-setting night with goals from a discrepancy analys is instrument centered around the school effectiveness literature.

"Give team members stickers to "spend" on goals that have been brainstormed and written down on butcher paper.

-Formulate a maintenance-of-effort package to insure that those programs that are successfully in place will remain. 
- Formulate one, three, and five year plans that are written down and communicated with the entire school community. "Create timelines and masterplans, specifying "Who", "What", "When", and "How Well".

-Writing measurable intended outcomes during the design phase strengthens later evaluation.

-Follow the eight step process to insure success (see Appendix E). - Initially set goals that are more likely to be successful and are easily attainable to build confidence.

- Initially set goals that address organizational aspects of the school (i.e., assertive discipline) before attempting more difficult goals in the area of Curriculum and Instruction (i.e., advisor/advisee program).

- Put together a small design team of approximately seven members to specify activities which could help reach desired outcomes. - Determine if the selected goals have implications for other schools or for the district itself. If they do, communicate with the district "link" person.

Implementation.

-Formulate small task forces from the planning team membership to carry out implementation goals.

-Balance the task force team with equal numbers of parents, teachers, and students to facilitate needed communication with the representative groups. 
- Encourage planning team members other than the steering committee members to take on the leadership roles of the task forces.

- Encourage student leadership on task forces with adequate adult guidance.

- Implementation progresses more quickly when task force members hold ad hoc meetings between monthly meetings.

- Broadening the base of input from non-involved staff will strengthen support for change.

Elicit district support when appropriate.

- Communicate with all who are impacted by the change.

- Provide guidance, support, resources, and motivation when needed.

-Formative evaluation should be an on-going component of implementation.

Evaluation.

- Before implementing a building planning team concept, collect hard and soft data about the school.

- More quantitative indicators of success can be determined if hard data such as test scores are utilized for evaluation.

- Subjective measures have been a more valid measure of MESP's success.

- More observable qualitative, rather than quantitative, indicators of success are evident as a result of building-based planning team efforts. 
- Anticipated outcomes created during the design phase serve as effective evaluation tools.

-Ask what went well during implementation and why.

- Surveys can be the vehicle for valuable input from parents, students, teachers, and pyramid members.

Celebration.

- Children need praise and so do adults.

- Celebration is a critical phase when goals have been reached.

- Celebrate on a regular, routine basis and also annually in a formal way.

- Celebration should be used by the leadership team as a tool for solidifying commitment and renewing motivation.

- Consciously find successful things and key in on them.

-Having informal brainstorming sessions to recall past accomplishments is an effective way to celebrate.

- Celebrating successes cements the bond between the diverse groups in the partnership.

"Creating and distributing a booklet entitled "Success Stories" containing successful accomplishments has proven effective.

"Publicly "toot your horn" in community newspapers.

- Plaques and certificates are extrinsic rewards which nurture intrinsic pride. 
How Do The Objectives of A Specific Program Influence The Decision To Decentralize?

The Battle Ground School District adopted the "Effective Schools Process" as a means to an end for effectively and substantively implementing school improvement goals. When the objectives of a program are impacted by variables over which the individual schools have more control, or where the variables can be more positively manipulated at the building level, then the decision is made to decentralize.

By giving autonomy to the buildings, all of those people who are impacted by the decisions can be a part of the decision-making process. Broadened influence and ownership has positively enhanced change. However, having a decentralized participatory governance did not mean that Pleasant Valley Intermediate was totally free to make decisions independent of the district. Pleasant Valley's MESP group needed to follow school board policy and also the direction set by state educational guidelines. Other district directives were established as follows:

1. The Management Team comprised of eleven principals and central office administrators would stay in place as the district communication and networking group.

2. The curriculum process would remain a district-wide endeavor.

3. The district Research and Development Committee would stay intact to provide quality information and set a general direction for school improvement.

4. Building Research and Development ( $\&$ D) Committees would be established in each school in addition to the ESP planning 
teams. The building $R \& D$ team would be comprised of the principal and voluntary teachers. Their responsibility would be to determine staff development needs and provide inservice at the building level for five contracted days. Two to three of those five days needed to fall within the realm of the general direction set by the district $R \& D$ Committee.

5. A district "link" person was assigned to each school ESP planning team. This communication network was designed to increase coordination and support from the district for building-based decisions. It was felt that there needed to be a commonality with regard to program design in certain areas. The district "link" needed to work in a positive way to affirm or redirect the school's focus on an "as needed" basis.

6. A basic rule of thumb regarding ESP building decisions was established: If the decision affects just your school, then the plan is affirmed. If it is a decision that has implications for other schools or for the district, however, then the decision needs to be discussed with the district "link". An example might be an issue dealing with report cards.

How Can The Situation Be Modeled?

Participatory leaders who are planning to implement a decentralized participatory structure should seek knowledge and advice from several sources. Effective training sessions are available through the 
Institute for the Development of Educational Activities (see Supplemental Reference Notes for the address). Current literature describes motivation theory, goal theory, and the school effectiveness literature. Educational practitioners who are currently leading partnerships can offer valuable guidance worth seeking out. Finally, case study research such as this exploratory study provides a comprehensive context from which a decentralized participatory structure can be replicated or redesigned.

\section{RECOMMENDATIONS AND IMPLICATIONS FOR FURTHER RESEARCH}

The preceding conclusions regarding the skills and knowledge base deemed necessary to effectively implement a decentralized participatory structure were developed from a single-case study. This researcher recommends utilizing a multiple-case design to verify or contradict the findings of this study. By using replication logic (Yin, 1984), case studies can be carefully selected to either predict similar results or produce contrary results but for predictable reasons. When several case studies find similar results, external validity is strengthened. A theoretical framework can emerge that would be generalizable.

A second recommendation would be to compare and contrast participatory planning teams that recruit members on a voluntary basis (as does the $I / D / E / A$ model) with participatory planning teams that have elected representatives. Several school-based management (SBM) models 
elect members to serve for two years, with renomination possible for one additional term. Identifying and comparing strengths and weaknesses of both paradigms could yield valuable information for future partnerships. A third recommendation relates directly to the leadership style of educational change agents who lead participatory partnerships. Much has been said in the literature regarding the necessity of these change agents to possess a predominantly participatory style. Research should be conducted to identify the correlation between leadership style and successful partnerships. The Blake and Mouton Managerial Grid Analys is could be utilized to determine leadership style. A comparison of leaders' style and the perceived success of their partnerships could provide fruitful information for future implementation of participatory processes.

In addition, this exploratory case study has surfaced conclusions and observations which can be utilized in conducting program evaluations of decentralized participatory structures.

The final recommendation relates to the socio-economic status of the parents of a school community. One ESP committee in the Battle Ground School District is struggling to recruit parents to be on the planning team. The principal perceives the problem to be directly related to the low socio-economic status of the parents in the school community. He believes the parents have low self-esteems and thus feel incapable of being equals with teachers in a planning situation. However, Joyce, et. al (1983) described the Urban/Rural School Development Program (see review of literature) which was a very successful 
decentralized partnership program involving extremely poor neighborhoods. Perhaps by investigating and comparing successful and unsuccessful partnerships in poor neighborhoods, useful data could be generated to help develop the participants' capacity to effectively participate. The disadvantaged student population is increasing in this nation. Finding ways to effectively and substantively involve these families could have an immense impact on their children's school achievement.

\section{SUMMARY}

Chapter Five describes the conclusions, observations, and recommendations for further research which have resulted from this exploratory case study. The chapter format is structured around the seven overarching questions which guided this study.

The conclusion section addresses the following two questions: (1) What skills must a participatory leader possess to effectively implement a decentralized participatory structure? and (2) What knowledge base

must a participatory leader possess to effectively implement a decentralized participatory structure?

The findings which were surfaced in this exploratory study are as follows:

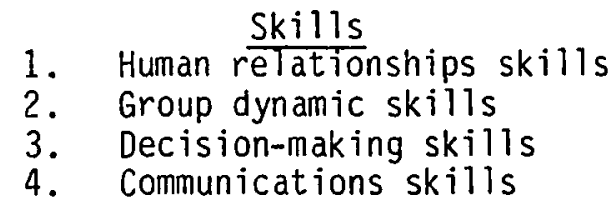




\section{Knowledge Base}

A participatory leader must possess knowledge of 1) the benefits of participatory decision-making, 2) the benefits of decentralization, 3) how to model a decentralized participatory structure, 4) the school effectiveness literature, 5) effective management practices, 6) a range of leadership styles, 7) effective planning procedures, 8) how to positively channel diversity, 9) motivation theory and ways to capitalize on motivation theory, 10) ways to develop participants' capacity to participate effectively, 11) goal theory and ways to set goals through other people, 12) how to balance high task and high relationship, 13) how people learn most effectively, 14) how to effectively facilitate the communication and coordination between and among identifiable groups which interlace with the participatory process, and 15) change strategy and how to effectively accomplish goals through other people.

The last five questions around which this chapter is structured relate to additional aspects, characteristics, and dimensions of decentralized participatory structures and processes. These five questions are:

- What do we need to know about the characteristics of decentralized program operations? 
- What has to occur for successful decentralization to take place?

- Why do educators practice decentralization?

- How do the objectives of a specific program influence the decision to decentralize and what is actually done?

- How can the situation be modeled?

These questions are addressed in the observations section. This chapter concludes with recommendations and implications for further research. 


\section{SUPPLEMENTAL REFERENCE NOTES}

A case study data base comprised of documents, tapes, notes and case study participant names has been established to verify a chain of evidence. Documents have been assigned a specific number and can be found in the case study data base. Interviews have been numbered, traceable to a tape and the interviewer's name. Telephone interviews can be traced to a name on a data base sheet. The case study data base is available through the case study researcher. The address is available through the Alumni Association, Portland State University, Portland, Oregon. I/D/E/A training materials are available from the Institute for the Development of Educational Activities, 259 Regency Ridge, Dayton, Ohio 45459.

1 School Recognition Application, Document Number One

2 National Recognition Summary, Document Number Three

3 Video Tape - Or. Richard Hersh, available through the Battle Ground School District, Battle Ground, WA

4 School Effectiveness Material, Document Number Three

5 Interview Fourteen, March, 1987, Curriculum Director

6 Interview Twelve, March, 1987, Superintendent

7 A Process Model For Curriculum Development, Document Number Four

8 Interview Nineteen, March, 1987, Assistant Superintendent 
9 I/D/E/A School Improvement Program, Document Number Five

10 Interview Fourteen, March, 1987, Curriculum Director

11 Report of the George Washington High School, Document Number Six

12 Interview Fourteen, March, 1987, Curriculum Director

13 Educational Effectiveness, Document Number Seven

14 Battle Ground Phi Delta Kappa Assessment, Document Number Eight

15 Telephone Interview Two, February, 1987, I/D/E/A Director

16 Interview Nineteen, March, 1987, Assistant Superintendent

17 Educational Effectiveness, Document Number Seven

18 Vision Statements posted at all school sites, Battle Ground, WA

19 Interview Three, February, 1987, Principal

20 What We know About How Adults Learn, Document Number Nine

21 Interview Six, February, 1987, Steering Committee Parent

22 School/Community Pyramid Groups, Document Number Ten

23 Curriculum Context, Document Number Eleven

24 Interview Nine, February, 1987, Steering Committee Parent

25 Sample Agenda - Meeting One, Document Number Twelve

26 Interview Twenty, April, 1987, Principal

27 Interview Three, February, 1987, Principal

28 Introduction to the Awareness Workshop, Document Number Thirteen

29 Brainstorming Packet, Document Number Fourteen

30 Consensus Decision-Making Packet, Document Number Fifteen

31 Interview Eleven, February, 1987, Steering Committee Teacher

32 Human Relationship Activities Packet, Document Number Sixteen

33 School Effectiveness Packet, Document Number Seventeen 
Brain Research Summary, Document Number Eighteen Education Commission of the States Report, Document Number Nineteen Forecasting Our World, Document Number Twenty Ways to Raise Student Achievement, Document Number Twenty-one Nine Principals of Challenge Education, Document Number Twenty-two Rate Your Community School, Document Number Twenty-three Real/Ideal Discrepancy Assessment, Document Number Twenty-five Rate Your School Community, Document Number Twenty-three Vision for School Improvement, Document Number Twenty-four Curriculum In Context, Document Number Eleven Interview Fourteen, March, 1987, Curriculum Director Curriculum In Context, Document Number Eleven Interview Three, February, 1987, Principal Interview Eleven, February, 1987, Steering Comittee Teacher Interview Eleven, February, 1987, Steering Committee Teacher Rationale for Task Groups, Document Number Twenty-six Curriculum in Context, Document Number Eleven Interview Twelve, March, 1987, Superintendent Recognition Application, Document Number One Interview Thirteen, March, 1987, Parent Interview Eleven, February, 1987, Steering Committee Teacher

55 Telephone Interview Seventeen, March, 1987, Student

6 Interview Three, February, 1987, Principal

7 Interview Three, February, 1987, Principal

Telephone Interview Twenty-nine, April, 1987 
59 Telephone Interview Twenty-nine, April, 1987

60 Planning Committee Membership List, Document Number Twenty-seven

61 Telephone Interview Twelve, March, 1987, Parent

62 Interview Fourteen, March, 1987, Curriculum Director

63 Interview Eleven, February 1987, Steering Committee Teacher

64 Telephone Interview Twelve, March, 1987, Parent

65 Telephone Interview Seventeen, March, 1987, Student

66 Interview Eleven, February, 1987, Teacher

67 Telephone Interview Twenty-nine, April, 1987, Parent

68 Telephone Interview Three, February, 1987, Parent

69 Telephone Interview Seventeen, March, 1987, Student

70 Interview Eleven, February, 1987, Steering Committee Teacher

71 Interview Nine, February, 1987, Steering Committee Parent

72 MESP Planning Materials, Document Number Thirty

73 Telephone Interview Twenty-one, Apri1, 1987

74 Interview Five, February, 1987, Teacher

75 Interview Eleven, February, 1987, Steering Committee Teacher

76 Vision of Excellence Statement, Document Number Twenty-nine

77 Telephone Interview Seventeen, March, 1987, Student

78 Interview Eleven, February, 1987, Steering Committee Teacher

79 Telephone Interview Twenty-nine, April, 1987, Parent

80 Interview Two, February, 1987, Teacher

81 Interview Fourteen, March, 1987, ESP Coordinator

82 Interview Eleven, February, 1987, Steering Committee Teacher

83 Interview One, February, 1987, Principal 
84 Interview Two, February, 1987, Teacher

85 Interview Two, February, 1987, Teacher

86 Telephone Interview Twenty-nine, Apri1, 1987, Parent

87 Interview Fourteen, March, 1987, ESP Coordinator

88 Telephone Interview Seventeen, March, 1987, Student

89 Telephone Interview Seventeen, March, 1987, Student

90 Telephone Interview Seventeen, March, 1987, Student

91 Telephone Interview Twenty-seven, Apri1, 1987, Principal

92 Telephone Interview Seventeen, March, 1987, Student

93 Telephone Interview Twenty-nine, Apri1, 1987, Parent

94 Interview Ten, February, 1987, Parent

95 Interview Eleven, February, 1987, Steering Committee Teacher

96 Interview Eight, February, 1987, Student

97 Interview Eighteen, March, 1987, Student

98 Interview Seventeen, March, 1987, Student

99 Interview Four, February, 1987, Teacher

100 Interview Nine, February, 1987, Steering Committee Parent

101 Interview Four, February, 1987, Teacher

102 Interview Twenty, Apri1, 1987, Principal

103 Interview Seven, February, 1987, Principal

104 Interview Thirteen, March, 1987, Parent

105 Interview Twenty, Apri1, 1987, Principal

106 Interview Eleven, February, 1987, Steering Committee Teacher

107 Interview Three, February, 1987, Principal

108 Interview Fourteen, March, 1987, ESP Coordinator 
109 Human Relationship Activities Packet, Document Number Sixteen

110 Interview Three, February, 1987, Principal

111 Interview Thirteen, March, 1987, Parent

112 Interview Three, February, 1987, Principal

113 Telephone Interview Three, February, 1987, Principal

114 Interview Nineteen, March, 1987, Assistant Superintendent

115 Interview Eleven, February, 1987, Steering Committee Teacher

116 Interview Twenty, April, 1987, Principal

117 Interview One, February, 1987, Principal

118 Interview Three, February, 1987, Principal

119 School Effectiveness Packet, Document Number Seventeen

120 Brain Research Summary, Document Number Eighteen

121 Middle School, Adolescent Research, Document Number Thirty-one

122 How to Teach Decision-making to Kids, Document Number Thirty-three

123 Interview Eleven, February, 1987, Steering Committee Teacher

124 Excellence at the Middle Level, Document Number Thirty-four

125 Interview Fourteen, March, 1987, ESP Coordinator

126 Invitation, Or. Johnston, Speaker, Document Number Thirty-five

127 Results of "Piece of Pie" Night, Document Number Thirty-six

128 Interview Thirteen, March, 1987, Parent

129 Excellence at the Middle Level, Document Number Thirty-four

130 MESP Steering Committee Memo, Document Number Thirty-five

131 Discipline Evaluation Survey, Document Number Thirty-seven

132 Pleasant Valley Teacher Handbook, Document Number Thirty-six 
133 Brochure - Staff Recognition, Document Number Thirty-eight

134 Monthly Activities Calendar, Document Number Thirty-nine

135 Patriot Profiles-staff biographical sketches, Document Number Forty

136 Intramural Packet, Document Number Forty-one

137 Advisory Program Packet, Document Number Forty-two

138 Career Fair Survey, Document Number Forty-three

139 Community Resource Bank Survey, Document Number Forty-four

140 Vertical File Material Search Memo, Document Number Forty-five

141 National Recognition Application, Document Number One

142 Interview One, February, 1987, Principal

143 MESP "Success Stories" Booklet, Document Number Forty-six

144 Interview Twenty-one, April, 1987, Superintendent

145 Interview Two, February, 1987, Teacher

146 Interview Thirteen, March, 1987, Parent

147 Interview Four, February, 1987, Teacher

148 Interview Twenty-one, Apri1, 1987, Superintendent

149 Interyiew Three, February, 1987, Principal

150 Telephone Interview Twenty-nine, Apri1, 1987, Parent

151 Interview Eleven, February, 1987, Steering Committee Teacher

152 Interview Eighteen, March, 1987, Student

153 Interview Twelve, March, 1987, Superintendent

154 Interview One, February, 1987, Principal

155 Interview Nine, February, 1987, Steering Committee Parent

156 Interview Eleven, February, 1987, Steering Committee Teacher 
157 Interview Eight, February, 1987, Student

158 Interview Twelve, March, 1987, Superintendent

159 Interview Three, February, 1987, Principal

160 Interview Ten, February, 1987, Parent

161 Interview Four, February, 1987, Teacher

162 Interview Eight, February, 1987, Student

163 Interview Twelve, March, 1987, Superintendent

164 Interview Fourteen, March, 1987, ESP Coordinator

165 Interview Ten, February, 1987, Parent

166 Interview Five, February, 1987, Teacher

167 Interview Seventeen, March, 1987, Student

168 Random selection of PVI students, March, 1987

169 Random selection of PVI students, March, 1987

170 National Recognition Summary, Doçument Number Two 


\section{REFERENCES}

Alexis, M. \& Wilson, C. (1967). Organizational decision-making. Englewood Cliffs, NJ: Prentice-Hall.

Argyris, C. (1973). Personality and organizational theory revisited. Administrative Science Quarterly, 18, 141-167.

Armenia, J. (1986, Fall/Winter). Interview with Dr. John Goodlad. Partnerships for educational renewal. In Curriculum in Context, Washington State ASCD, pp. 16-17.

Bacharach, S.B. \& Conley, S.C. (1986, May). Education reform: A managerial agenda. Phi Delta Kappan, pp. 641-645.

Bean, J.P. \& Kuh, G.D. (1984). A typology of planning problems. Journal of Higher Education, $\underline{55}, \underline{1}, 35-55$.

Bennis, W.G. (1969). Organizational development: Its nature, origins, and prospects. Reading, MA: Addison-Wesley.

Bennis, W. \& Nanus, B. (1985). Leaders. New York: Harper and Row.

Bennis, W.G., Benne, K.D. \& Chin, R. (Eds.)(1969). The planning of change. Holt, Rinehart, \& Winston, Inc.

Berman, P. \& McLaughlin, M. (1978). Federal programs supporting educational change: A model of educational change, Vol. VIII: Implementing and sustaining innovations. Santa Monica, CA: Rand.

Blake, R.R. \& Mouton, J.S. (1964). The managerial grid. Houston: Gulf. Blumer, H. (1966, December). Sociological analysis and the variable. American Sociological Review, 21, p. 689. 
Bozeman, W.C. \& Schmelzer, S. (1984, Spring). Strategic planning:

Applications in business and education. Planning \& Changing, pp. 35-49.

Brookover, W.B. \& Lezotte, L.W. (1979). Changes in school characteristics

coincident with changes in student achievement. East Lansing, Michigan:

Institute for Research on Teaching, College of Education, Michigan State

University. (ERIC Document Reproduction Service No. ED 181 005)

Carnegie Forum on Education and the Economy. (1986). A nation prepared:

Teachers for the 21 st century.

Carney, J. \& Chrispeels, J. (1984). Schools and communities working together: For effective schools and stronger communities. (ERIC Document Reproduction Service No. ED 250789 )

Carrol1, M.R. et al. (1980, November). New perspectives on planning in educational organizations. San Francisco: Farwest Laboratories.

Coch, L. \& French, J.R.P., Jr. (1948). Overcoming resistance to change. Human Relations, $\underline{1}, 512-532$.

Coleman, P. (1982). Administrative leadership, change and training programs for administrators. Canadian Journal of Education, I, pp. 44-58.

Conway, J.A. (1984, Summer). The myth, mystery and mastery of participative decision-making in education. Educational Administration Quarterly, pp. $11-40$.

Curriculum in Context. (1986, Fal1/Winter). Partnerships. Washington State ASCD, p. 4. 
Cusick, P.A. (1973). Inside high school. Holt, Rinehart \& Winston, Inc. Danzberger, J.P. \& Usdan, M.D. (1984, February). Building partnerships. Kappan, pp. 393-396.

Daresh, J.C. (1986). Effective home-school-community relations for secondary school improvement. Clearing House, pp. 312-315.

Davies, D. (1976, March-Apri1). Making citizen participation work. National Elementary Principal, pp. 20-29.

Davies, D. (1985). Parent involvement in the public schools in the 1980s: Proposals, issues, opportunities. Philadelphia: Research for Better Schools, Inc.

Edmonds, R. (1979, October). Effective schools for the urban poor. Educational Leadership, p. 16.

Eisner, E.W. (1978). The design and evaluation of educational programs. New York: Macmillan Company.

Evans, D.R. (1977, January). Responsive educational planning: Myth or reality. (ERIC Document Reproduction Service No. ED 180 064).

Everhart, R.B. (1975, Summer). Problems of doing fieldwork in educational evaluation. Human Organization, 34, p. 207.

Fairman, M. \& Renne, C. (1983, February). Sharpening the focus on goal focus. Educational Leadership, pp. 28-30.

Fantini, M.D. (1972). Community participation: Many faces, many directions. Educational Leadership, 29, pp. 676-680.

Fiedler, F.E. (1964). A contingency model of leadership effectiveness. In L. Berkowitz (Ed.), Advances in experimental social psychology, $\underline{1}$, New York: Academic Press. 
Fullan, M. (1982). The meaning of educational change. New York: Teachers College Press.

Goldman, S. \& Moynihan, W.J. (1975, June). Problems in educational planning at the school district level. Educational Technology, pp. 14-19.

Goodlad, J. (1983, Apri1). A study of schooling: Some implications for school improvement. Phi Delta Kappan, pp. 552-558.

Goodlad, J. (1984). A place called school. New York: McGraw-Hill.

Goodman, P.S. \& Pennings, J.M. (1977). New perspectives on organizational effectiveness. Jossey-Bass, San Francisco, CA.

Gorton, R.A. (1977). Parent apathy: Problem of solution. The Clearing House, 51, 93-94.

Guba, E. \& Lincoln, Y. (1982, Fall). The place of values in needs assessment. Educational Evaluation and Policy Analysis, pp. 311-320.

Guest, R.H. (1960). Organizational change: The effect of successful leadership. Homewood, IL: Dorsey Press, Inc.

Hager, J. \& Scarr, L. (1983, February). Effective schools - effective principals: How to develop both. Educational Leadership, pp. 38-40.

Hall, D. \& Alfred, S. (1976, January). Evaluation of the National Diffusion Network. Menlo Park, CA: Stanford Research Institute.

Hall, G. \& Loucks, S. (1975, Spring). Level of use of innovation framework for analyzation of innovation adoption. Journal of Teacher Education, pp. 52-56.

Hall, J. \& Williams, M.D. (1970). Group dynamics training and improved decision-making. Journal of Applied Behavior Science, $\underline{6}$, 27-32. 
Harvey, J.B. (1975). The abilene paradox: The management of agreement. In Organizational dynamics: Managerial decision-making. New York: AMACOM. Hersey, P. (1984). The situational leader. Warner. Hersh, R.H. (1981). What makes some schools and teachers more effective? Eugene, OR: Center for Educational Policy and Management. Herzberg, F. (1968, January-February). One more time: How do you motivate employees? Harvard Business Review, pp. 53-62.

Hoffman, R.L. (1979, Winter). Organizational problem solving: The role of small group research. The Journal of Applied Behavioral Science, 15, p. 381.

Hopkins, D. \& Wideen, M. (1984). Alternative perspectives on school improvement, Falmer Press: New York.

Isaac, S. (1971). Handbook in research and evaluation. Edits Publishers: San Diego.

Janis, I.R. (1972). Victims of group think: A psychological study of foreignpolicy decisions and fiascoes. Boston: Houghton-Mifflin.

Jennings, 3. (1979). "Community Control: A Grassroots Response," Journal of Education, Fall, pgs. 73-87.

Jones, B.L. \& Maloy, R.W. (1986, Spring). Collaborations and ill-structured problems of school improvement. Planning \& Change, pp. 3-8. Joyce, B. (1980). The continuous process of school improvement: Lessons learned from the past. Association of Teacher Educators: Reston, VA. Joyce, B.R., Hersh, R.H., and Mckibbin, M. (1983). The structure of school improvement. New York: Longman. 
Kappan. (1986, June). Toward a comprehensive strategy for addressing the teacher shortage. p. 712.

Kirst, M.W. (1983, Winter). Effective schools: Political environment and education policy. Planning and Changing, pp. 234-243.

Leithwood, K. \& Montgomery, D. (1982, Fall). The role of the elementary school principal in program improvement. Review of Educational Research, pp. 309-339.

Lewin, K. \& Lippitt, R. (1938). An experimental approach to the study of autocracy and democracy: A preliminary note. Sociometry, pp. 292-300. In Powers, D.R. \& Powers, M.F. (1983). Making participatory management work. Jossey-Bass, Inc., San Francisco, CA.

Lieberman, A. (1986, February). Collaborative work. Educational Leadership, p. 7.

Lightfoot, S.L. (1978). Wor Ids apart: Relatioriships between families and schools. New York: Basic Books Inc.

Likert, R. (1967). The human organization. New York: McGraw-Hill. Locke, E. (1968). Toward a theory of task motivation and incentives. Organizational Behavior and Performance, $\underline{3}, 157-189$.

Locke, E.A. \& Schweiger, D.M. (1979). Participation in decision-making: One more look. Research in Organizational Behavior, 1, p. 266

Long, D.C. et al. (1977, April). Legal constraints on decentralized decisionmaking in the public school system of the District of Columbia. (ERIC Document Reproduction Service No. ED 158 539). 
Mahoney, T.A. (1983). Perspectives of organizational structures for planning. In G.H. Copa \& J. Moss Jr. (Eds.), Planning and vocational education. New York: McGraw-Hill Book Co.

Maier, N.R.F. \& Maier, R.A. (1957). An experimental test of the effects of 'developmental' vs. 'free' discussions on the quality of group decisions. Journal of Applied Psychology, XLI, 320-23.

Mann, D. \& Lawrence, J. (1984, June). A delphi analysis of the instructionally effective school. In Making our schools more effective. Proceedings of three state conferences.

Mansbridge, J.J. (1973, March-June). Time, emotion, and inequality: Three problems of participatory groups. Journal of Applied Behavior Science, 9, 351-68.

Maslow, A.H. (1975). Some educational implications of the humanistic psychologies. In T. Roberts (Ed.), Four psychologies applied to education, New York: Schenkmar Publishing Co., pp. 304-313. McGregor, D. (1960). The human side of enterprise. New York: McGraw-Hill. McInerney, W.D. (1985, Winter). Participation in educational planning at the school district level. Planning \& Changing, pp. 206-215.

Miles, R.E. (1965, July/August). Human relations or human resources. Harvard Business Review, $\underline{43}, 149-56$.

Morgan, T.E. \& Scebra, J.8. (1977, January). Managing scarce educational resources. Educational Technology, pp. 47-49. 
Mott, P.E. (1972). The characteristics of effective organizations. New York: Harper and Row.

Mottley, C.M. (1972). Strategic planning. In F.J. Lynden \& E.G. Miller (Eds.), Planning programming budget, Chicago: Markham Publishing Co. Muth, R. \& Bolland, J.M. (1983, Winter). A key to effective problem solving. Social Context, pp. 214-225.

Oregon Department of Education (1976). Schools and communities: Setting goals. Salem, OR.

Pierce, L.C. (1980, June). School-based management. (ERIC Document Reproduction Service No. ED 188320 ).

Powers, D.R. \& Powers, M.F. (1983). Making participatory management work. Jossey-Bass, Inc., San Francisco, CA.

Purkey, S. \& Smith, M. (1982, June). Effective schools - A review. Wisconsin Center for Education Research: School of Education, University of Wisconsin at Madison.

Raaen, F.D. (1981). The school and its local environment. National Council for Innovation In Education. 0slo, Norway.

Rutter, M. (1981, February). School effects on pupil progress: Research findings and policy implications. Paper presented for National Institute of Education, U.S. Department of Education.

Sashkin, M. (1976, July). Changing toward participative management approaches: A model and methods. Academy of Management Review, 1, 75-86. 
Scarr, L.E. (1986, Winter). Sharing the base of power: Administrative structure of the future in the Lake Washington School District. Management Information, $\underline{6}$, p. 10 .

Schatzman, L. \& Strauss, A. (1970). Field research: Strategies for a natural Sociology. Englewood Cliffs, NJ: Prentice Hall, p. 7.

Schmuck, R.A. \& Runkel, P.J. (1985). The handbook of organizational development in schools. Palo Alto, CA: Mayfield Publishing Co.

Seeley, D.S. (1986, January 15). Rethinking the schools' human equation. Educational Week.

Sergiovanni, T. \& Carvey, J. (1980). The new school executive: A theory of administration. New York: Harper and Row.

Sergiovanni, T.J. (1984, February). Leadership and excellence in schooling. Educational Week.

Sharma, C.L. (1955, Apri1). Who should make what decisions? Administrator's Notebook, III, $1-4$.

Smith, A.G. \& Robbins, A.E. (1984). Multimethod policy research: A case study of structure and flexibility. In D.M. Fetterman (Ed.), Ethnography in educational evaluation. Sage Publications: Beverly Hills.

Smith, M.P. (1976, November). Barriers to organizational democracy in public administration. Administration \& Society, p. 284.

Stufflebeam, D.L. et al. (1971). Educational evaluation and decision-making. Itasca, IL: F.E. Peacock Publishing, Inc. 
The excellence report - Using it to improve your schools. (1983). American Association of School Administrators, Arlington, VA.

Tucker, M. (1986, July). Executive Director: Carnegie Forum on Education and the Economy. Talk given in Portland regarding the task force on teaching.

Tuckman, B.W. (1972). Conducting educational research. New York: Harcourt Brace Jovanoch, Inc.

Tunne11, G.B. (1977). Three dimensions of naturalism: An expanded definition of field research. Psychological Bulletin, 48, pp. 427-428.

Van de Ven, A.H. (1980). Problem solving, planning and innovation, Part I. Test of the program planning model. Part II. Speculations for theory and practice. Human Relations, 33, 757-779.

Vinokur, A. (1971). Review and theoretical analysis of the effects of group processes upon individual and group decisions involving risk. Psychological Bullet in, 76, 231-250.

Vroom, V.H. \& Yetton, P.W. (1973). Leadership and decision-making. Pittsburgh: University of Pittsburgh.

Vroom, V.H. (1960). Some personality determinants of the effects of participation. Englewood Cliffs, Nu: Prentice-Hall, Inc.

Watters, C. \& Talley, C. (1986, Fall/Winter). School-based management: A tool for partnership. In Curriculum in Context, Washington State ASCD.

Wickert, R.F. (1951). Turnover and employees' feelings of ego-involvement in the day-to-day operations of a company. Personnel Psychology, IV, 185-197. 
Wilson, S. (1977, Winter). The use of ethnographic techniques in educational research. Review of Educational Research, 47, p. 249.

Wolcott, H. (1975, Summer). Criteria for an ethnographic approach to research in schools. Human Organization, 34, p. 115.

Wolfe, R.0. (1986, Fall/Winter). Partnerships. Curriculum in Context, Washington State ASCD.

Wood, C.J. (1984, Fall). Participatory decision-making: Why doesn't it work? Educational Forum, pp. 55-64.

Wulff, R. (1986, October 15). Child's education begins with parents, home. Editorial. Columbian, p. A7, Vancouver, WA.

Wynne, E.A. (1985, October). Philosophy: How does it affect school management? How can we ensure good philosophy? NASSP Bulletin, pp. $63-72$.

Yin, R.K. (1984). Case Study Research. Beverly Hills, CA: Sage Publications.

Yuk1, G.A. (1981). Leadership in organizations. Englewood Cliffs, NJ: Prentice-Hall.

Zelditch, M. (1962). Some methodological problems of field studies. American Journal of Sociology, 67, pp. 566-576. 


\section{APPENDICES}


APPEMDIX A

\section{INTERVIEW PROTOCOL \\ FOR ADMINISTRATORS}

- What is the Effective Schools Process?

- What were the reasons for putting this structure in place?

- To what extent has the original plan worked? What aspects have worked; what aspects have not worked? Why?

- Do you perceive it as successful?

- What training has been received that you feel to be essential? Why? In what areas might further training be needed? Why? In what ways do you feel this training should/could have been adjusted?

- What are some indicators of success that justify maintaining the structure?

- What decisions should the planning teams make?

- What are some important factors when considering the formulation of such a structure? How do you go about it?

- What are some important factors that affect the maintenance of such a structure? How do you renew commitment?

- How important is good communication to the success of this structure?

- What do you believe are the most significant obstacles that may hinder, delay or destroy the effective formulation and maintenance of a partnership program? 
- What strategies have you used to overcome or circumvent these obstacles?

- What techniques have you used to positively influence the successful implementation and institutionalization of the partnership program?

- What skills and knowledge base do you believe an educational change agent must possess to successfully guide a partnership program?

- What are the consequences for those people who are and are not involved?

- What do you feel are the advantages and disadvantages/ strengths and weaknesses to a partnership program?

- To what extent has it helped or hindered your role as an educational leader?

- Describe the process for goal-setting; include both short and long-range planning.

- What sets the direction for goal-setting on your planning team? How do you determine or assure that the plan is credible? Appropriate? Realistic?

- In what ways will your partnership planning team utilize the data generated from the self-study instrument?

- How will you prioritize those areas of need where discrepancies exist in the self-study data?

- How do you intend to implement the goals that result from the self-study process? 
- How are building and district goals coordinated?

- What advice or guidelines would you feel compelled to offer to someone interested in developing or building a partnership program? 


\section{APPEÑOIX B}

\section{INTERVIEW PROTOCOL \\ FOR \\ PARENTS, TEACHERS, AND STUDENTS}

- What is MESP?

- Why do you think MESP was put into place?

- What are your expectations of MESP?

- Do you perceive it as successful?

- Why did you choose to be involved?

- What concerns did you have when you first joined MESP? Have these concerns changed? What are the reasons for the change?

- How is MESP different from other parent organizations (i.e., PTSA) ?

- What have you gained personally from participating?

- What would make MESP better or more effective?

- What decisions should MESP make?

- Have you experienced any frustrations working on MESP? Explain.

- What has MESP accomplished? What are some indicators of success that justify MESP's existence?

- What processes are used for goal setting? How does this insure a plan that is credible? Realistic? Appropriate?

- How would parents, teachers and students effect change if MESP did not exist? 
- What skills and knowledge base do you feel a leader must possess to effectively guide MESP?

- What are the consequences for those people who are not involved with MESP?

- What knowledge base and skills do you think a principal needs to effectively direct MESP?

- What keeps you involved?

- How has MESP enhanced your role as a parent, teacher or student?

- What are the strengths and weaknesses of the process?

- What contributions to MESP do you feel you can make in your role as parent, teacher or student?

- What are some key elements that make MESP work?

- What skills do you feel are essential for participants to possess? What training should be given to develop those skills?

- In what ways is MESP utilizing the data generated from the self study?

- What process is being used to prioritize the needs that surfaced as a result of the self study?

- How do you feel MESP contributed to the state and national recognition awards?

- What advice would you feel compelled to give to a parent, student or teacher who was considering joining MESP? 
APPENDIX C

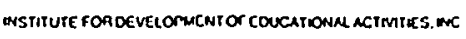

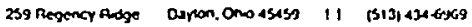

January 20, 1987

Mrs. Donna Carman

Battleground School District

18317 N.E. Cedar Drive

BattIeground, Ha 98604

Dear Donna:

It was pleasant to talk w1th you on the phone the other day and to learn that you are conducting a case study in one of the schools participating in scbool improvement.

I've enclosed a copy of the Charters' article we discussed on the phone and also some information regarding a pool of 1tems that we use as we interview planning teans, teachers and pareats. Or course the questioas asked and the emphasis Biven each concept varies greatly froa school to school and with the group of people we are talking with. I hope these things ulll be of sone assistance as jou mose into the data collection phase or your dissertation.

If you want to talk rurtber please doa't hesitate to call.

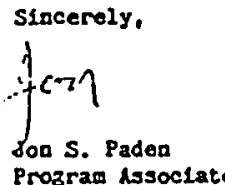

Prozrad Assoclate

JSP : wp

Enclosures 
The purpose of the Secondary School Recognition Program is to identify and call attention to a national group of schools that are unusually successful in meeting the educational needs of all of their students. In seeking successfut schools, the prograp also seeks schools that have overcome obstacles and problems and that are continuing to concentrate on improvement. It is assumed that these efforts will be reflected in program innovation as well, as improved outcones during the past several years.

This form is intended to provide a profile of your school. It requests Information about a variety of factors assoclated with success as well as Information about a number of outcomes. It also asks for information about changes that have occurred in your school as a result of your efforts to do a better job.

The 14 attributes of success which will be used to exanine the overall quality of your school include:

1. Clear educational goals,

2. High expectations for students.

3. Order, discipline. and freedor from drug use,

4. Revards and incentives for students,

5. Regular and frequent monftoring of student progress.

6. Development of good character and values,

7. Teacher efficacy.

8. Revards and Incentives for teachers

9. Concentration on acadeaic learning time.

10. Positive school clinate.

11. Adainistrative leadersnip.

12. Kell-articulated curriculium,

13. Evaluation for instructional inprovement, and

14. Parent and comunity support and involverent.

The following Indicators of success will be used to examine your school:

1. Student perfomance on stardardized achieveanent tests;

2. Student performance on minimum coapetency tests:

3. Student success in high school:

4. Daily student and teacher attendance rates and rates of student suspensions and other exclusions:

5. Dropout rates:

6. Awards for outstanding school programs and teaching: and

7. Student awards in acadealc or rocational competitions, e.g. science fairs. essay contests, and Industrial arts competitions.

In looking forward to the celebration of the blcentennial of the U.S. Constitution in 1987. special attention will be paid to prograns and courses that teach about democracy and the U.S. Constitution in a creative and effective way. as well as to the tesching of American history in generai. 
NINE PRINCIPLES OF CHALLENGE EDUCATION

(Forecast for 1980's)

The following principles are based on our forecast of the 1980's. These principles point the direction for selection of practices and prescriptions on which programs are designed for School improvement sites.

1. Leamers increasingly use education to anticipate and prepare for successful life transitions.

2. Schools increasingly assume the important role of coordinator and linker of resources in an effort to increase the positive impact on students while reducing the direct role of the school.

3. Students becone increasingly self-directed through planned activities leading to a self-educating adult role.

4. School/comunity values are accepted as appropriate program objectives, with planned developmental activities included in classroom processes.

5. Parents become active participants in the education of their children by sharing in planning and accountability.

6. Each student voluntarily pursues excelience in some area of his or her own choosing.

7. Everyone affected by a deciston is involved in the making of it, has omership of its intent, and contributes to the synergy of management processes.

8. Learners increasingly profit from the interdependence and integration of the educational efforts of home, school, and community. thus reducing redundancy white insuring depth and comprehensiveness of development.

9. Every participant in the act of educating youth -- parents, teachers, other students, out-of-school resource persons .- is also a learner.

How are the Nine Principles to be Used?

The principles represent our best forecast of the kinds of programs and practices that will be essential for effective schools in the future. Each site should explore or invent a variety of practices and programs for each principle. 
1. Students become increasingly self-directed as they move toward the aduit role of self-education.

2. Parents become active participants in the education of their children.

3. Each student voluntarily pursues excellence in some area of his or her own choosing. Excellence is developed, acknowledged, rewarded, and celebrated by the school comunity.

4. Every participant in the act of educating youth--parents, teachers. other students, out-of-school resource persons-- is also a learner.

5. Everyone affected by a decision is involved in its making, has ownership of its intent and contributes to the synergy of the group process.

6. Leamers increasingly use education to anticipate and prepare for successful life transitions.

7. Leamers increasingly profit from the interdependence and integration of the educational efforts of home, school and comminity.

8. Schools increasingly assume the inportant role of resources ifnker with other educating institutions, increasing the positive impact on youth by using conmunity resource and technology.

9. School-comunity values are accepted as approprlate program objectives. 
APPENDIX E-2

\section{STEPS TO INSURE SUCCESS}

Step One: TASK STATEMENT

Clearly write down a description of what your goal or task is which you intend to achieve.

Step Two: INTENDED EFFECTS

Describe the intended effects for participants. How will their lives (students be enhanced if your goal or task is successful. Try to be specific. Think in terms of detail.

Step Three: PRACTICES AND PROGRAMS TO ACHIEVE GOAL List the planned practices and programs that will help achieve your goal, task or intended outcomes.

Step Four: ESTABLISHING INDICATORS OF QUALITY Identify all your goal (Step One) what you would accept as evidence of goal achievement at three levels: minimum, adequate and excellence. What will it take for others to judge that your goal has been obtained. 
Step FiVe: ANTICIPATING PROBLEMS - PLANS OF PREVENTION

Identify all the things that could go wrong. What are the major constraining forces to the success of your plan? Consider time required, finance, skill of participants, permission from key decision-makers, community acceptance, resistance to change, etc.

\section{Step Six: ESTABLISHING IMPLEMENTATION SCHEDULE}

List tasks and assignments to insure implementation of your goal or task. Clarify expectations and establish a time line for completing subsequent tasks.

Step Seven: INFORMING OTHERS

Develop a comprehensive plan to inform key members of the school community and create an attractive image for your goal.

Step Eight: FINDING NEEDED RESOURCES

Prepare a plan to secure needed resources and funds. You may need to get advice and assistance beyond your group. Resources would include personnel needs, budget and others. 


\section{APPENDIX $F$}

\section{INTENDED OUTCOMES}

\section{STUDENTS}

1. Student's academic achievements will be increased and Rewarded, enabling each student to obtain higher achievement Scores and more easily reach minimum requirements.

2. Students will achieve a greater sense of self worth.

3. Students enjoyment of school will increase.

4. One student will be more easily able to expand his/her Interests.

\section{INTENDED OUTCOMES}

\section{STAFF}

1. Staff pride in PVI will increase.

2. Teachers will experience reduced tension and become encouraged As they see students becoming self-directed learners. less Emotional energy will be spent helping students learn.

3. Staff will have a greater sense of direction towards Establishing and implementing the program.

4. Staff will be challenged to expand their interests so that They can keep up with the students who are pursuing their Areas of strength. 


\section{INTENDED OUTCOMES}

\section{PARENTS}

1. Parents see the child as a competent learner as they meet Minimum standards.

2. Lines of communication will be opened so there will be a Mutual exchange of knowledge.

3. Parents will be more involved in the education and activities of their son/daughter.

4. Satisfaction with the program will increase pride in pvi.

\section{INTENDED OUTCOMES}

\section{COMUNITY}

1. The community will have pride because of the accomplishments of their school.

2. Lines of communication will be opened so there will be a Better exchange of knowledge.

3. Community input will increase as support and involvement Increase. 


\section{APPENDIX $G$}

\section{FIVE YEAR PLAN}

1. Program students toward success.

2. Identify strengths of students.

3. Pursue strengths of students.

4. Organizational and study skills stressed.

5. Work on decision making skills.

6. Stress the importance of taking advantage of the opportunity to get An education.

7. Stress a positive attitude towards life and towards school.

8. Increase academic learning time to result in greater attainment of Basic skills.

9. Establish a computer science committee.

10. Continue a strong pta commitment.

11. Involve community resources in the school program.

12. Increase communications between students, parents and teachers.

13. Set up school advisory committees.

14. Give more responsibilities/privileges to students as they progress From fifth to eighth graders to encourage pride, spirit, tradition, Growth, etc.

15. Establish $\mathrm{climate}$ for students to pursue strengths.

16. Provide opportunities for students to work on independent projects.

17. Teachers will use the district learning outline for each grade.

18. Tests given at each grade level to make sure minimum learning Skilis are acquired by all students based on adopted district wide Curriculum.

19. Retain or skip students when necessary.

20. Provide counseling for students.

21. Work on library skills. 


\section{APPEANDIX H}

\section{PLEASANT VALLEY INTERMEDIATE SCHOOL'S MESP}

(More Effective Schools Program)

(Phase One)

I. EACH STUDENT MAXIMIZES HIS/HER POTENTIAL AS A POSITIVE, PRODUCTIVE CONTRIBUTOR TO SOCIETY.

A. Program students toward success:

1. Discipline system

a. Make sure students, parents, and staff understand the need and reason for choosing current system. Help them buy into the system.

-- In-service beginning of year for staff

-- Information sheet sent home for parents (possibly use student artists to draw cartoons giving examples of expected behavior, consequences, etc.)

-- Explain the discipline program to students. Discuss need, etc.

b. Solicit suggestions at end of this year from students, parents, staff for improvements in program. Implement best ideas in the fall. (Send home questionnaire to parents, possibly fill out with students).

c. Continue to reward good behavior, i.e., notes home, certificates, classroom privileges, raffle tickets, etc.

-- Continue citizenship certificates at the end of this year

-- Need new ideas for rewards (perhaps this item could be mentioned and solicited on questionnaire home to parents).

-- Question of whether rewards need to be "something tangible", i.e., pencil, hamburger, or whether privileges are adequate. 
2. Reward academic and physical achievement

a. Continue Honor Roll -- printed in paper, printed certificates handed out at school assembly to give student something to take home to parents

-- This spring give out Honor Roll certificate at 8 th grade function or school assembly

-- Possibly give awards to students who have maintained honor roll average all year (4 quarters)

-- Possibly give awards to students who have maintained honor roll average all 4 years at P.V.I. ( $T$-shirt, Academic Letterman, etc.)

-- Possibly award parents for their help to their students, i.e., acknowledge their input into their students success academically.

-- Junior Beta Club (Paul has information on this)

-- Take pictures of honor students by grade or class to post on school bulletin board. Continue to post names

b. Physical fitness competition and awards

c. Spelling Bee, poetry contests, writing (Project WRITE) competition

d. Awards in various school areas, i.e., band, shop, math, drama

e. Knowledge Bowl training and competition

3. Accentuate the positive--BUILD SELF ESTEEM

a. Each teacher stress saying something positive to each student each day.

b. Stress identifying and pursuing excellence in areas of individual strength.

c. Provide leadership opportunities

-- Leadership training for students. Camps, class covered by classroom teacher, Saturday workshop, CEP class, etc. 
d. Counseling

-- In-service for teachers on their importance as role models for students.

e. Advisor--advisee program started (specified time planned in the day once a week).

f. Information for parents - communication with home

-- "Hints", information sent home on ways to encourage and reinforce self worth

-- What to expect from your adolescent, educational information on learning, etc.

-- Every parent make a commitment to have at least one 10 minute conversation daily with their child about what's happening at school, will benefit both parent (increased communication) and child (increased self worth).

-- Monthly letter home from teacher.

g. Information from student, i.e., "What would you like your parent to do to help you during this time?"

-- Column in school paper, "Dear Abby" type, question and answers

-- Poll or interview students and compile information sheet to be sent home to parents.

4. Help students see how they fit into society and understand society better.

a. Interaction with society

-- Cont inue resource speakers, field trips into community, ability week, career day, visits to places of work

-- Service project for school or community (individual or group, class, grade, interest group)

-- HS student council visitation, P.V.I. newspaper, column about what's happening at Prairie 
b. Counseling

-- Resource person to refer critical cases to professional help or agencies

-- Reference person to help staff deal with less severe situations

5. Teacher-Parent-Student communication

a. Review report cards/progress reports; could these be improved?

b. In-service for staff on importance of communication to parents. Knowledge that some of the most important communication to parents occurs through the students. What are students taking home at the end of the day as far as what happened at school today?

c. In-service for parents who will be serving as aides.

-- Expectations of them

-- Sheets giving them information (specific)

d. 5 th grade orientation for students and parents

-- Begin spring of 4 th grade

-- Follow-up of 5 th grade in fall

II. THE LEARNER WILL HAVE IDENTIFIED AND PURSUED EXCELLENCE IN HIS/HER AREAS OF STRENGTH

A. Identify Strengths

1. Student, parent, teacher questionnaire

a. Incoming 5th graders: Develop a form that asks parents, "What information can you give the teacher that would help them to do a better job teaching your student? Interests, strengths, weaknesses, other specific info the teacher should be aware of."

b. Use this form as a basis for 5 th grade, fall conference.

c. Possibly use again fall, 7th grade

d. Use for new students 
2. Ability, interest and achievement tests

a. Use 5 th and 7 th grade spring test scores as basis for fall 6th and 8th grade conferences with parents. Stress importance of parents coming in. Enable parent to see strengths and weaknesses of child, compared on national level. Be sure parent understands our school minimum standards.

b. Conference time may have to be provided for staff to accomplish this.

3. Counseling services to help students, parents and teachers.

\section{B. Pursue strengths:}

1. Basic class offerings

a. Ability grouping of math, reading, perhaps language.

b. Evaluate content of material in math and reading

c. Employ a variety of learning techniques

2. Electives

a. Continue shop and band

b. Offer another choice to change at quarter or semester with specialists or community volunteers teaching, i.e., foreign language, typing, computers, home etc., art (for 7 th and 8th graders)

c. Consider introducing Gifted Program

3. After school and noon hour opportunities

a. Intramural sports

b. Interest clubs

c. Interschool sports

d. Independent studies

e. Community Education classes

-- Stage band, wrestling, track, child care, hunter's safety, knitting, etc. 
f. Knowledge Bow] (or I-2-e)

III. Student will have become self directed

A. Organizational and study skills stressed

B. More responsibilities-privileges as students progress from 5 th to 8th grades to encourage pride, spirit, tradition, growth, such as:

- 5-8 require assignment books

- 5-8 require research papers of increasing difficulty

- 7-8 more independent projects

- 7-8 social gatherings at regular intervals

- 5-8 intramurals

- 7-8 interschool sports

- 7-8 exchange classes

- Student council 5-8

- Spirit Week ( 7 th and 8 th grade leaders as well as student council)

- Blue-Red game

- 8th grade-faculty game

- Assemblies (some just for 7 th and 8 th grades (some for 8 th)

- Perhaps allow 7th and 8th graders to order a-1a-carte hamburgers and salad every day

- 8th grade area

- Advanced students do some work at the high school

- 8th grade graduation party in the small gym

- 8th grade passes to some Prairie games to begin transition

C. Established climate to pursue strengths

1. Staff in-service on current research 

a. brain research
b. learning styles
c. Alfred Arth follow-up

2. Departmentalized 7 th and 8 th grade

D. Opportunities to work on Independent Projects

- band challenges

- band playing contests

- shop plan sheets

- electronic science work packet and supplies

- term papers, research papers

- computer offers endless possibilities

IV. The student will have learned the basic skills needed to continue learning, anticipate change, and make transitions the rest of their lives.

A. District learning outline for each grade

B. Tests at each grade level to make sure minimum learning skills are acquired by all students based on adopted district wide curriculum.

C. Retention or skipping where deemed necessary

D. Counseling provided

E. Library skills worked on

F. Decision-making skills worked on

G. General stress on the importance of taking advantage of the opportunity of getting an education!!!!!

ATTITUDE TOWARDS LEARNING IMPORTANT!!!!!

H. Stress a positive attitude towards life and towards work (school). 
I. Increase academic learning time to result in greater attainment of basic skills.

J. Establish computer science committee

V. Involve home, school and community in education process

A. Continue strong PTA commitment

B. Involve community resources, such as, social agencies, churches, businesses, community education. Examples: Canned food drive, counseling, resource speakers, field trips, career day, during and after school special classes.

C. Communications

See the following:

- Discipline system questionnaire

- Discipline system information sheet

- Publish honor roll

- Publish pictures and articles about students accomplishments

- Parenting information sheets sent home

- Monthly letter from teachers to parents

- Student column in school paper expressing their ideas on parenting and other subjects ("Dear Abby", type)

- Teacher-parent-student communication

- Student-parent-teacher questionnaire on student interests and strengths

- Ability, interest and achievement test scores. Conferences with parents

D. School Advisory Committee

- Students, staff, parents and community 


\section{APPENDIX I}

\section{3-84 TARGETS}

1. Reaffirm assertive discipline program.

2. Improve rewards for academic and physical achievement.

3. Build self-esteem.

4. Improve communications between teachers, parents and students.

5. Develop after school and lunch hour opportunities.

6. 0 thers
A. Staff recognition awards
B. Computer education
c. Math education
D. Instrumental music
E. Elective program
F. Special education
G. Volunteers
H. Outdoor education
I. A.S.B. fund-raising project
J. Extended learning 


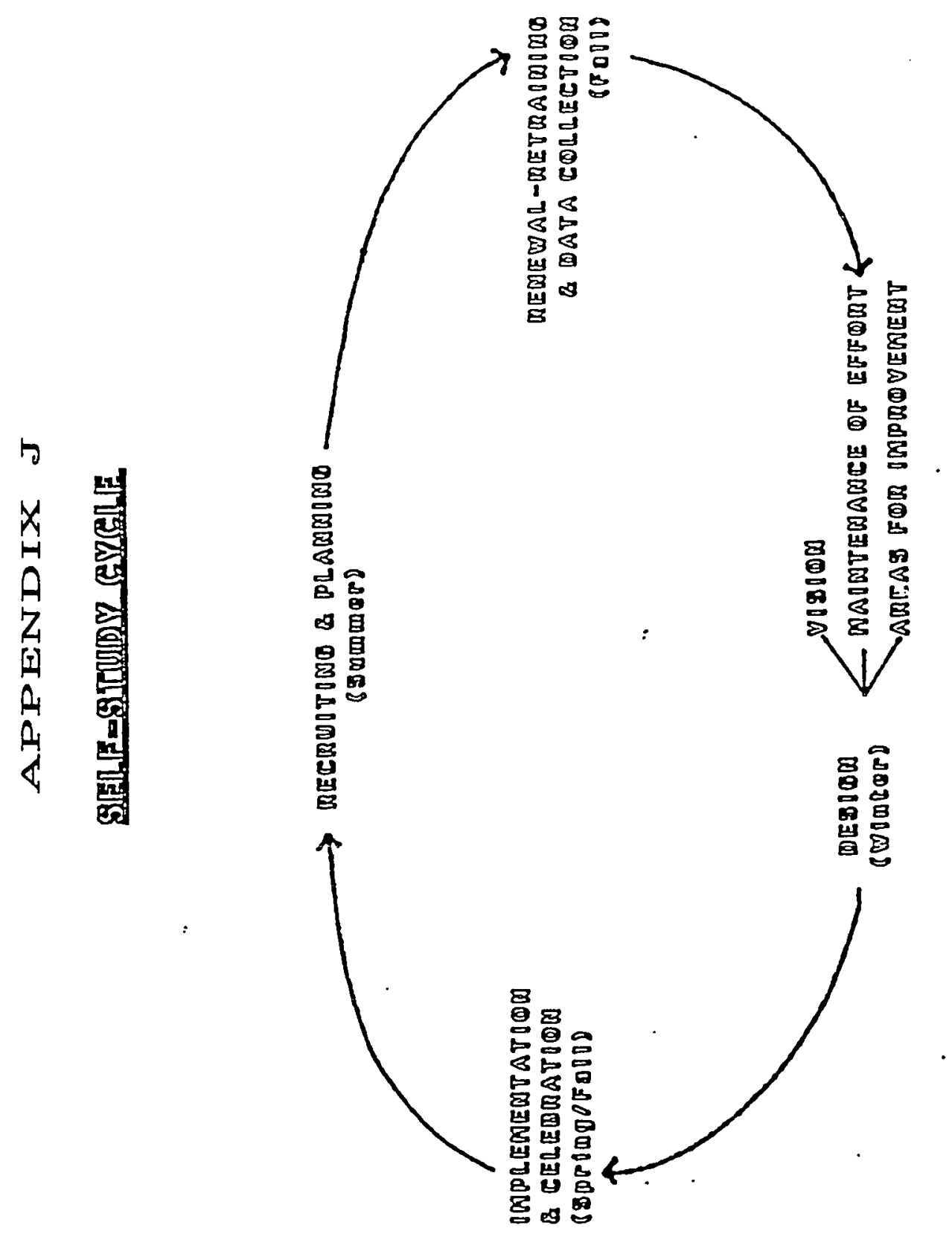




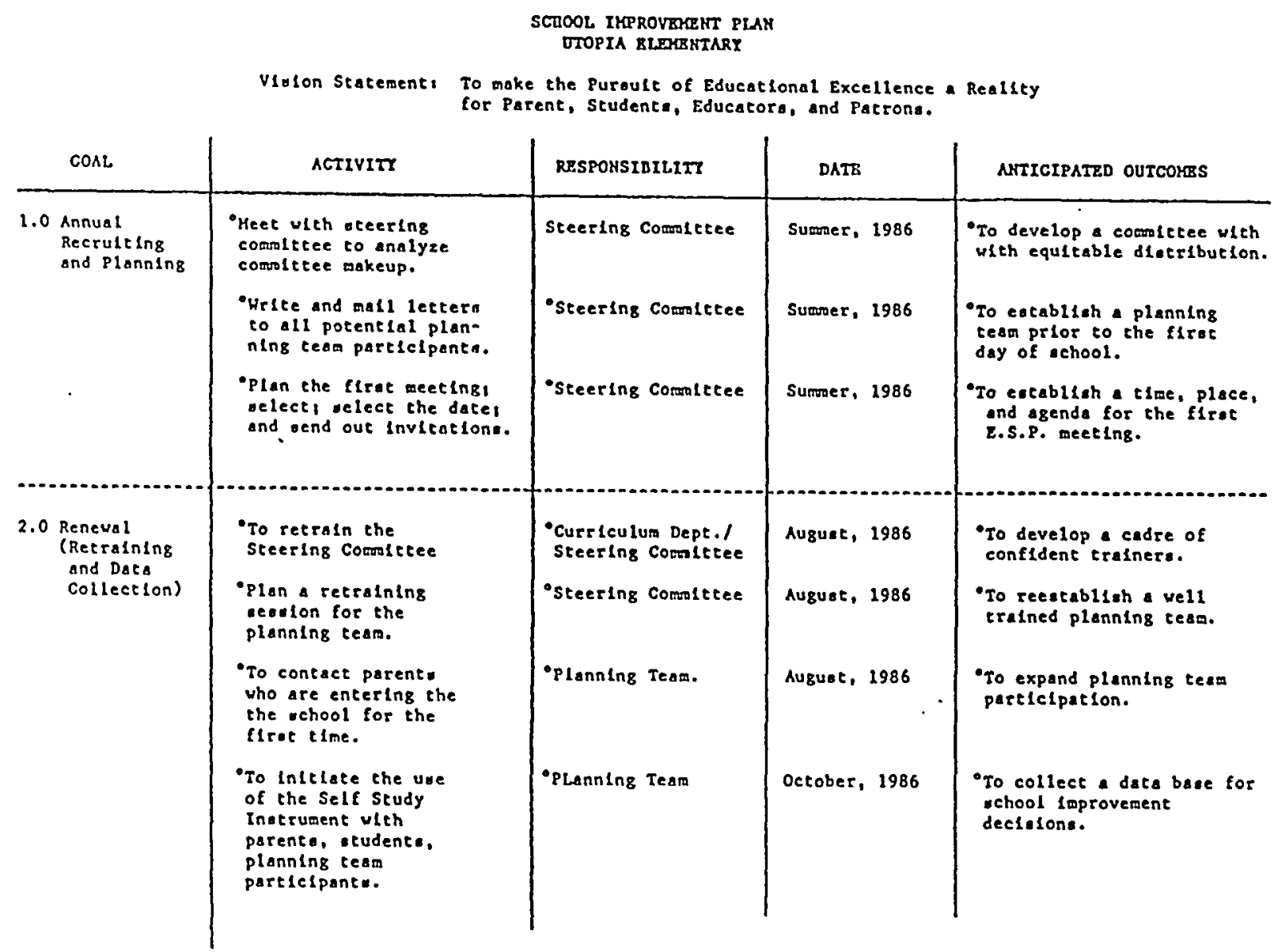




\begin{tabular}{|c|c|c|c|c|}
\hline GOAL & AGtivitr & RESPONSIBILITT & DATE & ANTICIPATRD OUTCOKRS \\
\hline $\begin{array}{c}3.0 \text { Dealgn a } \\
\text { plan for } \\
\text { unceesa }\end{array}$ & 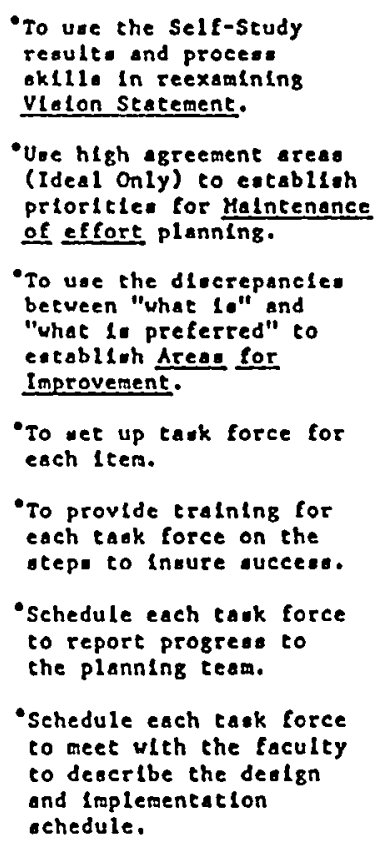 & 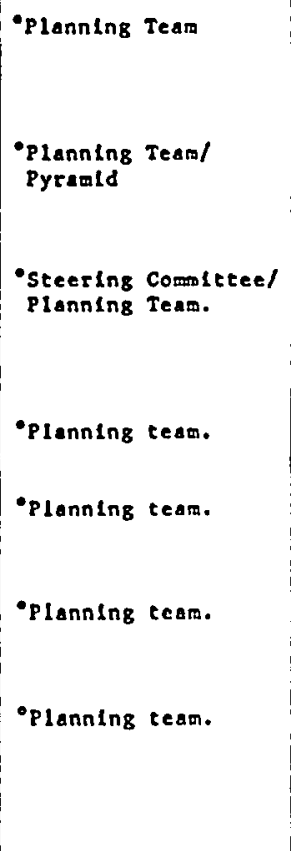 & $\begin{array}{l}\text {-HInter, } 1987 \\
\text {-Hinter, } 1987 \\
\text {-Hinter, } 1987 \\
\text {-Spring, } 1987 \\
\text {-Spring, } 1987 \\
\text {-Spring, } 1987 \\
\text {-Spring, } 1987 \text { ' }\end{array}$ & 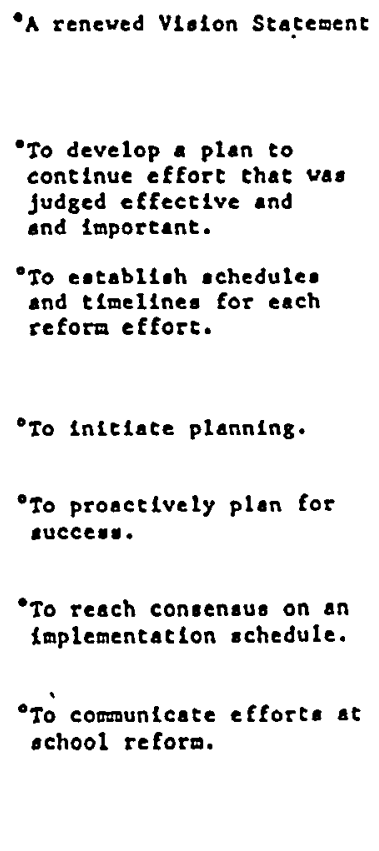 \\
\hline
\end{tabular}




\begin{tabular}{|c|c|c|c|c|}
\hline COAt. & Activits & RESPONSIBTLITK & DATB & ANTICIPATED OOTCORB \\
\hline $\begin{array}{l}\text { 4.0 Implementation } \\
\text { and } \\
\text { celebrat ion }\end{array}$ & 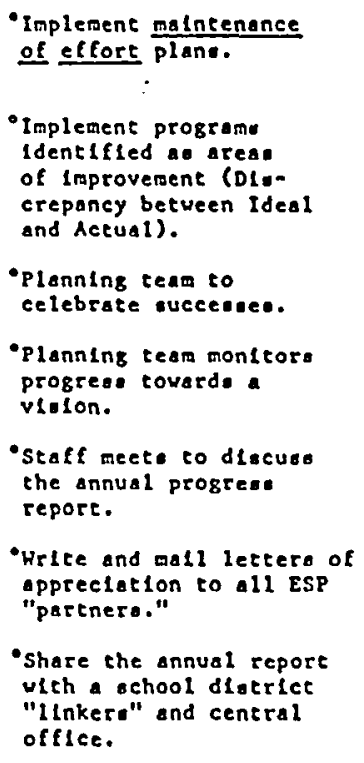 & 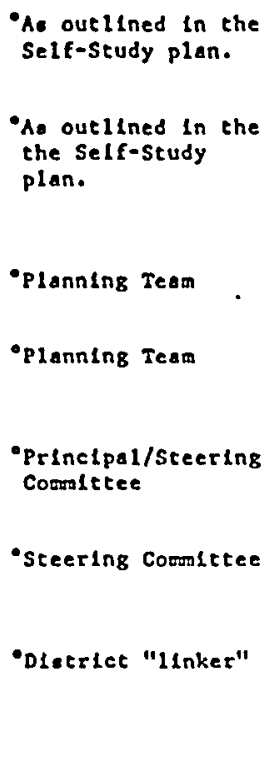 & 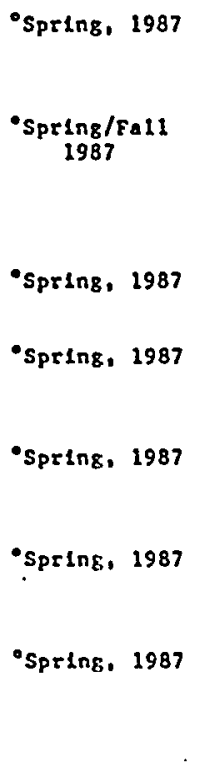 & 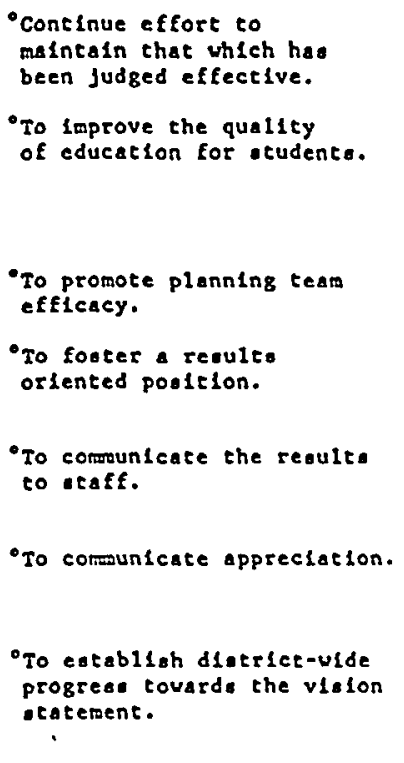 \\
\hline
\end{tabular}




\title{
APPENDIX K
}

\author{
SELF STUDY INSTRUNEAN \\ (Staff and Planing Team) \\ September 10, 1986
}

Please indicate the relative importance of each of the following items by using the rating ccale 4 to 1 . One of the purposes of this survey is to determine if a discrepancy exists between the "Ideal" conditions and "Actual" conditions affecting our school programs. Therefore, it will be necessary to evaluate each item two times. The flrst evaluation should be made by circling the muber just before each item that indlcates its relative importance if the perfect or IDEAL conditions could be established.

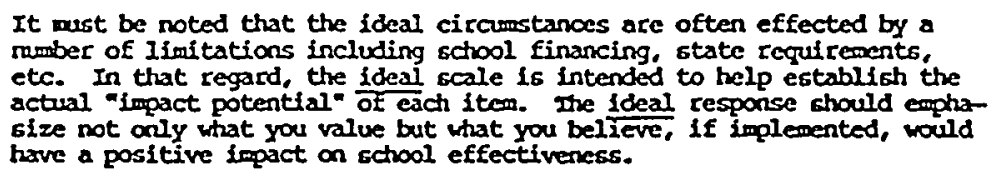

Then using the space following each Item, make the second evaluation by circling the number that indicates the relative importance of each item given the existing or Acturi conditions.

In the appropriate columa, please circle a:

"4" If you feel the item is ArmOST Achars important and must be emphasized;

" 3 " If you feel the item is FREDUEVILY important and could be emphasized;

"2" if you feel the item is occAsIowinLY important and could be ondtted;

"1" If you feel the item is ALMOST NEVER important and should be ooltted.

Please feel free to use the space following each item to delete or add to the items 11sted. Additional coments are welcome. Please use the bottom of the page or the reverse side as necessary. In addition, space has been made avallable at the end of the survey allowing you to include 1teas of personal interest. Be advised that the term teachers can also include other certifled specialists such as counselors, speech therapists, psychologists, etc. NOTE: If you do not have adequate information to answer a given question, please do NOT feel obligated to respond.

TOPIC 11 - CLEAR ACADERTC AND SOCTAL BEEAMTORAL COALS

Effective schools have developed a clear school-wide set of academic and social behavior coals. Basic skill achievement in reading, kriting, and mathematics is heavily emphasized by the entire teaching staff. Student behavior Is also emphasired wich promotes an orderly classroom and a positive school climate. There is no ambigulty. Teachers, parents, and students share the same understanding of the school's goals.

4321 . 1. Teachers make students and parents avare of the objectives and expectations of each course or subject area.

4321 2. The curriculum and the approaches to discipline ace developed and oupported by the staff. 
Self Study Instrument

Page 2

$\underline{\text { Ideal }}$

Toplc6

Actual

CIEAR ACADEXIC AND SOCIAL BERAVIORNL COALS (continued)

4321 . 3. There is a vision statement for this school that guides the

4321 instructional program.

43214 . The purpose or mission of this school is frequently discussed at faculty meetings, parent nights, Effective School project meetings, parent letters, assemblies, etc.

\section{TOPIC "2 - OFDER ND DISCIPLTNE}

Effective schools recognize order as a social necessity and seem to find a happy medium between promoting control and supporting spontaneity. Administrators, teachers, students, and parents understand the basic rules of conduct. Each person may expect that such rules will be und formly enforced. The attitude of each staff member is that "I have the right to enforce the cules even if the student is not assigned to my class or area of responsibility".

43215 . The school is orderly before, during, and after school.

6. Loss of instructional time for extra curricular activitles such as athietics, clubs, activitles, assemblies, field trips, etc. Is minimized.

4321 7. Students recelve consistent feedback from administrators and staff on what is acceptable behavior.

4321 B. Students can count on staff members to be fair.

9. Soclal problems wuch as drug and alcohol abuse are addressed adequately by the school.

10. Staff, students, and parents view this school as a safe and comfortable place.

4321 12. Staff members attempting to maintain discipline are supported by the adinistration.

Topic 13 - EMGa. EXPDCTHIans

Staff and adrinistrators in effective schools hold higher academic and social behavior expectations for their students than do staff and administrators in less effective schools. High expectatlons create clrcumstances where students recognize they are valued and respected for their potential.

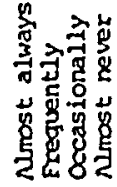

4321 12. There 16 an "I can" attitude in Echool.

4321 13. Appropriate reinforcement and feedback 16 given to each student regarding academic and soclal behavior. 
Self Study Instrument

Page 3

Ideal

Topics

Actual

IIIG EXPECTIIONS (continued)

4321 14. It is believed that instructional effectiveness has a greater effect on student achievement than family or ethnic background.

4321 15. It 15 belleved that all students in this school can master subject matter/acadenic skills as a direct result of the instructional program.

4321 16. Students in this school are motivated by acadeaic expectations set by the staff.

4321

4321

4321 17. High expectations for leaming are comunicated to all students and parents.

4321 18. Students in this school receive high grades only when they have demonstrated high echievement.

\section{TOPIC 44 - TEACGER EFEICACX}

Effective schools have staff members (1.e.., teachers, courselors, speech theraplsts, nurses, school psycholo gists, etc.) who hold a powerful bellef that they are totaliy capable of producing the intended effects. Efficacy is a sense of potency, and it is what provides a teacher with the energy needed for a relentless and persevering effort required to get many students to work. A cense of efficacy combined with high expectations for one's student conomicates powerfully to students that they can and will leam.

4321 19. Teachers observe or coach each other while they are teaching.

432120 . There 16 talk among teachers about the practice of teaching.

4321

4321 21. Staff are responsive to students" need for help.

4321

22. Students are given prompt feedback on the work they have completed.

4321 23. The staff directs the instructional setting from the time students arrive until the end of the session.

4321 24. The staff at our school are proud and confident of what they do.

432125 . people in our building ceek out training experiences that increase thelr ability to educate students.

4321 26. Teamork is evident in the school setting.

27. Kost instructional time is spent on student/teacher interaction, rather than on seat work assignments.

432128 . Leaming activities both challenge students and provide experiences for success.

4321 29. Staff believe that instcuctional/professional effectiveness significantly impacts student achievement. 
Self Study Instrument

Page 4

Ideal

Topics

Actual

TOPiC 15 - pervastve CARANG

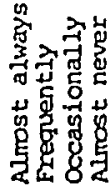

Students in effective schools know that the staff and adninistrators care about them. Caring is expressed in a variety of ways. High expectations, strict but fair

enforcement of rules, and personal interest all tell the student that the teacher is paying attention to them and cares about their achievement.

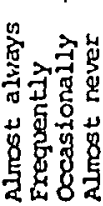

4321 30. There is a "Fe" spirit in this school and a sense of cohesiveness for students.

4321 31. The staff reinforces and encourages success for all students.

4321 32. New students, staff, and parents are made to feel welcowe and a part of the school comanity.

4321 33. Students are treated equally regardless of their achievement level.

4321 34. Students in the school are willing to approach the staff for advice or help.

432135 . Staff members genuinely care about students.

\section{TOPIC "6 - PUBLTC RERARDS AND RNCONTIVES}

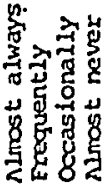

Effective schools have a system of clear and public rewards and incentives for achievement. Public display of excellent student wosk, honor roll, assemblies to honor student excellence, notes sent howe to parents, and verbal and non-verbal praise from teachers as often as possible - serve to motivate and sustain students' achievement of a school's high expectations for them.

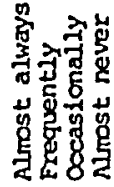

432136 . Student work is on display regularly.

4321 37. Rewards, calls, or notes are sent home for accomplishments.

38. The teaching staff takes opportunities to reward, pralse, and show appreciation to all students for success during instruction.

4321 39. Student projects and successes are featured in school newspapers and/or newsletters.

4321 40. Staff members are Individually recognized and rewarded for practlcing effective teaching strategles/services. 
Self Study Instrument

Page 5

Ideal

Topics

Actual

TOPiC 17 - ADRTMISTRATIVE LEADERSUIP

Effective schools have adrinistrative leaders, most often principals, who actively create the conditions being described. The principal is a person who helps to make sure these tasks are carried out appropriately. Such a person listens to staff requests and attempts to support those requests whenever reasonable. In effective schools, the adrinistration is seen by both staff and students as supportive, caring, and trustworthy, all of which helps create conditions for excellence.

4321 41. A process has been established to develop a school-wide consensus on a vision or purpose.

4321 42. School administrator(s) encourage the use of different instructional strategies.

4321 43. School administrator(s) are an important instructional resource in wy school.

4321 44. School administrator(s) recognize the collegial naturc of teaching and support cooperative teaching efforts.

4321 45. School administrator(s) encourage staff to try out new 1deas

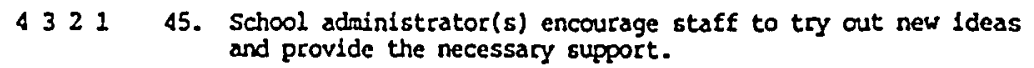

4321

46. School administrator( $\delta$ ) are active in securing resources, arranging opportunities for and promoting staff developoent.

4321 47. A plan for assessing comanity and school opinions about program strengths and needs exists and is used at the district and school level.

4321 48. At this school there is an ongoing effectlve staff development program based on teachers' needs.

4321 49. Feedback from school administrator(s) helps me improve wy teaching/services.

4321

4321

4321

4321 50. School administrator(s) are highly visible and make frequent informal contacts with parents, teachers, and students.

4321 51. School administrator(s) use decision making strategies that involve the people effected by their decisions. 
Self study Instrument

Page 6

Ideal

Topics

Actual

TOpiC "8 - SCTOOL - COMAUITY PARTNERSRIP

Effective schools have Dore contact with parents and conmunity members than less effective schools. Cantact with parents is proactive and goes well beyond concerns related to truancy and discipline. Parents and other comounity members are actively engaged in school activitles and well informed regarding school expectations, successes. and failures. Effective schools have more positive parent Initfated contacts than do less effective schools.

4321 52. Decisions about the school are reached through a process which involves staff, students, parents, and others from the commity.

4321

4321 53. Parents are considered important partners and are actively involved in working on school improvement tasks with staff and students.

4321

4321 54. A variety of methods are used to report student progress (1.e.., progress reports, conferences, and telephone calls) to parents.

4321 55. Fulles and consequences are clearly comounicated to, and understood by, students and parents.

432156 . The ctaff supports and encourages parent and comunity Involvement.

TOPIC N9 - HIG ACADEIC LEAREIIG IITE

Researchers have found that, up to a point, the more time one spends on a leaming task the more one learns. It has also been determined that It is 1mportant for students to be experiencing leaming at extremely high ouccess rates. This means that educators in more effective 6 chools maximize instoctional time and select curriculum materials wilch are most appropriate to student abilltles.

4321 57. Routines and procedures have been established so that noninstructional matters are handled routinely and efficiently.

4321 58. The predominant amount of instructional time 15 spent on student/teacher interaction in wich students are actively involved rather than individual seat work assignments.

4321 59. Administrators, teachers, and support staff enforce a policy of minimom intercuptions of teachers during instruction.

432160 . Assemblies, activities, and field trips are planned to minimize the loss of instructional time.

4321 61. Pull-out programs are planned to fit Into and enhance the total instructional program. 
Self study Instrument

Page 7

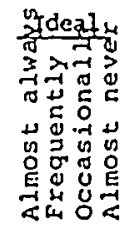

4321

4321

4321

4322

4321

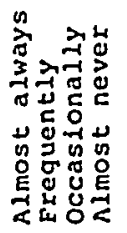

4322

4321

4321

4321

4321
Topics

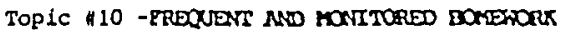

Teachers in effective schools, after fourth grade, require more homework more often and provide students with feedback about how well their homework was completed.

62. Homework is sequenced so that it does not happen all in one day.

63. A reasanable amount of homework is assigned on a regular basis.

64. Homework is promptly evaluated and retumed.

65. The hoonework that children bring howe is appropriate for their ability level.

66. Homework is a reinforcement or practice activity which is an extension of the daily lesson.

\section{TOPIC "11 -FREQUENT AND MONITORED STLDENT PRDRRESS}

Administrators and teachers in effective schools monitor student academic progress more frequently than do staffs in less effective schools. Such frequent monitoring serves an important diagnostic function, prevents students from fallIng behind, and tells students that what is belng taught is important.

67. Achievement data is used to change and lowpove the curriculum on a regular basis.

68. Curriculum improvement priorities have been based in part on assessment results.

69. Achlevedent is assessed in a varicty of ways, e.g., tests, teacher logs, competency standards, perfocmance reports.

70. Student assessment information (such as tests, skills checklist, etc.) is used to give specific feedback and plan appropriate instruetion.

71. There is a school-wide commitment to assessment and accountability.

Topic $" 12$ - THQRIYY COURED CARRIarurs

Effective schools have a curriculum which is closely related to both school-wide and indivitual grade level objectives. Teachers do not rely solely on comerctal products but tallor or create materials and activities to meet the agreed upon goals. In effective schools there is a comon comitment to a specific knowledge or skill base that should be learned. In addition, teachers are involved in decisions that effect district or school-wide curriculum. àctuartar

तेत्र

+ प्रम

of

E

4321

4321

4321

4321

4321

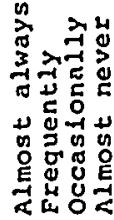

4321

4321

4321

4321

4321 
Self Study Instrurent

Page 8

$\underline{\text { Ideal }}$

Topics

Actual

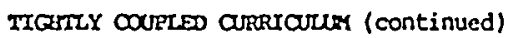

4321 72. There is a match between achievement tests given and curriculum 4321 taught.

4321 73. The teaching staff is uniformly cormitted to the same minimum and essential content/skills at each grade level or in each subject area.

4321 74. District adopted curriculum guides are used in planning for instraction.

432175 . Instructional topics are linked to the written curriculum and objectives.

4321 76. Building staff members participate in developing the district written curriculum and in the evaluation of curriculum materials scheculed for adoption.

4321 77. There is a direct linkage between individual school and district priorities and plans.

4321 78. The district has a written curriculum/program evaluation

4321 79. The district's curriculum specifically includes the development of critical thinking and higher order reasoning skills in addition to baslc skills.

TOPIC "13 - VARTETY OR TEACMING STRATEGTES

Research has demonstrated that teachers in effective schools use a greater varlety of teaching strategies than teachers in less effective schools. That is, teachers in effective schools are able to accomodate student differences by employing altemative teaching strategies when students are not succeeding.

432180 . The school has effective programs for students with special 4321 leaming needs.

4321 81. The school has effective procectures for identifying and assessing 4321 students with special leaming needs.

4321 82. Staff demonstrates a variety of teaching methods to match

4321 leaming objectives and student abilities.

4321 84. Staff chooses instructional activities which provide exten-

83. Staff encourages students to think and solve problems.

4321 sive student/teacher interaction.

85. Staff uses instructional techniques which prooote high success and achlevement levels for all students within each individual's capacity to achleve success. 
Self study Instrument

Page 9

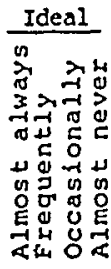

Topics

Actual

TOpic 114 - OPRORTUNITIES FOR STUDENT RESRONSIBILITY

Effective schools provide students with more opportundties

to engage in responsible behaviors. As an example, such

opportunities could include student government, discipline

panels, peer and cross-age tutoring, school fund raising

projects, and extra curricular activities.

4321 86. The staff encourages and models good behavior and rewards it with earned respansibility.

4321 87. Students have input into the development and evaluation of school practices and policies on discipline and behavioral norms.

4321 88. There are opportunities for students to take positions of responsibility in this school and to participate in decisions about school related issues.

4321 89. School is percelved as a place that encourages students to be confldent, self-directing, Independent, and successful.

4321

4321

4321

4321

4321 90. A system of student responsibility and accountablilty for leaming has been implemented.

TOPIC 15 - MCILITIES

Effective Schools feature a physical plant that is clean, pleasant, and generally well-kept. Custodians and other oupport personnel feel they are a part of the school comounity and contribute to school effectiveness.

4321 91. Physical/plant (building maintenance) problems are attended to lonediately.

4321 92. The physical condition of wy school is generally pleasant and well-kept.

4321

4321 93. The custodians feel they are an important part of the staff in our school.

4321 94. School facilities adequately meet the need of the academic

4321

432195 . School faclilities are adequate for the needs of the activity/ athletic programs.

Topic 16 - STUDENT ACTIVITIES

Effective Schools provide many opportunitles for students to participate in various extra-curclcular activities. student and comunity particlpation is high, positive, and very supportive.

432196 . comunity participation at school events is good. 
Self Study Instrument

Page 10

Ideal

Topics

Actual

STOENT ACTVITIES (continued)

4321 97. School events, such as athletic contests, musical and dram events, PLA, and social events are well attended by stafe.

98. School events, such as athletic contests, musical and drama

eve, and sochal events are well attended by students. program is high. (Answer only if approprtate)

4321 100. Many opportunities are made available for students to partici-

4321 pate in extra-curricular activities.

Topic 17 - SERICOS

In more effective schools, district support services are routinely available on an as-needed basis. comminication is an effective two-way process which generates the intended outcome in a convenient and timely way.

4321 101. School staff members participate with district support staff in the development and implementation of curricula.

4321 102. The staff at the school regularly requests and uses gervices provided by the distrlct support staff.

4321 103. Each student receives support services as needed (e.g., counseling, mursing, speech therapy, occupational/physical therapy, psychological services, etc.j.

4321 204. Transportation services are adequate for the needs of students.

4321 105. The food service program provides attractive, mutritlonal, and tasty meals.

4321 106. Staff feels that comanication lines with district administration is open.

4321 107. Staff is able to get the instructional materials they need in a timely manner.

4321 108. In-service prograns are available to staff allowing them to maintain a current understanding of teaching/service dellvery strategies.

4321 109. Comity education is effective in making educational, recreational, and entichment programs available to all residents of the district regardless of age. 
Self Study Instriment

Page 11

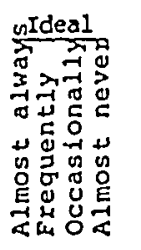

Topics

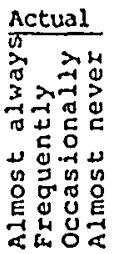

4321 110. The media center (library) in the school is adequate to meet

the needs of students and staff.

4321

4321 111. Instructional materials are available and easily accessible to students and staff.

4321 112. Films and other instructional materials provided by the Educational Service District 1112 are of good educational quality.

4321 113. A variety of instructional materials are used on a regular

4321 basis in our schools.

4321 114. The amount of supplementary instructional materiais used in our school is adequate for the needs of the students.

4321 115. The leaming resources program includes direct instruction activities which support and complement the school curriculum.

4321

4321

4321

\section{SUCGESTED AREAS}

4321 116. Please feel free to include items not previously made available. 4321 
Self Study Instrument

Page 12

DEMOCRAPHIC DATA

1. Are you currently a: Certlfied staff member

$\begin{array}{ll}\begin{array}{c}\text { (Please answer } \\ \text { only one) }\end{array} & \text { - Classified staff member } \\ & \text { Student } \\ \text { Parent } \\ \text { Comanity member }\end{array}$

2. If you are a certified'staff member, please check the appropriate grade level/subject/ service you are providing or teaching. (Answer only if appropriate)

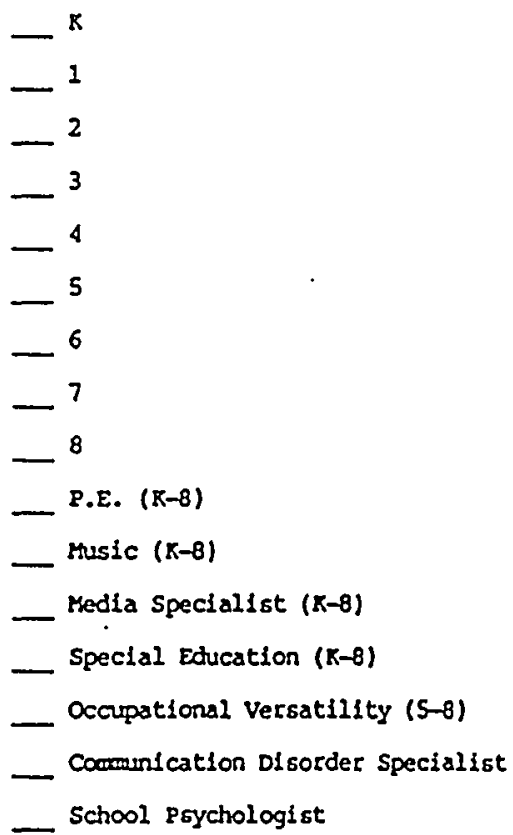

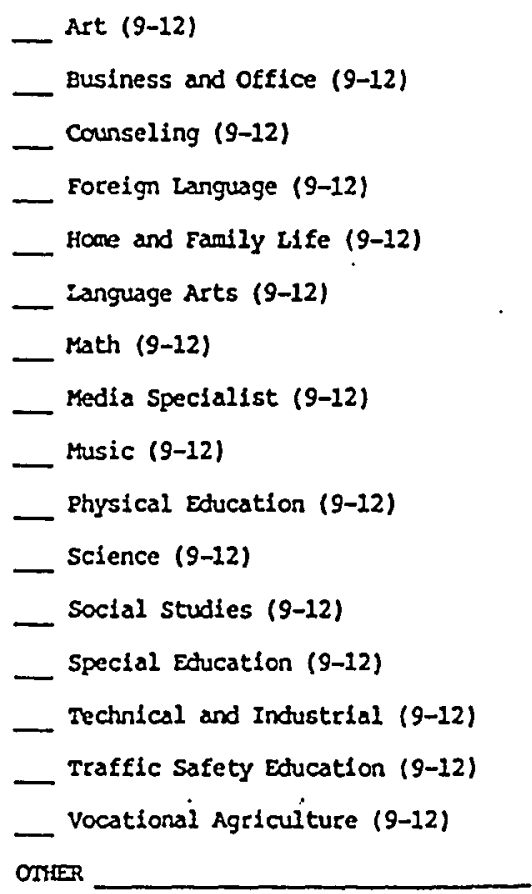

3. If you are a certified staff member, please indicate how many years of experience you have. (Answer only if approprlate)

- ${ }^{0-5}$ years $6-10$ years $-11-15$ years - more than 20 years

4. With wich cchool in the Battle Ground School District are you primarily affiliated?

5. You are a member of the ESP planning team. Y Y Y NES 
APPENDIXK L

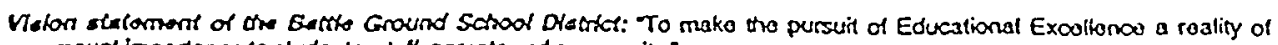
paramoum importanco to students, stall, parents and cornsmunity."

\section{Battle Ground School District \\ Analysis of Self-study Results A Plan for Improvement}

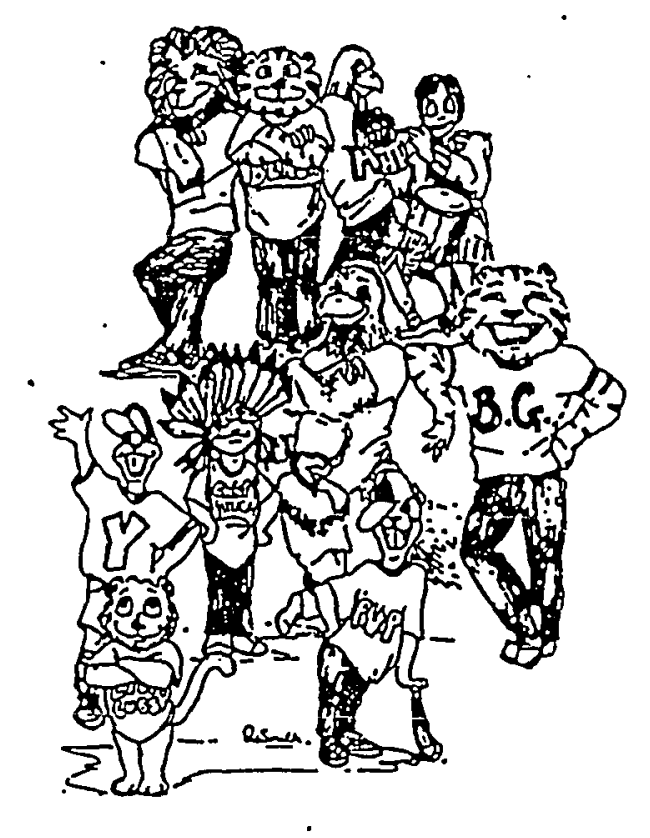

1986-87

\footnotetext{
- Battle Ground High School - Laurin Intemodiate - Chiel Umtuch Primary - Pteasant Valley Primary •

- Prairie High School - Lowisville Intermodiate - Glenwood Hoights Prmary - Yacolt Primary -

- Amboy Intermediate - Pleasant Valley Intemrodiate - Maple Grove Primary •
} 


\section{BATILE GROUND SCHOOL DISTRICT SELF STUDY INSTRUMENT DATA PVI}

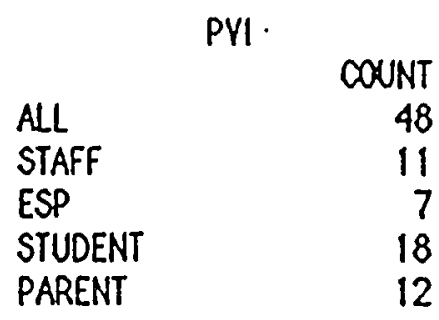

\begin{tabular}{lr}
\multicolumn{2}{c}{ MIDDLE SCHOOLS } \\
ALL & COUNT \\
STAFF & 272 \\
ESP & 65 \\
STUDENT & 45 \\
PARENT & 95 \\
& 65
\end{tabular}

\begin{tabular}{lr}
\multicolumn{2}{c}{ SCHOOL DISTRICT } \\
ALL & COUNT \\
STAFF & 831 \\
ESP & 280 \\
STUDENT & 124 \\
PARENT & 285 \\
PART & 140
\end{tabular}


Topic \# 1

CLEAR ACADEMIC AND SOCIAL BEHAYIORAL 6OALS

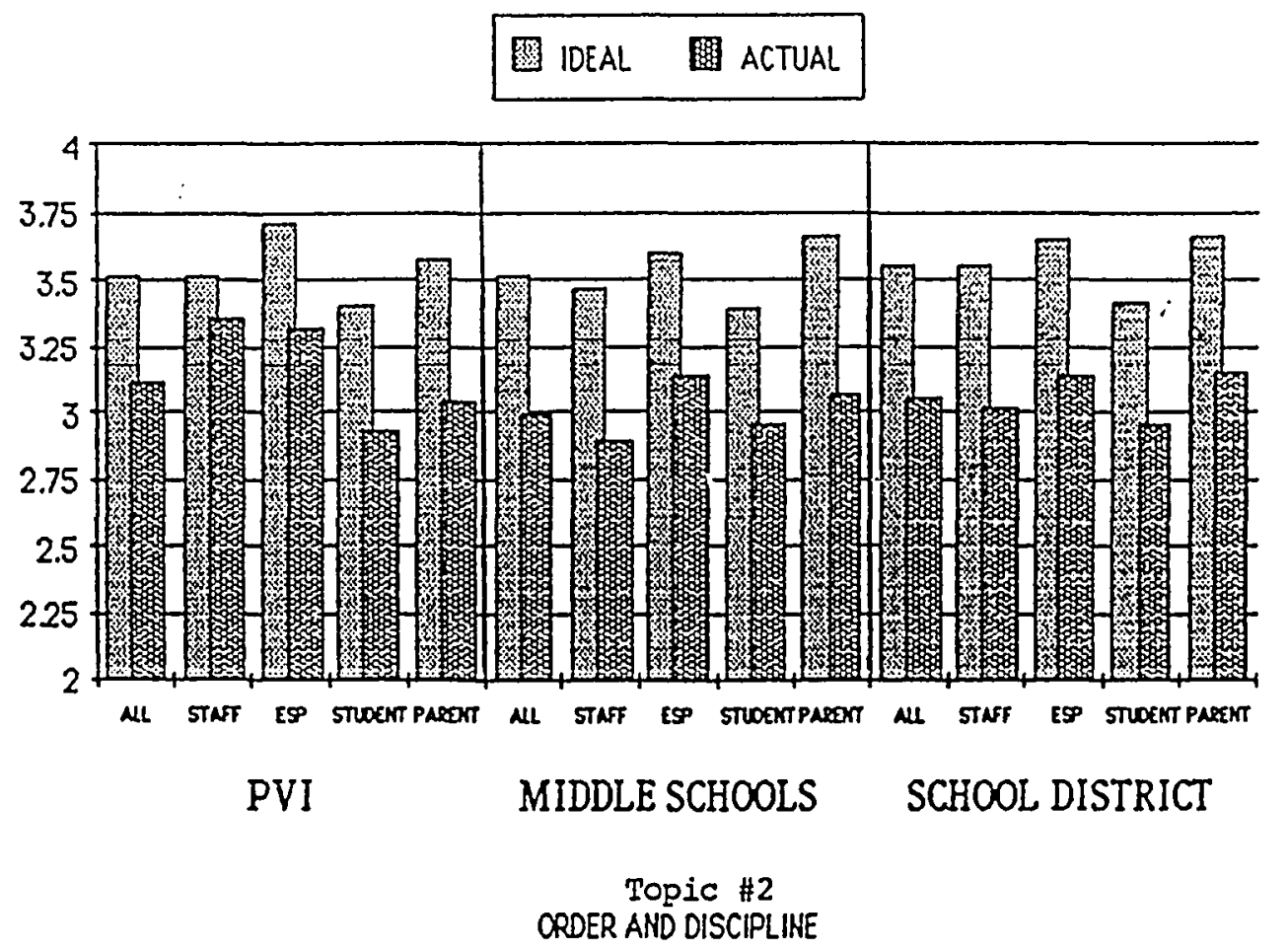

IDEAL 媦 ACTUAL

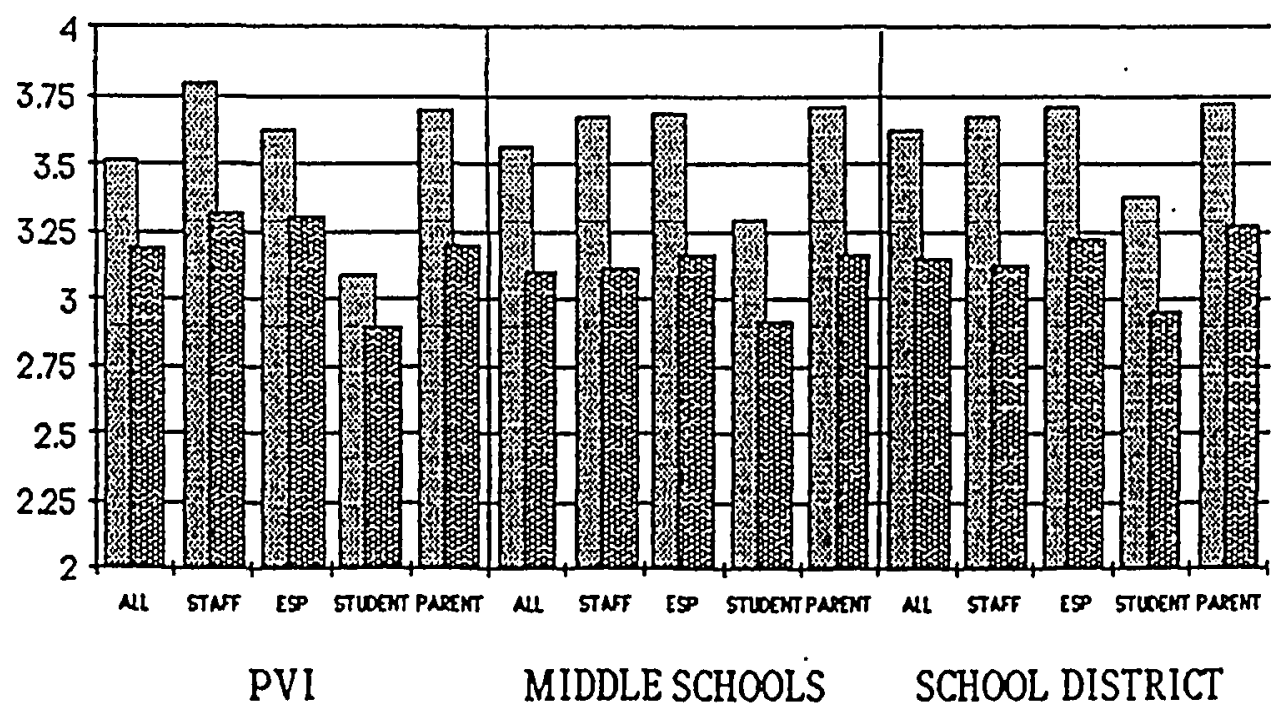


Topic $\$ 3$

HIGH EXPECTATIONS

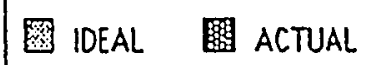

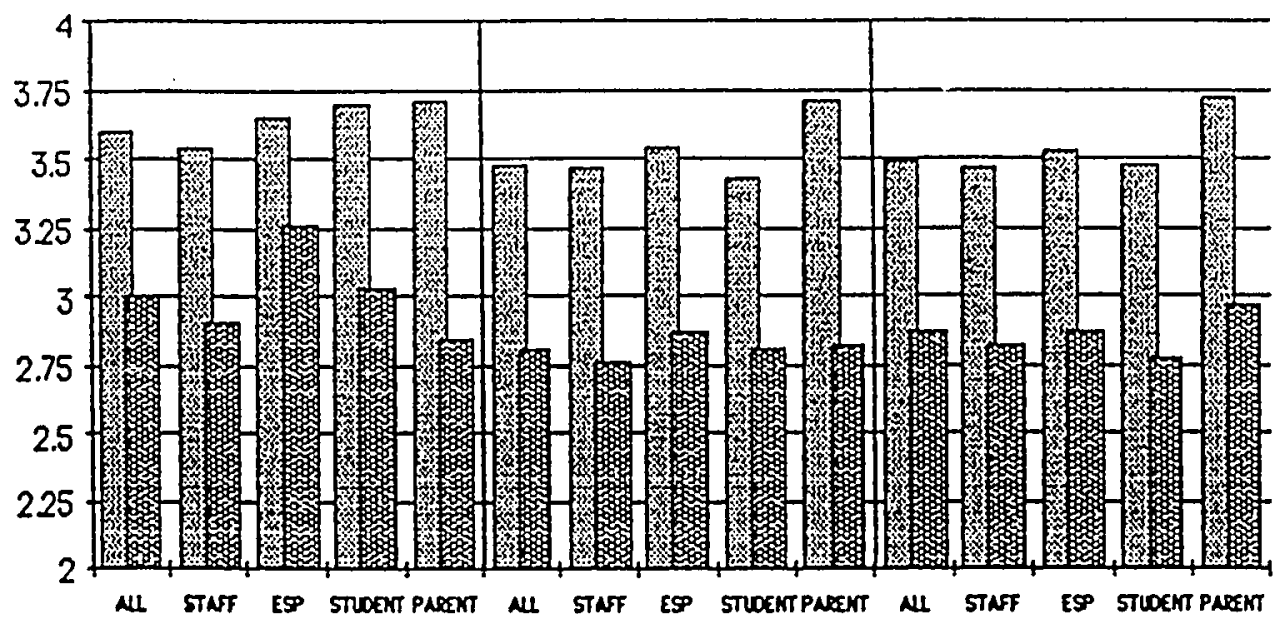

PVI MIDDLE SCHOOLS SCHOOL DISTRICT

Topic \#4

TEACHER EFFICACY

图 IDEAL 图 ACTUAL

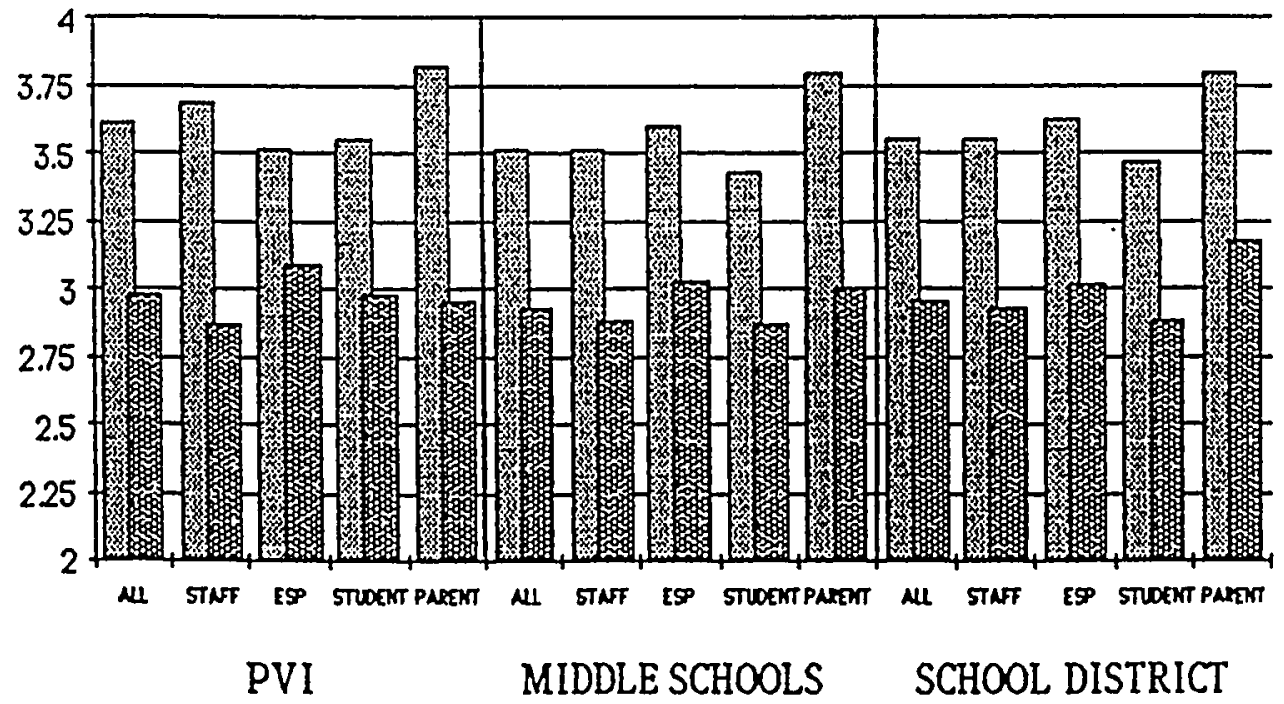


Topic \#5

PERVASIVE CARING

IDEAL 四 ACTUAL

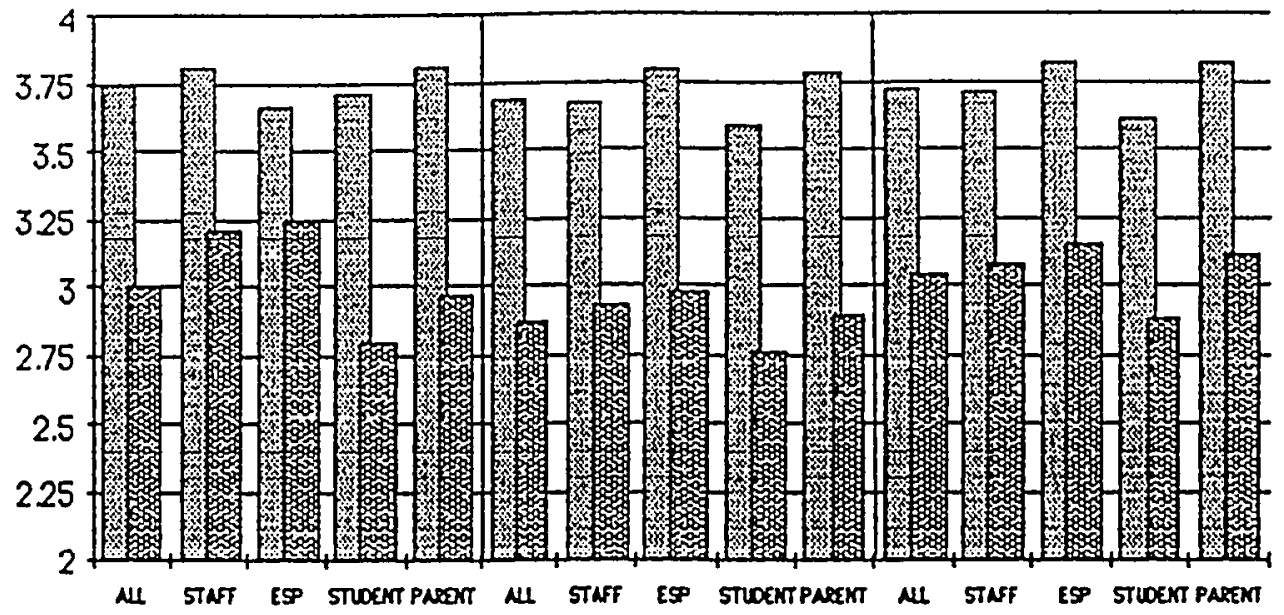

PVI MIDDLE SCHOOLS SCHOOL DISTRICT

Topic \#6

PUBLIC REWARDS AND INCENTIVES

圈 IDEAL 圈 ACTUAL

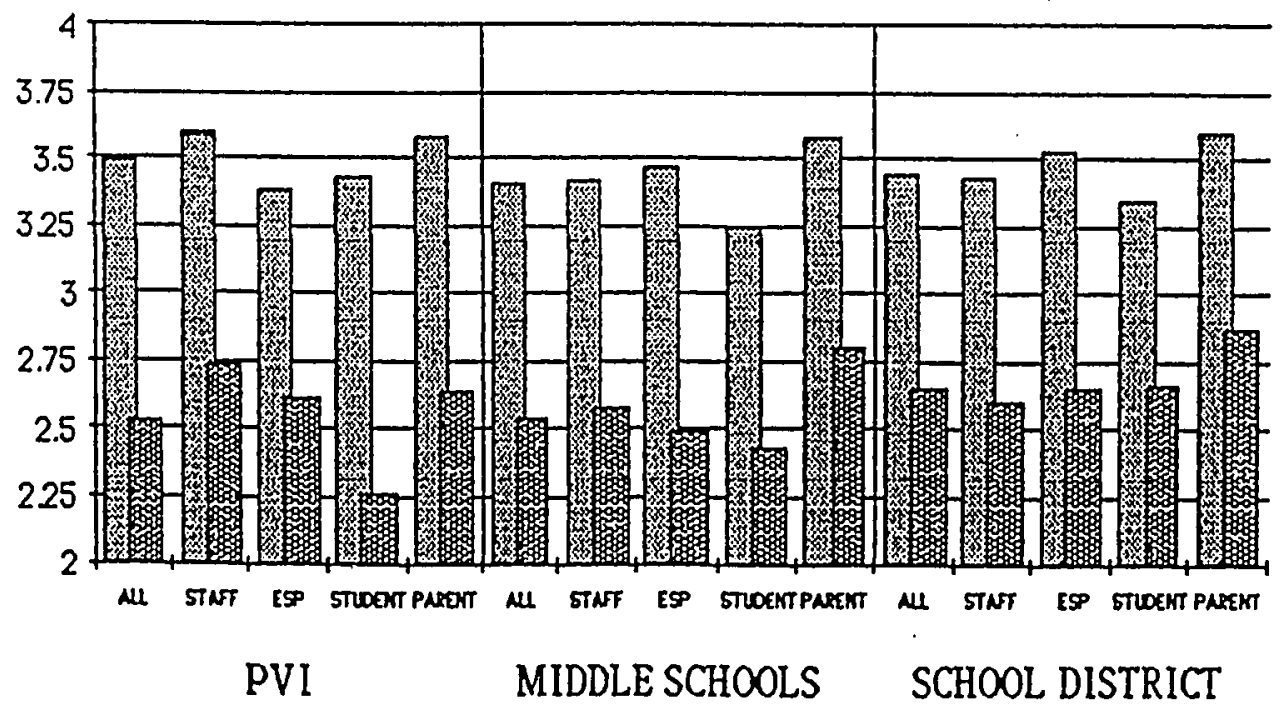


TOPiC \#7

ADMINISTRATIVE LEADERSHIP

圈 IDEAL 盟 ACTUAL

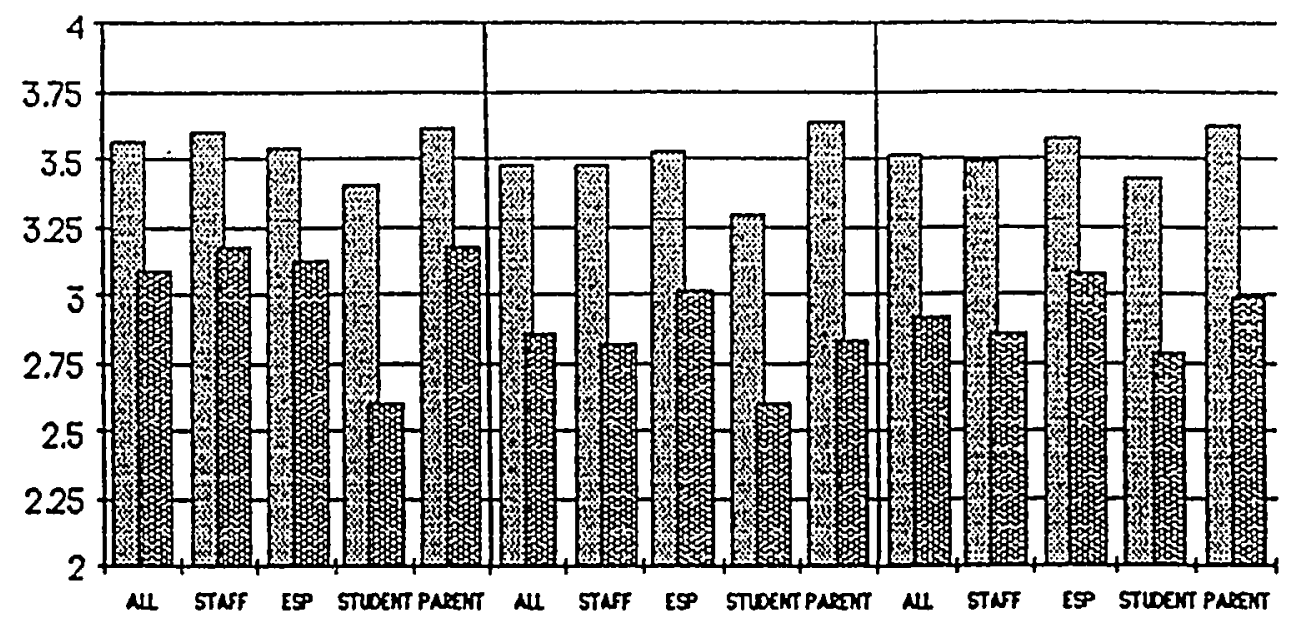

PVI MIDDLE SCHOOLS SCHOOL DISTRICT

\section{TOPIC \#8
SCHOOL-COMMUNITY PARTNERSHIP}

\section{图 IDEAL 通 ACTUAL}

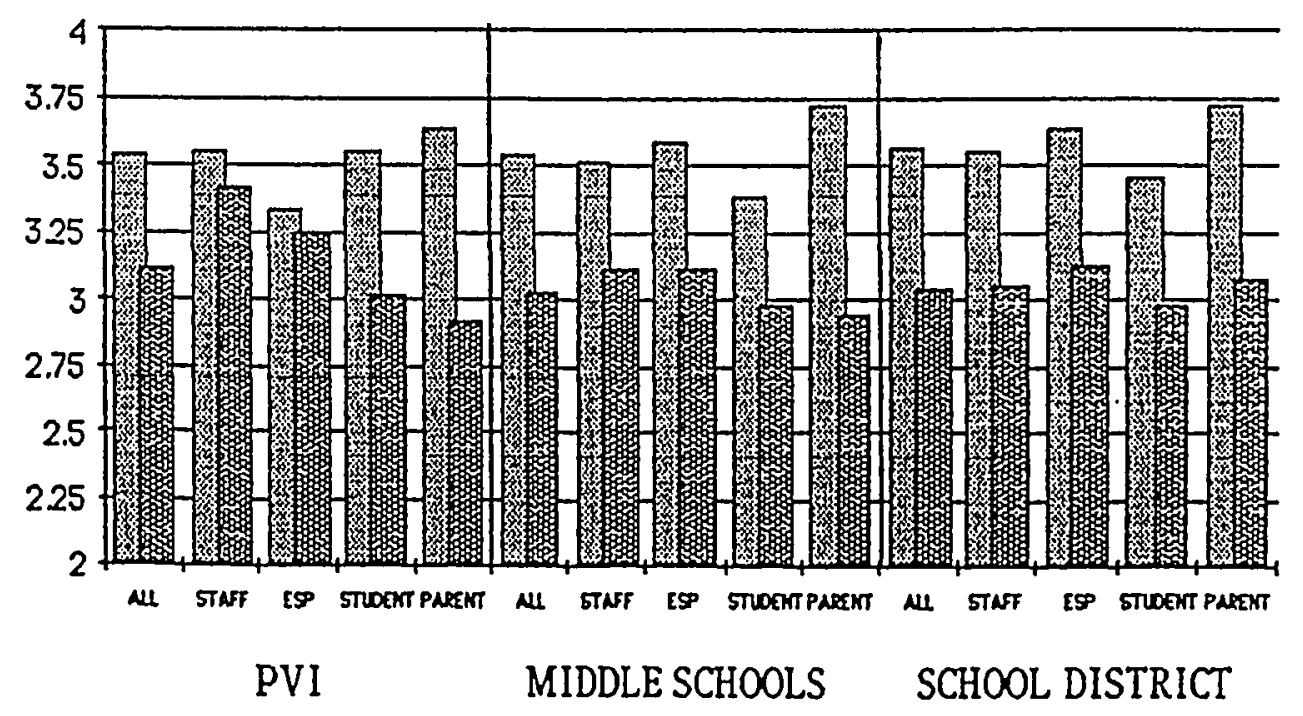


Topic \#9

HIGH ACADEMIC LEARNING TIME

IDEAL 圈 ACTUAL

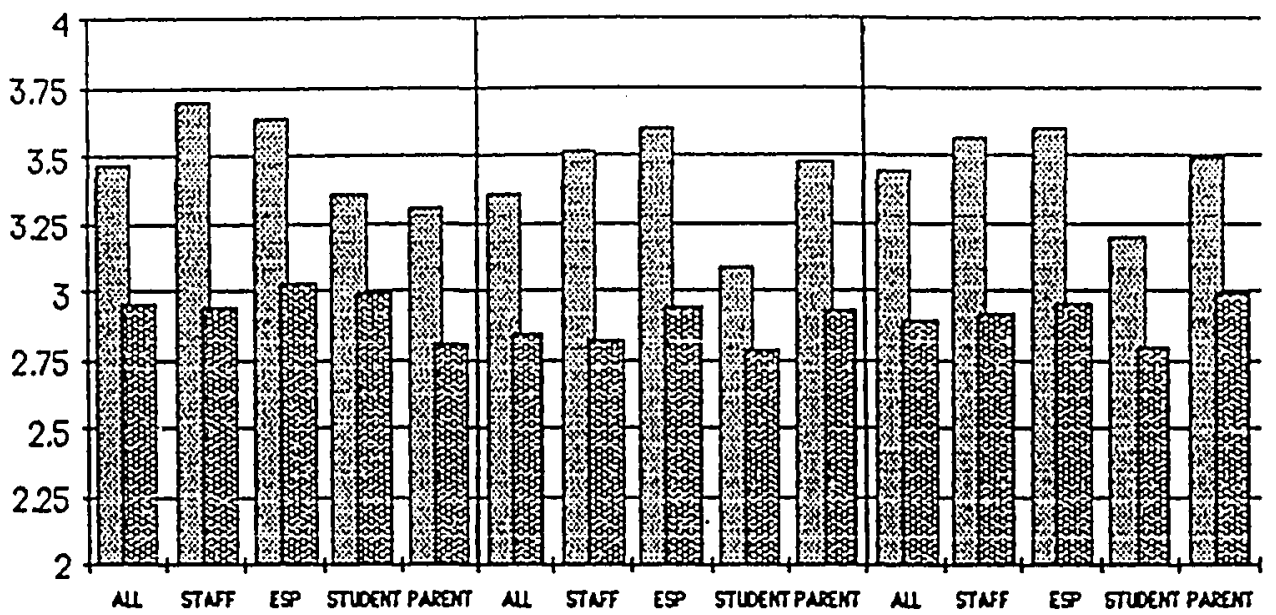

PVI

MIDDLE SCHOOLS SCHOOL DISTRICT

Topic \#10

FREQUENT AND MONITCRED HOTEWORK

圈 IDEAL 圈 ACTUAL

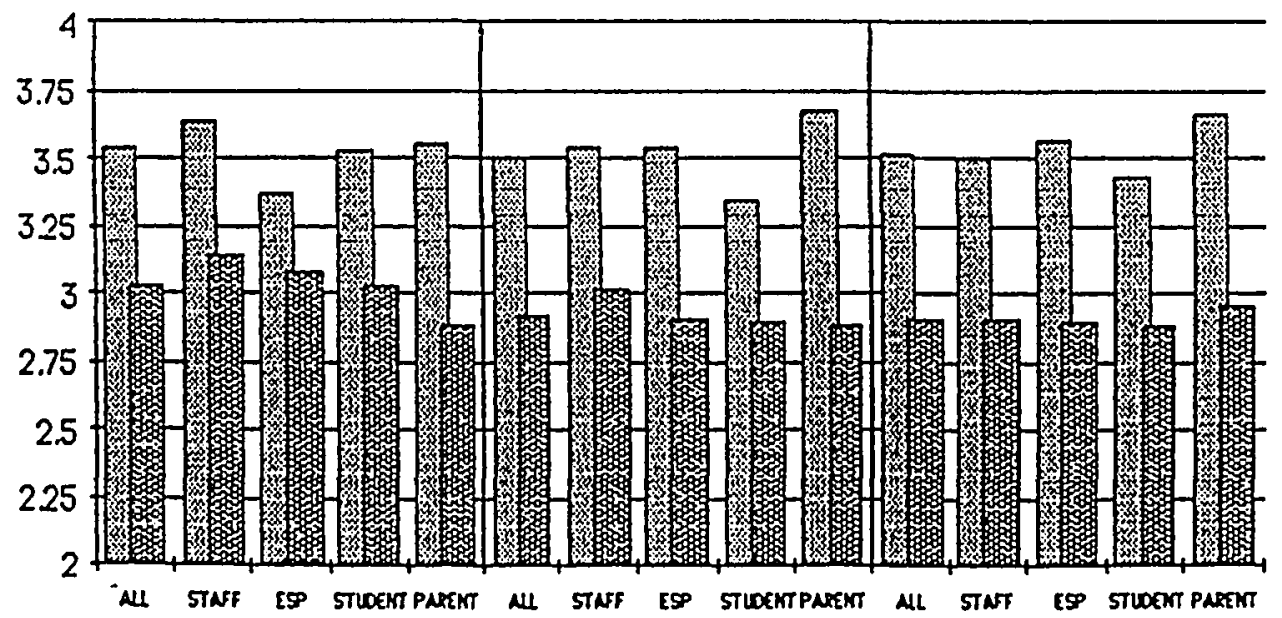

n PVI MIDDLE SCHOOLS SCHOOL DISTRICT 
Topic \#11

FREQJENT AND MONITORED STUDENT PROGRESS

맚 ACAL RUA

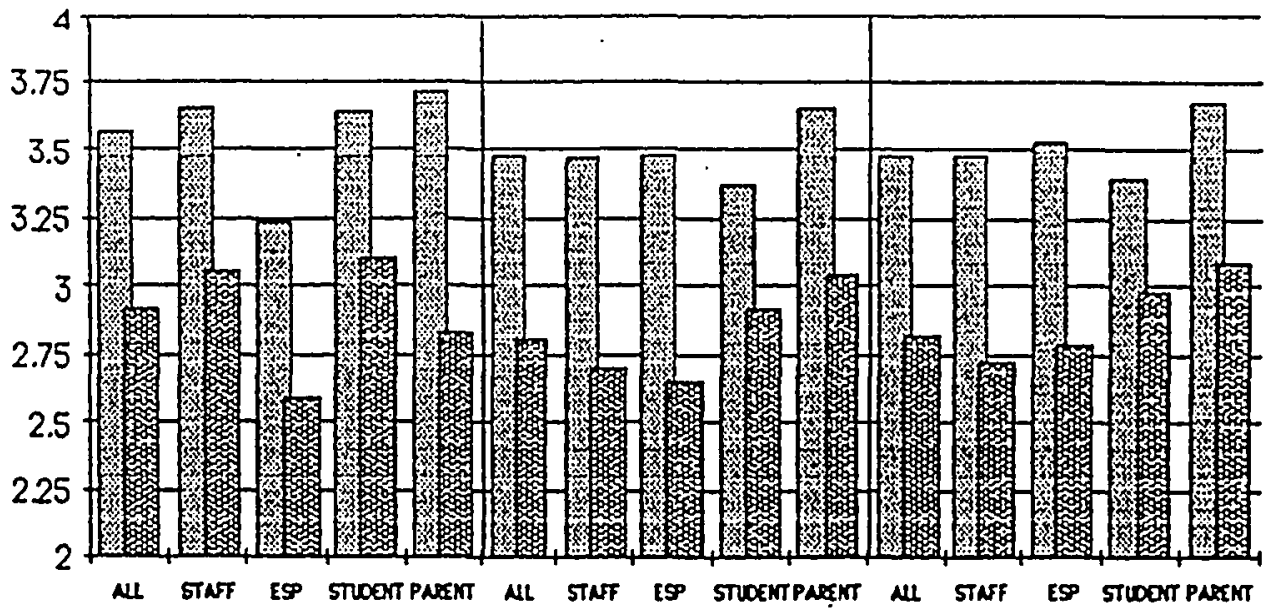

PVI MIDDLE SCHOOLS SCHOOL DISTRICT

Topic \#12

TIGHILY COUPLED CURRICULUM

圈 IDEAL 国 ACTUAL

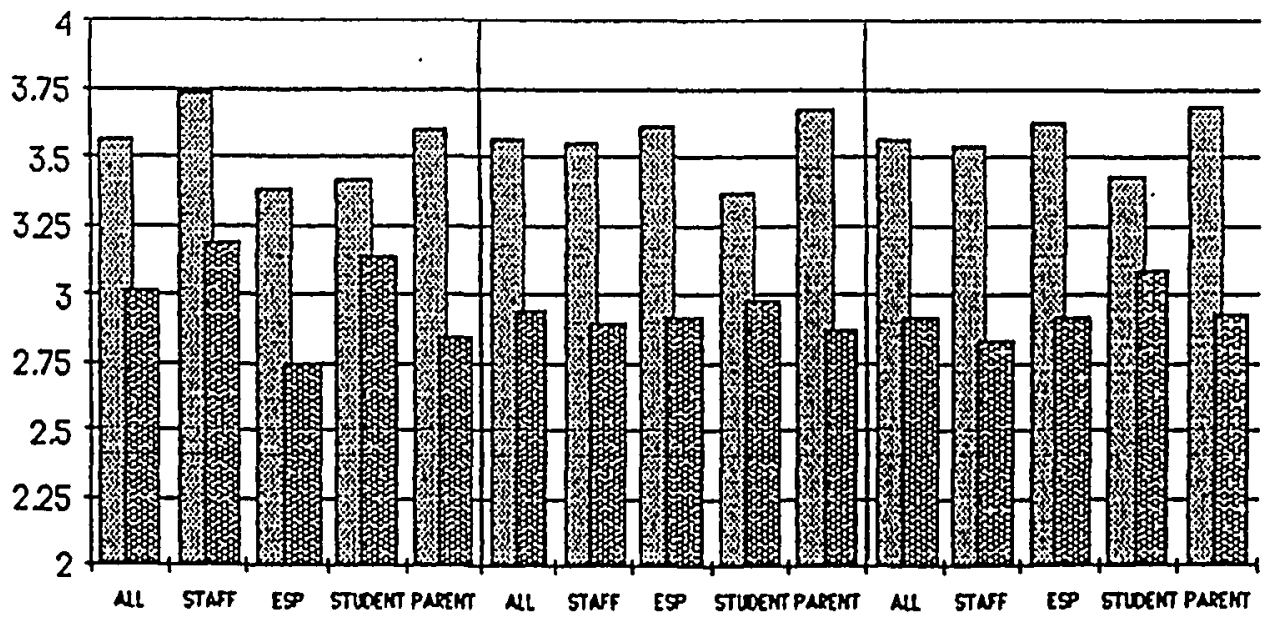

PVI MIDDLE SCHOOLS SCHOOL DISTRICT 
Topic \#13

VARIETY TEACHING STRATEGIES

圈 DEAL 䁖 ACTUAL

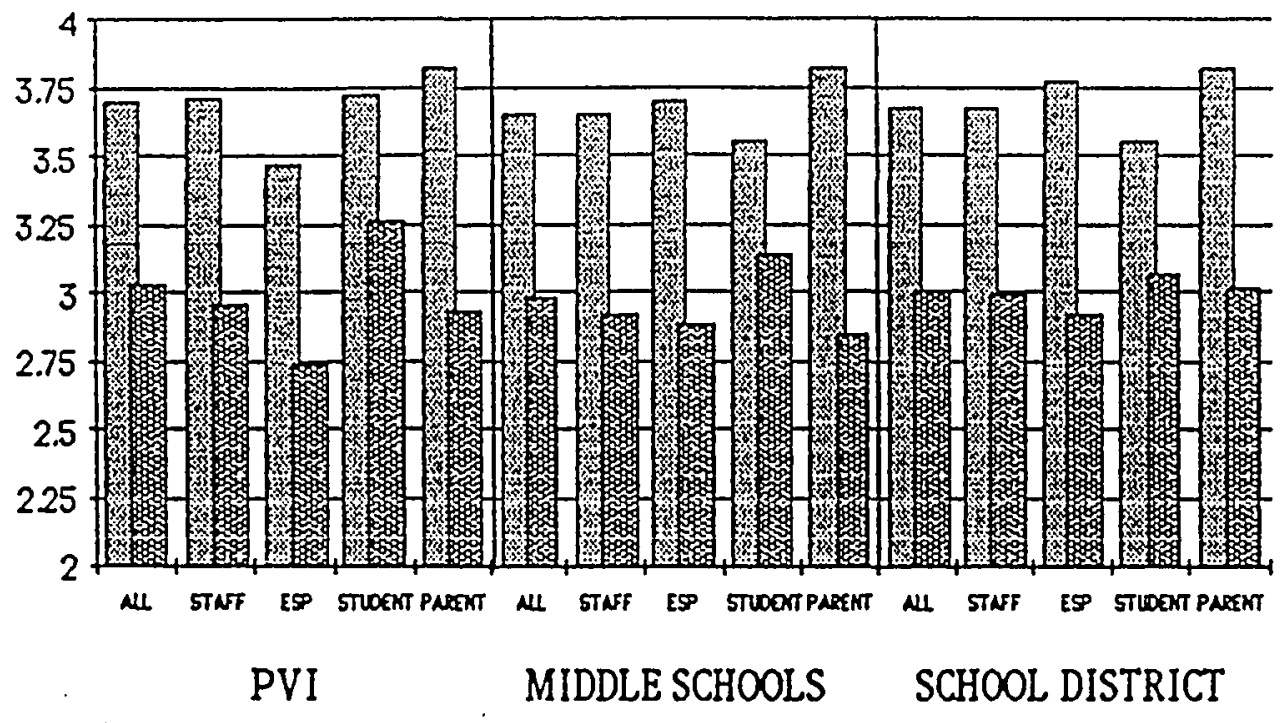

Topic \#14

OPPORTUNITIES FCR STUDENT RESPONSIBILITY

\section{圈 IDEAL 国 ACTUAL}

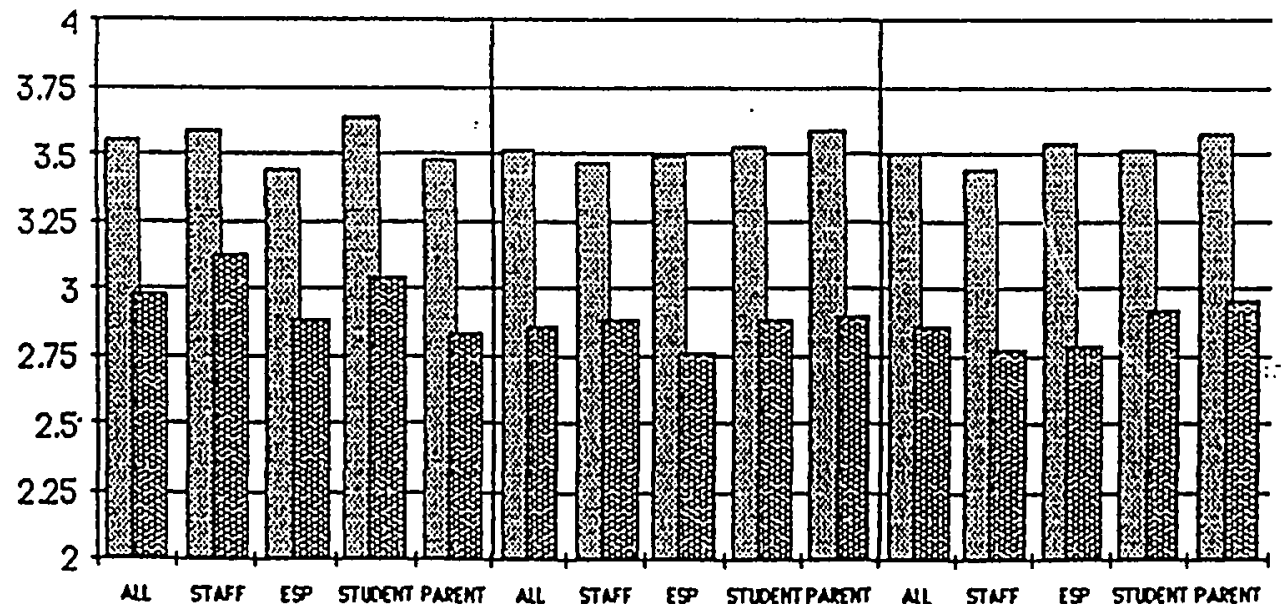

PVI

MIDDLE SCHOOLS SCHOOL DISTRICT 
Topic \#15

FACILITIES

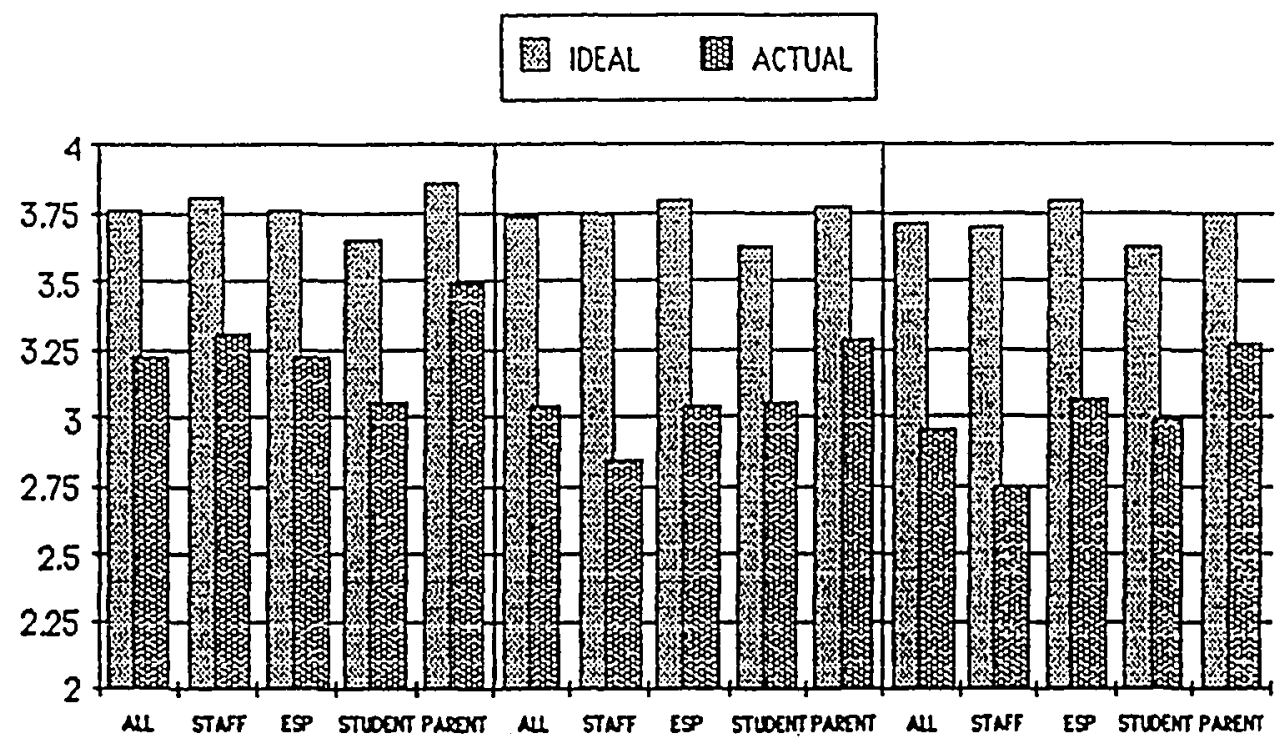

PVI

MIDDLE SCHOOLS SCHOOL DISTRICT

Topic \#16

STUDENT ACTIVITIES

IDEAL ACTUAL

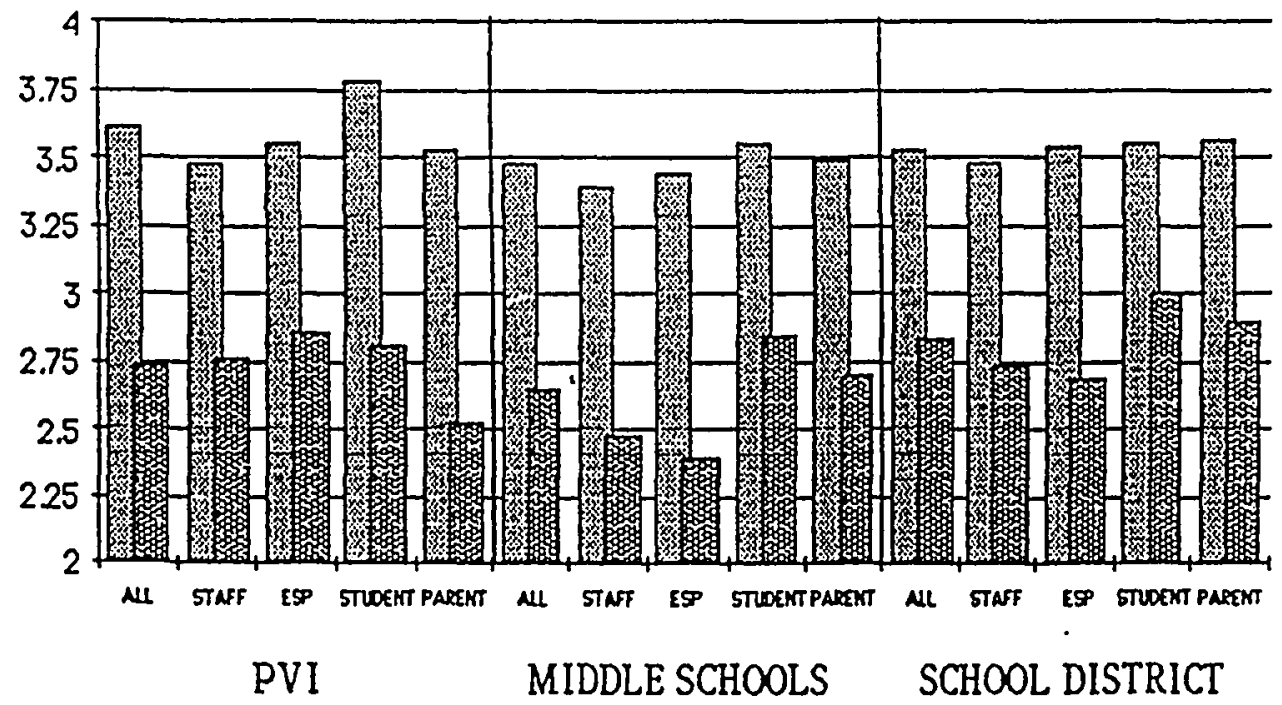


Topic \#17

SERVICES

\section{图 IDEAL 圈 ACTUAL}

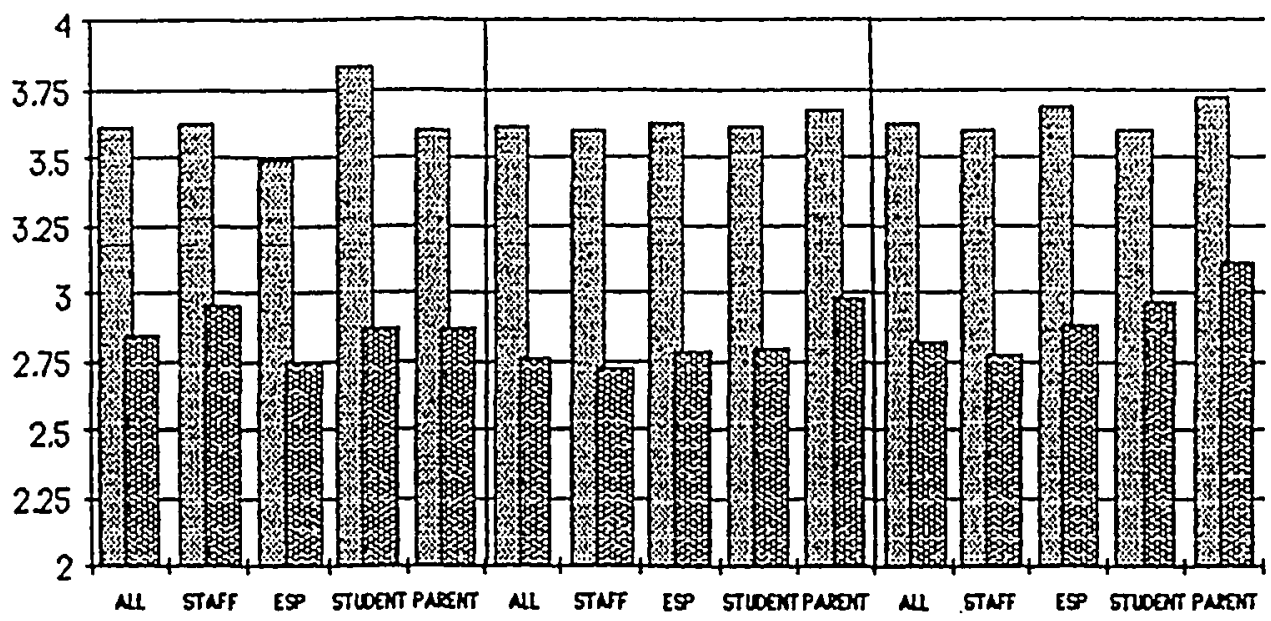

PVI MIDDLE SCHOOLS SCHOOL DISTRICT

Topic \#18

LEARNING RESOURCES

函 IDEAL 湖 ACTUAL

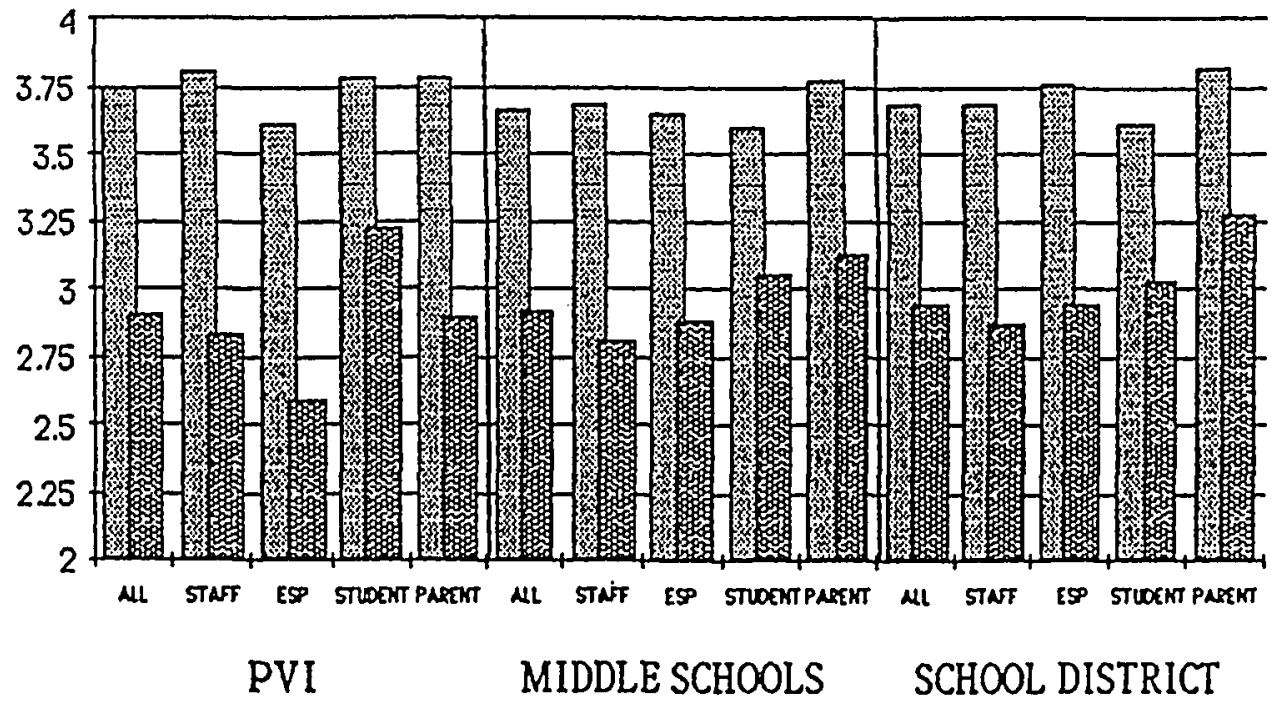


PYI TOPIC TABLES

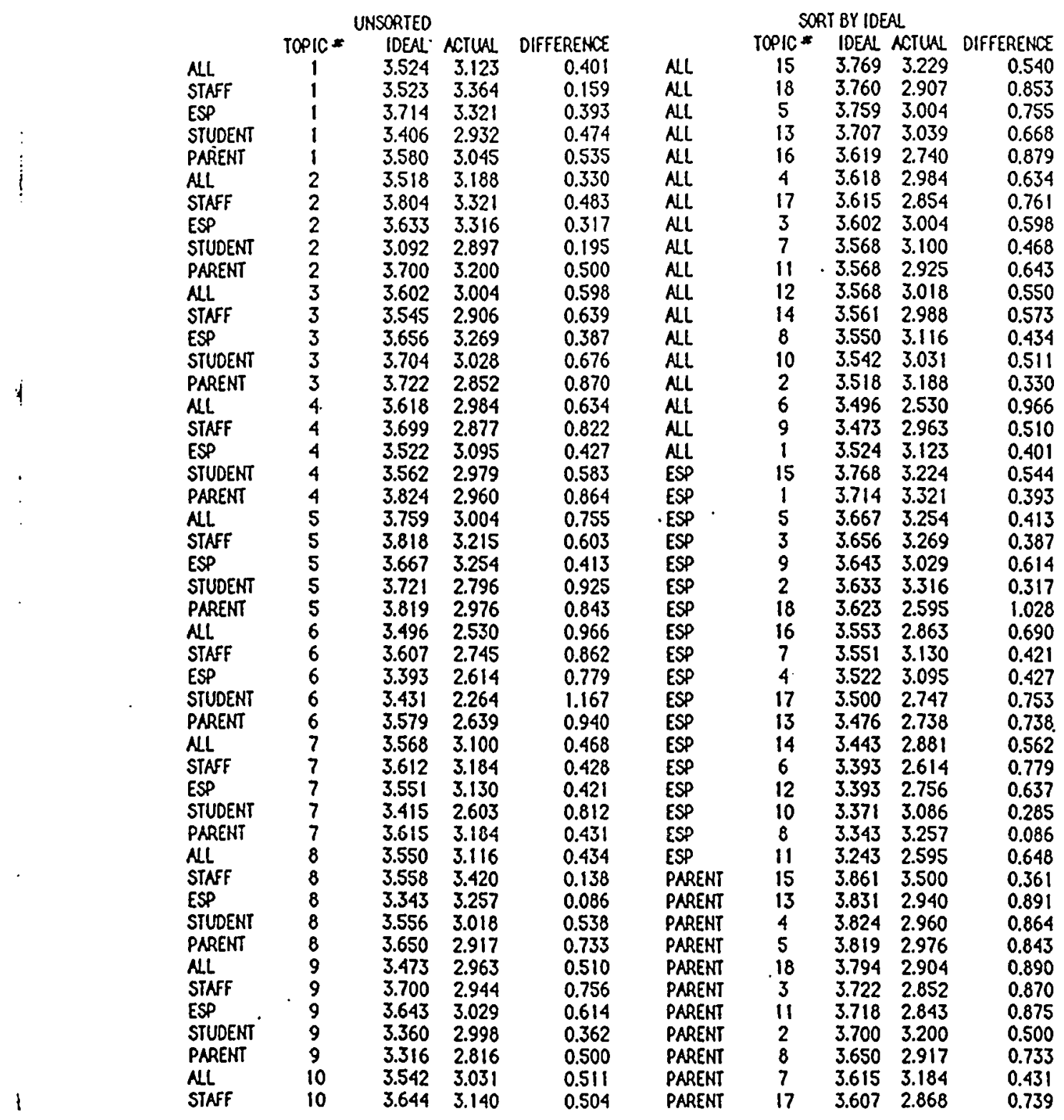


PVI TOPIC TABLES

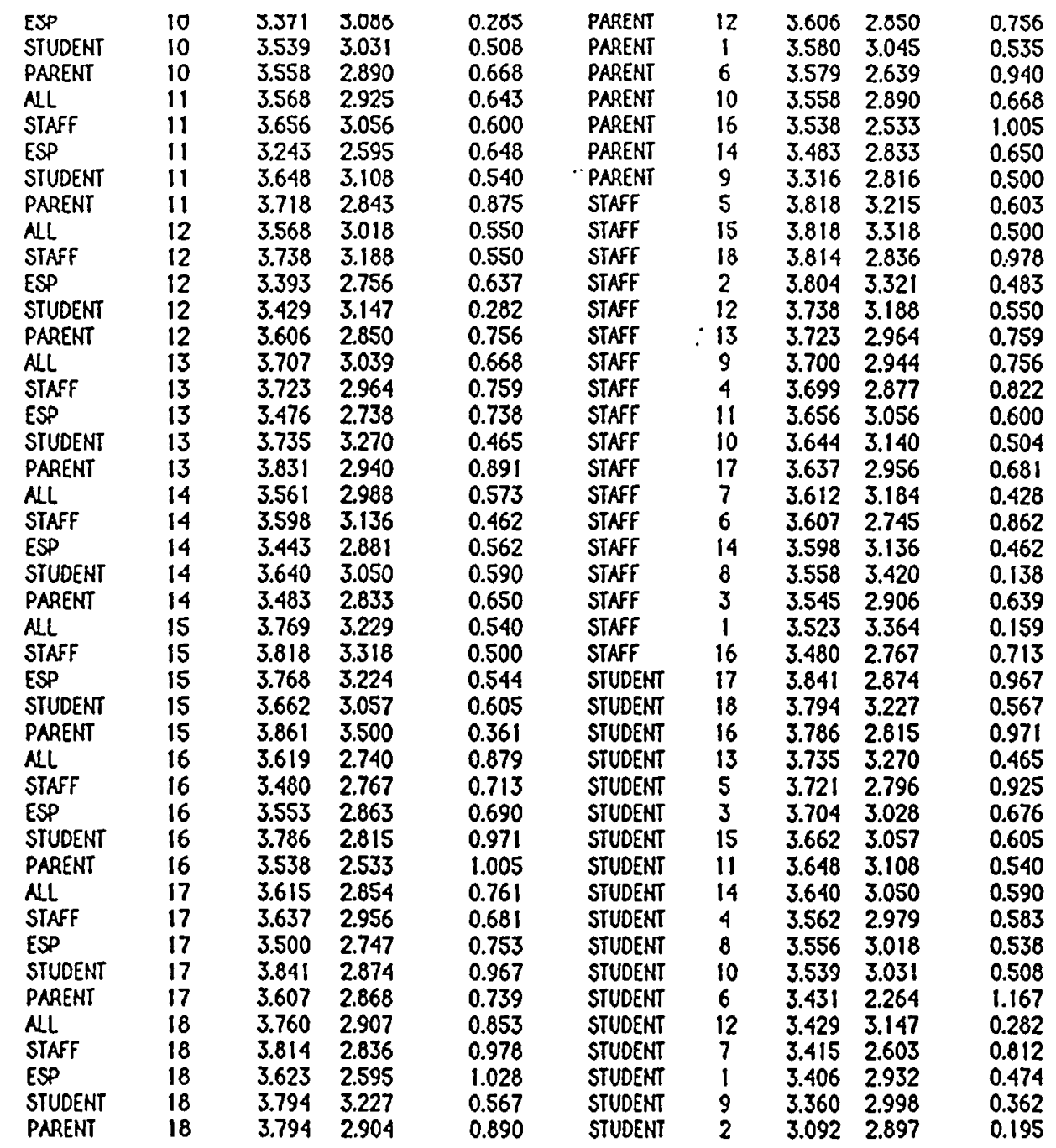


PYI TOPIC TABLES

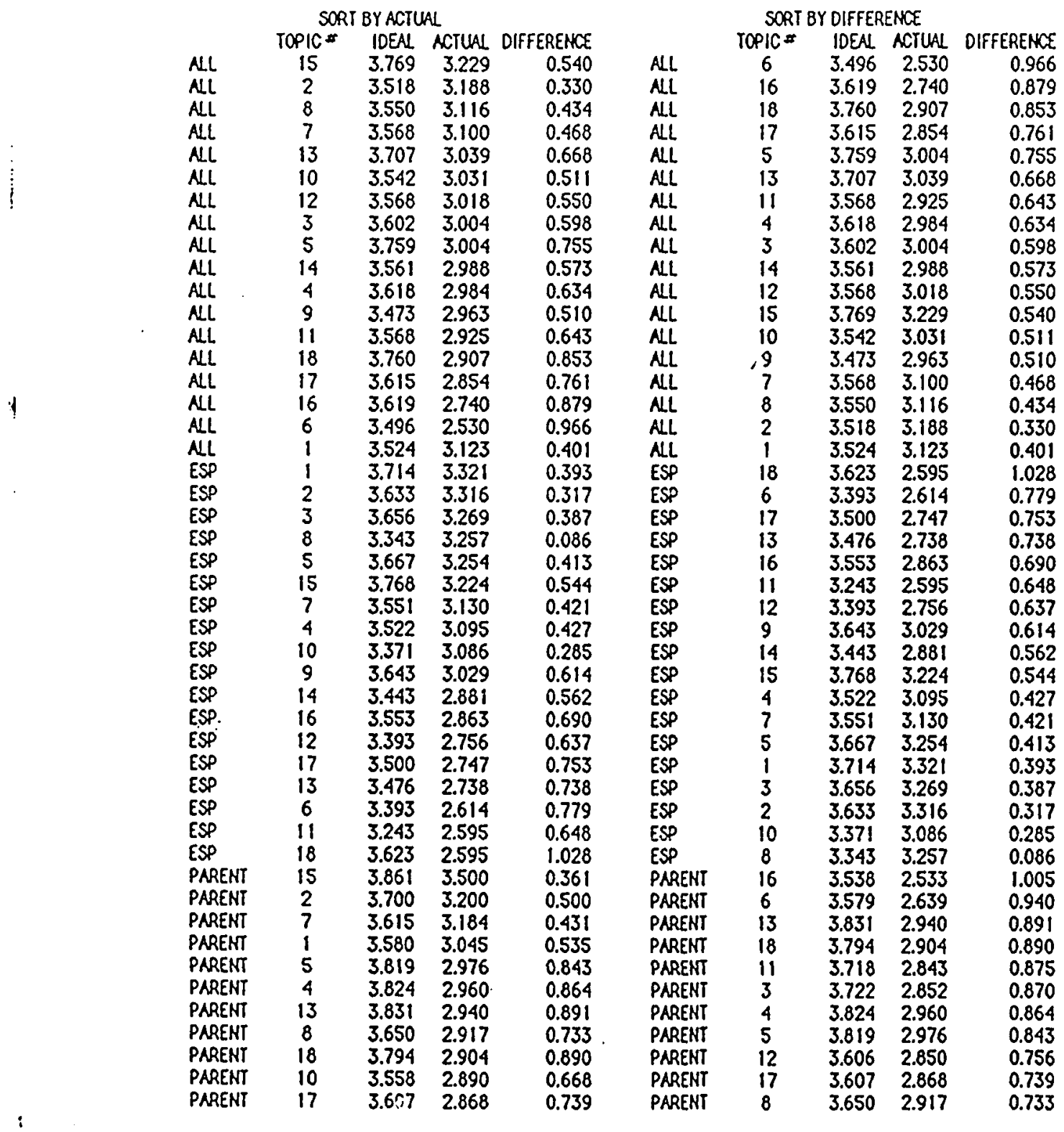


PYI TOPIC TABLES

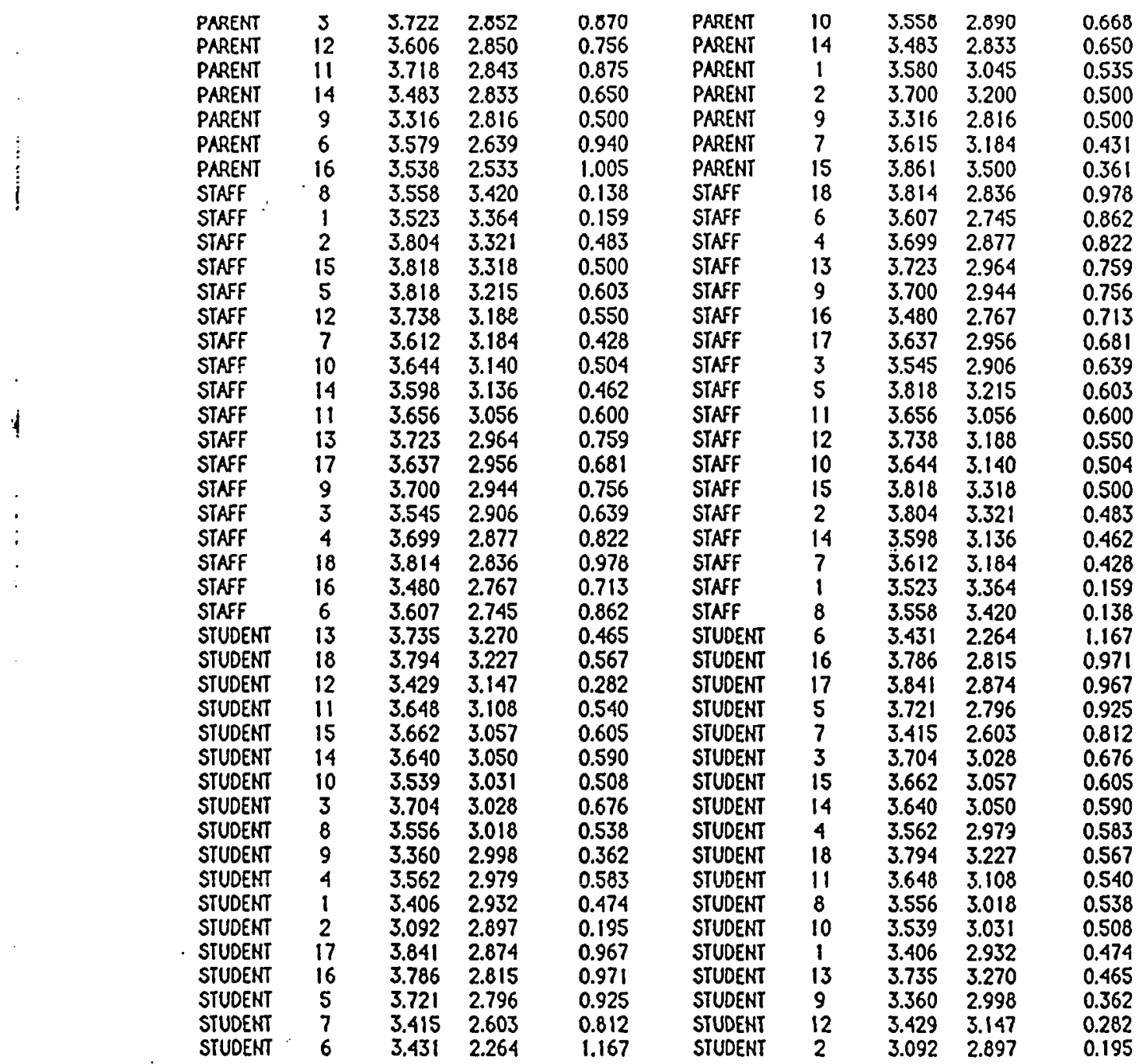

